UNIVERSIDADE DE SÃO PAULO

ESCOLA DE ENGENHARIA DE SÃO CARLOS

ÁREA DE PÓS-GRADUAÇÃO EM ENGENHARIA MECÂNICA

\title{
IDENTIFICAÇÃO MODAL DE UMA ESTRUTURA \\ AERONÁUTICA VIA ALGORITMO DE REALIZAÇÃO \\ DE SISTEMAS
}

VALDINEI SCZIBOR

Dissertação apresentada à Escola de Engenharia de São Carlos, da Universidade de São Paulo, como parte dos requisitos para obtenção do título de Mestre em Engenharia Mecânica.

ORIENTADOR: Prof. Dr. Flávio Donizeti Marques

SÃO CARLOS

2002 
Aos meus pais, Zeno Sczibor e Marília Vitória, dedico esta conquista com admiração e respeito. 


\section{AGRADECIMENTOS}

Meus sinceros agradecimentos ao Prof. Dr. Flávio Donizeti Marques pela orientação, incentivo e dedicação, imprescindíveis para a realização deste trabalho.

Ao Dr. Roberto Hideaki Tsunaki pelas valorosas discussões e ensinamentos transmitidos, que contribuíram de forma definitiva na conclusão deste trabalho.

Ao Prof. Dr. Paulo Varoto pela disponibilização dos equipamentos e das dependências do Laboratório de Dinâmica para realização dos ensaios.

Ao Prof. Dr. Benedito Di Giacomo pela disponibilização das dependências do Laboratório de Metrologia.

Aos amigos do Laboratório de Aeroelasticidade, Dinâmica de Vôo e Controle, Carlos, Daniela, Edson, Elizângela, Gasparini, Guilherme, José Cláudio, Luciane, Luis, Márcio, Renato e Werner pelo incentivo e companherismo.

Ao amigo de Laboratório Alexandre Caporali pela valorosa ajuda prestada durante este trabalho.

Ao amigo Leopoldo pela valorosa ajuda prestada durante os ensaios realizados no laboratório de Dinâmica.

Ao amigo Fábio Guilherme Ferraz pelas valorosas discussões durante este trabalho.

À Jaqueline Helena de Lima, pela dedicação e carinho desenvolvidos ao longo dos últimos anos, imprescindíveis para este trabalho.

À Murilo H. S. de Lima pelo carinho e companherismo.

Aos amigos Alessandro Nhani e Carla pelo incentivo e amizade.

Ao amigo João Teles pela amizade.

A todos que acreditaram e incentivaram de alguma forma a realização deste trabalho.

À CAPES pela bolsa de estudos concedida. 


\section{RESUMO}

SCZIBOR, V. (2002). Identificação Modal de uma Estrutura Aeronáutica via Algoritmo de Realização de Sistemas. São Carlos, 2002. 147p. Dissertação (Mestrado) - Escola de Engenharia de São Carlos, Universidade de São Paulo.

A determinação de características dinâmicas de estruturas aeronáuticas é um assunto extremamente importante na indústria aeroespacial, principalmente devido à demanda contínua para estruturas mais leves e conseqüentemente mais flexíveis. Neste contexto, estruturas aeroespaciais precisam ser submetidas a alguma forma de verificação modal antes do vôo, para assegurar que a aeronave é livre de fenômenos aeroelásticos indesejáveis. Esta análise freqüentemente inclui a identificação experimental de características dinâmicas como freqüência natural, fatores de amortecimento e forma dos modos usando ensaio modal. Neste trabalho foi realizado um ensaio de vibração no solo em uma asa metálica da aeronave Neiva Regente para obtenção das funções resposta em freqüência da estrutura. O método de identificação utilizado para este estudo é o Algoritmo de Realização de Sistemas - ERA. É um método de identificação considerado eficiente e poderoso, pois é capaz de identificar estruturas que apresentem comportamento dinâmico complexo. $\mathrm{O}$ algoritmo foi validado através de uma simulação de um modelo hipotético e de dados experimentais de uma viga de alumínio. Os resultados experimentais, porém, apresentam modos computacionais que devem ser eliminados. Para tanto foram utilizados três índices de confiança para qualificar os resultados, sendo estes: Colinearidade de Fase Modal Ponderada (MPCW), Coerência da Amplitude Modal Estendida (EMAC) e Indicador de Consistência Modal $(C M I)$. Os modos que apresentaram melhores índices de confiança são considerados o resultado final do processo de identificação. Desta forma, o processo de identificação foi aplicado para a semi-asa da aeronave Neiva Regente. A identificação revelou-se mais difícil, basicamente devido à complexidade da estrutura somado-se a problemas de ruído, o que levou a um número pequeno de modos identificados.

Palavras chave: Aeroelasticidade, Ensaios de vibração, ERA, Dinâmica Estrutural. 


\begin{abstract}
SCZIBOR, V. (2002). Modal Identification of an Aeronautical Structure via the Eigensystem Realization Algorithm. São Carlos, 2002. 147p. Dissertação (Mestrado) - Escola de Engenharia de São Carlos, Universidade de São Paulo.
\end{abstract}

The determination of the dynamic characteristics of aircraft structures has become an extremely important issue in the aerospace industry, primarily due to the continuous demand for lighter and consequently more flexible structures. In this context, most aerospace structural system must be subjected to some form of modal verification prior to flight in order to ensure that the aircraft is free from any dangerous aeroelastic instability phenomena. The verification procedure often includes the experimental identification of structural characteristics such as the natural frequency, damping factors and normal modes using modal testing. In this work, a ground vibration testing (GVT) of a metallic wing of the Neiva Regente aircraft was accomplished in order to assess the frequency response functions. The basic identification method used for this study is the Eigensystem Realization Algorithm - ERA. It is an identification method, which is considered efficient and powerful, because it is capable to identify structures that present complex dynamic behaviour. The algorithm was valited through data obtained from a simulation of a hypothetical model and dynamic measurement accomplished in an aluminium beam. The experimental results, nevertheless, present computacional modes that must be removed from the model. Three confidence factors were used to qualify the results, namely the Modal Phase Collinearity - Weighted (MPCW), Extended Modal Amplitude Coherence (EMAC) and Consistent-Mode Indicator (CMI). The modes that presented higher confidence factor values were considered as the final result of the identification process. Then, the identificatin process was applied to a semi-wing of the Neiva Regente aircraft. This case has revealed a much harder identification procedure, where the complexity of the structure plus noisy data have led to a small number of identified modes.

Keywords: Aeroelasticity, GVT, ERA, Structural Dynamics. 


\section{SUMÁRIO}

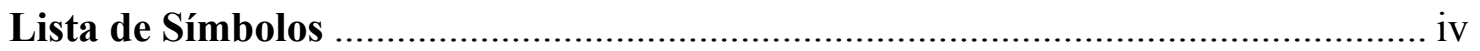

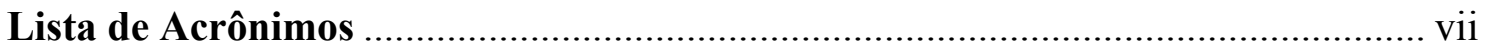

\section{CAPÍTULO 1}

INTRODUÇÃ

1.1 - Análise modal teórica em aeronáutica .................................................... 8

1.2 - Análise modal experimental em aeronáutica ............................................ 10

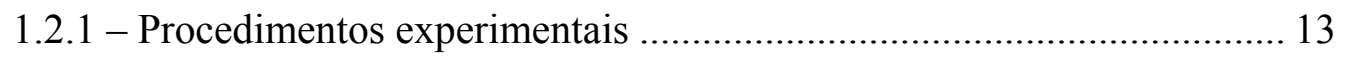

1.3 - Métodos de identificação de parâmetros modais ......................................... 15

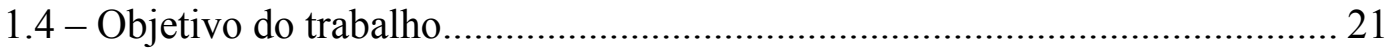

1.5 - Organização da dissertação ......................................................................... 21

\section{CAPÍTULO 2}

\section{IDENTIFICAÇÃO DE SISTEMAS DINÂMICOS - O ALGORITMO DE}

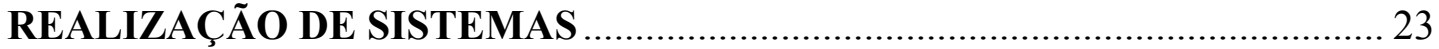

2.1 - Modelos no espaço de estado em tempo contínuo ...................................... 24

2.2 - Modelos de espaço de estado em tempo discreto ......................................... 28

2.3 - Parâmetros de Markov e a matriz Hankel ...................................................... 30

2.4 - Equações de estado nas coordenadas modais ............................................... 34

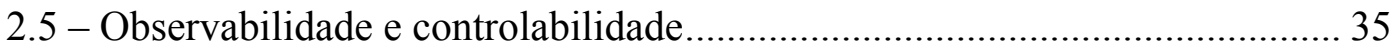

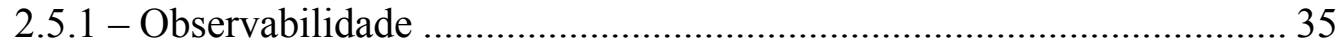

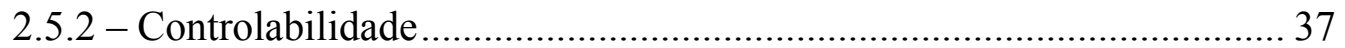

2.5.3 - Matriz Hankel e as matrizes de observabilidade e controlabilidade.... 38

2.6 - Algoritmo de Realização de Sistemas - ERA ............................................. 40

2.6.1 - Formulação básica do ERA …............................................................ 40 


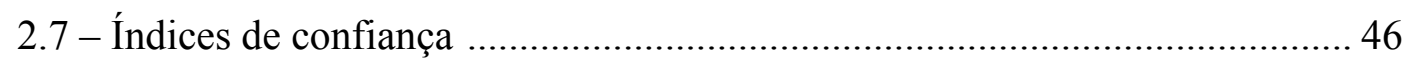

2.7.1 - Colinearidade de Fase Modal Ponderada - MPCW ............................. 48

2.7.2 - Coerência da Amplitude Modal Estendida - EMAC ............................ 49

2.7.3 - Indicador de Consistência Modal - CMI ............................................. 53

\section{CAPÍTULO 3}

VERIFICAÇÃO DO ALGORITMO DE REALIZAÇÃO DE

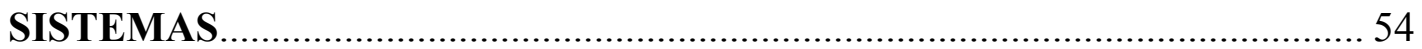

3.1 - Implementação dos algoritmos ................................................................. 54

3.1.1 - Obtenção dos parâmetros de Markov através de FRFs........................ 55

3.1.2 - Implementação do algoritmo $E R A$ e dos índices de confiança ............. 55

3.2 - Verificação do algoritmo para um sistema simulado ..................................... 58

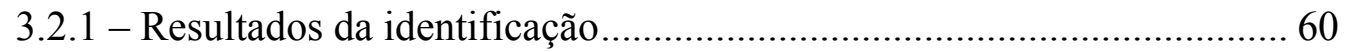

3.3 - Aplicação do algoritmo na identificação da dinâmica de uma



3.3.1 - Descrição da estrutura de teste.............................................................. 65

3.3.2 - Aquisição dos dados experimentais ....................................................... 67

3.3.3 - Implementação computacional............................................................ 70

3.3.4 - Resultados da identificação................................................................ 71

\section{CAPÍTULO 4}

APLICAÇÃO DO ALGORITMO DE REALIZAÇÃO DE SISTEMAS EM UMA ESTRUTURA AERONÁUTICA ……………………..... 81

4.1 - Descrição da estrutura de teste........................................................................ 81

4.2 - Aquisição dos dados experimentais ......................................................... 83

4.3 - Implementação dos algoritmos .................................................................... 86

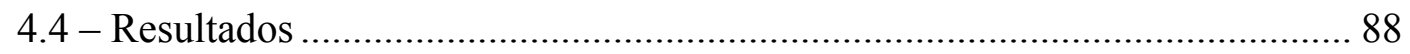

4.4.1 - Resultados da identificação.................................................................... 91

\section{CAPÍtULO 5}

CONCLUSÕES E SUGETÕES PARA TRABALHOS FUTUROS 
APÊNDICE A

Funções resposta em freqüência medidas no ensaio de impacto em uma viga de alumínio

APÊNDICE B

Funções resposta em freqüência medidas no ensaio de vibração no solo na semi-asa da aeronave Neiva Regente 


\section{LISTA DE SÍMBOLOS}

$\left[A_{c}\right] \quad$ Matriz de estado do modelo em tempo contínuo $(2 n \times 2 n)$

$\left[A_{d}\right] \quad$ Matriz de estado do modelo em tempo discreto $(2 n \times 2 n)$

$\left[B_{c}\right] \quad$ Matriz de influência de entrada do modelo em tempo contínuo $(2 n \times r)$

$\left[B_{d}\right] \quad$ Matriz de influência de entrada do modelo em tempo discreto $(2 n \times r)$

$\left[B_{d}\right]_{M} \quad$ Matriz de influência de entrada nas coordenadas modais $(2 n \times r)$

$\left[B_{2}\right] \quad$ Matriz de influência de entrada $(n \times r)$

[C] Matriz de amortecimento $(n \times n)$

$\left[C_{c}\right] \quad$ Matriz de influência de saída em tempo contínuo $(m \times 2 n)$

$\left[C_{d}\right] \quad$ Matriz de influência de saída em tempo discreto $(m \times 2 n)$

$\left[C_{d}\right]_{M} \quad$ Matriz de influência de saída nas coordenadas modais $(m \times 2 n)$

$\left[D_{c}\right] \quad$ Matriz de transmissão direta em tempo contínuo $(m \times r)$

$\left[D_{d}\right] \quad$ Matriz de transmissão direta em tempo discreto $(m \times r)$

$[H(k)] \quad$ Matriz Hankel no instante $k \Delta \mathrm{t}(\alpha m \times \beta r)$

[I] Matriz Identidade

$[K] \quad$ Matriz de rigidez $(n \times n)$

[M] Matriz massa $(n \times n)$

$\left[P_{p}\right] \quad$ Matriz de observabilidade

$\left[Q_{p}\right] \quad$ Matriz de controlabilidade

$[R] \quad$ Matriz dos valores singulares à esquerda de $[H(0)](\alpha m \times \alpha r)$

$\left[R_{2 n}\right] \quad$ Matriz com as $2 n$ primeiras colunas de $[R](\alpha m \times 2 n)$ 
Matriz dos valores singulares à direita de $[H(0)](\beta m \times \beta r)$

$\left[S_{2 n}\right] \quad$ Matriz com as $2 n$ primeiras colunas de $[S](\beta m \times 2 n)$

$\left[V_{d}\right] \quad$ Matriz de influência de saída para deslocamento $(m \times n)$

$\left[V_{v}\right] \quad$ Matriz de influência de saída para velocidade $(m \times n)$

$\left[V_{a}\right] \quad$ Matriz de influência de saída para aceleração $(m \times n)$

$\left[Y_{k}\right] \quad$ Parâmetro de Markov no instante $k \Delta \mathrm{t}(m \times r)$

$e^{\left[A_{c}\right] t} \quad$ Matriz de transição $(2 n \times 2 n)$

$\{f(w, t)\} \quad$ Vetor de esforços externos nas coordenadas generalizadas $(n \times l)$

$m \quad$ Número de saídas

n Graus de liberdade do sistema de segunda ordem

$r \quad$ Número de entradas

$\{u(t)\} \quad$ Vetor de entrada no tempo contínuo $(r \times 1)$

$\{u(k)\} \quad$ Vetor de entrada no tempo discreto $(2 n \times 1)$

$[\ddot{w}(t)] \quad$ Vetor aceleração generalizada $(n \times 1)$

$[\dot{w}(t)] \quad$ Vetor velocidade generalizada $(n \times 1)$

$[w(t)] \quad$ Vetor deslocamento generalizado $(n \times 1)$

$\{x(t)\} \quad$ Vetor de estado no tempo contínuo $(2 n \times 1)$

$\{x(k+1)\} \quad$ Vetor de estado no tempo discreto $(2 n \times 1)$

$\{x(k)\}_{M} \quad$ Vetor de estado no tempo discreto nas coordenadas modais $(2 n \times 1)$

$\{y(t)\} \quad$ Vetor de saída no tempo contínuo $(m \times 1)$

$\{y(k)\} \quad$ Vetor de saída no tempo discreto $(m \times 1)$

$\Delta t \quad$ Intervalo de tempo constante

[0] Matriz de elementos zero 


\section{Símbolos Gregos}

$\begin{array}{ll}\alpha & \text { Número de parâmetros de Markov em uma coluna de }[H(k)] \\ \beta & \text { Número de parâmetros de Markov em uma linha de }[H(k)] \\ {[\Lambda]} & \text { Matriz diagonal dos autovalores de }\left[A_{d}\right](2 n \times 2 n) \\ {[\Sigma]} & \text { Matriz dos valores singulares de }[H(0)](\alpha m \times \beta r) \\ {[\Psi]} & \text { Matriz modal }(2 n \times 2 n) \\ {\left[\Sigma_{2 n}\right]} & (2 n \times 2 n) \\ \left\{\phi_{j}\right\} & j \text {-ésimo modo (complexo) } \\ \xi_{n} & \text { Fator de amortecimento do modo } n \\ \omega_{n d} & \text { Freqüência natural amortecida do modo } n \\ \left\{\varphi_{j}\right.\end{array} \quad \begin{aligned} & j \text {-ésima linha da matriz de influência de entrada } \\ & \end{aligned}$

\section{Convenções}

[ ] Matriz

[]$^{\mathrm{T}} \quad$ Matriz transposta

[ $]^{+} \quad$ Pseudo-inversa de [ ]

\{\} Vetor ou Matriz coluna 


\section{LISTA DE ACRÔNIMOS}

CMI Indicador de Consistência Modal (Consistent-Mode Indicator)

EMAC Coerência da Amplitude Modal Estendida (Extended Modal Amplitude Coherence)

ERA Algoritmo de Realização de Sistemas (Eigensystem Realization Algorithm)

ERA/DC Algoritmo de Realização de Sistemas com Correlação de Dados (ERA Data Correlation)

FFT Transformada Rápida de Fourier (Fast Fourier Transform)

FRF Função Resposta em Freqüência (Frequency Response Functions)

FRI Função Resposta Impulsiva (Impulse Response Function)

IFFT Transformada Inversa de Fourier (Inverse Fast Fourier Transform)

MAC Critério de Correlação Modal (Modal Assurance Criteria)

MDOF Múltiplos Graus de Liberdade (Multiple Degree-Of-Freedom)

MIMO Múltiplas Entradas e Múltiplas Saídas (Multiple-Input-Multiple-Output) 
MPCW Colinearidade de Fase Modal Ponderada (Modal Phase CollinearityWeighted)

OKID (Observer/Kalman Filter Identification)

SDOF Um Grau de Liberdade (Single Degree-Of-Freedom)

SISO Uma Entrada e Uma Saída (Single-Input-Single-Output) 


\section{CAPÍTULO 1}

\section{INTRODUÇÃO}

Com o progresso alcançado pela indústria aeronáutica em termos de desempenho das aeronaves, os problemas relacionados ao projeto estrutural têm aumentado. Melhorias no desempenho das aeronaves modernas não se dá apenas pelo aumento na eficiência dos meios de propulsão, mas também pelo uso de materiais mais leves e pela otimização dos componentes estruturais e formas aerodinâmicas. Estruturas de aeronaves estão em constante desenvolvimento de forma a obter-se componentes mais leves, resistentes e confiáveis. Como conseqüência de tal tendência, as estruturas aeronáuticas também têm se tornado mais flexíveis aumentando a suscetibilidade à vibrações e instabilidades aeroelásticas.

Segundo BISPLINGHOFF et al. (1955), FUNG (1993) e DOWELL et al. (1978), instabilidades aeroelásticas podem ser desastrosas e são o resultado da interação mútua de forças inerciais, elásticas e aerodinâmicas que agem sobre as estruturas das aeronaves em vôo. Um modelo completo das forças aerodinâmicas, elásticas e inerciais é requerido para descrever a natureza aeroelástica de uma aeronave, ajudando a prevenir o surgimento de instabilidades (YATES, 1971). A 
Figura 1.1 ilustra a interação entre estes três tipos de forças determinando as condições necessárias para o potencial estático e instabilidade dinâmica.

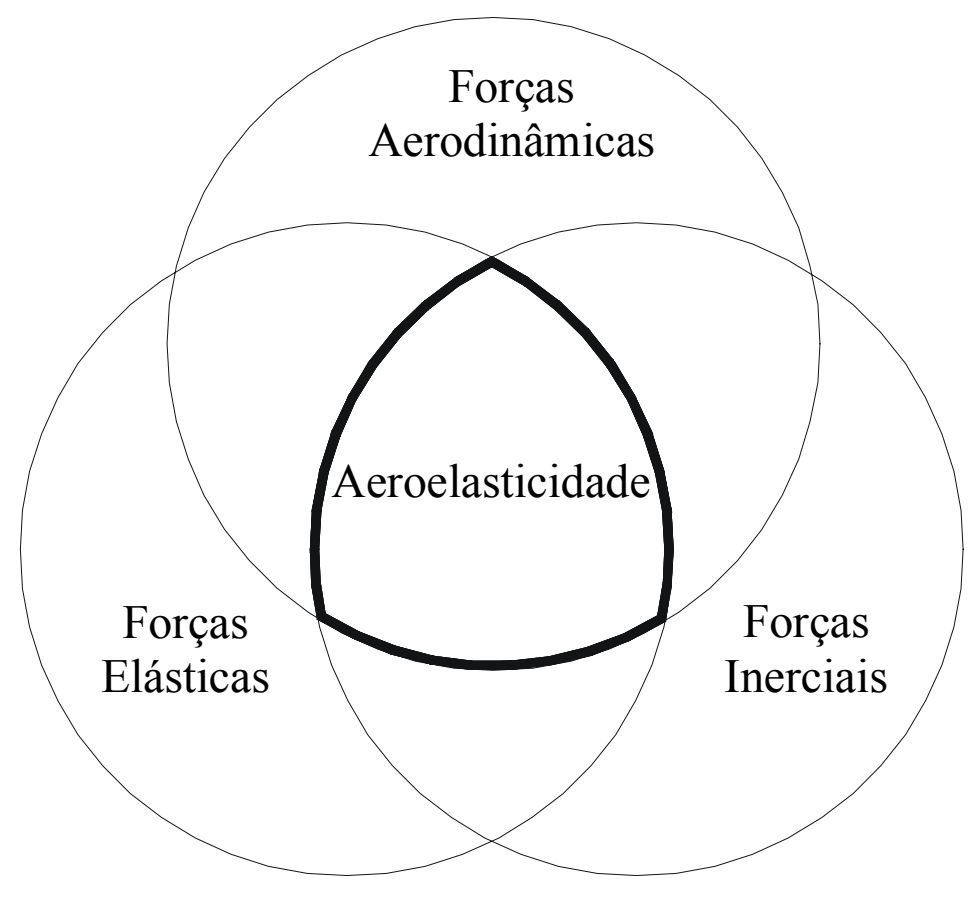

Figura 1.1 - Diagrama das forças que interagem na aeroelasticidade (YATES, 1971).

Portanto, os ensaios em aeroelasticidade são conduzidos para determinar e entender fisicamente os fenômenos aeroelásticos, como flutter, de forma que tais fenômenos possam ser levados em conta durante o projeto na indústria aeronáutica. Além disso, ensaios experimentais em túnel de vento são realizados na maioria de aeronaves, helicópteros e veículos de lançamento espacial para demonstrar que o projeto é livre de problemas aeroelásticos antes de ensaios em vôo, compulsórios para a indústria aeronáutica (RICKETTS, 1993). A Figura 1.2 mostra um experimento em túnel de vento de um modelo de avião, realizado na NASA Langley Research Center Hamilton, VA, EUA, para análise aeroelástica. 


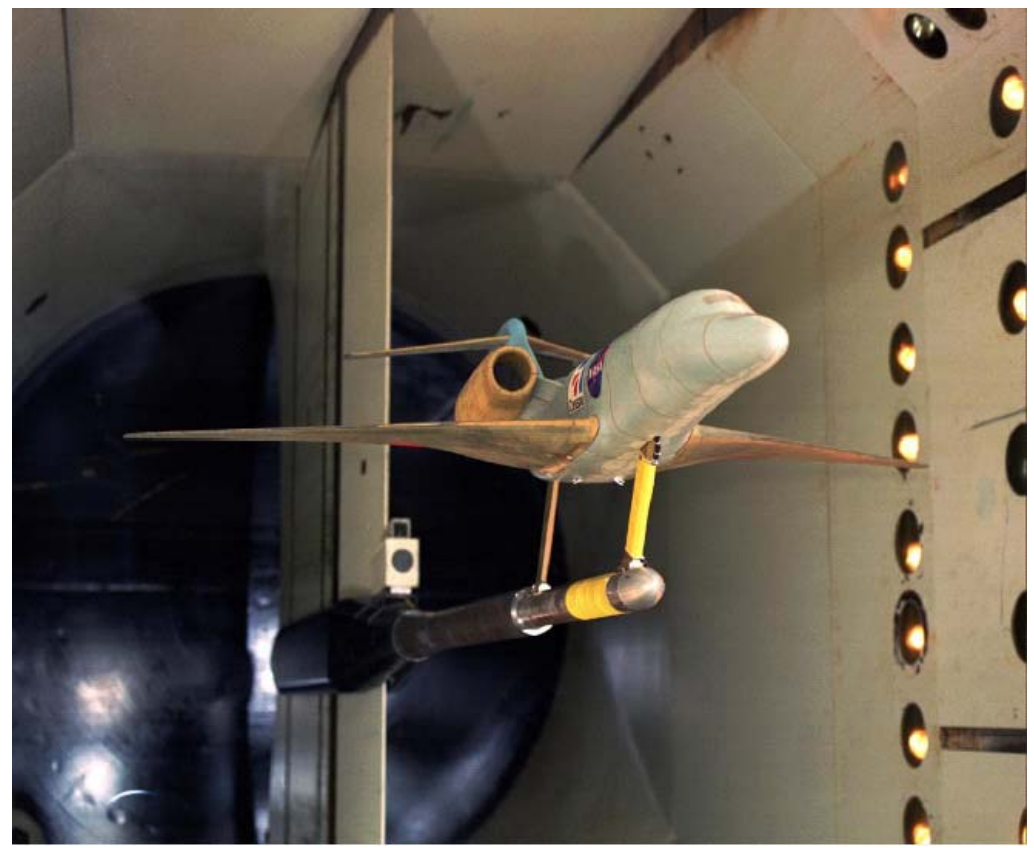

Figura 1.2 - Ensaio em túnel de vento - NASA Langley Research Center (NITZSCHE, 2001).

Enquanto que instabilidades aeroelásticas mais dramáticas são freqüentemente a causa para preocupação, é importante enfatizar que problemas de respostas aeroelásticas resultantes de vibração são de grande importância para a indústria aeronáutica em certas classes de aeronaves. Particularmente para aeronaves de asa fixa e de asas rotativas, fenômenos aeroelásticos não desejados podem levar a características dinâmicas impróprias. Tais estruturas podem sofrer excessiva vibração devido a sua flexibilidade estrutural, causando desconforto à tripulação e problemas de fadiga nos muitos dispositivos da aeronave. Para evitar problemas estruturais dinâmicos, engenheiros aeronáuticos devem ser capazes de prever as características dinâmicas principais da estrutura, como: freqüências naturais e forma dos modos.

Em aeroelasticidade os modos de uma aeronave são afetados pelas cargas aerodinâmicas. Neste cenário os procedimentos usuais utilizados pela indústria aeronáutica para validar um modelo aeroelástico são:

- $\quad$ Ensaios de vibração no solo;

- Os resultados obtidos são incorporados em modelos que promovem o acoplamento com um modelo aerodinâmico;

- Testes em vôo são realizados para validar o modelo aeroelástico. 
Tradicionalmente, estruturas aeroespaciais precisam ser submetidas a alguma forma de verificação modal antes do vôo, para assegurar que as características dinâmicas previstas para a estrutura da aeronave estão corretas. Esta análise freqüentemente inclui a identificação experimental de características dinâmicas como freqüência natural e forma dos modos usando ensaio modal, visando posterior análise aeroelástica.

No entanto, em estruturas aeronáuticas típicas a determinação de características dinâmicas não é uma tarefa fácil e direta. Modernas estruturas aeronáuticas são constituídas de muitos componentes agregados, fixados de uma maneira complexa (ALLEN \& HAISLER, 1985). A determinação de características dinâmicas de uma estrutura flexível pode ser realizada através de dois procedimentos. O primeiro, denominado análise modal teórica, procura obter as características dinâmicas da estrutura através de métodos analíticos e numéricos. $\mathrm{O}$ segundo procedimento, denominado identificação modal, obtém as características dinâmicas da estrutura através de dados experimentais (TSUNAKI, 1999).

A Figura 1.3(a) mostra as três fases através das quais uma análise de vibração teórica típica progride. Geralmente, inicia-se a descrição da estrutura através de suas características físicas, em termos de sua distribuição de massa, rigidez e amortecimento, e tal descrição é referida como sendo o modelo espacial ou analítico. Em seguida, é feita uma análise modal analítica do modelo espacial, o que fornece a descrição do comportamento da estrutura através de um conjunto de freqüências naturais com seus correspondentes modos naturais de vibrar e fatores de amortecimento modal, o chamado modelo modal. Tal solução descreve as várias formas nas quais a estrutura é capaz de vibrar naturalmente sem qualquer excitação ou força externa e portanto tais modos são chamados de modos normais ou naturais de vibrar da estrutura. A dificuldade na identificação de grandes estruturas aeronáuticas está relacionada à presença majoritária e em nível elevado de amortecimento não proporcional, tornando imprecisa a obtenção dos modos normais (reais) a partir dos modos complexos. Nestes casos, existe a necessidade de se identificar diretamente os modos reais. O terceiro estágio determina como a estrutura irá vibrar sob uma dada condição de excitação e especialmente, com quais amplitudes. Logicamente, isto não dependerá somente das propriedades inerentes da 
estrutura, mas também da natureza e magnitude da excitação imposta. Entretanto, é conveniente executar a análise da resposta da estrutura para uma excitação dita padrão, onde tais níveis de resposta descrevem o modelo da resposta da estrutura. Portanto, o modelo predito consistirá de um conjunto de funções resposta em freqüência (FRFs) ou um conjunto de correspondentes funções resposta impulsiva (FRIs), as quais devem ser definidos sobre uma faixa de freqüência aplicável.

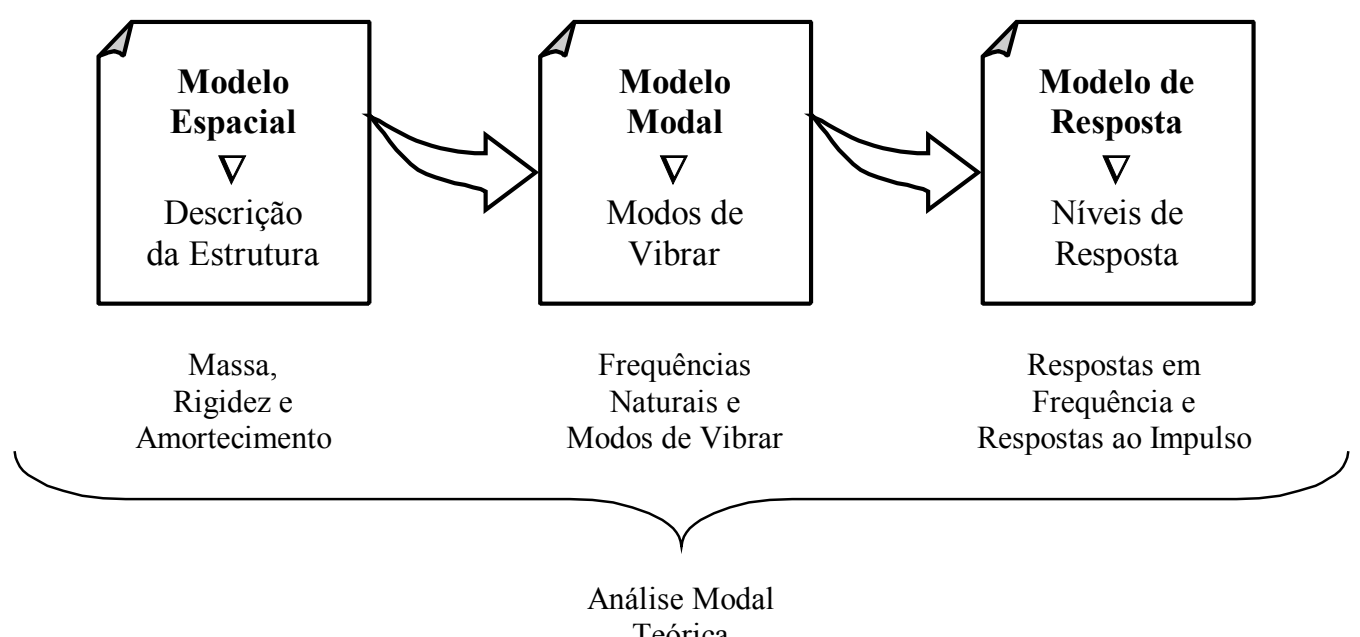

(a)

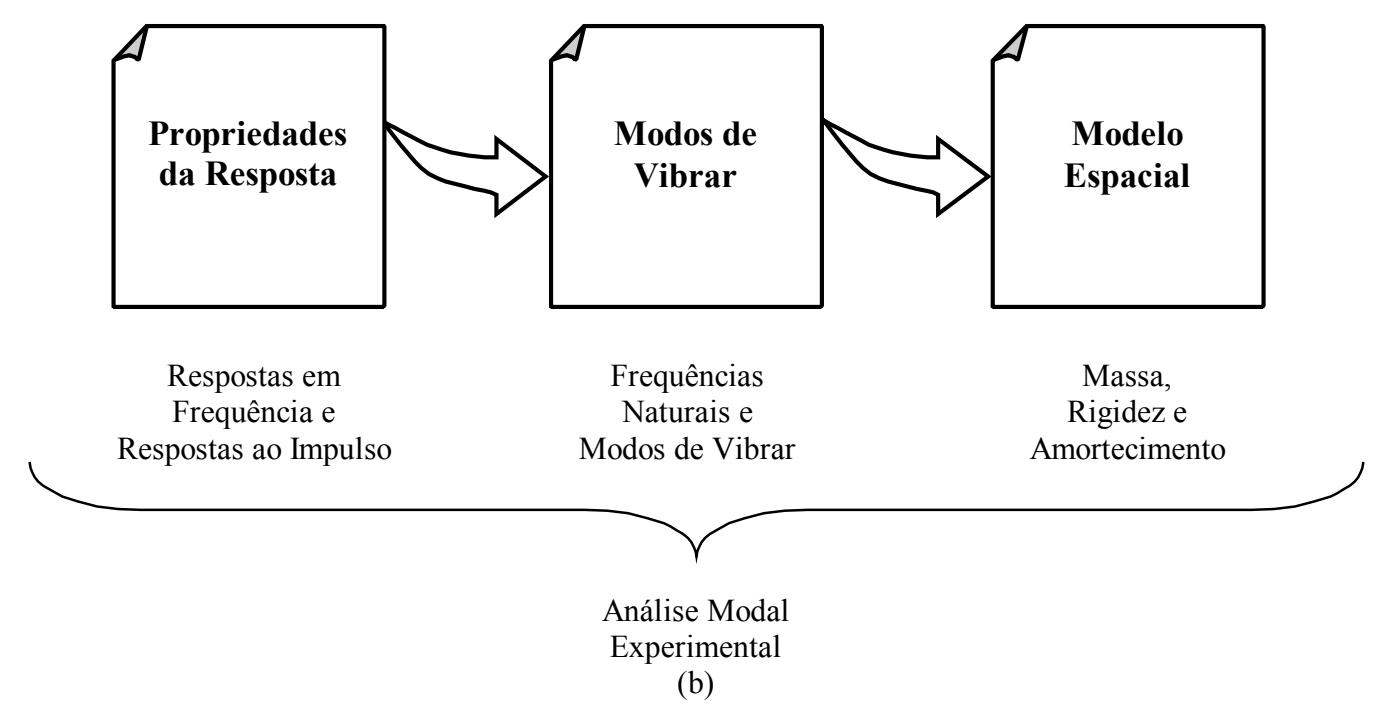

Figura 1.3 - Análise de vibração de uma estrutura. (a) Fases de uma análise de vibração teórica, (b) Fases de uma análise de vibração experimental. 
A Figura 1.3 (b) mostra o processo inverso, ou seja, a partir da descrição das propriedades da resposta medida experimentalmente (tal como as FRFs ou FRIs medidas), pode-se deduzir as propriedades modais e as propriedades espaciais (EWINS, 1984).

$\mathrm{O}$ método dos elementos finitos (MEF) tem sido uma das ferramentas teóricas mais bem sucedidas, entre outras, empregadas para obter características modais durante a fase de projeto na indústria aeronáutica. Com isso, o MEF alcançou uma fase avançada de desenvolvimento principalmente devido aos progressos alcançados pelos computadores. As indústrias aeroespaciais e centros de pesquisa podem modelar, por exemplo, uma estrutura de aeronave inteira, adquirindo resultados seguros em um período relativamente curto de tempo. Embora o MEF esteja consolidado na indústria aeroespacial, a verificação experimental da dinâmica estrutural de aeronaves é necessária e importante, principalmente devido à complexidade das estruturas aeronáuticas. Além disso, a análise modal baseada apenas na aproximação teórica apresenta inconvenientes. A maioria dos modelos teóricos são construídos adotando hipóteses simplificadoras no processo de formulação do modelo matemático (MARQUES et al., 2001).

Conseqüentemente, a ocorrência de modificações estruturais em aeronaves é comum em muitos projetos de pesquisa na indústria aeronáutica. Porém, é importante assegurar que estas modificações estruturais não afetem as características aeroelásticas da aeronave adversamente. $\mathrm{O}$ procedimento para verificar a ausência de instabilidades aeroelásticas nas aeronaves modificadas, idealmente envolvem uma combinação equilibrada de análises prévias juntamente com ensaios em túnel de vento, ensaios de vibração no solo e ensaios em vôo (FREUDINGER \& KEHOE, 1990).

Os ensaios de vibração no solo assumiram um papel fundamental na indústria aeronáutica, assegurando um entendimento razoável das instabilidades aeroelásticas da nova e modificada estrutura pesquisada (KEHOE \& FREUDINGER, 1993). O comportamento dinâmico da maioria das estruturas aeroespaciais é adequadamente descrito usando parâmetros modais (freqüências naturais, forma dos modos, fatores de amortecimento e massas modais). A aplicação predominante na área aeroespacial é a verificação e refinamento do modelo em elementos finitos. O 
objetivo da identificação modal estrutural é obter uma representação modal válida em cima de uma faixa de freqüência especificada para todos os graus de liberdade espaciais. (PAPPA et al., 1993).

A análise experimental para identificação modal geralmente trabalha com dados na forma de medidas de vibração de decaimento livre, função resposta em freqüência (FRFs), função resposta impulsiva (FRIs), etc. Também foram desenvolvidos algoritmos numéricos para calcular os parâmetros modais dos dados experimentais acima mencionados. Na década de 80, a NASA, EUA, começou a usar um algoritmo de identificação denominado ERA (Algoritmo de Realização de Sistemas), desenvolvido por JUANG \& PAPPA (1985) no NASA Langley Research Center Hamilton, VA, EUA. Segundo PAPPA et al. (1991), o ERA é um método de identificação considerado eficiente e poderoso, pois é capaz de identificar estruturas que apresentem comportamento dinâmico complexo.

Avanços em sistemas de aquisição e no campo de sensores/atuadores, também estão fornecendo novas possibilidades para a avaliação das características dinâmicas de aeronaves. Técnicas atuais fornecem muitos modos para calcular parâmetros modais de sistemas de uma entrada e uma saída, ou SISO (do inglês single-input-single-output), e para sistemas de múltiplas entradas e múltiplas saídas, ou MIMO (multiple-input-multiple-output). Centros de referência em pesquisas aeroespaciais como NASA Dryden Flight Research Center, EUA, mostram as principais pesquisas nesta área, as técnicas modernas em uso e realça o papel vital de avaliação de parâmetros modais, em particular, ensaios de vibração no solo (KEHOE \& FREUDINGER, 1993 e ABEL, 1997).

Neste cenário os dados de ensaios de vibração no solo para a indústria aeronáutica possuem aplicações tais como:

- avaliar ou estimar a importância de modificações estruturais;

- verificar ou atualizar os modelos teóricos (modelos em elementos finitos, por exemplo);

- além de serem compulsórios para a indústria aeronáutica. 


\section{1 - ANÁLISE MODAL TEÓRICA EM AERONÁUTICA}

A análise modal teórica exige que inicialmente se formule um modelo matemático representado por um conjunto de matrizes da estrutura usando, por exemplo, alguma técnica de discretização espacial. Como resultado do processo de discretização, obtém-se as características espaciais da estrutura representadas pelas matrizes de massa, de rigidez e, eventualmente, de amortecimento. Estes modelos são posteriormente usados na busca de formulações que possibilitem um desacoplamento do sistema. O problema desacoplado leva às freqüências naturais e aos modos normais de vibrar.

A validade dos resultados da análise dinâmica depende das aproximações envolvidas na formulação do modelo matemático da estrutura. $\mathrm{O}$ método dos elementos finitos é freqüentemente utilizado nesta fase. Uma das principais dificuldades na formulação do modelo matemático é capturar o comportamento dinâmico do sistema com um número limitado de graus de liberdade. Uma das decisões críticas no processo de formulação do modelo matemático é a determinação das hipóteses simplificadoras e condições de contorno (TSUNAKI, 1999).

O desenvolvimento de qualquer conceito teórico na área de vibração incluindo análise modal, depende da compreensão do conceito do número de graus de liberdade de um sistema. Esse conceito é muito importante na análise modal, pois o número de modos de vibração de um sistema mecânico é igual ao seu número de graus de liberdade (ALLEMANG \& BROWN, 1996). Dentro deste aspecto, há métodos de análise de um grau de liberdade (em inglês, $S D O F$ ) e de múltiplos graus de liberdade-MDOF.

A análise dinâmica foi profundamente envolvida no projeto estrutural dentro da área aeroespacial nas últimas décadas, tornando-se uma ferramenta importante na determinação das características dinâmicas de estruturas. Neste contexto, o método dos elementos finitos (MEF) foi um avanço notável em análise modal teórica principalmente na indústria aeronáutica. Entretanto, incertezas como a determinação de condições de contorno e propriedades do material na aplicação do método, bem como uma estimativa das características do amortecimento estrutural, ainda são as principais limitações decorrentes desse método (ZHANG, 1985). 
O MEF é usado no projeto e análise de aeronaves para modelar matematicamente a estrutura para diversos objetivos como análise aeroelástica e do comportamento dinâmico estrutural. O MEF é usado para modelar o avião completo como também os componentes estruturais isoladamente. Segundo STOCKWELL (1995), o procedimento de verificação do modelo é essencialmente importante e imprescindível para a indústria aeronáutica, pois são utilizados para análise dinâmica e aeroelástica da estrutura.

A verificação de um modelo é realizada através da comparação entre o modelo teórico e os parâmetros modais experimentais (PAPPA, 1990). Se diferenças significativas são encontradas, ajustes no modelo são realizados. A correlação nos resultados experimentais e teóricos conduzem ao refinamento do modelo teórico, tornando os resultados mais confiáveis nas previsões teóricas (REAVES et al., 1992).

$\mathrm{O}$ processo de ajuste do modelo teórico apresenta vários métodos e aproximações no caso de estruturas complexas. COLLINS et al. (1974) apresentou um método usando freqüências naturais e forma dos modos de dados experimentais de um veículo espacial para modificar os parâmetros estruturais do modelo em elementos finitos através da matriz de rigidez e massa, preservando a consistência do modelo. Já CHEN \& GARBA (1980) propuseram um método denominado de matriz de perturbação para calcular a matriz Jacobiana e computa os novos autovalores e autovetores para execução das estimativas dos parâmetros modais. Os ensaios experimentais foram realizados em uma nave espacial para validar o método proposto.

KABE (1985) apresentou um trabalho que utiliza, além dos dados de modos de vibração, informações de ligações estruturais para otimizar a ajustagem da matriz de rigidez deficiente. Os ajustes executados são tais que a mudança de porcentagem para cada coeficiente de rigidez é minimizado. A configuração física do modelo analítico é preservada e o modelo ajustado reproduzirá exatamente os modos usados na identificação. Recentemente, BUEHRIE et al. (2001) e FLEMING et al. (1998) propuseram um trabalho com o objetivo de validar um modelo em elementos finitos utilizando resultados de análise modal experimental em uma fuselagem de avião. 


\section{2 - ANÁLISE MODAL EXPERIMENTAL EM AERONÁUTICA}

A análise modal experimental de estruturas tornou-se uma poderosa ferramenta de análise para a determinação das características dinâmicas de estruturas. Os trabalhos de pesquisa na área denominada análise modal experimental estão relacionados com um conjunto de técnicas que possibilitam a obtenção de modelos matemáticos precisos para uma determinada estrutura, a partir de ensaios experimentais (EWINS, 1984).

Segundo JUANG \& PAPPA (1988), a evolução da análise modal experimental pode ser dividida em três fases distintas. A primeira fase ocorreu nas décadas de 40 a 60, onde predominava o uso de técnicas analógicas e não havia o uso direto do computador na análise. Nesta época, muitos trabalhos ocorreram na indústria aeronáutica, onde ensaios experimentais eram realizados para análise da precisão dos modos normais calculados, usados em análise aeroelástica e comportamento dinâmico. Os trabalhos mais importantes para contribuição neste período foram o de KENNEDY \& PANCU (1947), que introduziram a ajustagem de curvas para decomposição das funções resposta em freqüência nos modos consistentes e o trabalho de LEWIS \& WRISLEY (1950), que apresentaram uma técnica para obtenção dos modos individuais da estrutura, utilizando múltiplos excitadores e excitação senoidal. A segunda fase ocorreu na década de 70 , quando ocorreu a revolução digital e com isso o surgimento de novas técnicas de medida, aquisição e processamento de dados experimentais, principalmente com uso da transformada rápida de Fourier $(F F T)$ para calcular funções resposta em freqüência. A terceira fase ocorreu a partir de 1980 até os dias atuais com o uso de computadores de capacidade cada vez maior e com a introdução de técnicas experimentais e de análise avançadas.

A utilização das técnicas de ensaio experimental ocorre principalmente nas áreas de pesquisa e desenvolvimento e em indústrias com produtos de alto valor agregado, como nas indústrias aeroespacial e automotiva. Alguns autores como EWINS (1984) e ALLEMANG \& BROWN (1996), referem-se a estes ensaios como ensaios modais. 
Após a Segunda Guerra Mundial o desenvolvimento de técnicas em ensaio modal ocorreu principalmente nas indústrias aeronáutica, onde ensaios em aeronaves e veículos espaciais eram realizados com o objetivo de identificar propriedades dinâmicas confiáveis da estrutura (METWALLI \& FEIJÓ, 1985).

Esse campo de atuação na ciência aeronáutica é referido como Ensaios de Vibração no Solo. Um entendimento profundo sobre ensaios de vibração requer o domínio de várias áreas, incluindo instrumentação, processamento de sinais, avaliação de parâmetros e análise de vibração.

As principais atividades nesta área são realizadas em centros de pesquisas aeroespaciais como NASA Dryden Flight Research Center, EUA. Devido à incertezas no modelo analítico e dificuldades associadas com a identificação direta de distribuição de massa, rigidez e amortecimento, a determinação experimental de características modais de estruturas tornou-se uma técnica clássica em ensaios de vibração no solo na indústria aeronáutica (IBRAHIM, 1987).

Neste contexto, os ensaios de vibração no solo reúnem e integram uma vasta gama de aplicações na indústria aeronáutica, dentre as quais estão a verificação e correlação de modelos teóricos usados em análise de flutter, avaliação da importância de modificações estruturais, identificação e avaliação de fenômenos inesperados, previsão de fadiga, detecção de falhas, entre outras (ALLEMANG \& BROWN, 1993).

Desta forma, para assegurar que a aeronave é livre de fenômenos aeroelásticos indesejáveis, as estruturas aeroespaciais precisam ser submetidas a alguma forma de verificação modal antes do vôo. Neste contexto, uma das principais áreas na indústria aeronáutica é a identificação das propriedades dinâmicas da estrutura a partir de sinais medidos.

Através dos ensaios de vibração no solo são obtidas as características da resposta do sistema, geralmente dadas através de funções resposta em freqüência. A partir destes dados experimentais procuram-se os parâmetros modais do sistema, que são dados pelas freqüências naturais, os fatores de amortecimento modais e os modos de vibrar da estrutura sob estudo. A partir destes parâmetros é possível obter-se um modelo matemático para o sistema e este modelo pode então ser comparado com o 
modelo teórico formulado inicialmente. Desta comparação pode-se fazer os ajustes necessários no modelo teórico (RAMSEY, 1983).

Uma variedade de técnicas de ensaios de vibração no solo para uma estrutura aeronáutica nova ou modificada são estudados por KEHOE (1987), COX et al. (1986) e KEHOE \& VORACEK (1989). Nestes trabalhos são apresentadas as técnicas de excitação, técnicas de fixação da estrutura, aquisição e manipulação dos dados, que são utilizados no Centro de Pesquisa da NASA Dryden Flight Research Center, EUA, em diversas aeronaves. A Figura 1.4 apresenta o ambiente de ensaio de vibração no solo da aeronave F-18. O ensaio foi realizado na aeronave para validar o modelo em elementos finitos usado na análise aeroelástica.

As últimas três décadas testemunharam o desenvolvimento de uma grande quantidade de métodos de identificação. Além disso, foram desenvolvidos algoritmos numéricos com o objetivo de calcular parâmetros modais através de dados experimentais. Um dos algoritmos desenvolvidos por JUANG \& PAPPA (1985) na década de 80 na NASA Langley Research Center, EUA, foi o ERA. O algoritmo é considerado eficiente e poderoso, pois é capaz de identificar estruturas que apresentem comportamento dinâmico complexo.

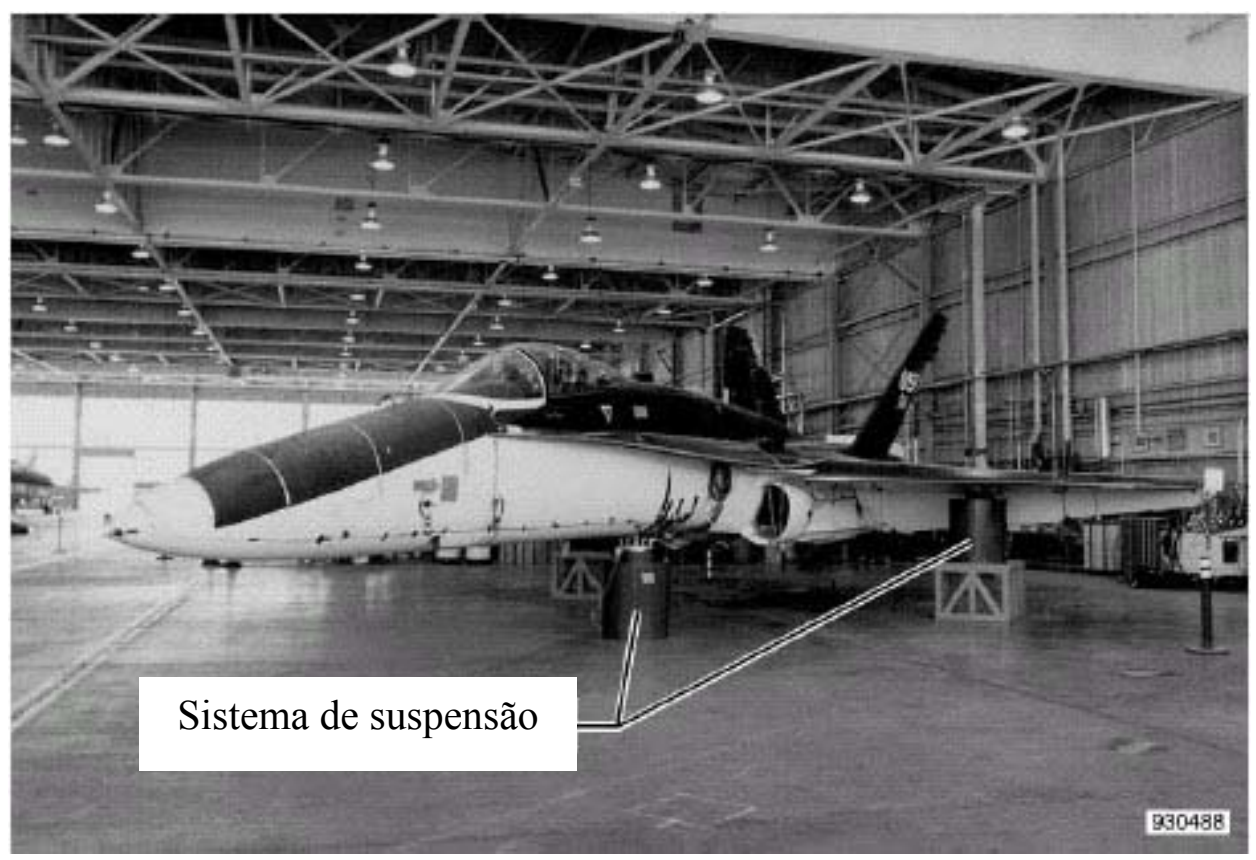

Figura 1.4 - Esquema do ensaio experimental (KEHOE \& FREUDINGER, 1993). 


\subsection{1 - PROCEDIMENTOS EXPERIMENTAIS}

Conseqüentemente, os procedimentos experimentais utilizados em ensaios modais são de grande importância, pois a precisão e a consistência na identificação de parâmetros modais depende diretamente da qualidade e da forma de obtenção dos dados experimentais (TSUNAKI, 1999).

O espaço característico é o principal conceito em procedimentos utilizados em ensaio modal, caracterizando as diversas maneiras de realizá-lo. As definições e conceitos sobre espaço característico descritos nesta seção, são baseados em ALLEMANG \& BROWN (1996).

O espaço de medida para um problema de identificação modal pode ser visualizado ocupando um volume com os eixos coordenados definidos em termos de três conjuntos característicos. Dois eixos do volume correspondem à informação espacial e o terceiro eixo à informação temporal. As coordenadas espaciais são definidas em termos dos graus de liberdade de entrada e saída (resposta) do sistema. O eixo temporal pode ser tanto tempo ou freqüência, dependendo do domínio das medidas. Estes três eixos definem um volume tridimensional que é denominado espaço característico.

Desta forma, os métodos de identificação que utilizam sistemas de uma entrada e uma saída, possuem baixa informação espacial e, com isso, proporcionam pouca informação sobre as formas modais. Já os métodos de identificação de sistemas de uma entrada e várias saídas, possuem boa informação espacial e possibilitam a identificação dos parâmetros modais com razoável precisão devido à distribuição das respostas. Os dados experimentais para esses sistemas podem ser representados por retas contidas em um plano paralelo ao plano formado pelos eixos de resposta e freqüência/tempo, como apresentado na Figura 1.5.

Muitos algoritmos de identificação modal, como o $E R A$, utilizam dados na forma de múltiplas entradas e múltiplas saídas. Neste caso, os dados experimentais para esses sistemas são formados por planos paralelos no espaço característico, como mostrado na Figura 1.6. Os métodos com capacidade de processar os dados obtidos desta forma, podem identificar melhor modos localizados 
e acoplados, devido à grande quantidade de informações espaciais e temporais contidas nos dados.

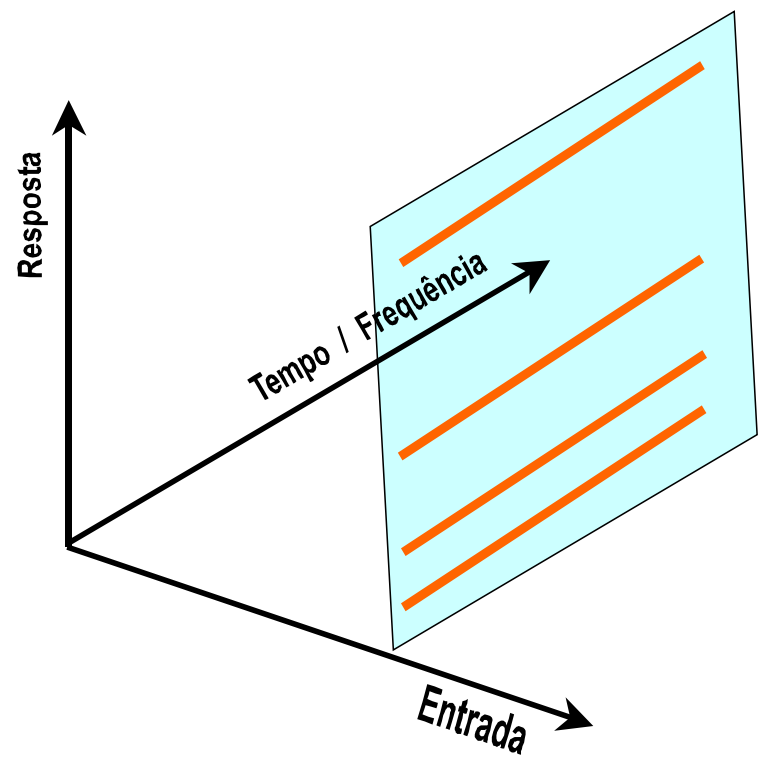

Figura 1.5 - Espaço característico de sistemas de uma entrada e múltiplas saídas (TSUNAKI, 1999).

A obtenção de dados experimentais na forma de múltiplas entradas e múltiplas saídas é aquela que proporciona melhor consistência e melhor qualidade no processo de identificação. Conseqüentemente, é a forma que requer uma maior capacidade nos equipamentos de aquisição e processamento de dados e um maior número de sensores.

Por outro lado, é possível realizar várias aquisições distintas na forma de uma entrada e uma saída e agrupá-las para formar um conjunto de dados de múltiplas entradas e múltiplas saídas. 


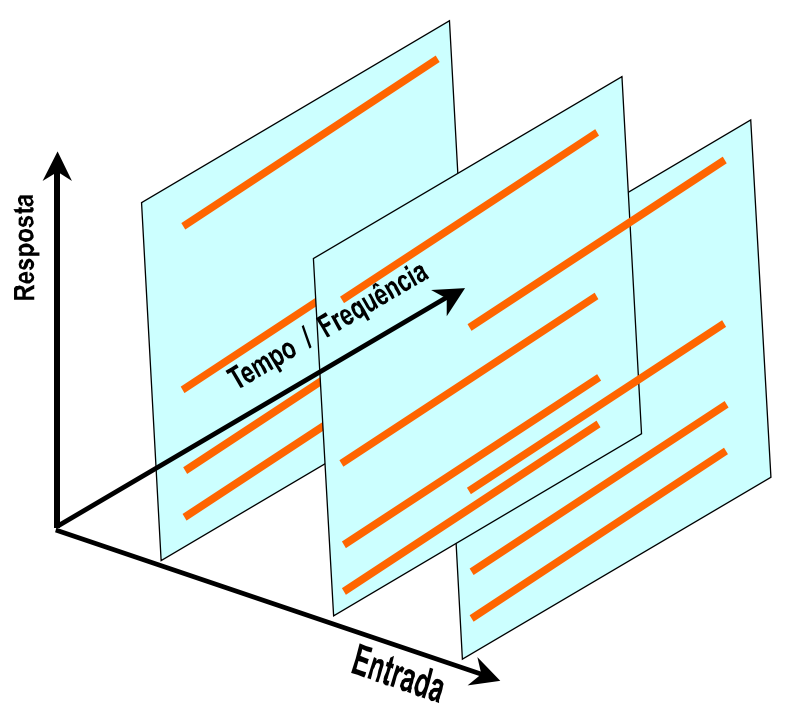

Figura 1.6 - Espaço característico de sistemas de múltiplas entradas e múltiplas saídas (TSUNAKI, 1999).

\section{3 - MÉTODOS DE IDENTIFICAÇÃO DE PARÂMETROS MODAIS}

O objetivo dos métodos de determinação de parâmetros modais é estimar as características dinâmicas de um sistema através da medição de dados de entrada e/ou saída. A partir do início da década de 1970, ocorreu um forte desenvolvimento de métodos de identificação de parâmetros modais, resultantes das facilidades proporcionadas pela implementação de um algoritmo que realizasse eficientemente o cálculo computacional de séries de Fourier (MAIA \& SILVA, 1997).

Os métodos criados desde então diferem entre si em respeito ao tipo de dados de entrada, ao tipo de processamento matemático dos dados e ao tipo de saída produzida.

Durante as últimas três décadas, várias pesquisas foram desenvolvidas para fornecer ferramentas confiáveis na identificação de propriedades dinâmicas de uma estrutura. Neste contexto, vários métodos foram desenvolvidos para a identificação de parâmetros modais de uma estrutura mecânica através de dados na forma de resposta impulsiva, de decaimento livre ou de função resposta em freqüência. Esta consideração faz com que os algoritmos deste grupo de estudos 
estejam no domínio do tempo e no domínio da freqüência. Os parâmetros modais são geralmente obtidos através da ajustagem de curvas aos dados medidos e esta ajustagem é feita baseada no método dos mínimos quadrados. Deve-se ainda observar que a identificação modal pode ser do tipo modo a modo, onde cada modo é identificado separadamente, ou multi-modos, onde vários modos são identificados simultaneamente em uma faixa de freqüência (IBRAHIM, 1985).

Os métodos de identificação modal, independentemente do domínio sob o qual são definidos, são classificados como métodos diretos e indiretos. Os métodos diretos, menos comuns, são aqueles que identificam o modelo espacial, ou seja, as matrizes de massa, rigidez e amortecimento. Os métodos indiretos são aqueles que identificam o modelo modal dado pelos parâmetros globais, que são as freqüências naturais e os fatores de amortecimento modal e pelos parâmetros denominados locais a partir dos quais são determinados os modos de vibrar (PAZIANI, 2002).

$\mathrm{Na}$ prática, os métodos de identificação no domínio da freqüência têm predominado devido à difusão de analisadores de espectro microprocessados. Estes métodos fornecem melhores resultados comparados com os métodos no domínio do tempo quando a faixa de freqüência ou números de modos escolhidos são relativamente pequenos. Já os métodos no domínio do tempo apresentam melhores resultados quando a faixa de freqüência escolhida é relativamente grande (MAIA \& SILVA, 1997).

Os métodos de identificação no domínio da freqüência usam como dados de entrada a FRF do sistema. Um dos primeiros métodos nesta área foi proposto por KENNEDY \& PANCU (1947). O método apresenta aplicações na determinação de freqüências naturais e níveis de amortecimento em uma estrutura aeronáutica. Este método realiza a identificação modo a modo e é conhecido como método de ajustagem do círculo. Sua aplicação é restrita a sistemas que possuam freqüências naturais distantes umas das outras.

Segundo VAROTO (1991), a identificação multi-modos no domínio da freqüência pode ser feita usando-se duas formas equivalentes da FRF do sistema: a forma polinomial e a forma em frações parciais. Na primeira procura-se ajustar os dados experimentais à uma função de transferência dada pelo quociente de dois polinômios. Na forma de frações parciais, os parâmetros modais são obtidos 
diretamente da ajustagem de curvas. Recentemente, VAROTO (1991), apresentou o método de identificação na forma polinomial através de um ensaio experimental em uma placa de alumínio.

A identificação de parâmetros modais no domínio do tempo usa a resposta ao impulso do sistema na extração dos parâmetros modais. Esta resposta ao impulso é geralmente obtida tomando-se a transformada inversa de Fourier (IFFT) dos dados da FRF do sistema. A desvantagem deste método é que a seqüência de parâmetros de Markov (resposta ao impulso) obtida é distorcida por efeito de aliasing. Recentemente, BAYARD (1992) desenvolveu um método para obtenção dos parâmetros de Markov de FRFs sem distorções. O inconveniente deste método é que o problema de ajuste de curvas precisa ser resolvido por otimização não-linear ou por um algoritmo iterativo linear aproximado, sofrendo de problemas de convergência. Posteriormente, o algoritmo de Bayard foi modificado de tal forma que o problema de ajuste de curvas é reformulado como um problema linear que pode ser resolvido por método de mínimos quadrados em um só passo, evitando inúmeras iterações (CHEN et al., 1994).

Assim, tem-se o método da exponencial complexa de mínimos quadrados proposto por BROWN et al. (1979), o método de polireferência no domínio do tempo apresentado por VOLD et al. (1982) e o método de Ibrahim no domínio do tempo (IBRAHIM \& MIKULCIK, 1977). Este último consegue identificar a ordem do modelo usando fatores de coerência modal a partir de sinais afetados por ruído. Nos três algoritmos citados acima, os dados são modelados como uma expansão ponderada de modos efetivos de vibração. Em outras palavras, a partir dos dados, é derivada uma equação homogênea de diferenças finitas que tem nos modos de vibração suas soluções características. Logo, é calculada a contribuição de cada modo de vibração na resposta do sistema.

Uma abordagem unificada dos métodos de identificação no domínio do tempo resultou na revisão do Método Direto de Identificação de Parâmetros de Sistemas (LEURIDAN et al., 1986). Este método permite a análise simultânea de dados do tipo MIMO para estimar os parâmetros modais de estruturas, utilizando um modelo multi-variável na forma de uma equação não-homogênea de diferenças finitas. 
Nos últimos anos, muitos algoritmos para a construção de representação de espaço de estado de sistemas lineares apareceram na teoria de identificação de sistemas. Um dos algoritmos utilizados na área aeroespacial a partir da década de 80 foi o Algoritmo de Realização de Sistemas (ERA). Segundo PAPPA et al. (1991), o ERA é um moderno e poderoso método de identificação modal, capaz de identificar estruturas que apresentem comportamento dinâmico complexo. É um método no domínio do tempo, de múltiplas entradas e múltiplas saídas que identifica eficientemente muitos modos simultaneamente, inclusive modos pobremente excitados e agrupados. O algoritmo foi desenvolvido por JUANG \& PAPPA (1985) combinando o algoritmo de realização de sistemas de Ho-Kalman com a decomposição em valores singulares, para obter uma realização mínima do sistema.

A utilização da decomposição em valores singulares pelo $E R A$ possibilita a determinação da ordem do sistema através da análise dos valores singulares. A sensibilidade deste algoritmo na presença de ruído foi estudada por JUANG \& PAPPA (1986), utilizando índices de confiança para a separação entre modos computacionais e modos físicos. JUANG et al. (1988) desenvolveram um método baseado no ERA denominado Algoritmo de Realização de Sistemas com Correlação de Dados $(E R A / D C)$ com o intuito de minimizar a influência de ruído nos resultados da identificação. Outra variante do algoritmo é o Observer/Kalman Filter, cujo objetivo é comprimir a informação numa menor quantidade de dados e, desta forma, reduzir o esforço computacional e melhorar os resultados obtidos. Os parâmetros de Markov são obtidos a partir de um filtro de Kalman aplicados aos dados experimentais e, posteriormente são utilizados para a identificação através do $E R A$. Este método necessita da aquisição simultânea de dados de entrada e saída no domínio do tempo (JUANG et al., 1993).

Da mesma forma que o $E R A$, outros algoritmos de realização foram desenvolvidos recentemente, tais como o algoritmo Q-Markov, usado originalmente para a redução de modelos (LIU \& SKELTON, 1993), e o algoritmo $M D V V$, assim denominado por MOONEN et al. (1989). Uma comparação entre o ERA, ERA/DC, $Q-M a r k o v$ e o $M D V V$ foi feita por LEW et al. (1993), onde mostram que o ERA/DC fornece melhores resultados na análise de uma estrutura composta por treliças de 
$20 m$ de altura, usada para análise e pesquisa na área de análise estrutural no laboratório Langley Research Center da NASA, Estados Unidos.

Um estudo realizado por COOPER (1997) desenvolve uma versão on-line do $E R A / D C$ baseada na decomposição $Q R$ e apresenta alguns resultados obtidos com dados afetados por um ruído na medição. Já PETERSON (1995), desenvolveu uma formulação algébrica alternativa do $E R A$ para um cálculo computacional eficiente. Com esta formulação, conseguiu-se processar uma grande quantidade de dados com uma maior velocidade em comparação com a versão original do $E R A$. Para isto, foi usada a decomposição de autovalores parciais do produto interno ou externo da matriz Hankel e de sua transposta. Além disso, apresentou algumas estratégias para a implementação do algoritmo em computadores de arquitetura moderna.

Recentemente, TASKER et al. (1998) desenvolveram dois novos algoritmos para identificação de parâmetros modais em tempo real ou on-line. Estes métodos são baseados na estimação de parâmetros modais em tempo real utilizando o método do subespaço. Segundo os autores, os métodos são relacionados com o $E R A$ através de uma recente derivação estendida do $E R A$. Um estudo experimental e teórico foi desenvolvido por TASKER et al. (1998) aplicando-se a teoria desenvolvida no trabalho citado anteriormente em uma estrutura composta por treliças. A identificação em tempo real vem sendo tradicionalmente utilizada na área de processamento de sinais e engenharia de controle. Somente em anos recentes têmse intensificado os esforços na sua utilização ou adaptação à área de dinâmica estrutural.

Devido as dificuldades na análise dos resultados da identificação, alguns algoritmos visando a automatização do processo de identificação têm sido propostos. Algumas destas propostas, baseadas no ERA, fazem uso intensivo de índices de confiança e proporcionam a identificação autônoma de estruturas (TSUNAKI, 1999).

PAPPA et al. (1997a) utilizaram dois índices, $C M I$ e $M A C$, para realizar a condensação modal dos resultados obtidos de múltiplas estimativas (conjunto de resultados de uma identificação), com o objetivo de obter um método de identificação autônomo para ser utilizado como uma técnica de detecção de danos estruturais através do monitoramento contínuo ou periódico da estrutura, principalmente de espaçonaves. A aplicação desses algoritmos de condensação 
modal são utilizados por PAPPA et al. (1997b) na identificação de parâmetros modais no leme do ônibus espacial. A Figura 1.7 mostra o ônibus espacial e o ambiente de ensaio experimental. Um outro trabalho apresentado por PAPPA (1997c), utilizando os algoritmos de condensação modal, é realizado em um equipamento da estação espacial no laboratório Langley Research Center da NASA, Estados Unidos, tendo como objetivo a identificação de parâmetros modais experimentais para a validação do modelo analítico.
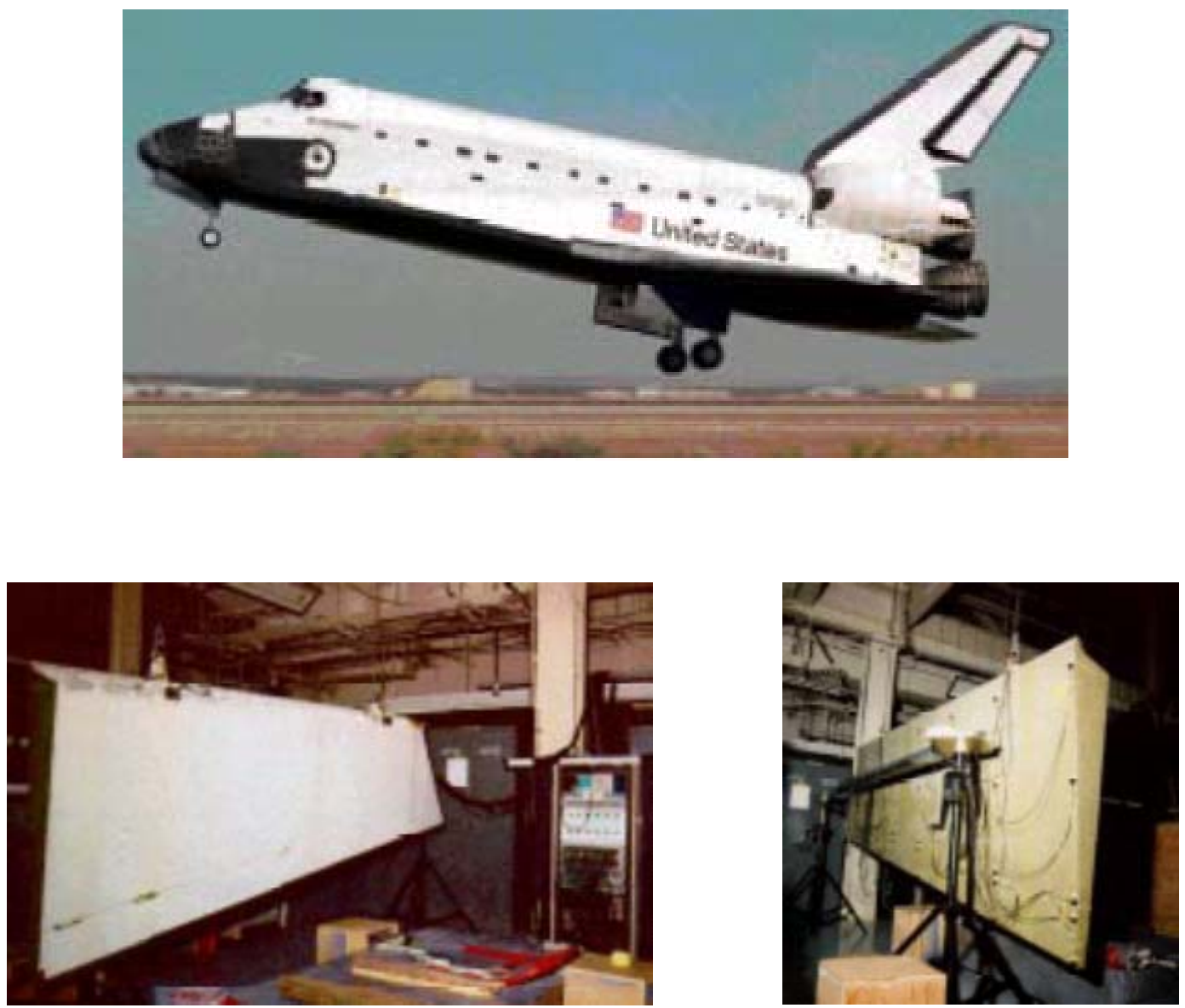

Figure 1.7 - Esquema do ensaio experimental (PAPPA et al., 1997b). 


\section{4 - OBJETIVOS DO TRABALHO}

O objetivo deste trabalho é identificar o comportamento dinâmico de uma estrutura aeronáutica. Para isso, um ensaio modal experimental em uma das semiasas da aeronave Neiva Regente é realizado. O método de identificação utilizado para a obtenção dos parâmetros globais do sistema, freqüências naturais e fatores de amortecimento modal, e também dos modos de vibrar da estrutura é o Algoritmo de Realização de Sistemas - ERA. O algoritmo é previamente verificado através da identificação de parâmetros modais de um modelo hipotético e de uma estrutura real, no caso, uma viga de alumínio.

Em seguida, aplica-se o algoritmo para dados experimentais medidos na semi-asa da aeronave Neiva Regente, obtendo, então, as características dinâmicas. Os aspectos relacionados à montagem experimental, aquisição e tratamento dos dados também são discutidos. Os resultados obtidos da aplicação do $E R A$ são então quantificados através de índices de confiança. Os índices Colinearidade de Fase Modal Ponderada, Coerência da Amplitude Modal Estendida e Indicador de Consistência Modal são apresentados, visando à qualificação dos parâmetros modais identificados

As técnicas experimentais utilizadas para análise de vibração em estruturas aeronáuticas, a aplicação do $E R A$, seu estudo e análise são consideradas as principais contribuições deste trabalho para o campo de identificação modal no contexto da aeroelasticidade.

\section{5 - ORGANIZAÇÃO DA DISSERTAÇÃO}

Este primeiro Capítulo apresenta uma introdução ao assunto abordado neste trabalho de pesquisa e a revisão da literatura relacionada com o tema. Em seguida, são apresentados os objetivos pretendidos por este trabalho.

O Capítulo 2 é dedicado à teoria envolvida na realização de sistemas dinâmicos através de conceitos relativos à representação de modelos dinâmicos no espaço de estado em tempo contínuo e em tempo discreto. É dado um significado aos 
parâmetros de Markov, relacionando-os às propriedades do sistema. São desenvolvidos os conceitos relativos às equações de estado nas coordenadas modais e os fundamentos de observabilidade e controlabilidade. Posteriormente, é desenvolvida a formulação básica do Algoritmo de Realização de Sistemas - ERA, assim como a definição dos índices de confiança $E M A C, M P C W$ e $C M I$.

No Capítulo 3 são apresentados os resultados da verificação do Algoritmo de Realização de Sistemas. Inicialmente, a aplicação do ERA é realizada em um sistema simulado de três graus de liberdade (massa-mola-amortecedor). Em seguida, a identificação de parâmetros modais de uma viga de alumínio é procedida através de dados experimentais.

No Capítulo 4 são apresentados os resultados da aplicação do Algoritmo de Realização de Sistemas em uma estrutura aeronáutica, ou seja, na semi-asa da aeronave Neiva Regente.

O último Capítulo trata das conclusões gerais sobre os resultados do trabalho e o que foi alcançado em termos do que é proposto. Seguem, então, sugestões para trabalhos futuros.

Finalmente, os Apêndices A e B são apresentados e tratam dos dados relativos às funções resposta em freqüência (FRF) medidos sobre a viga de alumínio e sobre a semi-asa do Neiva Regente durante os ensaios experimentais realizados neste trabalho. Estes dados serviram de base para a geração das funções resposta ao impulso, estas utilizadas como base do método de identificação proposto. 


\section{CAPÍTULO 2}

\section{IDENTIFICAÇÃO DE SISTEMAS DINÂMICOS - O}

\section{ALGORITMO DE REALIZAÇÃO DE SISTEMAS}

No estudo de um sistema dinâmico é importante conhecer o modelo matemático que descreve seu comportamento. Na descrição dos métodos utilizados para o desenvolvimento deste trabalho, é necessário o conhecimento de conceitos envolvidos na representação matemática de sistemas dinâmicos. Realização é uma forma de identificar um sistema dinâmico preservando propriedades básicas deste sistema. Um sistema dinâmico pode ter várias realizações equivalentes, em diferentes formas. $\mathrm{Na}$ forma de espaço de estado, representa-se um sistema como um conjunto de $n$ equações diferenciais de primeira ordem (se for contínuo no tempo) ou equações de diferença (se for discreto no tempo) de primeira ordem, as quais podem ser organizadas na forma matricial. A principal vantagem desta representação é que permite analisar um sistema com múltiplas entradas e múltiplas saídas.

Em certas situações não é possível obter um modelo analítico com a precisão desejada. Nestes casos, torna-se necessária a obtenção de um modelo através de dados experimentais. O algoritmo de realização de sistemas é um algoritmo de realização mínima, além disso, é balanceado internamente, o que garante que o modelo realizado seja completamente observável e controlável. Um problema relacionado com a realização de sistemas é a determinação da ordem do modelo, pois existem infinitas realizações que representam a mesma relação de 
entrada e saída. Realização mínima significa o modelo com a menor dimensão de espaço de estado, dentre os possíveis sistemas que têm a mesma relação de entrada e saída, dentro de um grau de precisão específico (JUANG \& PAPPA, 1985).

Para tanto, este capítulo é dividido como se segue. Inicialmente, são desenvolvidos e discutidos conceitos relativos à representação de modelos dinâmicos no espaço de estado em tempo contínuo e em tempo discreto. É dado um significado aos parâmetros de Markov e a matriz Hankel, relacionando-os às propriedades do sistema. Na seqüência, são desenvolvidos os conceitos relativos às equações de estado nas coordenadas modais. Em seguida, os fundamentos de observabilidade e controlabilidade de sistemas são apresentados. Posteriormente, é apresentada a formulação básica do Algoritmo de Realização de Sistemas - ERA, utilizado para o processo de identificação neste trabalho. Finalmente, são apresentados os três índices de confiança utilizados para qualificar os dados da identificação.

\section{1 - MODELOS NO ESPAÇO DE ESTADO EM TEMPO CONTÍNUO}

As equações de movimento de um sistema dinâmico, linear, invariante no tempo, de dimensão finita, com $n$ graus de liberdade ( $n$ GDL) podem ser representadas através de um sistema de equações diferenciais de segunda ordem

$$
[M]\{\ddot{w}(t)\}+[C]\{\dot{w}(t)\}+[K]\{w(t)\}=\{f(w, t)\}
$$

onde $[M],[C]$ e $[K]$ são as matrizes de massa, de amortecimento e de rigidez, respectivamente, todas de dimensão $n \times n ;\{\ddot{w}(t)\},\{\dot{w}(t)\}$ e $\{w(t)\}$ são os vetores aceleração, velocidade e deslocamento generalizado, respectivamente, todos de dimensão $n \times 1$; e $\{f(w, t)\}$ é o vetor força nas coordenadas generalizadas, $n \times 1$. Nota-se que $\{f(w, t)\}$ também pode ser expresso por

$$
\{f(w, t)\}=\left[B_{2}\right]\{u(t)\}
$$


onde $\left[B_{2}\right]$ é a matriz de influência de entrada que caracteriza a localização e os tipos de entrada, dimensão $n \times r,\{u(t)\}$ é o vetor de entrada, dimensão $r \times 1$, onde $r$ é o número de entradas (excitações externas). Substituindo a equação (2.2) no sistema dado pela equação (2.1), obtém-se

$$
[M]\{\ddot{w}(t)\}+[C]\{\dot{w}(t)\}+[K]\{w(t)\}=\left[B_{2}\right]\{u(t)\}
$$

A equação (2.3) pode ser reescrita como um sistema de $2 n$ equações diferenciais de primeira ordem:

$$
\{\dot{x}(t)\}=\left[A_{c}\right]\{x(t)\}+\left[B_{c}\right]\{u(t)\}
$$

onde

$$
\begin{aligned}
& {\left[A_{c}\right]=\left[\begin{array}{cc}
{[0]} & {[I]} \\
-[M]^{-1}[K] & -[M]^{-1}[C]
\end{array}\right]} \\
& {\left[B_{c}\right]=\left[\begin{array}{c}
{[0]} \\
-[M]^{-1}\left[B_{2}\right]
\end{array}\right]} \\
& \{x(t)\}=\left\{\begin{array}{l}
\{w(t)\} \\
\{\dot{w}(t)\}
\end{array}\right\}
\end{aligned}
$$

sendo que, $\left[A_{c}\right]$ é a matriz de estado $(2 n \times 2 n),\left[B_{c}\right]$ é a matriz de influência de entrada $(2 n \times r),\{x(t)\}$ é o vetor de estado $(2 n \times 1),[0]$ é a matriz de zeros $(n \times r)$ e $[I]$ é a matriz identidade de ordem $n$.

O sistema dado pela equação (2.4) corresponde às denominadas equações de estado. O sub-índice $c$ indica que as matrizes $\left[A_{c}\right]$ e $\left[B_{c}\right]$ pertencem à representação do sistema em tempo contínuo.

$\mathrm{Na}$ identificação experimental de parâmetros modais manipulam-se medidas (respostas) relacionadas ao vetor de estado ou à sua derivada. Assim, 
conforme o tipo de sensor (acelerômetro, extensômetro, vibrômetro à laser, etc.), pode-se medir, diretamente ou não, aceleração, velocidade ou deslocamento (TSUNAKI, 1999).

Segundo JUANG (1994), um sistema dinâmico de equações que expresse $m$ quantidades de medidas de saída pode ser representado na seguinte forma:

$$
\{y(t)\}=\left[V_{a}\right]\{\ddot{w}(t)\}+\left[V_{v}\right]\{\dot{w}(t)\}+\left[V_{d}\right]\{w(t)\}
$$

onde $\{y(t)\}$ é o vetor de saída do sistema, medido através de sensores, de dimensão $m \times 1 ;\left[V_{a}\right],\left[V_{v}\right]$ e $\left[V_{d}\right]$ são as matrizes de influência de saída para aceleração, velocidade e deslocamento, respectivamente, de dimensão $m \times n$.

Essas matrizes de influência de saída contém informações da localização dos pontos de medida em relação às variáveis nas coordenadas generalizadas, e podem conter também fatores de conversão entre as unidades físicas das medidas de saída e as unidades das variáveis de estado (JUANG, 1994).

Isolando o vetor aceleração na equação (2.3), substituindo-a na equação (2.5) obtém-se

$$
\begin{aligned}
\{y(t)\} & =\left(\left[V_{d}\right]-\left[V_{a}\right][M]^{-1}[K]\right)\{w(t)\}+ \\
& +\left(\left[V_{v}\right]-\left[V_{a}\right][M]^{-1}[C]\right)\{\dot{w}(t)\}+\left[V_{a}\right][M]^{-1}\left[B_{2}\right]\{u(t)\}
\end{aligned}
$$

A equação (2.6) pode ser reescrita como

$$
\{y(t)\}=\left[C_{c}\right]\{x(t)\}+\left[D_{c}\right]\{u(t)\}
$$

onde

$$
\begin{gathered}
{\left[C_{c}\right]=\left[\left[V_{d}\right]-\left[V_{a}\right][M]^{-1}[K] \quad\left[V_{v}\right]-\left[V_{a}\right][M]^{-1}[C]\right]} \\
\mathrm{e} \\
{\left[D_{c}\right]=\left[V_{a}\right][M]^{-1}\left[B_{2}\right]}
\end{gathered}
$$


sendo que, $\left[C_{c}\right]$ é a matriz de influência de saída no espaço de estado, de dimensão $m \times 2 n ;\left[D_{c}\right]$ é a matriz de transmissão direta, de dimensão $m \times r$. A matriz $\left[D_{c}\right]$ é diferente de zero quando se realizam medidas de aceleração.

As equações (2.4) e (2.7) constituem o modelo no espaço de estado em tempo contínuo, que caracteriza totalmente a dinâmica do sistema e sua relação com as diversas medidas de saída que podem ser realizadas.

A solução completa da equação (2.4) pode ser obtida em duas etapas. Segundo FURUTA et al. (1988), inicialmente considera-se a equação homogênea,

$$
\{\dot{x}(t)\}=\left[A_{c}\right]\{x(t)\}
$$

Dada a condição inicial $\left\{x\left(t_{0}\right)\right\}$ no tempo $t=t_{0}$, pode-se facilmente obter a solução da equação (2.9) através de

$$
\{x(t)\}=e^{\left[A_{c}\right]\left(t-t_{0}\right)}\left\{x\left(t_{0}\right)\right\}
$$

onde $e^{\left[A_{c}\right]\left(t-t_{0}\right)}$ é denominada matriz de transição de dimensão $2 n \times 2 n$, que pode ser aproximada por uma série que converge uniformemente, dada por

$$
e^{\left[A_{c}\right]\left(t-t_{0}\right)}=\left[I_{2 n}\right]+\left[A_{c}\right]\left(t-t_{0}\right)+\frac{1}{2 !}\left[A_{c}\right]^{2}\left(t-t_{0}\right)^{2}+\ldots
$$

$\mathrm{Na}$ segunda etapa procura-se a solução particular da equação (2.4). Segundo MEIROVITCH (1990), esta solução é dada por

$$
\{x(t)\}=e^{[A c]\left(t-t_{0}\right)}\{\Phi(t)\}
$$

onde $\{\Phi(t)\}$ é um vetor $2 n \times 1$. Derivando no tempo a equação (2.12), obtém-se

$$
\{\dot{x}(t)\}=\left[A_{c}\right] e^{\left[A_{c}\right]\left(t-t_{0}\right)}\{\Phi(t)\}+e^{\left[A_{c}\right]\left(t-t_{0}\right)}\{\dot{\Phi}(t)\}
$$


Substituindo a equação (2.12) e a sua derivada dada na equação (2.13) no sistema dado pela equação (2.4), obtém-se

$$
e^{\left[A_{c}\right]\left(t-t_{0}\right)}\{\dot{\Phi}(t)\}=\left[B_{c}\right]\{u(t)\}
$$

Isolando $\{\dot{\Phi}(t)\}$ na equação (2.14) e integrando de $t_{0}$ a $t$, obtém-se

$$
\{\Phi(t)\}=\int_{t_{0}}^{t} e^{\left[A_{c}\right]\left(t_{0}-\tau\right)}\left[B_{c}\right]\{u(\tau)\} d \tau
$$

Substituindo a equação (2.15) na equação (2.12), tem-se

$$
\{x(t)\}=\int_{t_{0}}^{t} e^{\left[A_{c}\right](t-\tau)}\left[B_{c}\right]\{u(\tau)\} d \tau
$$

A solução completa da equação de estado é a soma da solução homogênea dada na equação (2.10) com a particular dada pela equação (2.16), válida para $t>t_{0}$,

$$
\{x(t)\}=e^{\left[A_{c}\right]\left(t-t_{0}\right)}\left\{x\left(t_{0}\right)\right\}+\int_{t_{0}}^{t} e^{\left[A_{c}\right](t-\tau)}\left[B_{c}\right]\{u(\tau)\} d \tau
$$

\section{2 - MODELOS NO ESPAÇO DE ESTADO EM TEMPO DISCRETO}

A hipótese fundamental para que se possa transformar a solução da equação (2.17) da equação de estado em tempo contínuo, em uma representação em tempo discreto é que o sistema tenha entradas discretizadas no tempo.

Dados intervalos de tempo igualmente espaçados de $\Delta t$, de forma que a variável tempo $t$ assuma os valores

$$
t=0, \Delta t, 2 \Delta t, 3 \Delta t, \ldots, k \Delta t,(k+1) \Delta t, \ldots
$$


o vetor de estado $\{x(t)\}$ pode ser obtido num dado tempo $t=(k+1) \Delta t$, em relação ao estado no tempo imediatamente anterior, $t_{0}=k \Delta t$, e através da equação (2.17), tem-se

$$
\{x((k+1) \Delta t)\}=e^{\left[A_{c}\right] \Delta t}\{x(k \Delta t)\}+\int_{k \Delta t}^{(k+1) \Delta t} e^{\left[A_{c}\right]((k+1) \Delta t-\tau)}\left[B_{c}\right]\{u(\tau)\} d \tau
$$

Assume-se que o vetor de entrada $\{u(\tau)\}$ é constante entre intervalos de tempo. Segundo JUANG (1987), este vetor deve satisfazer a relação

$$
\{u(\tau)\}=\{u(k \Delta t)\} \text { para } k \Delta t \leq \tau \leq(k+1) \Delta t ; k=0,1,2,3, \ldots
$$

Substituindo $\{u(\tau)\}$, dado pela equação (2.20), na equação (2.19), obtémse

$$
\{x((k+1) \Delta t)\}=e^{\left[A_{c}\right] \Delta t}\{x(k \Delta t)\}+\left[\int_{k \Delta t}^{[(k+1) \Delta t} e^{\left[A_{c}\right]((k+1) \Delta t-\tau)}\left[B_{c}\right] d \tau\right]\{u(k \Delta t)\}
$$

A equação (2.21) é simplificada mudando-se a variável de integração para $\widehat{\tau}=(k+1) \Delta t-\tau$ e os respectivos limites de integração, ou seja:

$$
\{x((k+1) \Delta t)\}=e^{\left[A_{c}\right] \Delta t}\{x(k \Delta t)\}+\left[\int_{0}^{\Delta t} e^{\left[A_{c}\right] \bar{\tau}}\left[B_{c}\right] d \hat{\tau}\right]\{u(k \Delta t)\}
$$

\section{Definindo}

$$
\left[A_{d}\right]=e^{\left[A_{c}\right] \Delta t}
$$

$\mathrm{e}$

$$
\left[B_{d}\right]=\int_{0}^{\Delta t} e^{\left[A_{c}\right] \hat{\tau}}\left[B_{c}\right] d \hat{\tau}
$$


onde o subscrito $d$ é relativo ao tempo discreto, e utilizando-se a notação:

$$
\begin{gathered}
\{x(k+1)\}=\{x(k+1) \Delta t\} \\
\{u(k)\}=\{u(k \Delta t)\}
\end{gathered}
$$

a equação (2.22) pode ser escrita como

$$
\{x(k+1)\}=\left[A_{d}\right]\{x(k)\}+\left[B_{d}\right]\{u(k)\} \quad \text { para } k=0,1,2, \ldots
$$

A equação de saída (2.7) também pode ser expressa em tempo discreto observando-se que $\left[C_{d}\right]=\left[C_{c}\right]$ e $\left[D_{d}\right]=\left[D_{c}\right]$. Assim

$$
\{y(k)\}=\left[C_{d}\right]\{x(k)\}+\left[D_{d}\right]\{u(k)\}
$$

As equações (2.25) e (2.26) formam a representação das equações de estado em tempo discreto de um sistema dinâmico.

\section{3 - PARÂMETROS DE MARKOV E A MATRIZ HANKEL}

Seja o sistema linear representado pelas equações (2.25) e (2.26). Uma das vantagens desse sistema, é a facilidade de se obter os vetores de saída e de estado para uma entrada específica.

Seja o vetor de entrada representado pela seqüência:

$$
\{u(0)\},\{u(1)\},\{u(2)\}, \cdots,\{u(k)\}
$$


Supondo condições iniciais nulas $\{x(t=0)\}=\{x(0)\}=\{0\}$, os vetores de estado e de saída (equações (2.25) e (2.26)), podem ser obtidos para o vetor de entrada (2.27):

$$
\begin{aligned}
\{x(0)\}= & \{x(0)\}, \\
\{y(0)\}= & {\left[C_{d}\right]\{x(0)\}+\left[D_{d}\right]\{u(0)\}, } \\
\{x(1)\}= & {\left[A_{d}\right]\{x(0)\}+\left[B_{d}\right]\{u(0)\}, } \\
\{y(1)\}= & {\left[C_{d}\right]\left[A_{d}\right]\{x(0)\}+\left[C_{d}\right]\left[B_{d}\right]\{u(0)\}+\left[D_{d}\right]\{u(1)\}, } \\
\{x(2)\}= & {\left[A_{d}\right]^{2}\{x(0)\}+\left[A_{d}\right]\left[B_{d}\right]\{u(0)\}+\left[B_{d}\right]\{u(1)\}, } \\
\{y(2)\}= & {\left[C_{d}\right]\left[A_{d}\right]^{2}\{x(0)\}+\left[C_{d}\right]\left[A_{d}\right]\left[B_{d}\right]\{u(0)\} } \\
& +\left[C_{d}\right]\left[B_{d}\right]\{u(1)\}+\left[D_{d}\right]\{u(2)\}, \\
\vdots & \\
\{x(k)\}= & {\left[A_{d}\right]^{k}\{x(0)\}+\sum_{i=1}^{k}\left[A_{d}\right]^{i-1}\left[B_{d}\right]\{u(k-1)\}, } \\
\{y(k)\}= & {\left[C_{d}\right]\left[A_{d}\right]^{k}\{x(0)\}+\sum_{i=1}^{k}\left[C_{d}\right]\left[A_{d}\right]^{i-1}\left[B_{d}\right]\{u(k-1)\}+\left[D_{d}\right]\{u(k)\} }
\end{aligned}
$$

Os últimos dois termos da seqüência (2.28) descrevem o vetor de estado e de saída em qualquer instante de tempo $k \Delta t$ em função da seqüência (2.27), que representa um vetor de entrada genérico.

A resposta pode ser obtida considerando-se inicialmente que somente uma das variáveis de entrada será ativada, por exemplo $\left\{u_{1}\right\}$. Com isso, o vetor de entrada (2.27) com entrada na variável $\left\{u_{1}\right\}$ pode ser escrito como:

$$
\left\{\begin{array}{l}
1 \\
0 \\
\vdots \\
0
\end{array}\right\},\left\{\begin{array}{l}
0 \\
0 \\
\vdots \\
0
\end{array}\right\}, \cdots,\left\{\begin{array}{l}
0 \\
0 \\
\vdots \\
0
\end{array}\right\}
$$


Desta forma, para condições iniciais nulas $\{x(0)\}=\{0\}$, a substituição de (2.29) no vetor de saída em (2.28), resulta

$$
\begin{gathered}
\{y(0)\}=\left[D_{d}\right]\left\{\begin{array}{l}
1 \\
0 \\
\vdots \\
0
\end{array}\right\}, \\
\{y(1)\}=\left[C_{d}\right]\left[B_{d}\right]\left\{\begin{array}{l}
1 \\
0 \\
\vdots \\
0
\end{array}\right\}, \\
\{y(2)\}=\left[C_{d}\right]\left[A_{d}\right]\left[B_{d}\right]\left\{\begin{array}{l}
1 \\
0 \\
\vdots \\
0
\end{array}\right\}, \\
\vdots \\
\{y(k)\}=\left[C_{d}\right]\left[A_{d}\right]^{k-1}\left[B_{d}\right]\left\{\begin{array}{l}
1 \\
0 \\
\vdots \\
0
\end{array}\right\}
\end{gathered}
$$

onde o vetor de saída em cada instante de tempo tem dimensão $m \times 1$. Deve-se repetir o mesmo procedimento para as variáveis de entrada, resultando em vetores de saída semelhantes. Justapondo os vetores de saída de mesmo instante de tempo em matrizes, tem-se:

$$
\begin{aligned}
{\left[Y_{0}\right] } & =\left[D_{d}\right], \\
{\left[Y_{1}\right] } & =\left[C_{d}\right]\left[B_{d}\right], \\
{\left[Y_{2}\right] } & =\left[C_{d}\right]\left[A_{d}\right]\left[B_{d}\right], \\
& \vdots \\
{\left[Y_{k}\right] } & =\left[C_{d}\right]\left[A_{d}\right]^{k-1}\left[B_{d}\right]
\end{aligned}
$$


sendo

$$
\left[Y_{k}\right]= \begin{cases}{\left[D_{d}\right],} & k=0 \\ {\left[C_{d}\right]\left[A_{d}\right]^{k-1}\left[B_{d}\right],} & k>0\end{cases}
$$

onde $\left[Y_{k}\right]$ são matrizes de dimensão $m \times r$, correspondentes à resposta do sistema no instante de tempo $k \Delta t$. A $n$-ésima coluna de $\left[Y_{k}\right]$ é a resposta do sistema ao pulso aplicado na $n$-ésima entrada, mantendo-se todas as outras entradas iguais a zero. As matrizes $\left[Y_{k}\right]$ são denominadas de parâmetros de Markov do sistema (TSUNAKI, 1999).

Substituindo a equação (2.32) no vetor de saída da equação (2.28) resulta:

$$
\{y(k)\}=\left[C_{d}\right]\left[A_{d}\right]^{k}\{x(0)\}+\sum_{i=0}^{k}\left[Y_{i}\right]\{u(k-i)\}
$$

Para condições iniciais nulas $\{x(0)\}=\{0\}$, a equação (2.33) torna-se:

$$
\{y(k)\}=\sum_{i=0}^{k}\left[Y_{i}\right]\{u(k-i)\}
$$

Segundo JUANG (1994), essa descrição do sistema através da equação (2.34) é freqüentemente denominada de descrição por seqüência ponderada e expressa de forma compacta, através das respostas $\left[Y_{k}\right]$, a relação entre o vetor de saída e o vetor de entrada qualquer. Além disso, esta descrição não requer o conhecimento de estados intermediários.

Os parâmetros de Markov $\left[Y_{k}\right]$, podem ser então utilizados adequadamente na forma matricial, como:

$$
[H(k-1)]=\left[\begin{array}{cccc}
{\left[Y_{k}\right]} & {\left[Y_{k+1}\right]} & \cdots & {\left[Y_{k+\beta-1}\right]} \\
{\left[Y_{k+1}\right]} & {\left[Y_{k+2}\right]} & \cdots & {\left[Y_{k+\beta}\right]} \\
\vdots & \vdots & \ddots & \vdots \\
{\left[Y_{k+\alpha-1}\right]} & {\left[Y_{k+\alpha}\right]} & \cdots & {\left[Y_{k+\alpha+\beta-2}\right]}
\end{array}\right]
$$


A matriz $[H(k-1)]$ é denominada de matriz Hankel generalizada de dimensão $\alpha m \times \beta r$, onde $\alpha$ é o número de parâmetros de Markov numa coluna de $[H(k-1)], \beta$ o números de parâmetros de Markov numa linha de $[H(k-1)], m$ e $r$ são os números de saídas e entradas, respectivamente.

Desta forma, utilizando-se a matriz Hankel generalizada, os métodos de identificação têm a disposição, em uma única matriz, a informação necessária para realizar a identificação. Com isso, a identificação pode ser realizada em um único passo (TSUNAKI, 1999).

\section{4 - EQUAÇÕES DE ESTADO NAS COORDENADAS MODAIS}

A representação desacoplada de um modelo no espaço de estado é obtida através da transformação das equações de estado em coordenadas modais. A matriz

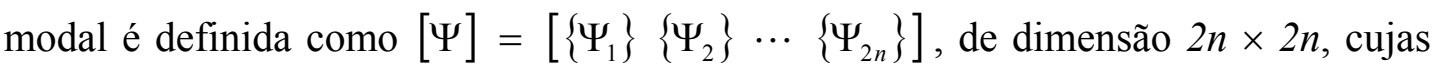
colunas são formadas pelos autovetores de $\left[A_{d}\right]$. Desta forma, podemos desenvolver uma transformação linear entre o vetor das coordenadas modais $\{x(k)\}_{M}$ e o vetor de estado $\{x(k)\}$ em tempo discreto, tal que

$$
\{x(k)\}=[\Psi]\{x(k)\}_{M}
$$

Substituindo a equação (2.36) na equação de estado (2.25) e multiplicando-a por $[\Psi]^{-1}$, temos

$$
\{x(k+1)\}_{M}=[\Lambda]\{x(k)\}_{M}+\left[B_{d}\right]_{M}\{u(k)\}
$$

onde $[\Lambda]=[\Psi]^{-1}\left[A_{d}\right][\Psi]=\operatorname{diag}\left[\lambda_{1}, \lambda_{2}, \cdots, \lambda_{2 n}\right], 2 n \times 2 n$, é a matriz diagonal formada pelos autovalores da matriz de estado. A matriz diagonal $[\Lambda]$ define o amortecimento modal e as freqüências naturais do sistema em tempo contínuo, através da relação $\left[\Lambda_{c}\right]=\frac{1}{\Delta t} \ln [\Lambda]$. A matriz $\left[B_{d}\right]_{M}=[\Psi]^{-1}\left[B_{d}\right]$ é a matriz de influência de entrada nas coordenadas modais, $2 n \times r$ e definem a amplitude modal inicial de cada modo em relação a uma determinada entrada. 
Substituindo a equação (2.36) na equação de saída (2.26) temos

$$
\{y(k)\}=\left[C_{d}\right]_{M}\{x(k)\}_{M}+\left[D_{d}\right]\{u(k)\}
$$

onde $\left[C_{d}\right]_{M}=\left[C_{d}\right][\Psi]$ é a matriz de influência de saída de dimensão $m \times 2 n$. As colunas da matriz $\left[C_{d}\right]_{M}$ contêm informação da forma dos modos conforme a localização espacial dos sensores.

As equações (2.37) e (2.38) formam a representação das equações de estado nas coordenadas modais.

\section{5 - OBSERVABILIDADE E CONTROLABILIDADE}

Observabilidade e controlabilidade são dois importantes conceitos na teoria de sistemas no espaço de estado. Controlabilidade está ligada à existência de uma função de controle que consiga levar a saída do sistema a um valor desejado. Observabilidade se relaciona com a possibilidade de determinar o comportamento interno do sistema (de todos os seus estados), dados somente os sinais de entrada e saída do sistema.

A localização dos acelerômetros está diretamente ligada ao grau de observabilidade do sistema e a localização das excitações está diretamente ligada ao grau de controlabilidade do sistema (TSUNAKI, 1999).

A seguir são apresentados os aspectos essenciais dos conceitos de observabilidade e de controlabilidade e algumas propriedades associadas a estes conceitos, baseados na teoria apresentada em JUANG (1994).

\subsection{1 - OBSERVABILIDADE}

A observabilidade está relacionada com a influência do vetor de estado no vetor de saída. Um estado $\{x(p)\}$ de um sistema linear é observável se pode ser determinado, conhecendo-se os vetores de entrada $\{u(k)\}$ e os vetores de saída $\{y(k)\}$, sobre um intervalo finito de tempo discreto, $0<k \leq p$. Se todos os estados são observáveis, o sistema é denominado completamente observável ou simplesmente, observável. 
Dado o estado inicial $\{x(0)\}$ e o vetor de entrada $\{u(k)\}=\left\{0_{r \times 1}\right\}$, $k=0,1,2, \cdots, p-1$, a condição necessária e suficiente para que o sistema seja completamente observável é que o estado inicial possa ser reconstruído através do vetor de saída $\{y(k)\}$.

Teorema 2.1: O sistema linear, em tempo discreto e de dimensão finita, de ordem $2 n,\{x(k+1)\}=\left[A_{d}\right]\{x(k)\}+\left[B_{d}\right]\{u(k)\}$, com a equação de medida de ordem $m,\{y(k)\}=\left[C_{d}\right]\{x(k)\}+\left[D_{d}\right]\{u(k)\}$, é observável se e se somente se a matriz de observabilidade $\left[P_{p}\right\rfloor$, de dimensão $m p \times 2 n$, tem posto $2 n$.

Substituindo o vetor de entrada $\{u(k)\}=\{0\}$ nas equações (2.28), tem-se

$$
\begin{aligned}
\{y(0)\} & =\left[C_{d}\right]\{x(0)\}, \\
\{y(1)\} & =\left[C_{d}\right]\left[A_{d}\right]\{x(0)\}, \\
\{y(2)\} & =\left[C_{d}\right]\left[A_{d}\right]^{2}\{x(0)\}, \\
& \vdots \\
\{y(p-1)\} & =\left[C_{d}\right]\left[A_{d}\right]^{p-1}\{x(0)\}
\end{aligned}
$$

Esta equação pode ser escrita na forma matricial, como

$$
\left[\begin{array}{c}
\{y(0)\} \\
\{y(1)\} \\
\{y(2)\} \\
\vdots \\
\{y(p-1)\}
\end{array}\right]=\left[P_{p}\right]\{x(0)\}
$$

onde

$$
\left[P_{p}\right]=\left[\begin{array}{c}
{\left[C_{d}\right]} \\
{\left[C_{d}\right]\left[A_{d}\right]} \\
{\left[C_{d}\right]\left[A_{d}\right]^{2}} \\
\vdots \\
{\left[C_{d}\right]\left[A_{d}\right]^{p-1}}
\end{array}\right]
$$

é a matriz de observabilidade $(m p \times 2 n)$. Existe uma única solução da equação (2.40) se e somente se $\left[P_{p}\right\rfloor$ tem posto de $2 n$. 
Baseado no Teorema 2.1, uma interpretação física do conceito de observabilidade pode ser dada através da equação de medida nas coordenadas modais $\{y(k)\}=\left[C_{d}\right]_{M}\{x(k)\}_{M}+\left[D_{d}\right]\{u(k)\}$. Supondo-se que exista somente um sensor, a equação de medida resulta:

$$
\{y(k)\}=\left\{c_{1} c_{2} \cdots c_{2 n}\right\}_{M}\left\{\begin{array}{c}
x_{1}(k) \\
x_{2}(k) \\
\vdots \\
x_{2 n}(k)
\end{array}\right\}_{M}+\left[D_{d}\right]\{u(k)\}
$$

Se algum elemento $c_{i}=0$, ou seja, se o sensor estiver localizado sobre a linha nodal do $i$-ésimo modo, então não haverá contribuição da coordenada $x_{i m}$ na saída $\{y(k)\}$, desta forma, este modo não será observável.

\subsection{2 - CONTROLABILIDADE}

A controlabilidade refere-se a influência do vetor de entrada no vetor de estado, não precisando da equação de saída. O problema principal é determinar se é possível levar ao sistema de um estado inicial a qualquer estado arbitrário pela ação de um vetor de entrada (vetor de controle).

O estado $\{x(p)\}$ de um sistema é dito controlável se a partir de um estado inicial qualquer $\{x(0)\}$, o sistema atingir o estado $\{x(p)\}$ em um intervalo de tempo finito sob alguma ação de controle. Se todos os estados são controláveis, o sistema é denominado completamente controlável ou simplesmente, controlável.

Teorema 2.2: O sistema linear, em tempo discreto e de dimensão finita, de ordem $2 n,\{x(k+1)\}=\left[A_{d}\right]\{x(k)\}+\left[B_{d}\right]\{u(k)\}$, é controlável se e somente se a matriz de controlabilidade $\left\lfloor Q_{p}\right\rfloor$, de dimensão $2 n \times$ pr, têm posto $2 n$.

Seja o estado inicial $\{x(0)\}=\{0\}$. Assim, o vetor de estado da equação (2.28) torna-se

$$
\{x(p)\}=\sum_{i=1}^{p}\left[A_{d}\right]^{i-1}\left[B_{d}\right]\{u(p-i)\}
$$


ou em uma forma compacta



Define-se a matriz de controlabilidade $\left\lfloor Q_{p}\right\rfloor$ de dimensão $2 n \times p r$.

$$
\left.\left[Q_{p}\right]=\mid\left[\begin{array}{llll}
\left.B_{d}\right] & {\left[A_{d}\right.}
\end{array}\right]\left[B_{d}\right]\left[A_{d}\right]^{2}\left[B_{d}\right] \cdots\left[A_{d}\right]^{p-1}\left[B_{d}\right]\right\rfloor
$$

Baseado no Teorema 2.2, uma interpretação física do conceito de controlabilidade pode ser dada através da equação de estado nas coordenadas modais $\{x(k+1)\}_{M}=[\Lambda]\{x(k)\}_{M}+\left[B_{d}\right]_{M}\{u(k)\}$. Supondo-se que exista somente um excitador, a equação de estado fica igual a:

$$
\left\{\begin{array}{c}
x_{1}(p) \\
x_{2}(p) \\
\vdots \\
x_{2 n}(p)
\end{array}\right\}=[\Lambda]\{x(p-1)\}_{M}+\left\{\begin{array}{c}
b_{1} \\
b_{2} \\
\vdots \\
b_{2 n}
\end{array}\right\}_{M}\{u(p-1)\}
$$

Se algum elemento $b_{i}=0$, ou seja, se o excitador estiver localizado sobre a linha nodal do $i$-ésimo modo, então a entrada não conseguirá excitar o $i$-ésimo modo (a coordenada modal $x_{i M}$ ), desta forma, este modo não será controlável.

\subsection{3 - MATRIZ HANKEL E AS MATRIZES DE OBSEVABILIDADE E CONTROLABILIDADE}

A matriz Hankel generalizada dada pela equação (2.35) pode ser escrita em termos das matrizes de observabilidade da equação (2.41) e controlabilidade da 
equação (2.45). Substituindo os parâmetros de Markov da equação (2.32) na matriz Hankel, tem-se:

$$
[H(k-1)]=\left[\begin{array}{cccc}
{\left[C_{d}\right]\left[A_{d}\right]^{k-1}\left[B_{d}\right]} & {\left[C_{d}\right]\left[A_{d}\right]^{k}\left[B_{d}\right]} & \cdots & {\left[C_{d}\right]\left[A_{d}\right]^{k+\beta-2}\left[B_{d}\right]} \\
{\left[C_{d}\right]\left[A_{d}\right]^{k}\left[B_{d}\right]} & {\left[C_{d} \llbracket\left[A_{d}\right]^{k+1}\left[B_{d}\right]\right.} & \cdots & {\left[C_{d}\right]\left[A_{d}\right]^{k+\beta-1}\left[B_{d}\right]} \\
\vdots & \vdots & \ddots & \vdots \\
{\left[C_{d}\right]\left[A_{d}\right]^{k+\alpha-2}\left[B_{d}\right]} & {\left[C_{d} \llbracket\left[A_{d}\right]^{k+\alpha-1}\left[B_{d}\right]\right.} & \cdots & {\left[C_{d}\right]\left[A_{d}\right]^{k+\alpha+\beta-3}\left[B_{d}\right]}
\end{array}\right]
$$

Reagrupando a equação (2.47), tem-se:

$[H(k-1)]=\left[\begin{array}{c}{\left[C_{d}\right]} \\ {\left[C_{d}\right]\left[A_{d}\right]} \\ {\left[C_{d}\right]\left[A_{d}\right]^{2}} \\ \vdots \\ {\left[C_{d}\right]\left[A_{d}\right]^{\alpha-1}}\end{array}\right]\left[A_{d}\right]^{k-1}\left[\left[B_{d}\right]\left[A_{d}\right]\left[B_{d}\right]\left[A_{d}\right]^{2}\left[B_{d}\right] \cdots\left[A_{d}\right]^{\beta-1}\left[B_{d}\right]\right]$

ou seja

$$
[H(k-1)]=\left[P_{\alpha}\right]\left[A_{d}\right]^{k-1}\left[Q_{\beta}\right]
$$

A equação (2.48) expressa a matriz Hankel $[H(k-1)]$ em função das matrizes de observabilidade $\left[P_{\alpha}\right]$, controlabilidade $\left[Q_{\beta}\right\rfloor$ e da matriz de estado $\left[A_{d}\right]$.

Para $k=1$ a matriz Hankel torna-se

$$
[H(0)]=\left[P_{\alpha}\right]\left\lfloor Q_{\beta}\right\rfloor
$$


Uma das vantagens de expressar a matriz Hankel na forma da equação (2.49) é tornar mais explícita uma discussão sobre o seu posto. O posto da matriz Hankel é igual ao menor posto entre as matrizes de observabilidade e controlabilidade. As matrizes de observabilidade e controlabilidade têm posto menor ou igual ao posto da matriz de estado. Se o sistema for completamente observável e controlável, o posto das matrizes de observabilidade e de controlabilidade é o mesmo e é idêntico à ordem do sistema (TSUNAKI, 1999).

\section{6 - ALGORITMO DE REALIZAÇÃO DE SISTEMAS - ERA}

O ERA é um algoritmo de realização mínima e tem duas etapas bem definidas: formulação básica de uma realização de ordem mínima e identificação de parâmetros modais. Na etapa de formulação básica é usada a decomposição singular da matriz Hankel, que foi obtida dos parâmetros de Markov (resposta ao impulso), para determinar a ordem das matrizes do modelo no espaço de estado em tempo discreto, ou seja, a realização propriamente dita. $\mathrm{Na}$ etapa de identificação, são estimados os parâmetros modais do sistema realizado.

A seguir é apresentada a formulação básica do algoritmo, baseado na teoria apresentada em JUANG (1994), e TSUNAKI (1999).

\subsection{1 - FORMULAÇÃO BÁSICA DO ERA}

A formulação do ERA baseia-se nas relações existentes entre as matrizes Hankel no tempo $k=1,[H(0)]$, e no tempo $k=2,[H(1)]$.

O ERA inicia-se com a decomposição da matriz Hankel no tempo $k=1$, $[H(0)]$, de dimensão $\alpha m \times \beta r$, em valores singulares, onde $\alpha$ é o número de parâmetros de Markov numa coluna de $[H(0)]$, e $\beta$ é o número de parâmetros de Markov numa linha de $[H(0)]$ (equação 2.35). A escolha do número de valores 
singulares relevantes define a ordem do modelo e o número de modos identificados. Assim, tem-se:

$$
[H(0)]=[R][\Sigma][S]^{T}
$$

onde as colunas das matrizes $[R]$, dimensão $\alpha m \times \alpha m$ são os vetores singulares à esquerda de $[H(0)]$, ou seja, autovetores de $[H(0)][H(0)]^{T}$, e $[S]$, dimensão $\beta r \times \beta r$, são os vetores singulares à direita de $[H(0)]$, ou seja, autovetores de $[H(0)]^{T}[H(0)]$. As colunas das matrizes $[R]$ e $[S]$ são ortonormais, ou seja,

$$
[R]^{T}[R]=[I]=[S]^{T}[S]
$$

A matriz de dimensão $\alpha m \times \beta r,\left[\sum\right]$, dada na equação (2.51) é formada pelos valores singulares de $[H(0)]$, tendo a forma:

$$
[\Sigma]=\left[\begin{array}{cc}
{\left[\Sigma_{2 n}\right]} & {[0]} \\
{[0]} & {[0]}
\end{array}\right]
$$

com

$$
\left[\Sigma_{2 n}\right]=\operatorname{diag}\left[\sigma_{1}, \sigma_{2}, \cdots, \sigma_{2 n}\right], \text { para } \sigma_{1} \geq \sigma_{2} \geq \cdots \sigma_{2 n} \geq 0
$$

Pode-se formar a matriz $\left[R_{2 n}\right]$, dimensão $\alpha m \times 2 n$ e $\left[S_{2 n}\right]$, dimensão $\beta r \times 2 n$, somente com as $2 n$ primeiras colunas de $[R]$ e $[S]$, respectivamente. Desta forma, obtém-se

$$
[R]=\left[\left[R_{2 n}\right]\left[R_{0}\right]\right]
$$

e

$$
[S]=\left[\begin{array}{ll}
{\left[S_{2 n}\right]} & \left.\left[S_{0}\right]\right]^{T}
\end{array}\right.
$$

sendo

$$
\left[R_{2 n}\right]^{T}\left[R_{2 n}\right]=\left[I_{2 n}\right]=\left[S_{2 n}\right]^{T}\left[S_{2 n}\right]
$$


Substituindo as equações (2.53), (2.55) e (2.56) na equação (2.51), temos

$$
\begin{aligned}
{[H(0)] } & \left.\left.\left.=\llbracket\left[R_{2 n}\right]\left[R_{0}\right]\right]\left[\begin{array}{cc}
{\left[\Sigma_{2 n}\right]} & {[0]} \\
{[0]} & {[0]}
\end{array}\right] \llbracket S_{2 n}\right]\left[S_{0}\right]\right]^{T} \\
& =\left[R_{2 n}\right]\left[\sum_{2 n}\right]\left[S_{2 n}\right]^{T}
\end{aligned}
$$

Suponha-se que existe uma matriz $[H(0)]^{+}$que satisfaça a relação,

$$
\left[Q_{\beta}\right][H(0)]^{+}\left[P_{\alpha}\right]=\left[I_{2 n}\right]
$$

sendo $\left[I_{2 n}\right]$ a matriz identidade de ordem $2 n,\left\lfloor Q_{\beta}\right\rfloor$ a matriz de controlabilidade e $\left[P_{\alpha}\right]$ a matriz de observabilidade. Utilizando a equação (2.50), $[H(0)]^{+}$deve satisfazer a relação,

$$
\begin{aligned}
{[H(0)][H(0)]^{+}[H(0)] } & =\left[P_{\alpha}\right]\left[Q_{\beta}\right][H(0)]^{+}\left[P_{\alpha}\right]\left[Q_{\beta}\right] \\
& \left.=\left[P_{\alpha}\right] \mid Q_{\beta}\right\rfloor \\
& =[H(0)]
\end{aligned}
$$

Pode-se dizer assim que a matriz $[H(0)]^{+}$é a pseudo-inversa da matriz $[H(0)]$.

Através da equação (2.60) é possível à obtenção de mais uma expressão para a matriz pseudo-inversa $[H(0)]^{+}$, ou seja:

$$
[H(0)]^{+}=\left[S_{2 n}\right]\left[\sum_{2 n}\right]^{-1}\left[R_{2 n}\right]^{T}
$$


Para obter uma realização de ordem mínima, os parâmetros de Markov $\left[Y_{k}\right]$ são manipulados algebricamente. Da equação (2.35) tem-se a seguinte matriz Hankel,

$$
[H(k-1)]=\left[\begin{array}{cccc}
{\left[Y_{k}\right]} & {\left[Y_{k+1}\right]} & \cdots & {\left[Y_{k+\beta-1}\right]} \\
{\left[Y_{k+1}\right]} & {\left[Y_{k+2}\right]} & \cdots & {\left[Y_{k+\beta}\right]} \\
\vdots & \vdots & \ddots & \vdots \\
{\left[Y_{k+\alpha-1}\right]} & {\left[Y_{k+\alpha}\right]} & \cdots & {\left[Y_{k+\alpha+\beta-2}\right]}
\end{array}\right]
$$

Desta forma, pode-se escrever

$$
\begin{aligned}
{\left[Y_{k}\right]=} & {\left[\begin{array}{llll}
{\left[I_{m}\right]} & {\left[0_{m}\right]_{1}} & {\left[0_{m}\right]_{2}} & \left.\left[0_{m}\right]_{\alpha-1}\right]
\end{array}\right.} \\
& {\left.\left[\begin{array}{cccc}
{\left[Y_{k}\right]} & {\left[Y_{k+1}\right]} & \cdots & {\left[Y_{k+\beta-1}\right]} \\
{\left[Y_{k+1}\right]} & {\left[Y_{k+2}\right]} & \cdots & {\left[Y_{k+\beta}\right]} \\
\vdots & \vdots & \ddots & \vdots \\
{\left[Y_{k+\alpha-1}\right]} & {\left[Y_{k+\alpha}\right]} & \cdots & {\left[Y_{k+\alpha+\beta-2}\right.}
\end{array}\right]\right]\left[\begin{array}{c}
{\left[I_{r}\right]} \\
{\left[0_{r}\right]_{1}} \\
{\left[0_{r}\right]_{2}} \\
\vdots \\
{\left[0_{r}\right]_{\beta-1}}
\end{array}\right] }
\end{aligned}
$$

Em uma forma compacta, tem-se

$$
\left[Y_{k}\right]=\left[E_{m}\right]^{T}[H(k-1)]\left[E_{r}\right]
$$

onde

$$
\left[E_{m}\right]=\left[\begin{array}{c}
{\left[I_{m}\right]} \\
{\left[0_{m}\right]_{1}} \\
{\left[0_{m}\right]_{2}} \\
\vdots \\
{\left[0_{m}\right]_{\alpha-1}}
\end{array}\right] \quad \text { e } \quad\left[E_{r}\right]=\left[\begin{array}{c}
{\left[I_{r}\right]} \\
{\left[0_{r}\right]_{1}} \\
{\left[0_{r}\right]_{2}} \\
\vdots \\
{\left[0_{r}\right]_{\beta-1}}
\end{array}\right]
$$


Substituindo a equação (2.49) na equação (2.64), obtém-se:

$$
\left[Y_{k}\right]=\left[E_{m}\right]^{T}\left[P_{\alpha}\right]\left[A_{d}\right]^{k-1}\left[Q_{\beta}\right]\left[E_{r}\right]
$$

Inserindo-se a identidade (2.59) nos dois lados da matriz de estado na equação (2.66), tem-se:

$$
\left[Y_{k}\right]=\left[E_{m}\right]^{T}\left[P_{\alpha}\right]\left[Q_{\beta}\right][H(0)]^{+}\left[P_{\alpha}\right]\left[A_{d}\right]^{k-1}\left[Q_{\beta}\right][H(0)]^{+}\left[P_{\alpha}\right]\left[Q_{\beta}\right]\left[E_{r}\right]
$$

e usando a equação (2.50), $[H(0)]=\left[P_{\alpha}\right]\left\lfloor Q_{\beta}\right\rfloor$, a equação (2.67) resulta em

$$
\left[Y_{k}\right]=\left[E_{m}\right]^{T}[H(0)][H(0)]^{+}\left[P_{\alpha}\right]\left[A_{d}\right]^{k-1}\left[Q_{\beta}\right][H(0)]^{+}[H(0)]\left[E_{r}\right]
$$

Substituindo $[H(0)]^{+}=\left[S_{2 n}\right]\left[\sum_{2 n}\right]^{-1}\left[R_{2 n}\right]^{T}$, dada pela equação (2.61) na equação (2.68), obtém-se:

$\left[Y_{k}\right]=\left[E_{m}\right]^{T}[H(0)]\left[S_{2 n}\right]\left[\sum_{2 n}\right]^{-1}\left[R_{2 n}\right]^{T}\left[P_{\alpha} \rrbracket\left[A_{d}\right]^{k-1}\left[Q_{\beta}\right]\left[S_{2 n}\right]\left[\sum_{2 n}\right]^{-1}\left[R_{2 n}\right]^{T}[H(0)]\left[E_{r}\right](2.69)\right.$

A inversa da matriz de valores singulares pode ser decomposta na forma:

$$
\left[\Sigma_{2 n}\right]^{-1}=\left[\Sigma_{2 n}\right]^{-1 / 2}\left[\Sigma_{2 n}\right]^{-1 / 2}
$$

e substituindo na equação (2.69), resulta

$$
\left[Y_{k}\right]=\left[E_{m}\right]^{T}[H(0)]\left[S_{2 n}\right]\left[\sum_{2 n}\right]^{-1 / 2}[\Pi]\left[\sum_{2 n}\right]^{-1 / 2}\left[R_{2 n}\right]^{T}[H(0)]\left[E_{r}\right]
$$

onde

$$
\left.[\Pi]=\left[\sum_{2 n}\right]^{-1 / 2}\left[R_{2 n}\right]^{T}\left[P_{\alpha}\right]\left[A_{d}\right]^{k-1}\left[Q_{\beta}\right] S_{2 n}\right]\left[\sum_{2 n}\right]^{-1 / 2}
$$


Substituindo $[H(0)]=\left[R_{2 n}\right]\left[\sum_{2 n}\right]\left[S_{2 n}\right]^{T}$ da equação (2.58) na equação (2.71) e relacionando-a na equação (2.57), obtém-se

$$
\left[Y_{k}\right]=\left[E_{m}\right]^{T}\left[R_{2 n}\right]\left[\sum_{2 n}\right]^{1 / 2}[\Pi]\left[\sum_{2 n}\right]^{1 / 2}\left[S_{2 n}\right]^{T}\left[E_{r}\right]
$$

A equação (2.72) pode ser escrita como:

$$
[\Pi]=\left(\left[\sum_{2 n}\right]^{-1 / 2}\left[R_{2 n}\right]^{T}\left[P_{\alpha}\right]\left[A_{d}\right]\left[Q_{\beta}\right]\left[S_{2 n}\right]\left[\sum_{2 n}\right]^{-1 / 2}\right)^{k-1}
$$

A equação (2.74) é comprovada e demonstrada através de uma manipulação algébrica desenvolvida por TSUNAKI (1999).

Como $[H(1)]=\left[P_{\alpha}\right]\left[A_{d}\right]^{k-1}\left[Q_{\beta}\right]$, então chega-se em:

$$
[\Pi]=\left(\left[\sum_{2 n}\right]^{-1 / 2}\left[R_{2 n}\right]^{T}[H(1)]\left[S_{2 n}\right]\left[\sum_{2 n}\right]^{-1 / 2}\right)^{k-1}
$$

Com isso, substituindo a equação (2.74) na equação (2.73), resulta

$$
\left[Y_{k}\right]=\left[E_{m}\right]^{T}\left[R_{2 n}\right]\left[\Sigma_{2 n}\right]^{1 / 2}\left(\left[\Sigma_{2 n}\right]^{-1 / 2}\left[R_{2 n}\right]^{T}[H(1)]\left[S_{2 n}\right]\left[\Sigma_{2 n}\right]^{-1 / 2}\right)^{k-1}\left[\sum_{2 n}\right]^{1 / 2}\left[S_{2 n}\right]^{T}\left[E_{r}\right]
$$

Finalmente, comparando a equação (2.76) com a equação $\left[Y_{k}\right]=\left[C_{d}\right]\left[A_{d}\right]^{k-1}\left[B_{d}\right]$ (equação (2.32)), obtém-se a seguinte realização:

$$
\begin{aligned}
& {\left[A_{d}\right]=\left[\sum_{2 n}\right]^{-1 / 2}\left[R_{2 n}\right]^{T}[H(1)]\left[S_{2 n}\right]\left[\sum_{2 n}\right]^{-1 / 2}} \\
& {\left[B_{d}\right]=\left[\sum_{2 n}\right]^{1 / 2}\left[S_{2 n}\right]^{T}\left[E_{r}\right]} \\
& {\left[C_{d}\right]=\left[E_{m}\right]^{T}\left[R_{2 n}\right]\left[\sum_{2 n}\right]^{1 / 2}}
\end{aligned}
$$


As matrizes $\left[A_{d}\right],\left[B_{d}\right]$ e $\left[C_{d}\right]$ representadas na equação (2.77) é uma realização mínima do sistema. A ordem da matriz $\left[A_{d}\right]$ é $2 n$, definindo assim, a ordem do sistema. A matriz $\left[D_{d}\right]$ está representada pelo parâmetro de Markov no instante zero. Desta forma, essa realização pode ser transformada para um modelo de tempo contínuo, ou para as equações de estado nas coordenadas modais, obtendo-se os parâmetros modais do sistema.

O ERA pode ser resumido nas seguintes etapas:

1) Construção da matriz Hankel no tempo $k=1$, $[H(0)]$ e no tempo $k=2,[H(1)]$, através dos parâmetros de Markov do sistema $\left[Y_{k}\right]$;

2) Decomposição de $[H(0)]$ em valores singulares;

3) Determinar a ordem do sistema $2 n$, examinando os valores singulares de $[H(0)]$;

4) Obtenção das matrizes $\left[\Sigma_{2 n}\right],\left[R_{2 n}\right]$ e $\left[S_{2 n}\right]$ a partir das equações $(2.53),(2.55)$ e (2.56);

5) Obtenção da realização de ordem mínima através da equação (2.77);

6) Transformação do modelo realizado para as coordenadas modais e extração dos parâmetros modais.

\section{7 - ÍNDICES DE CONFIANÇA}

Uma característica importante do $E R A$ quando utilizado na identificação de estruturas que apresentem comportamento dinâmico complexo, é a identificação de um número maior de modos do que aqueles realmente existentes na faixa de freqüência analisada, dificultando a análise dos resultados da identificação. Desta forma, inúmeros índices foram desenvolvidos para qualificar e quantificar numericamente a qualidade ou precisão dos parâmetros modais identificados, tornando possível distinguir modos estruturais dos modos computacionais. Por outro lado, não existe garantia de que todos os modos verdadeiros (ou significativos), dentro da faixa de freqüência analisada, sejam identificados (TSUNAKI, 1999).

Esta seção apresenta a forma de obtenção de três índices de confiança: Colinearidade de Fase Modal Ponderada-MPCW; Coerência da Amplitude Modal 
Estendida - EMAC; e Indicador de Consistência Modal - CMI. PAPPA et al. (1993), apresentaram resultados positivos da aplicação destes índices no processo de identificação de parâmetros modais em equipamentos de uso aeroespacial.

$\mathrm{Na}$ formulação dos índices de confiança são utilizados conceitos relacionados com as matrizes de influência de entrada e saída nas coordenadas modais, definidas pelas equações (2.37) e (2.38). As formas dos modos (complexos) correspondem às colunas da matriz de influência de saída nas coordenadas modais, definida em (2.38), ou seja

$$
\left[C_{d}\right]_{M}=\left\lfloor\begin{array}{llllll}
\left\{\phi_{1}\right\} & \left\{\phi_{2}\right\} & \cdots & \left\{\phi_{j}\right\} & \cdots & \left\{\phi_{2 n}\right\}
\end{array}\right\rfloor
$$

onde $\left\{\phi_{j}\right\}$ é o $j$-ésimo modo (complexo).

Os fatores de participação modal são definidos em função dos elementos da matriz de influência de entrada. Os fatores de participação modal para o $j$-ésimo modo, correspondem à $j$-ésima linha da matriz de influência de entrada nas coordenadas modais, ou seja

$$
\left[B_{d}\right]_{M}=\left[\begin{array}{c}
\left\{\varphi_{1}\right\}^{T} \\
\left\{\varphi_{2}\right\}^{T} \\
\vdots \\
\left\{\varphi_{j}\right\}^{T} \\
\vdots \\
\left\{\varphi_{2 n}\right\}^{T}
\end{array}\right]
$$

onde $\left\{\varphi_{j}\right\}$ é o vetor contendo os componentes do fator de participação modal do $j$ ésimo modo. 


\subsection{1 - COLINEARIDADE DE FASE MODAL PONDERADA - MPCW}

O $M P C W$ quantifica a consistência espacial dos resultados da identificação. Para modos normais clássicos (reais), todos o pontos de uma estrutura movimentam-se exatamente em fase ou fora de fase. Em outras palavras, a forma do modo corresponde a um vetor real, ou vetor monofase.

O comportamento monofase implica no fato de a matriz de variânciacovariância das partes real e imaginária dos vetores das formas modais apresentarem apenas um autovalor diferente de zero. Entretanto, se os ângulos de fase da forma dos modos identificados não são correlacionados, os dois autovalores desta matriz serão aproximadamente iguais. O $M P C W$ quantifica o grau de comportamento monofase através da comparação do tamanho relativo dos autovalores da matriz de variância-covariância (PAPPA et al., 1993).

Seja $\left\{\phi_{j}^{R}\right\}$ e $\left\{\phi_{j}^{I}\right\}$, respectivamente, a parte real e imaginária do modo $\left\{\phi_{j}\right\}$. Define-se $M P C W$ do $j$-ésimo modo como

$$
\operatorname{MPCW}(j)=\left(\frac{\lambda_{j}^{+}-\lambda_{j}^{-}}{\lambda_{j}^{+}+\lambda_{j}^{-}}\right)^{2}
$$

onde

$$
\lambda_{j}^{+,-}=\frac{\left\{\phi_{j}^{R}\right\}^{T}\left\{\phi_{j}^{R}\right\}+\left\{\phi_{j}^{I}\right\}^{T}\left\{\phi_{j}^{I}\right\}}{2} \pm\left\{\phi_{j}^{R}\right\}^{T}\left\{\phi_{j}^{I}\right\} \sqrt{\left(\frac{\left\{\phi_{j}^{I}\right\}^{T}\left\{\phi_{j}^{I}\right\}-\left\{\phi_{j}^{R}\right\}^{T}\left\{\phi_{j}^{R}\right\}}{2\left\{\phi_{j}^{R}\right\}^{T}\left\{\phi_{j}^{I}\right\}}\right)+1}
$$

Os valores numéricos que o $M P C W$ pode assumir variam entre 0 e 1 . Um valor próximo de 0 significa um modo com ângulos de fase completamente não correlacionados e um valor próximo de 1 significa um modo real (TSUNAKI, 1999). 


\subsection{2 - COERÊNCIA DA AMPLITUDE MODAL ESTENDIDA - EMAC}

A formulação do índice $E M A C$ apresentada nesta seção, é baseado na teoria apresentada em TSUNAKI (1999) e PAPPA et al. (1993).

O EMAC quantifica a consistência temporal dos parâmetros modais identificados. A evolução temporal, de $t_{0}=0$ a $t=T_{1}$, dos componentes da forma modal é comparada com os correspondentes componentes localizados no último bloco de linhas da matriz de observabilidade modal (o bloco correspondente à $\left.t=T_{1}\right)$. Esta comparação possibilita a obtenção de um índice de consistência temporal.

Seja $t=T_{1}$ o tempo correspondente ao último bloco de linhas da matriz de observabilidade modal. A evolução temporal no tempo $t=T_{1}$, para o $i$-ésimo componente do $j$-ésimo modo, pode ser calculada através de

$$
\hat{\phi}_{i j}\left(T_{1}\right)=\phi_{i j} e^{s_{j} T_{1}}
$$

onde

$$
\begin{aligned}
& \hat{\phi}_{i j}\left(T_{1}\right) \text { é a estimativa do componente } i \text { no tempo } T_{1} \\
& \phi_{i j} \text { é a } i \text {-ésima componente do } j \text {-ésimo modo; } \\
& s_{j} \text { é o autovalor de tempo contínuo do modo } j .
\end{aligned}
$$

Obtida uma estimativa da componente do modo, dada por (2.80), deve-se compará-la com a correspondente componente da matriz de obsevabilidade modal. Seja a matriz de observabilidade modal, $\alpha m$ por $2 n$, definida por

$$
\left[P_{\alpha}\right]_{M}=\left[R_{2 n}\right]\left[\Sigma_{2 n}\right]^{1 / 2}[\Psi]
$$

O bloco formado pelas $m$ últimas linhas de $\left[P_{\alpha}\right]_{M}$ é uma matriz que contém a forma dos modos no tempo $t=T_{1}$. Desta forma, utilizando a notação $\widetilde{\phi}_{i j}\left(T_{1}\right)$ para indicar a $i$-ésima componente do $j$-ésimo modo desta matriz, pode-se 
compará-la com $\hat{\phi}_{i j}\left(T_{1}\right)$. Inicialmente, comparam-se as magnitudes destas componentes através do índice dado por

$$
\begin{aligned}
\operatorname{Mag}_{i j}^{s} & =\frac{\left|\hat{\phi}_{i j}\left(T_{1}\right)\right|}{\left|\widetilde{\phi}_{i j}\left(T_{1}\right)\right|} \text {, para }\left|\hat{\phi}_{i j}\left(T_{1}\right)\right| \leq\left|\widetilde{\phi}_{i j}\left(T_{1}\right)\right| \\
& =\frac{\left|\widetilde{\phi}_{i j}\left(T_{1}\right)\right|}{\left|\hat{\phi}_{i j}\left(T_{1}\right)\right|} \text {, para }\left|\widetilde{\phi}_{i j}\left(T_{1}\right)\right|<\left|\hat{\phi}_{i j}\left(T_{1}\right)\right|
\end{aligned}
$$

Um índice para relacionar os ângulos de fase também pode ser desenvolvido, dado por

$$
\begin{gathered}
\operatorname{Ang}_{i j}^{s}=1-\frac{\left|a \tan 2\left(\frac{\widetilde{\phi}_{i j}\left(T_{1}\right)}{\hat{\phi}_{i j}\left(T_{1}\right)}\right)\right|}{\frac{\pi}{4}}, \text { para }\left|a \tan 2\left(\frac{\widetilde{\phi}_{i j}\left(T_{1}\right)}{\hat{\phi}_{i j}\left(T_{1}\right)}\right)\right| \leq \frac{\pi}{4} \\
=0, \text { para }\left|a \tan 2\left(\frac{\widetilde{\phi}_{i j}\left(T_{1}\right)}{\hat{\phi}_{i j}\left(T_{1}\right)}\right)\right|>\frac{\pi}{4}
\end{gathered}
$$

Portanto, pode-se definir um EMAC de saída para a $i$-ésima componente do $j$-ésimo modo utilizando-se os dois índices definidos em (2.82) e (2.83), através de

$$
E M A C_{i j}^{s}=\operatorname{Mag}_{i j}^{s} \operatorname{Ang}_{i j}^{s}
$$

Um EMAC de entrada pode ser desenvolvido empregando o mesmo procedimento utilizado para o cálculo do $E M A C$ de saída. Compara-se a evolução temporal dos componentes de participação modal, de $t_{0}=0$ a $t=T_{2}$, com os correspondentes componentes no último bloco de colunas da matriz de controlabilidade modal (o bloco correspondente à $t=T_{2}$ ). 
Seja $t=T_{2}$ o tempo correspondente ao último bloco de colunas da matriz de controlabilidade modal. A evolução temporal no tempo $t=T_{2}$, para a $i$-ésima componente do fator de participação modal do $j$-ésimo modo, pode ser calculada através de

$$
\hat{\varphi}_{i j}\left(T_{2}\right)=\varphi_{i j} e^{s_{j} T_{2}}
$$

onde

$$
\begin{aligned}
& \hat{\varphi}_{i j}\left(T_{2}\right) \text { é a estimativa do componente } i \text { no tempo } T_{2} \\
& \varphi_{i j} \text { é a } i \text {-ésima componente do } j \text {-ésimo modo; } \\
& s_{j} \text { é o autovalor de tempo contínuo do modo } j .
\end{aligned}
$$

Obtida uma estimativa da $i$-ésima componente do fator de participação modal, dada por (2.85), deve-se compará-la com a correspondente componente da matriz de controlabilidade modal. Seja a matriz de controlabilidade modal, $2 n$ por $\beta r$, definida por

$$
\left[Q_{\beta}\right]_{M}=[\Psi]^{-1}\left[\Sigma_{2 n}\right]^{1 / 2}\left[S_{2 n}\right]^{T}
$$

O bloco formado pelas $r$ últimas colunas de $\left\lfloor Q_{\beta}\right\rfloor_{M}$ formam uma matriz que contém os fatores de participação modal no tempo $t=T_{2}$. Utilizando a notação $\widetilde{\varphi}_{i j}\left(T_{2}\right)$ para indicar a $i$-ésima componente do fator de participação modal do $j$-ésimo modo, podese compará-la com $\hat{\varphi}_{i j}\left(T_{2}\right)$. Inicialmente, comparam-se as magnitudes destas componentes através do índice

$$
\begin{aligned}
\operatorname{Mag}_{i j}^{E} & =\frac{\left|\hat{\varphi}_{i j}\left(T_{2}\right)\right|}{\left|\widetilde{\varphi}_{i j}\left(T_{2}\right)\right|} \text {, para }\left|\hat{\varphi}_{i j}\left(T_{2}\right)\right| \leq\left|\widetilde{\varphi}_{i j}\left(T_{2}\right)\right| \\
& =\frac{\left|\widetilde{\varphi}_{i j}\left(T_{2}\right)\right|}{\left|\hat{\varphi}_{i j}\left(T_{2}\right)\right|} \text {, para }\left|\widetilde{\varphi}_{i j}\left(T_{2}\right)\right|<\left|\hat{\varphi}_{i j}\left(T_{2}\right)\right|
\end{aligned}
$$


Um índice para relacionar os ângulos de fase também pode ser desenvolvido, dado por

$$
\begin{gathered}
A n g_{i j}^{E}=1-\frac{\left|a \tan 2\left(\frac{\widetilde{\varphi}_{i j}\left(T_{2}\right)}{\hat{\varphi}_{i j}\left(T_{2}\right)}\right)\right|}{\frac{\pi}{4}}, \text { para }\left|a \tan 2\left(\frac{\widetilde{\varphi}_{i j}\left(T_{2}\right)}{\hat{\varphi}_{i j}\left(T_{2}\right)}\right)\right| \leq \frac{\pi}{4} \\
=0, \text { para }\left|a \tan 2\left(\frac{\widetilde{\varphi}_{i j}\left(T_{2}\right)}{\hat{\varphi}_{i j}\left(T_{2}\right)}\right)\right|>\frac{\pi}{4}
\end{gathered}
$$

Portanto, pode-se definir um EMAC de entrada para a $i$-ésima componente do fator de participação modal do $j$-ésimo modo utilizando-se os dois índices definidos em (2.87) e (2.88), através de

$$
E M A C_{i j}^{E}=\operatorname{Mag}_{i j}^{E} A n g_{i j}^{E}
$$

Finalmente, um EMAC global para o $j$-ésimo modo pode ser obtido pela equação

$$
E M A C_{j}=\frac{\left(\sum_{i=1}^{m} E M A C_{i j}^{S}\left|\phi_{i j}\right|^{2}\right)\left(\sum_{i=1}^{r} E M A C_{i j}^{E}\left|\varphi_{i j}\right|^{2}\right)}{\left(\sum_{i=1}^{m}\left|\phi_{i j}\right|^{2}\right)\left(\sum_{i=1}^{r}\left|\varphi_{i j}\right|^{2}\right)}
$$

Os valores numéricos que o $E M A C$ pode assumir variam entre 0 e 1 . De modo geral, considera-se que um valor acima de 0,9 significa boa consistência temporal na forma dos modos identificados e um valor abaixo de 0,1 significa baixa consistência. 


\subsection{3 - INDICADOR DE CONSISTÊNCIA MODAL - CMI}

O CMI é calculado utilizando-se os dois índices definidos em (2.79) e (2.91). Ele quantifica simultaneamente a consistência temporal e a consistência espacial, obtida pela multiplicação entre $M P C W$ e $E M A C$ :

$$
C M I=M P C W^{*} E M A C
$$

Valores de $C M I$ maiores de 0,8 significam que o modo foi identificado com alto grau de confiança. Valores de $C M I$ menores de 0,2 significa modos identificados com baixo grau de confiança ou modos não físicos (TSUNAKI, 1999). 


\section{CAPÍTULO 3}

\section{VERIFICAÇÃO DO ALGORITMO DE \\ REALIZAÇÃO DE SISTEMAS}

Uma vez estabelecida a formulação teórica do algoritmo de realização de sistemas - ERA, é importante verificar a eficácia deste método na identificação de parâmetros modais de sistemas dinâmicos. Desta forma, este Capítulo apresenta os resultados de verificações do algoritmo obtidos para uma simulação de um modelo hipotético e para um ensaio experimental de uma estrutura real.

Inicialmente é descrita a implementação computacional e a estrutura lógica dos algoritmos envolvidos no método proposto. Posteriormente o algoritmo é verificado para um sistema simulado de três graus de liberdade (massa-molaamortecedor). Em seguida, a identificação dos parâmetros modais de uma viga de alumínio é procedida através de dados experimentais.

\section{1 - IMPLEMENTAÇÃO DOS ALGORITMOS}

Esta seção descreve a implementação computacional realizada na análise dos dados colhidos. 


\subsection{1 - OBTENÇÃO DOS PARÂMETROS DE MARKOV ATRAVÉS DE FRFS}

Os dados experimentais de entrada para o ERA é o conjunto de respostas ao impulso, denominadas de seqüência de parâmetros de Markov, que formam a matriz Hankel. Uma das dificuldades que ocorre na aplicação de métodos de identificação baseados na realização de sistemas, como o $E R A$, é a obtenção dos parâmetros de Markov experimentalmente.

$\mathrm{Na}$ prática, a disponibilidade de dados no domínio da freqüência têm predominado devido à difusão de analisadores de espectro microprocessados. Desta forma, existe grande interesse na obtenção das seqüências de parâmetros de Markov a partir de funções resposta em freqüência - FRFs. Além disso, inúmeras técnicas estão disponíveis para a minimização das várias inconsistências na estimação de FRFs, o que é conveniente nestes casos (TSUNAKI, 1999).

Tradicionalmente, a transformada inversa de Fourier é utilizada para transformar os dados do domínio da freqüência para o domínio do tempo, transformando as FRFs do sistema em seqüências de parâmetros de Markov. Segundo OPPENHEIM (1975), um erro inerente a este procedimento é a distorção das seqüências de parâmetros de Markov por efeitos de aliasing.

\subsection{2 - IMPLEMENTAÇÃO DO ALGORITMO ERA E DOS ÍNDICES DE CONFIANÇA}

A implementação do $E R A$ e dos índices de confiança $E M A C, M P C W$ e $C M I$, utilizados neste trabalho, podem ser divididos nas seguintes etapas descritas a seguir. Na primeira montam-se as matrizes Hankel $[H(0)]$ e $[H(1)]$ através dos parâmetros de Markov. Numa segunda etapa aplica-se a decomposição em valores singulares na matriz $[H(0)]$. Na terceira etapa, estabelece-se a ordem do sistema $2 n$. Na quarta etapa obtém-se as matrizes $\left[\sum_{2 n}\right],\left[R_{2 n}\right],\left[S_{2 n}\right]$ e as matrizes do sistema realizado $\left[A_{d}\right],\left[B_{d}\right]$ e $\left[C_{d}\right]$. Numa quinta etapa, transforma-se o sistema para as coordenadas modais, obtendo assim as matrizes $[\Lambda],\left[B_{d}\right]_{M}$ e $\left[C_{d}\right]_{M}$. Finalmente, na sexta etapa, obtém-se os parâmetros modais do sistema e calculam-se os índices de 
confiança $E M A C, M P C W$ e $C M I$. A Figura 3.1, traz o fluxograma que mostra a seqüência das etapas descritas.

Além disso, é realizada uma etapa de condensação modal através de critérios de exclusão baseado no tipo de análise que está sendo feita. Esta etapa é destinada à eliminação, dentro de critérios específicos, de parâmetros modais mal identificados ou de modos computacionais.

Alguns dos critérios utilizados na etapa de eliminação de parâmetros modais devem ser estabelecidos através do conhecimento prévio do comportamento dinâmico da estrutura sob análise.

O principal processo de eliminação executado pelo algoritmo consiste na qualificação dos parâmetros modais identificados, através dos índices de confiança EMAC, $M P C W$ e $C M I$.

A qualificação através do $E M A C$ quantifica a consistência temporal dos parâmetros modais identificados. De modo geral, considera-se que um valor acima de 0,9 significa boa consistência temporal dos modos identificados e um valor abaixo de 0,1 significa baixa consistência (TSUNAKI, 1999).

A qualificação através do $M P C W$ verifica quanto o modo complexo se aproxima de um modo real clássico. Ou seja, verifica a consistência espacial dos resultados da identificação. De um modo geral, um valor próximo de 0 significa um modo com ângulos de fase completamente não correlacionados e um valor próximo de 1 significa um modo real (TSUNAKI, 1999).

Uma das dificuldades de utilizar o $M P C W$ e o $E M A C$ isoladamente, é o fato de que estes índices são unidimensionais, isto é, um quantifica a consistência espacial e o outro a consistência temporal dos resultados da identificação. Desta forma, o índice $C M I$ foi criado para quantificar simultaneamente a consistência temporal e a espacial. Valores de $C M I$ maiores que 0,8 significam que o modo foi identificado com alto grau de confiança e valores menores que 0,2 significa modos identificados com baixo grau de confiança ou modos não físicos (TSUNAKI, 1999). 


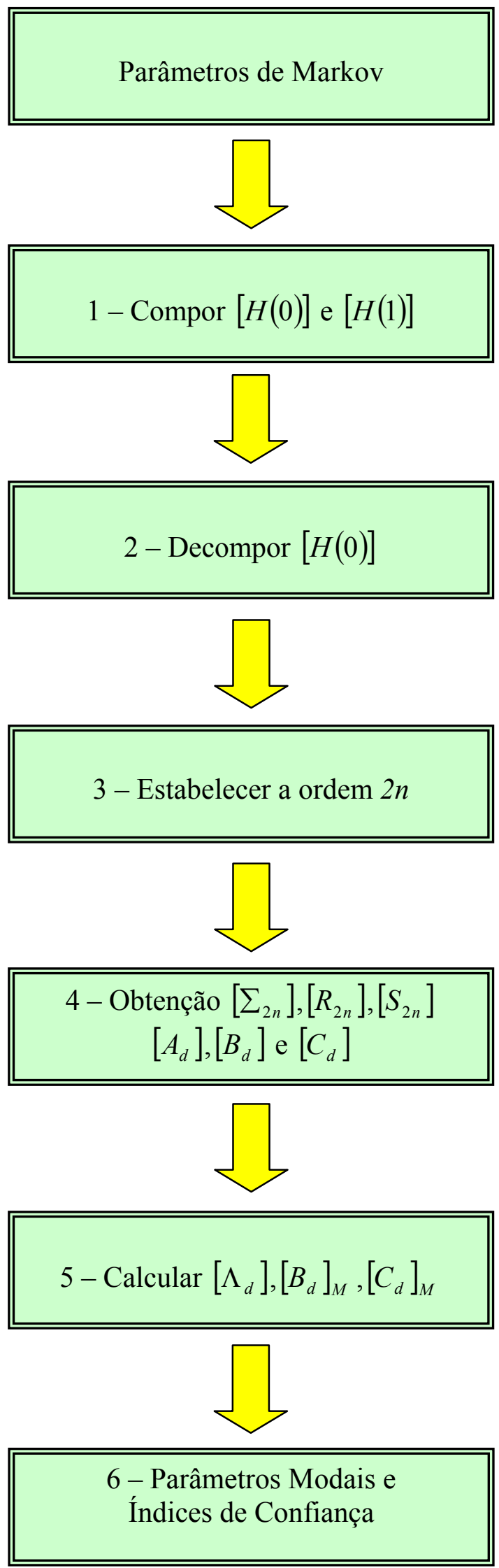

Figura 3.1 - Fluxograma da implementação do $E R A, E M A C, M P C W$ e $C M I$. 


\section{2 - VERIFICAÇÃO DO ALGORITMO PARA UM SISTEMA SIMULADO}

Tendo em vista a validação do $E R A$, a identificação de parâmetros modais de um sistema (massa-mola-amortecedor) com três graus de liberdade é apresentada. Conforme ilustra a Figura 3.2, uma força, $\mathrm{F}(\mathrm{t})$, aplicada na massa $\mathrm{m} 1$ corresponde à entrada do sistema e os deslocamentos u1(t) e u2(t) são as saídas medidas. Para tornar a simulação próxima do caso de um experimento real, os sinais adquiridos da simulação deste sistema são acrescidos de um ruído aleatório, aplicado na resposta impulsiva do sistema. As características espaciais, massa, rigidez e coeficiente de amortecimento são respectivamente: $\mathrm{m} 1=\mathrm{m} 2=\mathrm{m} 3=1 \mathrm{~kg} ; \mathrm{k} 1=\mathrm{k} 2=\mathrm{k} 3=\mathrm{k} 4=1 \mathrm{~N} / \mathrm{m}$; e $\mathrm{c} 1=\mathrm{c} 2=\mathrm{c} 3=\mathrm{c} 4=0,1$. Para a simulação admite-se que as unidades sejam todas compatíveis.

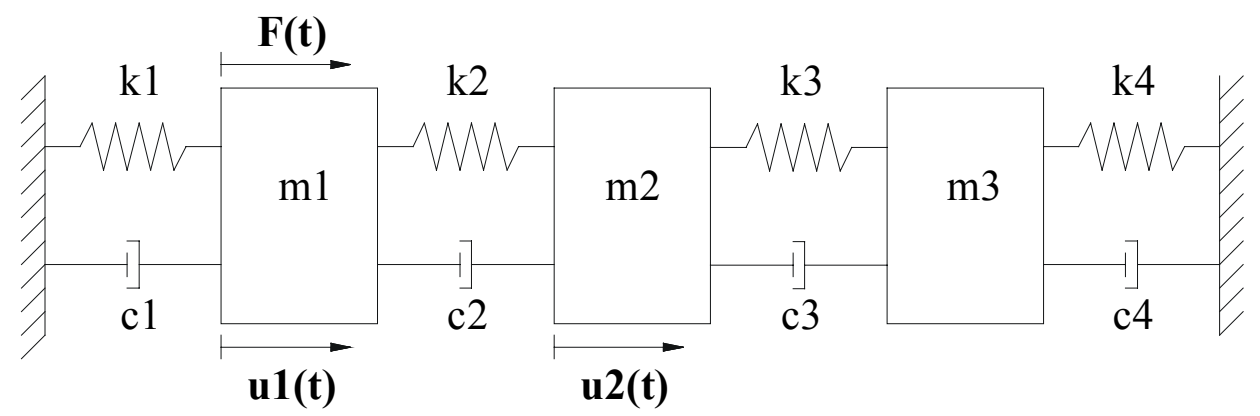

Figura 3.2 - Sistema massa-mola-amortecedor.

Inicialmente, para o caso do sistema hipotético simulado, são obtidas as respostas impulsivas (ou seqüência de parâmetros de Markov) e as respostas em freqüência do sistema, como mostram as Figura 3.3 e Figura 3.4. Para simular uma condição realista de medições com ruídos, os parâmetros de Markov foram afetados por um ruído branco, amplitude entre [-1 1] e multiplicados por um fator de ruído $\delta=0,2$. Desta forma, soma-se o ruído gerado aos parâmetros de Markov reais do sistema. 

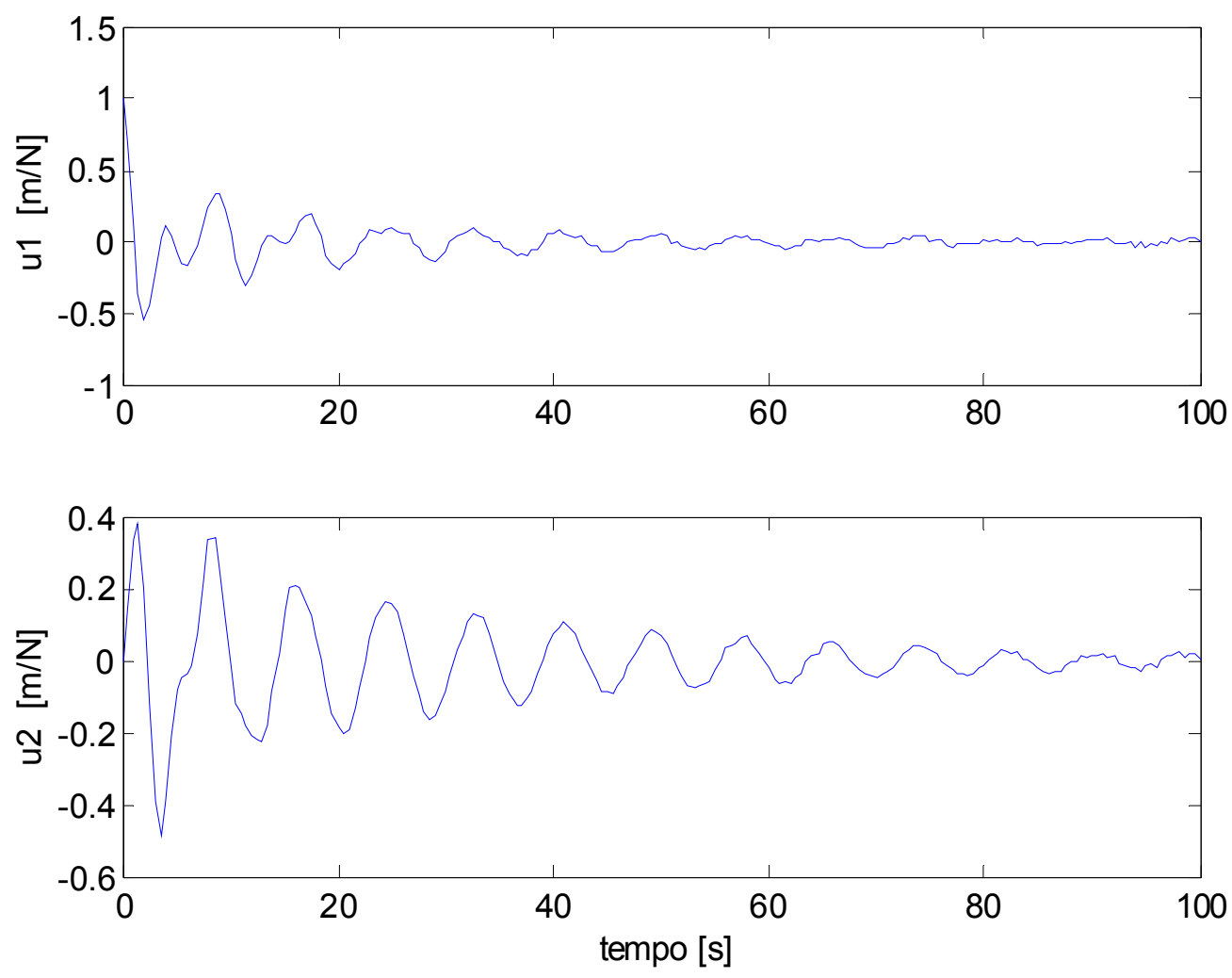

Figura 3.3 - Respostas impulsivas do sistema.


Figura 3.4 - Respostas em freqüência do sistema. 


\subsection{1 - RESULTADOS DA IDENTIFICAÇÃO}

Na seqüência são apresentados os resultados da identificação em que os dados de entrada são as respostas ao impulso do sistema. Inicialmente, são geradas as matrizes de Hankel no tempo discreto $k=1,[H(0)]$, e no tempo discreto $k=2$, $[H(1)]$. Os parâmetros $\alpha$ e $\beta$ irão definir a dimensão da matriz de Hankel, conforme equação (2.35). A dimensão escolhida é de 180 linhas, ou seja, $\alpha=90, m=2$ por 90 colunas, $\beta=90, r=1$.

Após montar as matrizes Hankel, é realizada a decomposição em valores singulares de $[H(0)]$ e o gráfico do logaritmo dos valores singulares $\Sigma$ em função do número de valores singulares é apresentado na Figura 3.5. A decomposição apresenta 90 valores singulares para a matriz de Hankel $[H(0)]$. Entretanto, da Figura 3.5 podese observar que os valores singulares mais significativos vão até aproximadamente 6 , o que fornece uma primeira estimativa da ordem mínima para o sistema a ser identificado. No caso ideal onde o sinal experimental não apresenta ruído, os valores singulares da matriz Hankel não relevantes (ou seja, os diferentes de $2 n$, como visto na equação (2.53)) seriam nulos. No entanto, devido à presença de ruído no sinal do sistema, surgem modos residuais não nulos na decomposição em valores singulares.

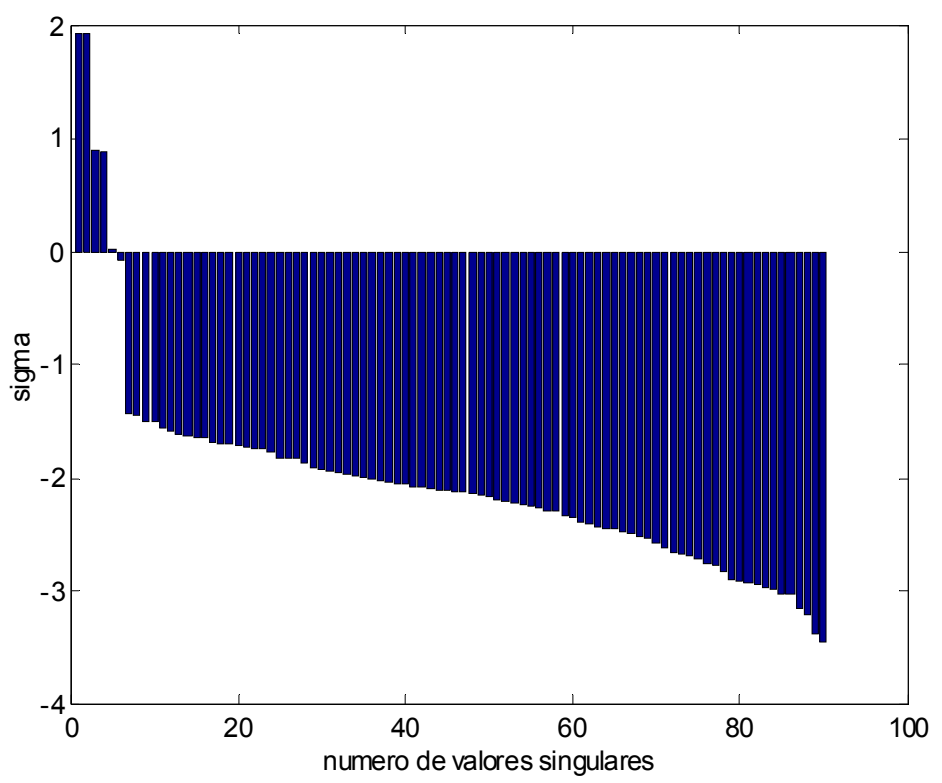

Figura 3.5 - Gráfico dos valores singulares de $[H(0)]$. 
Outra forma de se estimar a ordem mínima do sistema estudado pode ser dada pelo critério IAE, Integral of Absolute Error (MOREIRA, 1998), dada pela equação:

$$
I A E=\sum_{O_{M I N}}^{O_{M A X}} \max \left|F R I-F R I_{e}\right|
$$

onde FRI é a resposta impulsiva real e $\mathrm{FRI}_{\mathrm{e}}$ é a resposta impulsiva estimada do modelo.

Através da primeira estimativa para a ordem mínima dada pela Figura 3.5, pode-se definir uma faixa de possíveis ordens para o sistema estudado. Iniciando-se com o menor valor da faixa definida $o_{\min }$ até o maior valor definido, $o_{\max }$, os parâmetros de Markov ou funções de resposta ao impulso estimados, FRI $\mathrm{e}_{\mathrm{e}}$, são obtidos para cada ordem compreendida nesta faixa. Por fim, o erro absoluto pode ser calculado pela equação 3.1 , dado pelo máximo da diferença entre cada $\mathrm{FRI}_{\mathrm{e}}$ estimada e a correspondente FRI real do sistema.

Para o exemplo estudado, através da Figura 3.5, foi definida uma faixa que vai de $o_{\min }=2$ até $o_{\max }=12$. Os valores obtidos para o critério IAE na faixa definida podem ser observados pela Figura 3.6. Nota-se pela figura que o erro tende a um valor constante para uma ordem igual e superior a seis. Portanto, define-se 6 como sendo o valor da ordem mínima para o sistema estudado.

$\mathrm{Na}$ realidade, existe um compromisso entre a escolha dos parâmetros $\alpha$ e $\beta$ e a determinação da ordem da realização. Isto significa que, tomando um conjunto de amostras do ensaio menor ou maior do que o necessário, o valor do limiar de erro pode variar. Assim sendo, não se pode afirmar que existe um critério objetivo para se determinar a ordem de uma realização para um dado sistema (MOREIRA, 1998).

Selecionada a ordem do modelo estimado para o sistema, o próximo passo é executar a identificação propriamente dita. Na Tabela 3.1 estão os resultados da identificação dos parâmetros modais identificados para a ordem escolhida, ou seja, $2 n=6$. Além disso, são apresentados os autovalores reais do sistema. 


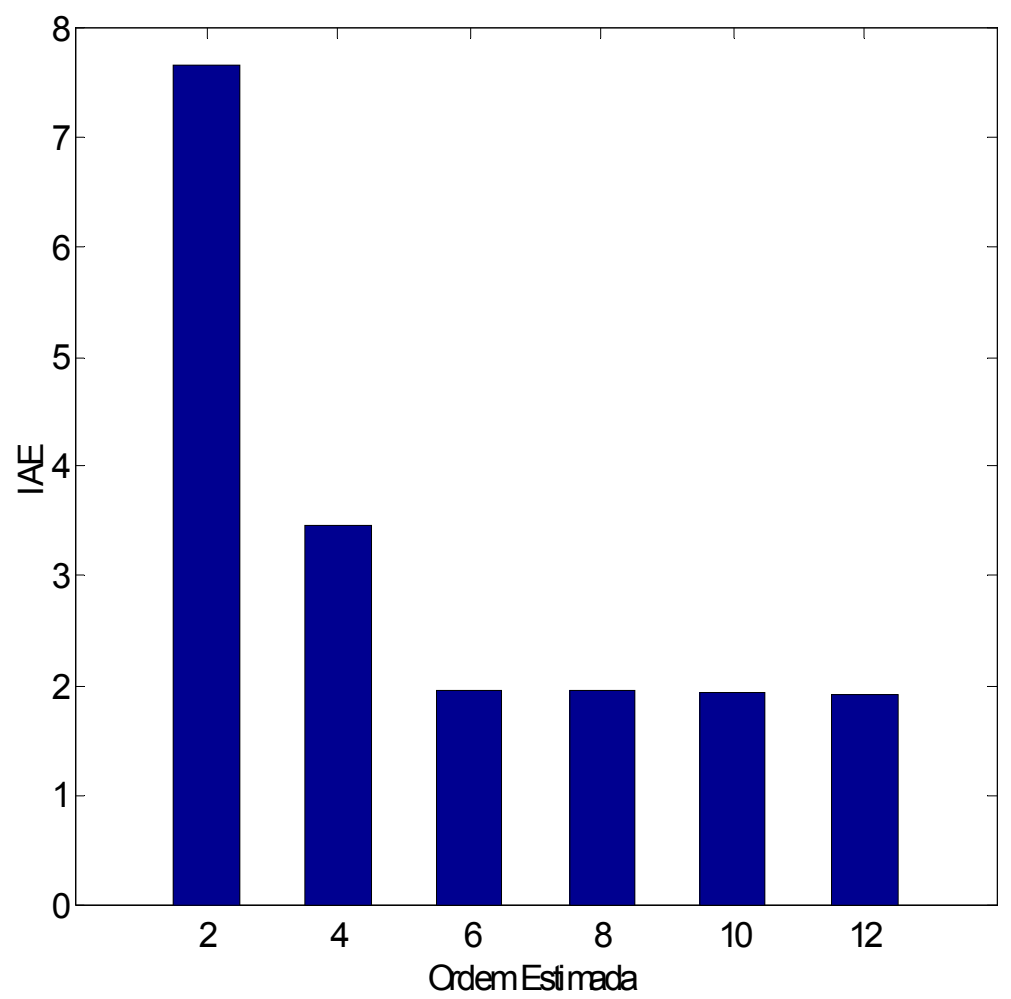

Figura 3.6 - Gráfico do erro $\times$ ordem estimada.

Tabela 3.1 - Autovalores e fatores de amortecimento identificados para o valor de ordem do sistema.

\begin{tabular}{|c|c|c|c|}
\hline \multicolumn{4}{|c|}{ Identificação - ER $\boldsymbol{A}$} \\
\hline Modo & Autovalores reais & Autovalores estimados & $\xi_{n}$ \\
\hline 1 & $-0,0047 \pm 0,1217 \mathrm{i}$ & $-0,0046 \pm 0,1217 \mathrm{i}$ & 0,0380 \\
\hline 2 & $-0,0159 \pm 0,2245 \mathrm{i}$ & $-0,0156 \pm 0,2244 \mathrm{i}$ & 0,0697 \\
\hline 3 & $-0,0272 \pm 0,2928 \mathrm{i}$ & $-0,0286 \pm 0,2915 \mathrm{i}$ & 0,0983 \\
\hline
\end{tabular}


Desta forma, obtida a ordem mínima do sistema estudado, as funções de resposta ao impulso real e a correspondente identificada são apresentadas como mostra a Figura 3.7. Além disso, a Figura 3.7 traz os erros absolutos estimados, através da equação 3.1 .
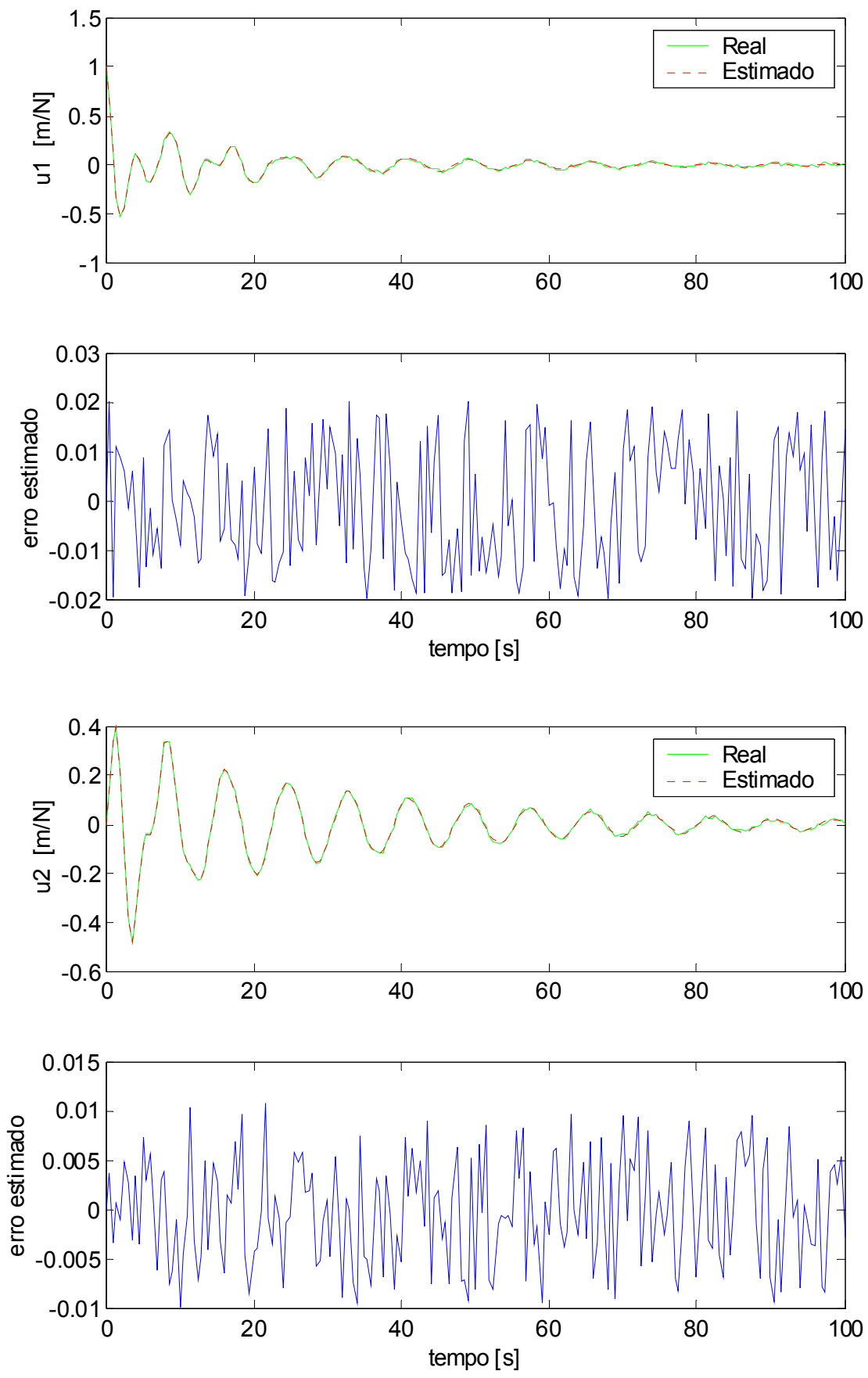

Figura 3.7 - Comparação das respostas dos sistemas real e identificado de ordem 6 e respectivos erros estimados. 
Por fim, para confirmar se o modelo identificado pode ser considerado uma realização de ordem mínima do sistema, o gráfico da função resposta em freqüência, FRF, do sistema real e do modelo identificado são apresentados na Figura 3.8 e demonstram uma considerável concordância entre o sistema real e o modelo identificado.


Figura 3.8 - Respostas em freqüência dos sistemas real e identificado de ordem 6.

\section{3 - APLICAÇÃO DO ALGORITMO NA IDENTIFICAÇÃO DA DINÂMICA DE UMA VIGA ATRAVÉS DE DADOS EXPERIMENTAIS}

Para verificar o método de identificação de parâmetros modais proposto foi realizado um ensaio experimental em uma viga de alumínio. Nesta seção é apresentada a configuração do experimento realizado. Posteriormente, é descrita a implementação computacional do método $E R A$, assim como a implementação da 
qualificação dos resultados através dos índices de confiança. Finalmente, são apresentados os resultados obtidos no processo de identificação.

\subsection{1 - DESCRIÇÃO DA ESTRUTURA DE TESTE}

O modelo experimental utilizado para validação do algoritmo proposto é uma viga de alumínio. As dimensões da viga são: $600 \mathrm{~mm}$ de comprimento, $50,9 \mathrm{~mm}$ de largura e 3,3 $\mathrm{mm}$ de espessura. A configuração da montagem da viga simula um engaste. A simulação das condições de engaste foi feita fixando-se uma das extremidades da viga de alumínio entre duas chapas de aço através de parafusos e posteriormente este conjunto foi fixado rigidamente em uma base inercial, conforme mostra a Figura 3.9.

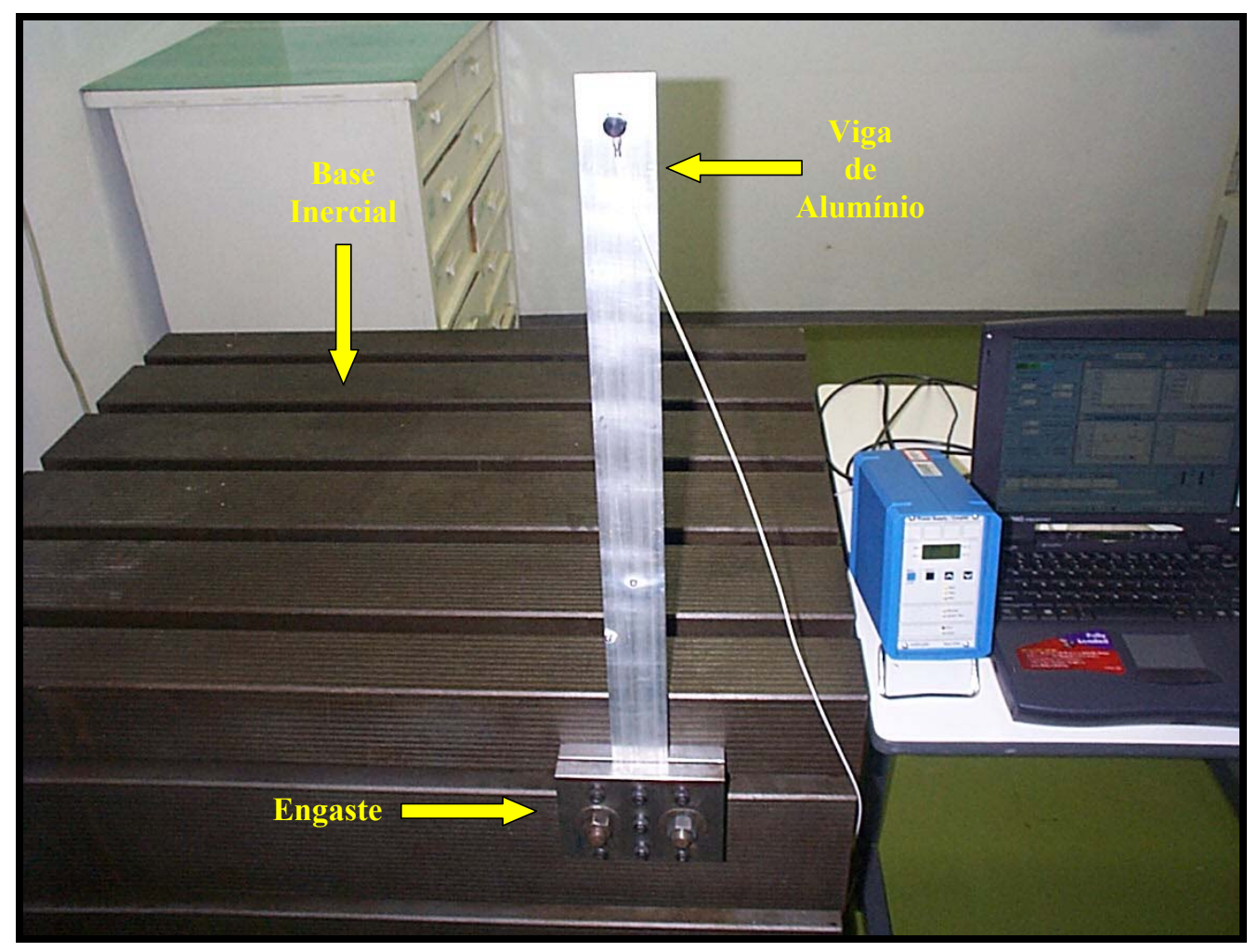

Figura 3.9 - Viga de alumínio utilizada no experimento e aparato de fixação. 
Para a realização dos ensaios, foram marcadas sobre a viga as localizações dos pontos de saída e entrada. A Figura 3.10 apresenta os 2 pontos de entrada (excitação) e as dimensões da viga. A localização dos pontos de entrada, $\boldsymbol{A}$ e $\boldsymbol{B}$, foram escolhidos arbitrariamente mas suficientemente importantes para a excitação de todos os modos na faixa de freqüência de interesse. A localização dos pontos de saída é apresentada na Figura 3.11. Não foram seguidos critérios rígidos para a escolha do número de pontos de saída (medição). Foi assumido que 30 pontos distribuídos uniformemente sobre a estrutura são suficientes para proporcionar bons resultados e boa resolução espacial.

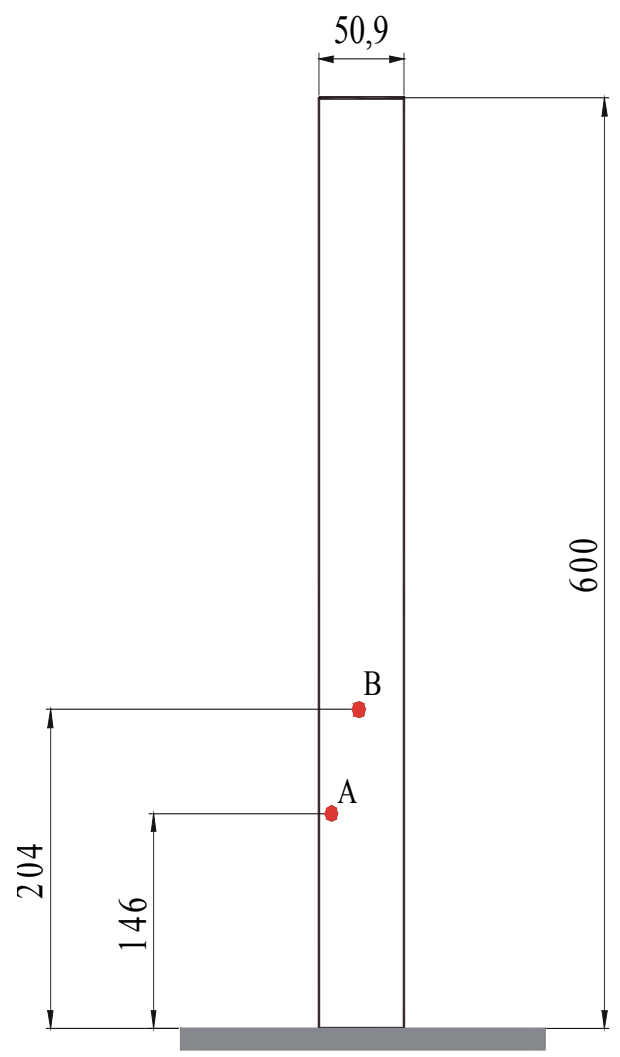

Figura 3.10 - Localização dos pontos de entrada (excitação) e dimensões da viga (dimensões em $\mathrm{mm}$ ). 

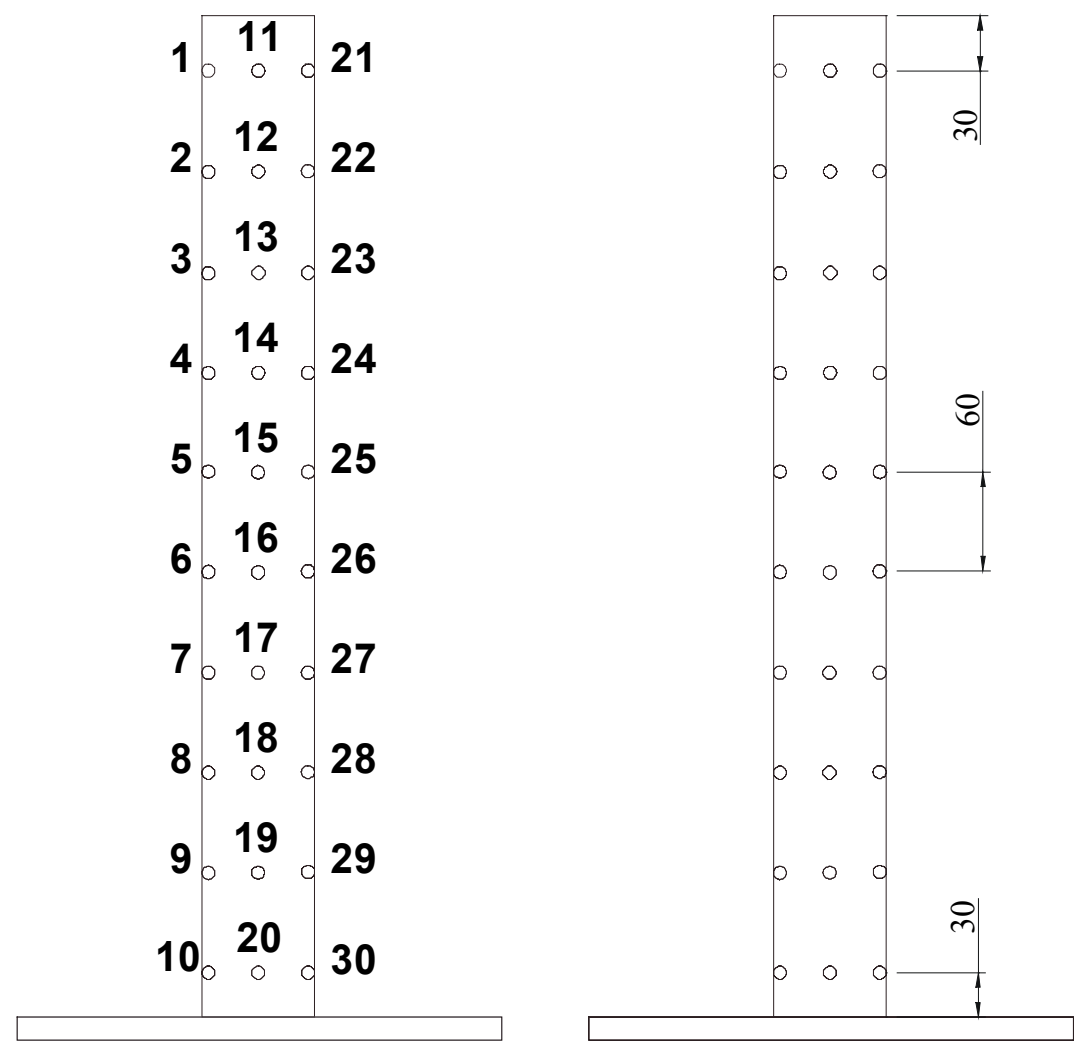

Figura 3.11 - Localização e dimensões dos pontos de saída (dimensões em $\mathrm{mm}$ ).

\subsection{2 - AQUISIÇÃO DOS DADOS EXPERIMENTAIS}

Os ensaios foram realizados com o objetivo de obter funções resposta em freqüência (FRFs) da viga.

A excitação da estrutura, promovida manualmente, foi proporcionada através do impacto de um martelo instrumentado. Foram escolhidos 2 pontos de excitação, conforme mostra a Figura 3.10. Como saída foram medidas as acelerações em cada um dos 30 pontos descritos na Figura 3.11. Nos pontos de entrada foram fixadas pequenas esferas de aço para garantir a excitação na direção perpendicular ao plano da viga. A resposta do sistema foi captada através de um acelerômetro piezoelétrico cuja fixação à viga de alumínio foi feita com a utilização de uma fina camada de cêra vermelha da Kistler.

Os ensaios foram realizados aplicando-se a entrada impulsiva em um dos 2 pontos de entrada. As FRFs foram obtidas para cada um dos pontos de saída, 
totalizando 60 FRFs. No apêndice A, pode-se encontrar todas as FRFs medidas no ensaio de impacto proposto. A FRF pode ser obtida através das medidas da força de entrada e da aceleração em cada ponto de saída. Os sinais das medidas de força e de aceleração são amplificados através de amplificadores de carga apropriados e são processados por um analisador de sinais. Posteriormente, a FRF gerada pelo analisador de sinais é transmitida para um microcomputador. A Figura 3.12 mostra o ambiente de ensaio com os principais equipamentos utilizados.



Figura 3.12 - Vista geral da montagem do experimento e equipamentos.

A Tabela 3.2 relaciona os equipamentos utilizados nos ensaios experimentais, com seus modelos e algumas especificações técnicas. 
Tabela 3.2 - Relação dos equipamentos utilizados

\begin{tabular}{||l||}
\hline EQUIPAMENTOS UTILIZADOS \\
\hline Analisador de sinais SignalCalcACE - Modelo 6714. \\
\hline Amplificador de Sinal KistlerPower Supply/Coupler - Modelo 5134. \\
\hline Martelo de Impacto Kistler - Modelo 9724. \\
Sensibilidade $=2,0 \mathrm{mV} / \mathrm{N}$. \\
Massa $=250$ gramas. \\
\hline Acelerômetro Kistler - Model $-8636 \mathrm{C} 10$. \\
Sensibilidade $=506 \mathrm{mV} / \mathrm{g}$. \\
Massa $=5.5$ gramas. \\
\hline Microcomputador. \\
\hline$\Delta t=0,0008 ; \Delta f=0,3906$ \\
\hline
\end{tabular}

A faixa de freqüência analisada foi limitada entre 0 e $625 \mathrm{~Hz}$. De forma a excitar a estrutura adequadamente dentro desta faixa, o martelo de impacto foi utilizado com a ponteira de plástico duro (Kistler - modelo 9904A), a mais adequada ao experimento proposto.

As FRFs foram obtidas utilizando o recurso de médias. Foi tomada a média de cinco FRFs de cada ponto. Este recurso, favorece a minimização do ruído presente na resposta. Além disso, foi utilizada uma janela exponencial nos sinais de força e de aceleração. A janela exponencial reduz o sinal à zero ou a valores próximos de zero à medida que o sinal aproxima-se do fim da janela (McCONNELL, 1995). Este recurso é necessário para tornar apropriada a relação sinal/ruído no fim da janela. Caso não fosse empregada janela alguma, o sinal conteria na sua porção final uma grande quantidade de ruído, fato este que prejudicaria ou até mesmo inviabilizaria o processo de identificação.

Outro motivo para a utilização da janela exponencial reside em evitar o truncamento durante o processo de aquisição do sinal antes que este decaia suficientemente à valores bem próximos de zero. Caso a resposta medida apresentasse truncamento, todo o processamento posterior deste sinal estaria 
comprometido devido ao leakage, e a identificação revelar-se-ia imprecisa. O fenômeno de leakage é a conseqüência direta da aquisição de uma porção do sinal temporal que não apresenta um número inteiro de ciclos dentro da janela, provocando o "vazamento" da energia contida nas freqüências ressonantes para outras regiões do espectro em freqüências. Tomando o sinal em termos de janelas no tempo, minimiza-se os efeitos do processamento de sinais que são periódicos dentro da respectiva janela (PAZIANI, 2002).

\subsection{3 - IMPLEMENTAÇÃO COMPUTACIONAL}

Da adequada interposição de todas as rotinas programadas resultaram basicamente três algoritmos considerados definitivos para o efeito da identificação dos parâmetros modais da viga de alumínio. O primeiro algoritmo manipula os dados de resposta com o objetivo de gerar as funções resposta ao impulso necessárias para a aplicação do $E R A$, o segundo realiza todos os cálculos relacionados ao $E R A$ e à qualificação dos resultados obtidos através dos índices de confiança $E M A C, M P C W$ e $C M I$ e o terceiro algoritmo é reservado à produção dos gráficos tridimensionais das formas modais.

Inicialmente o programa carrega as partes real e imaginária de todas as 60 funções resposta em freqüência medidas sobre a viga. Em seguida, as 60 FRFs são recompostas somando-se à parte real de cada resposta à sua respectiva parte imaginária multiplicada pelo número imaginário $i$.

O passo seguinte consiste na geração das funções resposta ao impulso a partir das FRFs. A obtenção das seqüências de parâmetros de Markov ou resposta ao impulso é realizada através da transformada inversa de Fourier. Desta forma, o algoritmo realiza o processo descrito para os dados referentes aos 60 pontos simultaneamente e fornece uma matriz contendo todas as 60 FRIs, cujas linhas representam as respostas ao impulso correspondentes.

$\mathrm{O}$ algoritmo designado para realizar os cálculos relacionados ao ERA e aos procedimentos de qualificação através dos índices de confiança, utiliza os dados 
de FRIs geradas conforme descrito acima para efetuar a identificação, conforme mostrado no fluxograma da Figura 3.1.

Alguns dos critérios utilizados na etapa de eliminação de parâmetros modais devem ser estabelecidos através do conhecimento prévio do comportamento dinâmico da estrutura. No caso do modelo ensaiado (viga de alumínio) o algoritmo elimina fatores de amortecimento maiores que $5 \%$, pois se considera que não sejam encontrados valores desta magnitude na estrutura ensaiada.

Outros critérios podem ser utilizados para eliminar modos computacionais. Um destes critérios é o que elimina modos com freqüência dentro da faixa de $1 \%$ do final da faixa de freqüência analisada (TSUNAKI, 1999).

O principal processo de eliminação executado pelo algoritmo consiste na qualificação dos parâmetros modais identificados, através dos índices de confiança $E M A C, M P C W$ e $C M I$. Neste caso, são considerados modos confiáveis, valores de $M P C W$ maiores que $50 \%$ e valores de $C M I$ maiores que $30 \%$.

Após a qualificação dos modos através dos índices, são calculadas as freqüências naturais associadas a estes modos e os respectivos fatores de amortecimento são recalculados.

Finalmente, é criada uma matriz dos modos reais obtidos dos modos complexos, a ser utilizada no algoritmo de representação gráfica.

Após o processo de identificação e geração dos gráficos dos modos, são selecionados e reservados os melhores resultados, ou seja, os modos cujos valores de $C M I$ forem os maiores possíveis.

\subsection{4 - RESULTADOS DA IDENTIFICAÇÃO}

Esta seção apresenta os resultados dos procedimentos de identificação através do $E R A$ e de qualificação utilizando os índices de confiança $E M A C, M P C W$ e CMI.

Os dados experimentais originais são as funções resposta em freqüência (FRF) medidas sobre a viga de alumínio durante os ensaios experimentais. A Figura 3.13 mostra os dados de três FRFs, do conjunto total das 60 FRFs medidas, 
apresentadas no Apêndice A. A notação utilizada para indicar a localização da entrada e da saída das FRFs é descrita em função das marcações assinaladas na viga de alumínio mostrada nas Figura 3.10 e 3.11. Desta forma, FRF - A05 indica que esta função resposta em freqüência foi obtida medindo-se a força aplicada no ponto $\boldsymbol{A}$ e a aceleração no ponto 05 .

A partir das FRFs medidas podem ser obtidas as respostas ao impulso correspondentes ou seqüência de parâmetros de Markov. O conjunto das resposta ao impulso formam os dados de entrada para o Algoritmo de Realização de Sistemas $E R A$. As respostas ao impulso foram obtidas através da tomada da transformada inversa de Fourier das funções resposta em freqüência, como mostra a Figura 3.14. Estas funções resposta ao impulso correspondem às FRFs mostradas na Figura 3.13.

Uma pré-análise do modelo testado é realizada calculando-se o espectro de potência médio (EPM), através da equação:

$$
\operatorname{EPM}\left(\omega_{i}\right)=\frac{\sum_{j=1}^{N}\left|H_{j}\left(\omega_{i}\right)\right|^{2}}{N}
$$

onde $H_{j}\left(\omega_{i}\right)$ é o valor da $j$-ésima FRF na freqüência $\omega_{i}$ e $N$ é o número total de FRFs.

A Figura 3.15 apresenta o resultado do espectro de potência médio, aplicado ao conjunto total das FRFs obtidas. O EPM apresenta um pico na freqüência natural de cada modo e a sua amplitude relativa. Um outro dado que se pode tirar do EPM é uma estimativa da ordem do sistema através do número total de picos existentes. 



Figura 3.13 - Funções resposta em freqüência para a viga engastada. 

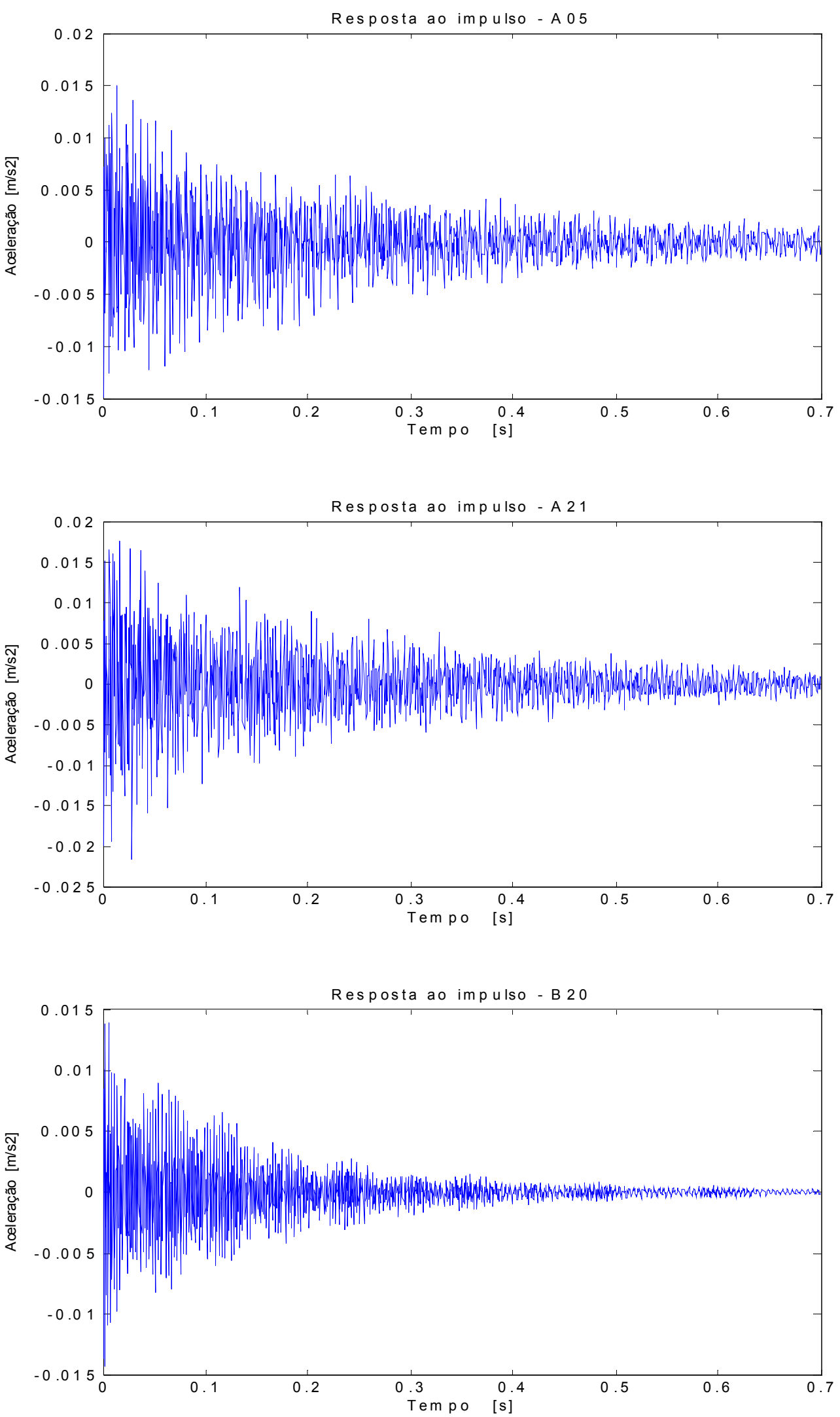

Figura 3.14 - Respostas ao impulso obtidas pela transformada inversa de Fourier a partir das FRFs. 


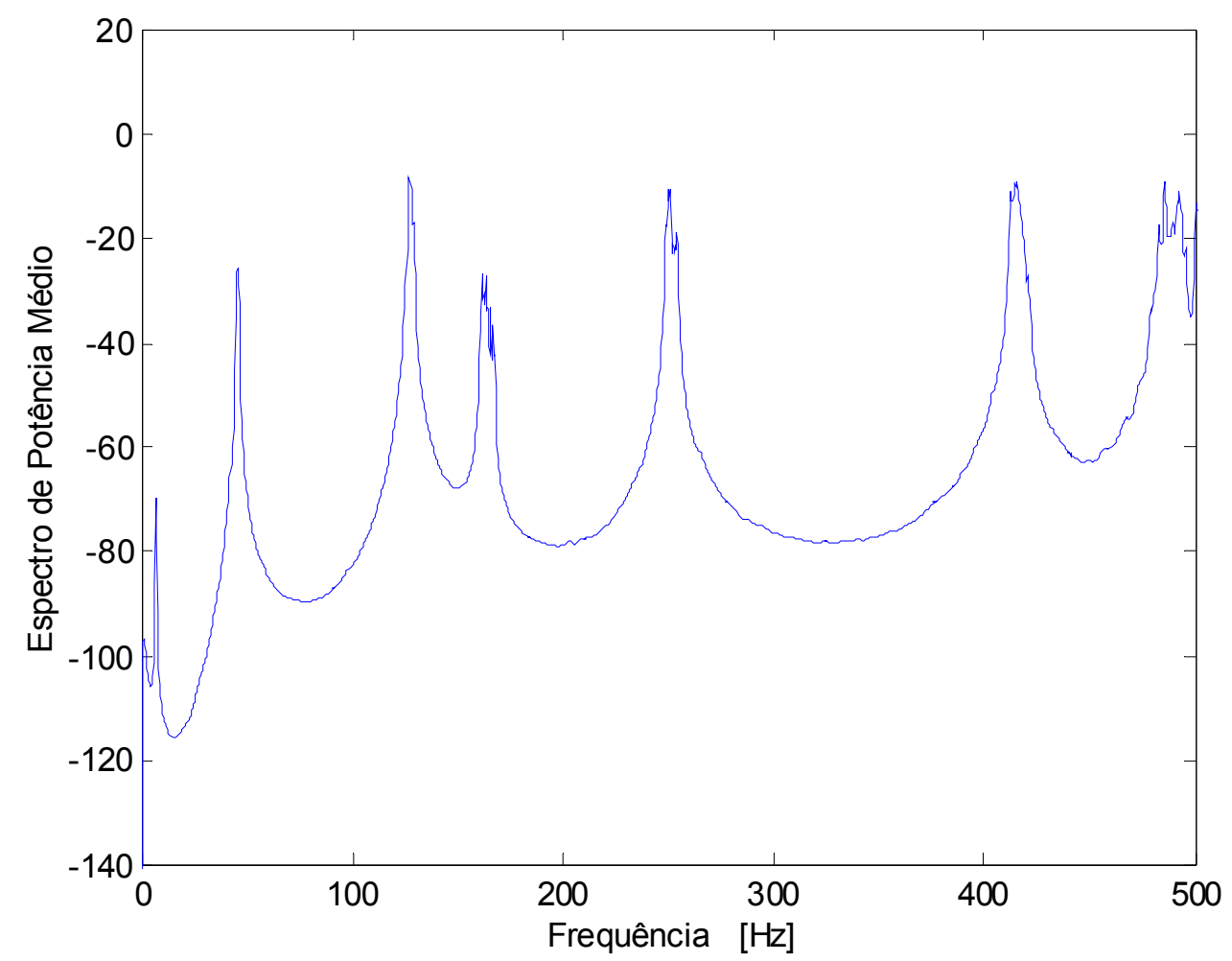

Figura 3.15 - Espectro de potência médio - EPM.

Com os dados das respostas ao impulso montam-se as matrizes Hankel no tempo $k=1,[H(0)]$, e no tempo $k=2[H(1)]$ (equação (2.35)), cuja dimensão é determinada pelos parâmetros $\alpha$ e $\beta$ (números de parâmetro de Markov numa coluna e numa linha da equação (2.35), respectivamente). No caso, a dimensão escolhida é de 1200 linhas ( $\alpha=40, m=30)$ por 120 colunas $(\beta=60, r=2)$.

Através do $E R A$, a identificação é realizada decidindo-se o número de modos existentes nas matrizes Hankel para análise dos valores singulares. O número de modos assumidos é estabelecido ao se reter os $2 n$ primeiros valores singulares da decomposição em valores singulares de $[H(0)]$ e as correspondentes $2 n$ primeiras colunas das matrizes de vetores singulares, ou seja, escolhendo-se a dimensão de $\left[\sum_{2 n}\right],\left[R_{2 n}\right]$ e $\left[S_{2 n}\right]$ (equações $(2.53,2.55$ e 2.56$\left.)\right)$.

A identificação de todos os modos de vibrar da estrutura não ocorreu em uma única ocasião. São necessárias algumas análises para proporcionar a completa 
identificação do sistema. Em cada análise, diferentes valores de modos assumidos, $2 n$, foram inseridos no algoritmo, que forneceu resultados diferentes para as diversas combinações de valores fornecidos. Utilizando todas as estimativas do número de modos assumidos, $2 n$, os melhores resultados dos valores do índice de confiança CMI identificados foram selecionados. Desta forma, foram tomados os melhores modos, assim como as respectivas freqüências naturais e fatores de amortecimento. Deve ser citado que os modos que apresentaram $M P C W$ menor que $50 \%$ e $C M I$ menor que $30 \%$ simultaneamente não foram reproduzidos graficamente.

O resultado final do processo de identificação é composto dos parâmetros globais do sistema, ou seja, as freqüências naturais e os fatores de amortecimento modal, e também dos modos de vibrar da estrutura.

De modo a localizar a identificação de um determinado modo dentro do processo de identificação dos parâmetros modais da estrutura, a Tabela 3.3 fornece, além dos valores das freqüências naturais e dos fatores de amortecimento, as estimativas da ordem do sistema $2 n$. Desta forma, é possível conhecer qual estimativa foi capaz de fornecer a melhor identificação. Também é apresentado o valor do $C M I$ de cada modo. A grandeza do índice está relacionada com a qualidade da representação gráfica do modo real. Os modos com índices menos expressivos ou que se encontram muito próximos aos seus limites tendem a fornecer representações gráficas visualmente mais precárias.

As Figuras 3.16 a 3.21 apresentam as representações gráficas dos modos de vibrar identificados e qualificados da estrutura de ensaio. O método utilizado para a conversão consiste em que cada elemento do modo real é equivalente à magnitude vezes o cosseno da fase do elemento correspondente do modo complexo.

As FRFs identificadas podem ser obtidas através das matrizes que representam o modelo de estado nas coordenadas modais em tempo discreto identificadas. A Figura 3.22 apresenta o gráfico da função resposta em freqüência (FRF) do sistema real e do modelo identificado, correspondente as FRFs mostradas na Figura 3.13. 
Tabela 3.3 - Características dinâmicas obtidas com o modelo identificado

\begin{tabular}{|c|c|c|c|c|}
\hline \multicolumn{7}{|c|}{ Algoritmo de Realização de Sistemas - ER A } \\
\hline \hline \multirow{2}{*}{ Modo } & $\begin{array}{c}\omega_{n d} \\
{[\mathrm{~Hz}]}\end{array}$ & $\begin{array}{c}\xi_{n} \\
\%\end{array}$ & $\begin{array}{c}C M I \\
\%\end{array}$ & $\begin{array}{c}\text { Estimativa } \\
2 n\end{array}$ \\
\hline 1 & 7,1 & 0,92 & 92,0 & 120 \\
\hline 2 & 45,3 & 0,68 & 85,7 & 72 \\
\hline 3 & 127,3 & 0,27 & 70,8 & 28 \\
\hline 4 & 161,6 & 0,29 & 65,9 & 90 \\
\hline 5 & 250,8 & 0,21 & 46,0 & 22 \\
\hline 6 & 415,3 & 0,20 & 34,2 & 22 \\
\hline
\end{tabular}

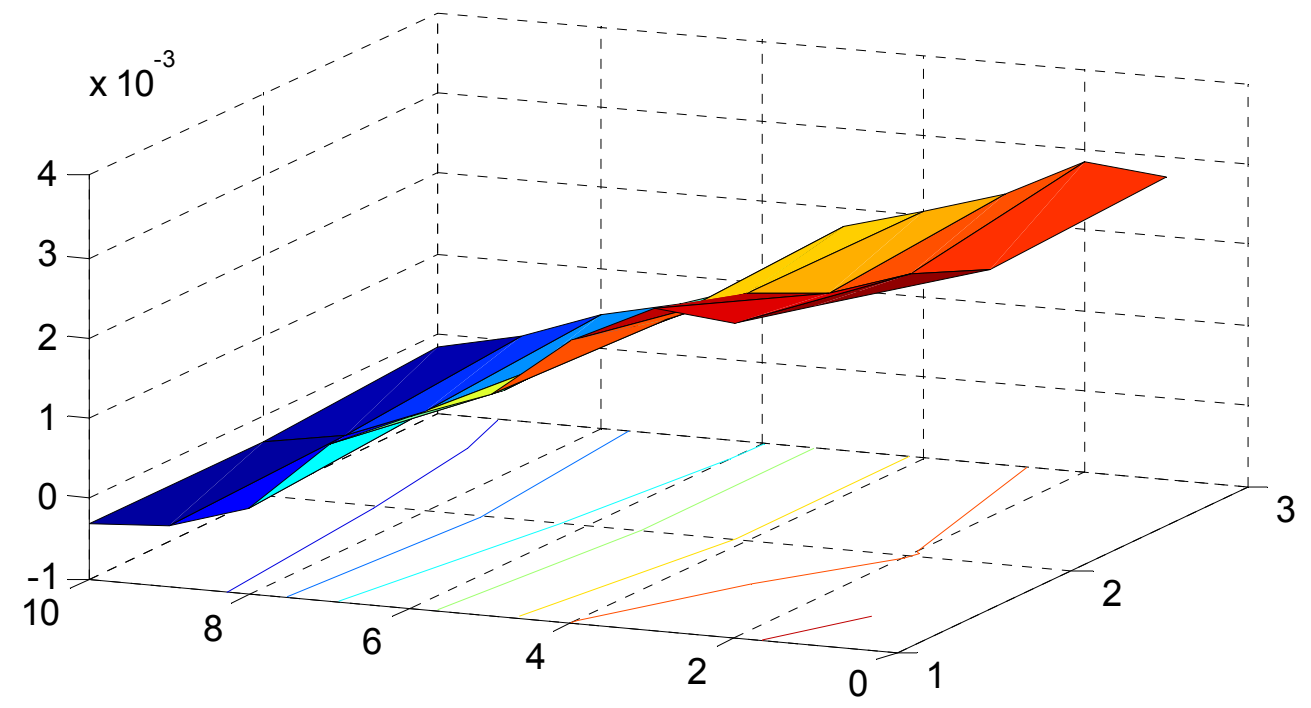

Figura 3.16 - Primeiro modo - 7,1 Hz 


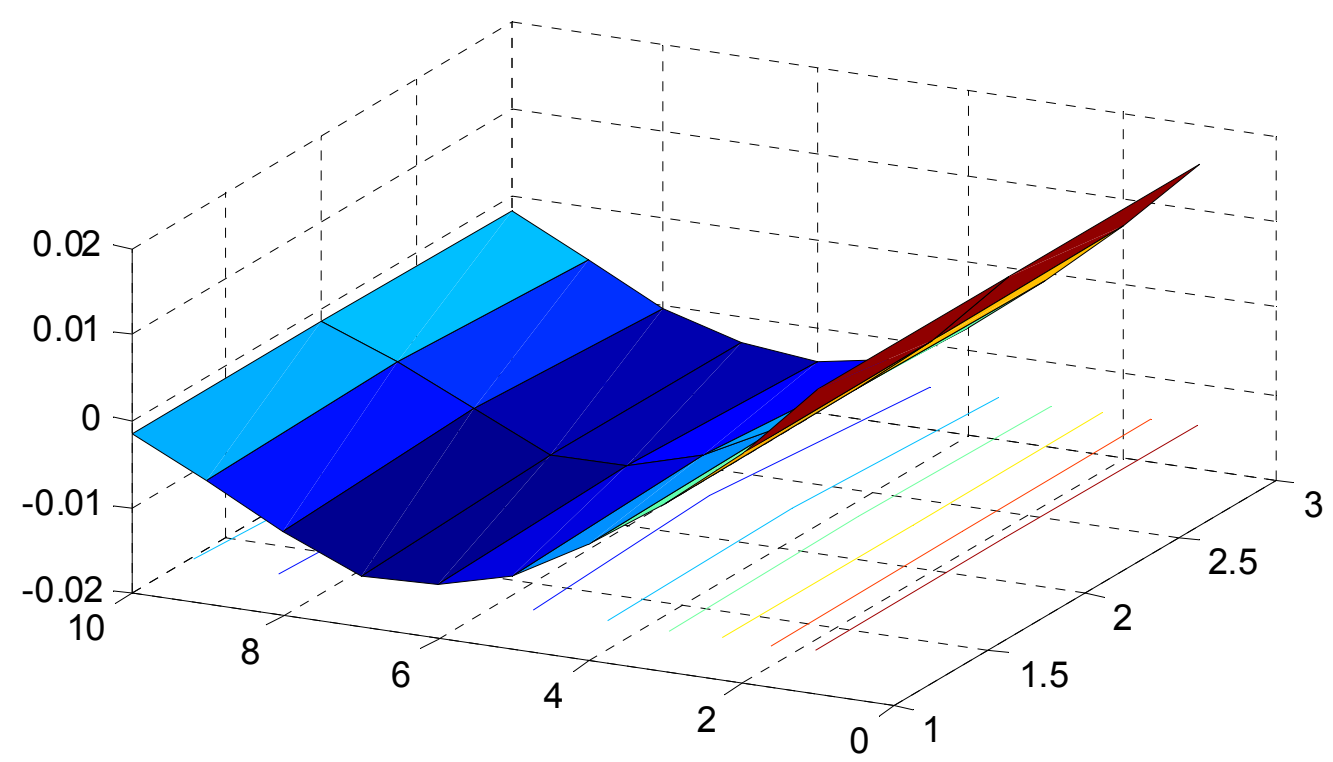

Figura 3.17 - Segundo modo $-45,3 \mathrm{~Hz}$

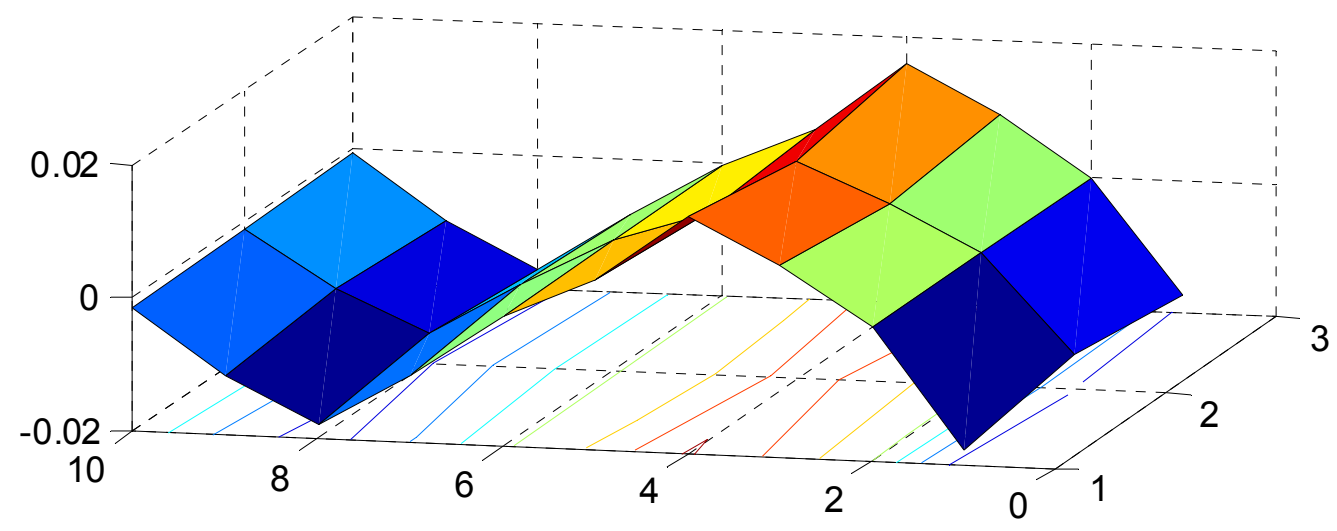

Figura 3.18 - Terceiro modo - 127,3 Hz 


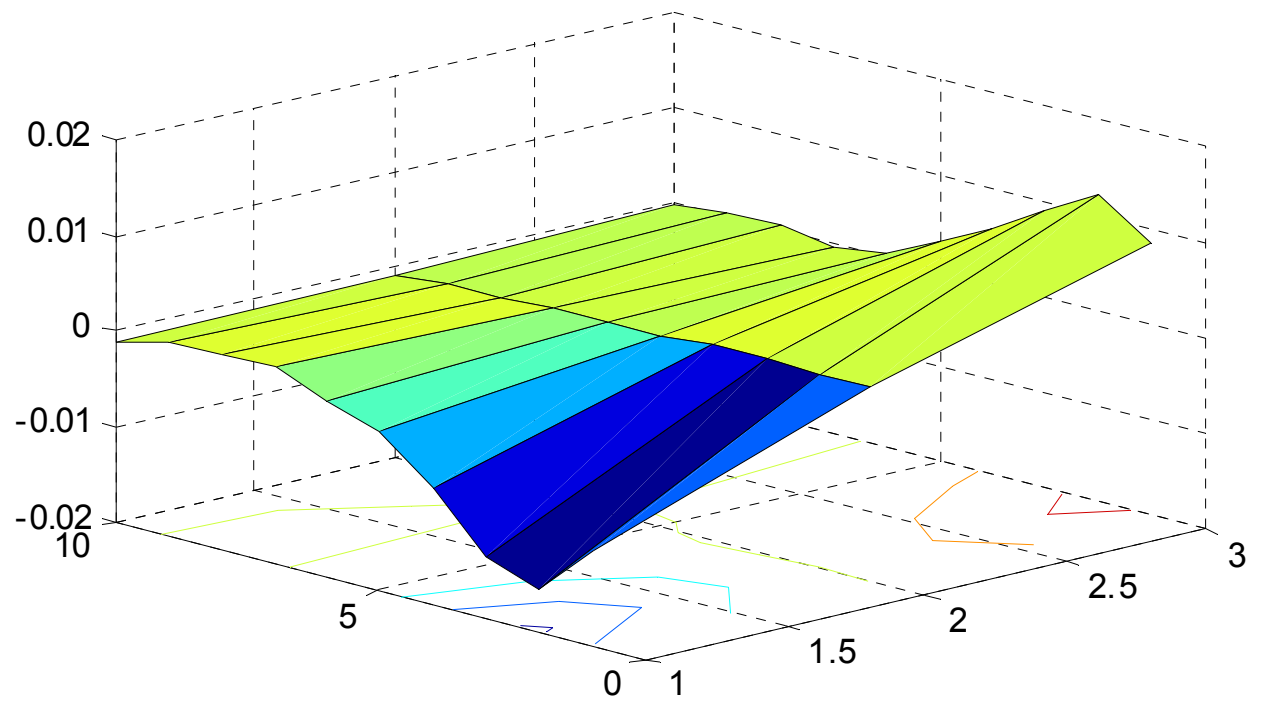

Figura 3.19 - Quarto modo - 161,6 Hz

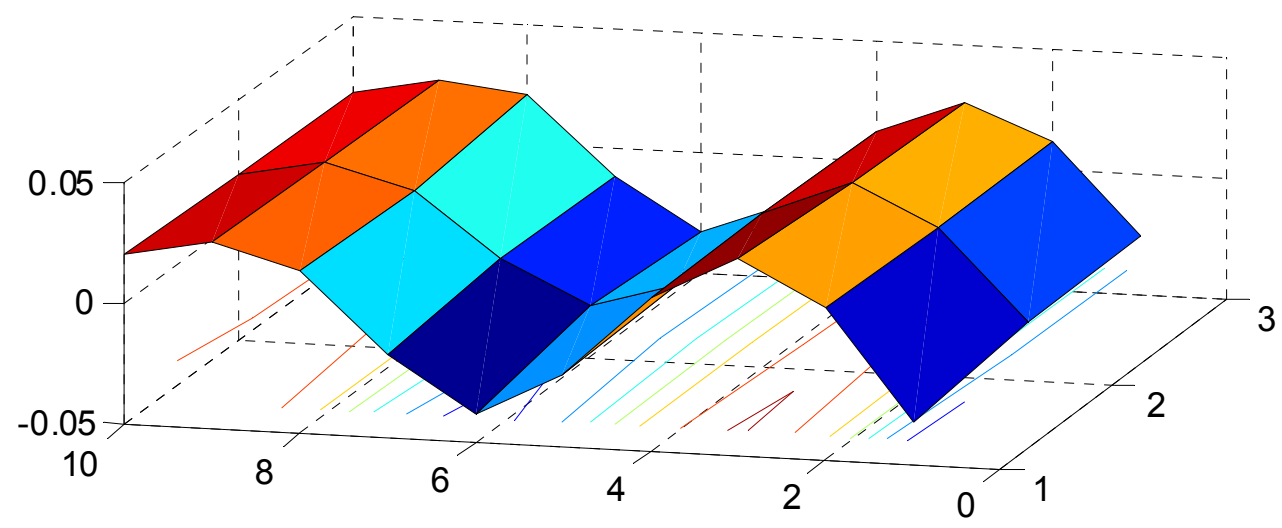

Figura 3.20 - Quinto modo - 250,8 Hz

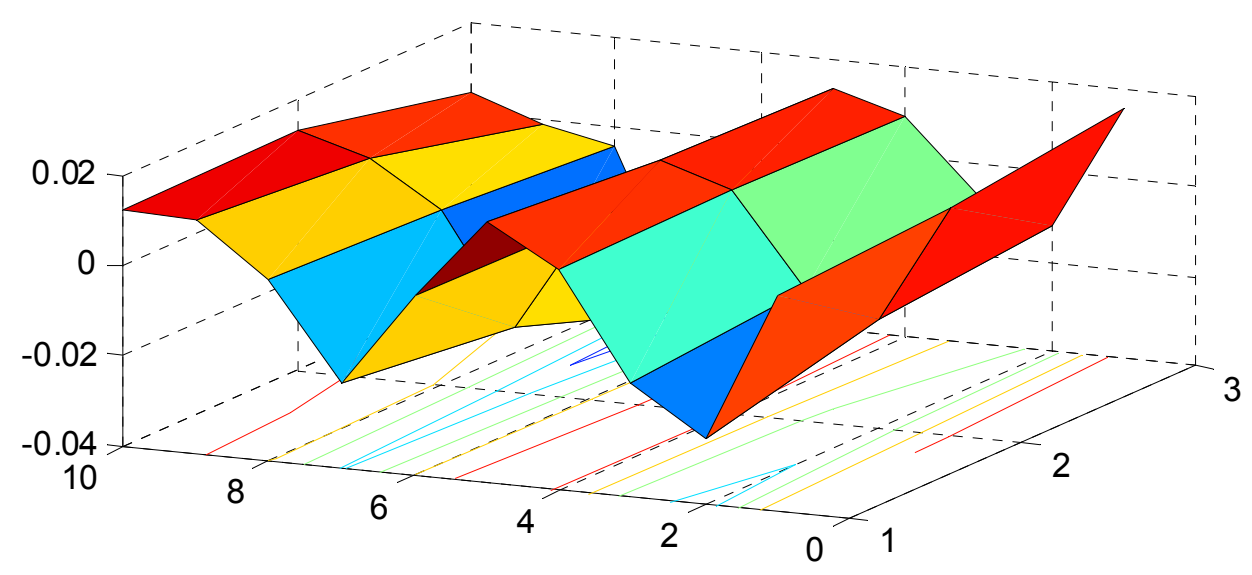

Figura 3.21 - Sexto modo $-415,3 \mathrm{~Hz}$ 



Figura 3.22 - Respostas em freqüência do sistema real e identificado. 


\section{CAPÍTULO 4}

\section{APLICAÇÃO DO ALGORITMO DE REALIZAÇÃO DE SISTEMAS EM UMA ESTRUTURA AERONÁUTICA}

Neste capítulo é apresentada a configuração do experimento realizado. Em seguida, é descrita a implementação computacional do ERA, assim como a implementação da qualificação dos resultados através dos índices de confiança. Posteriormente, são apresentados os resultados obtidos no processo de identificação da estrutura proposta.

\section{1 - DESCRIÇÃO DA ESTRUTURA DE TESTE}

A estrutura aeronáutica utilizada no processo de identificação é uma das semi-asas da aeronave Neiva Regente C-42. O avião foi fabricado nos anos 60 pela Sociedade Construtora Aeronáutica Neiva Ltda, Botucatu, SP, hoje uma das subsidiárias da EMBRAER, Empresa Brasileira de Aeronáutica, São José dos Campos, SP. É do tipo quadriplace, monomotor, monoplano de asa alta. Sua construção é quase que totalmente metálica sendo a fuselagem semi-monocoque e as 
semi-asas estaiadas com montantes simples. A Figura 4.1 mostra as 3 vistas da aeronave Regente, com suas respectivas dimensões em metros.

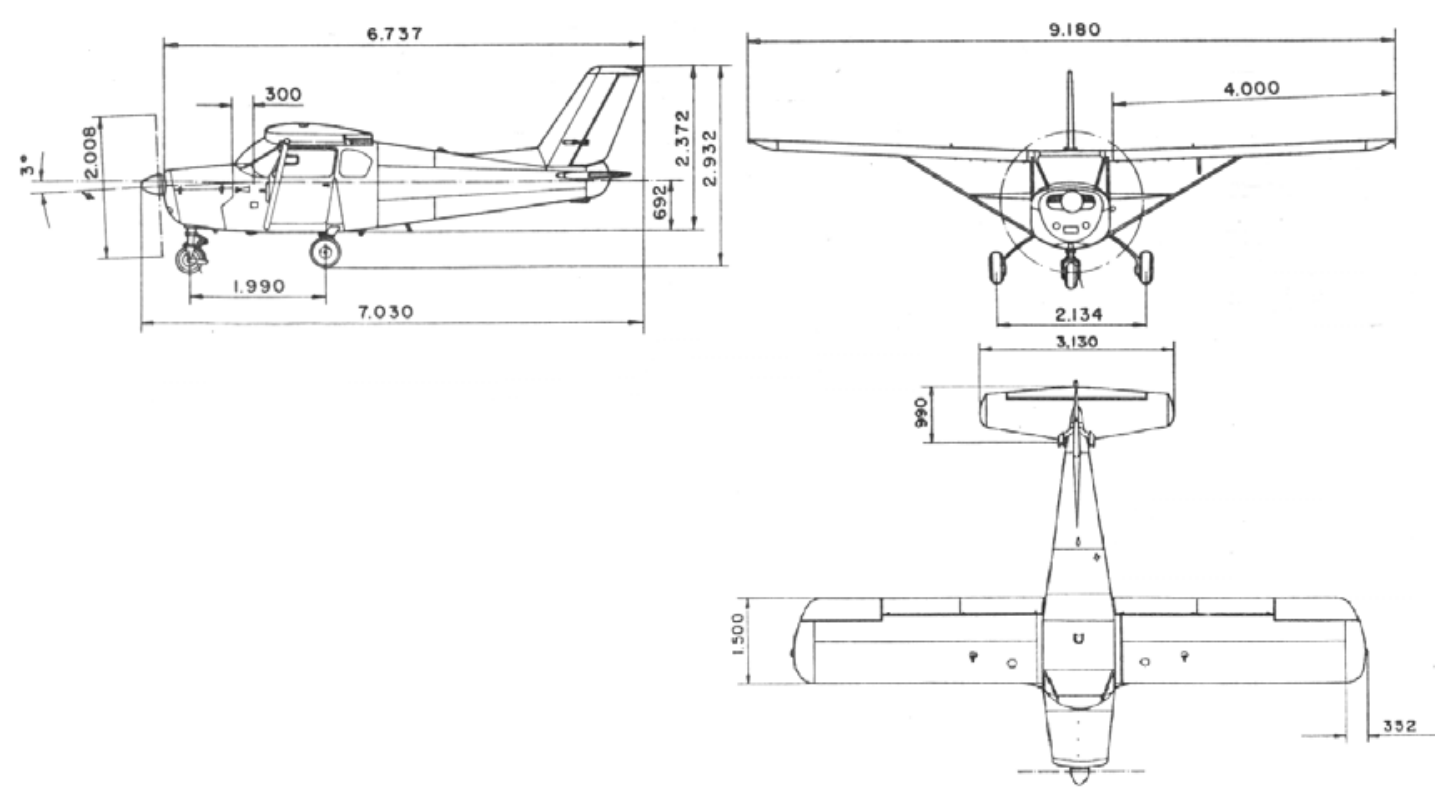

Figura 4.1 - Três vistas da aeronave Neiva Regente (dimensões em metros).

A estrutura da semi-asa tem as seguintes características: construção convencional, semi-monocoque com duas longarinas fabricadas em chapa dobrada em "C", nervuras moldadas, revestimento trabalhante rebitado e ponta destacável de fibra de vidro, de dimensão $3200 \times 1600$. A Figura 4.2 mostra a semi-asa ensaiada.

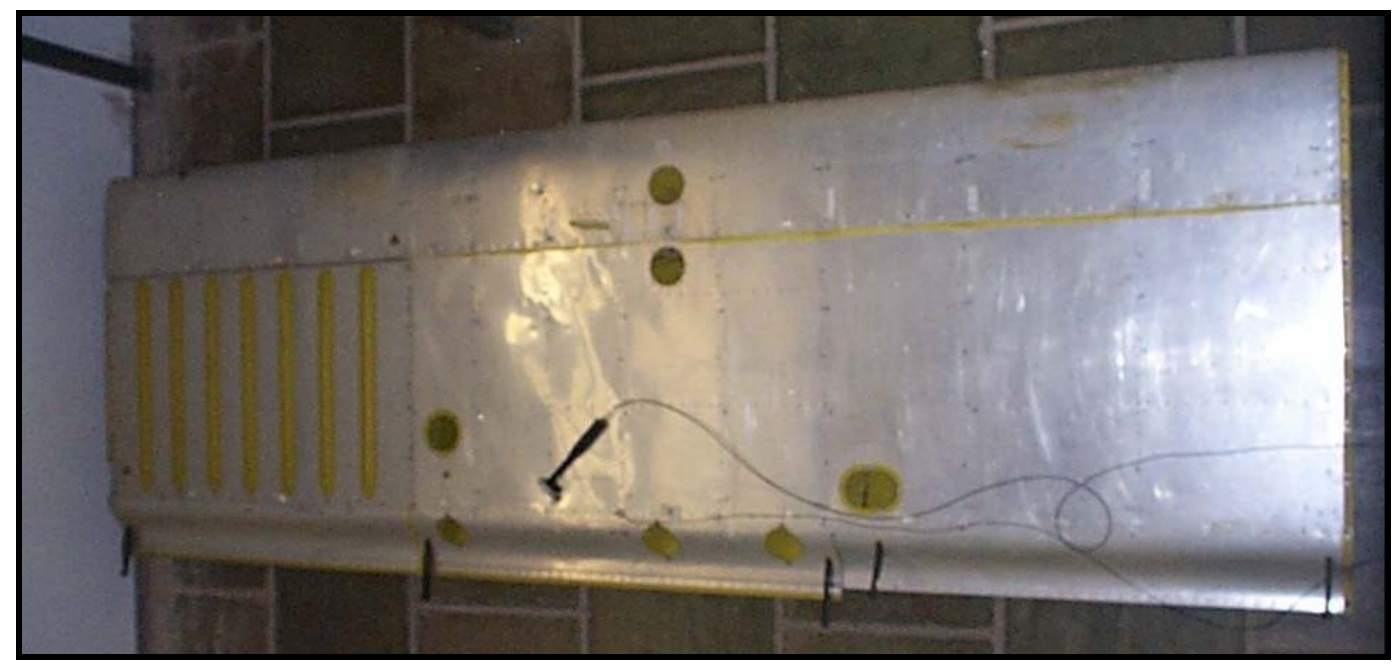

Figura 4.2 - Semi-asa do Neiva Regente utilizada nos experimentos. 
A Figura 4.3 mostra o ambiente do ensaio experimental. A configuração do experimento realizado na semi-asa simula uma aproximação da condição livrelivre. Esta condição foi conseguida suspendendo a semi-asa através de cabos e molas flexíveis pelos suportes do flape, ailerão e montante.

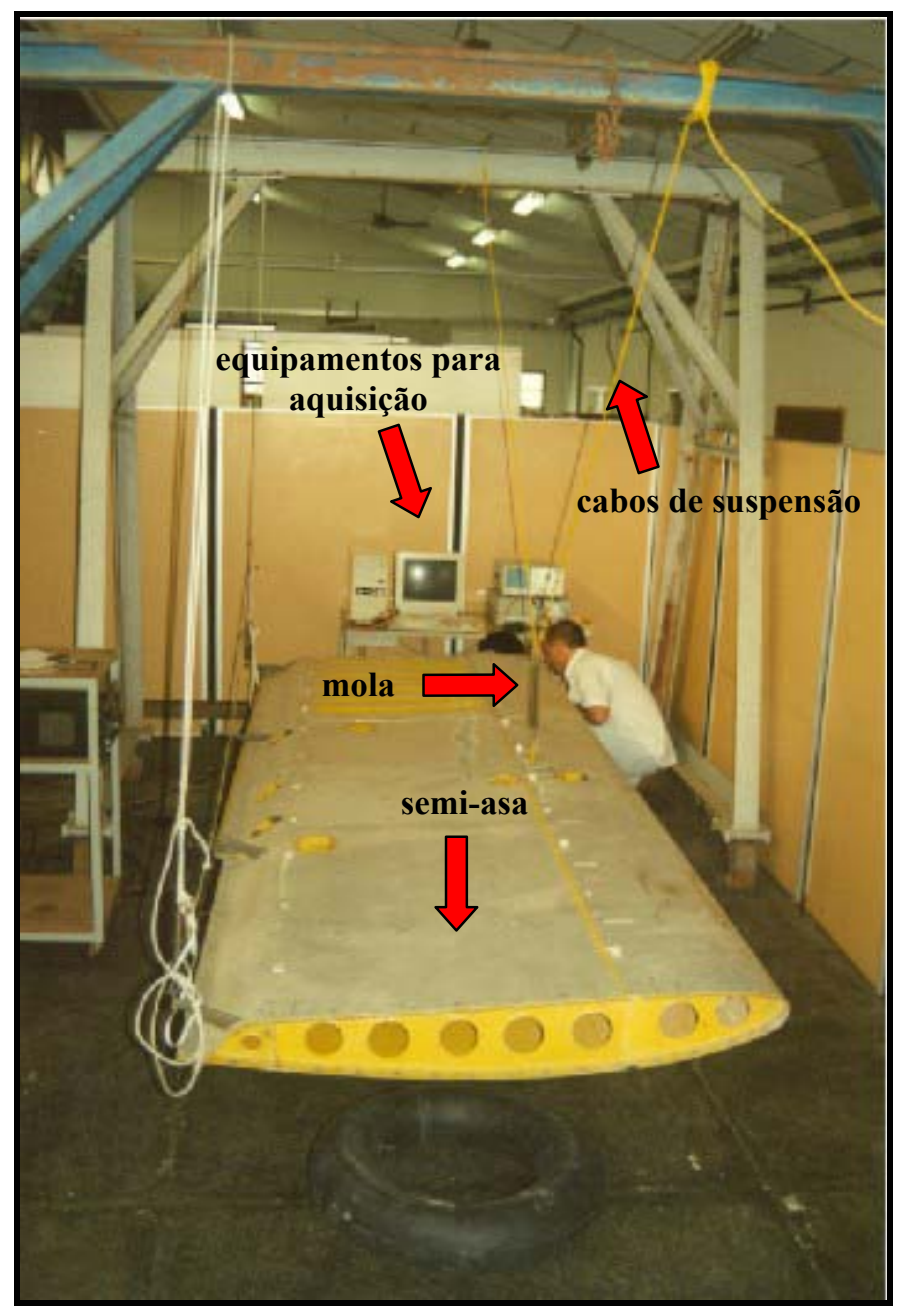

Figura 4.3 - Vista geral da montagem do experimento.

\section{2 - AQUISIÇÃO DOS DADOS EXPERIMENTAIS}

Os ensaios foram realizados com o objetivo de obter funções resposta em freqüência (FRFs) da asa. Para realizar os ensaios, utilizou-se de procedimento similar ao usado no experimento da viga engastada (Capítulo 3). A asa foi marcada 
com a localização dos pontos de saída e as entradas foram aplicadas nas fixações das duas longarinas com a fuselagem, longarina traseira $\boldsymbol{A}$ e longarina dianteira $\boldsymbol{B}$. A asa foi excitada utilizando-se um excitador eletrodinâmico. Embora tenham sido utilizadas outras formas de excitação, os resultados experimentais apresentados aqui foram obtidos usando-se a excitação senoidal de freqüência variável (chirp). As medidas de aceleração foram tomadas ao longo das longarinas. Foram medidos quinze pontos ao longo de cada longarina, totalizando trinta pontos de medidas de aceleração. Então, para cada ponto de excitação, sessenta FRFs foram medidas no total. Um acelerômetro piezoelétrico foi usado e sua fixação à asa foi feita com a utilização de cera apropriada. A Figura 4.4 mostra um dos pontos de excitação e um dos pontos de medida da estrutura.

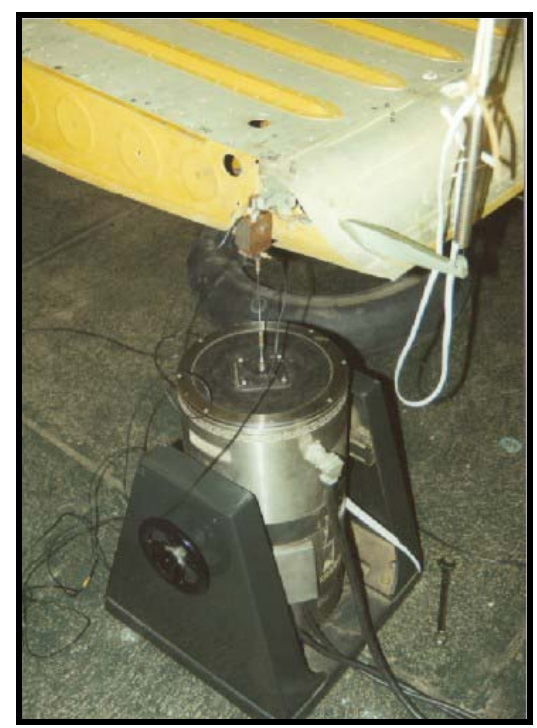

(a) Ponto de excitação

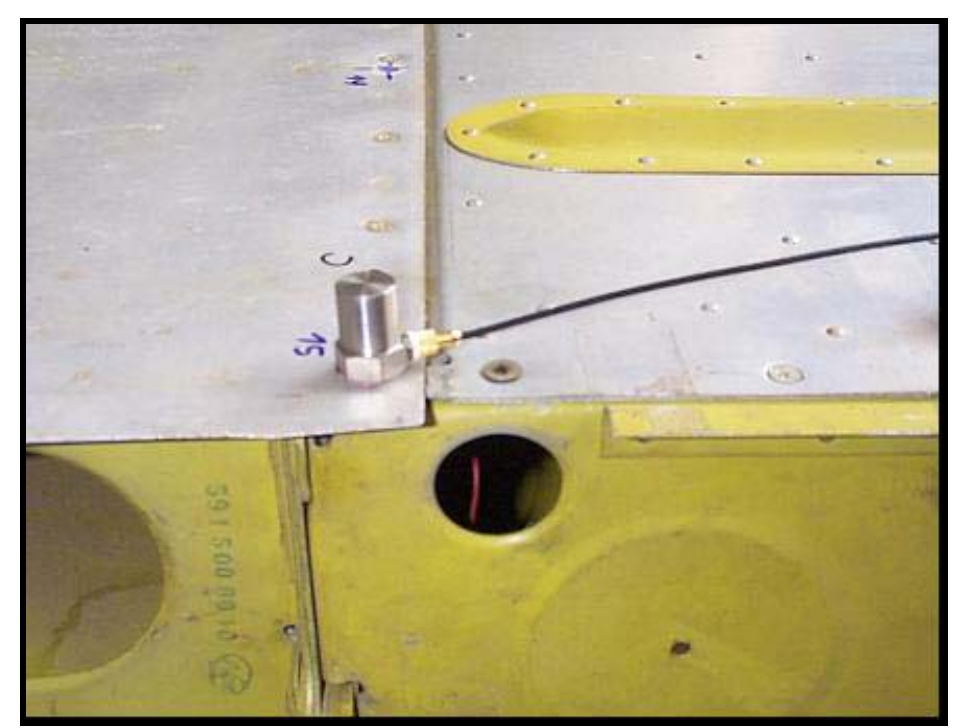

(b) Ponto de medida

Figure 4.4 - Pontos de excitação e medida para o experimento com a semi-asa do Neiva Regente.

A Figura 4.5 ilustra o esquema do ensaio com os principais equipamentos discriminados. Um analisador espectral (1) alimenta um amplificador (2) com uma tensão $V(t)$ que por sua vez envia um sinal elétrico para os circuitos do excitador (3) que transforma este sinal elétrico amplificado em calor e movimento da armadura. A força que o excitador transmite à estrutura (5) é medida através de um transdutor de 
força (4) e as acelerações através de acelerômetros (6) colocados sobre a estrutura. Ambos, transdutor e acelerômetro, têm seus sinais amplificados (7), processados pelo analisador espectral e enviados para o computador (8).

A Tabela 4.1 relaciona os equipamentos utilizados nos ensaios experimentais, com seus modelos e algumas especificações técnicas. No apêndice B, pode-se encontrar todas as FRFs medidas no ensaio de vibração da semi-asa. A faixa de freqüência analisada foi limitada entre 0 e $500 \mathrm{~Hz}$. As FRFs determinadas foram submetidas ao recurso de médias a fím de minimizar o nível de ruído presente nos dados. Embora tenham sido utilizadas outras funções janela, os resultados experimentais apresentados aqui foram obtidos utilizando-se uma janela Hanning no processo de aquisição dos dados.

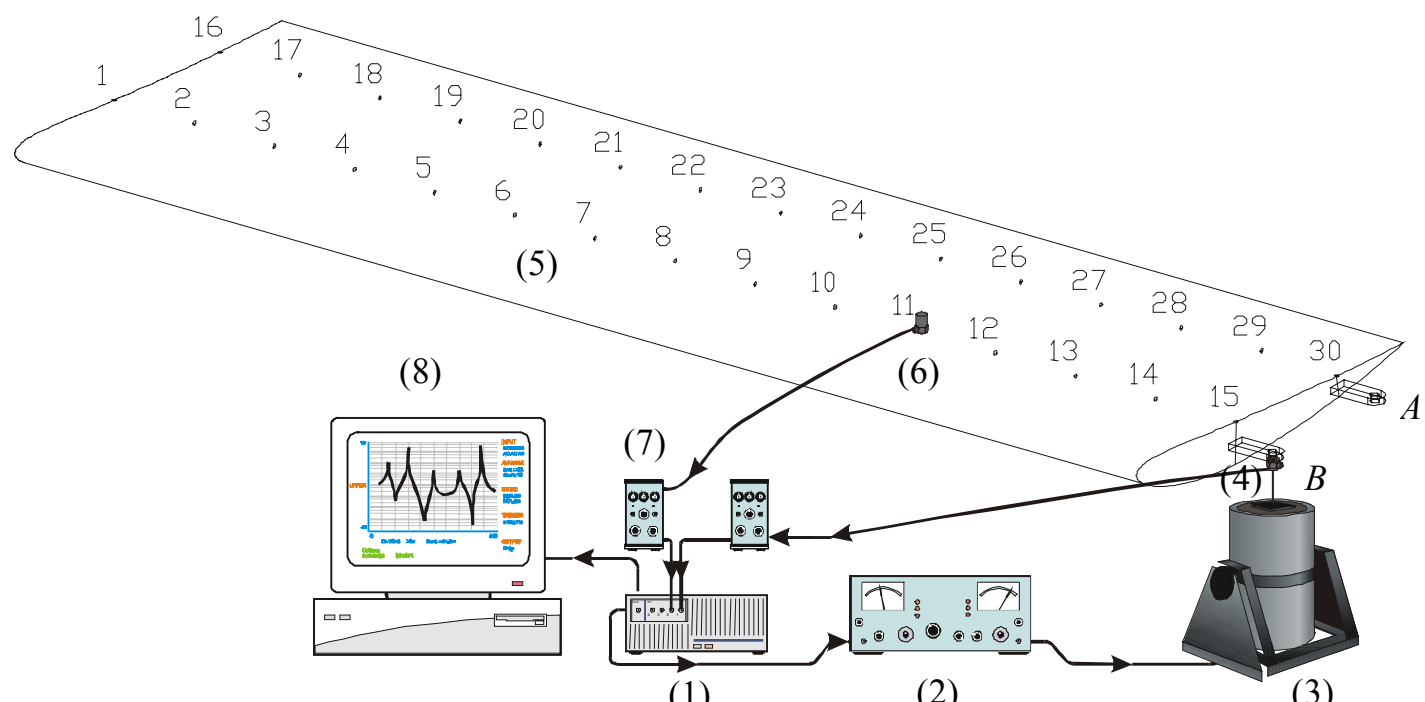

(1)

(2)

(3)

Figura 4.5 - Esquema do ensaio experimental - equipamentos utilizados. 
Tabela 4.1 - Relação dos equipamentos utilizados no experimento da semi-asa do Neiva Regente.

\begin{tabular}{||l|c||}
\hline EQUIPAMENTOS UTILIZADOS & \\
\hline Analisador espectral Tektronix - Modelo 2630. & $(1)$ \\
\hline Amplificador de Sinal $B \& K-$ Modelo 2707. & $(4)$ \\
\hline $\begin{array}{l}\text { Transdutor de força Kistler - Modelo } 912 . \\
\text { Sensibilidade }=13,3 p C / N .\end{array}$ \\
\hline $\begin{array}{l}\text { Acelerômetro } B \& K-\text { Modelo } 4383 . \\
\text { Sensibilidade }=30,5 p C / g .\end{array}$ \\
\hline Excitador eletrodinâmico $B \& K-$ Modelo 4812. & $(3)$ \\
\hline Condicionador de Sinais - Kistler Power Supply. & (7) \\
\hline Computador. & $(8)$ \\
\hline \hline
\end{tabular}

\section{3 - IMPLEMENTAÇÃO DOS ALGORITMOS}

Esta seção descreve a implementação computacional realizada na análise dos dados colhidos da semi-asa do Neiva Regente.

Todos os algoritmos programados para a análise da semi-asa foram realizados através de procedimento similar ao realizado no experimento da viga de alumínio engastada (Capítulo 3).

Uma característica importante do $E R A$ quando utilizado na identificação de estruturas que apresentem comportamento dinâmico complexo, é a identificação de um número maior de modos do que aqueles realmente existentes na faixa de freqüência analisada, dificultando a análise dos resultados da identificação.

Desta forma, a condensação modal para os dados da semi-asa é realizada através de duas etapas. A primeira etapa é destinada à eliminação, dentro de critérios específicos, de parâmetros modais mal identificados ou de modos computacionais. A segunda etapa consiste na qualificação dos parâmetros modais identificados, através dos índices de confiança. 
No caso da estrutura aeronáutica ensaiada, um critério estabelecido é de que modos com amortecimento superior a 10\% devem ser eliminados, pois se considera que não sejam encontrados valores desta magnitude na semi-asa. Além disso, são eliminados também modos com freqüência dentro da faixa de $1 \%$ do final da faixa de freqüência analisada.

O principal processo de eliminação executado pelo algoritmo consiste na qualificação dos parâmetros modais identificados, através dos índices de confiança $E M A C, M P C W$ e $C M I$. Desta forma, para este caso, são considerados modos confiáveis, valores de $M P C W$ superiores a $50 \%$ e valores de $C M I$ superiores que $30 \%$. A Tabela 4.2 apresenta os critérios utilizados para a eliminação de parâmetros modais, onde $\omega_{n d}$ é a freqüência natural amortecida, $\omega_{\max }$ é o limite superior da faixa de freqüência analisada e $\omega_{\min }$ é o limite inferior da faixa de freqüência analisada.

Tabela 4.2 - Critérios utilizados na eliminação de parâmetros modais.

\begin{tabular}{|c|c|}
\hline Critério & Elimininação \\
\hline Amortecimento $<0 \%$ & Modos computacionais \\
\hline Amortecimento $>10 \%$ & Modos mal identificados \\
\hline $0,99 \omega_{\max } \leq \omega_{n d} \leq \omega_{\max }$ & Freqüência de aquisição \\
\hline$\omega_{n d}=0$ & Modos de corpo rígido \\
\hline$\omega_{n d} \leq 0,01 \omega_{\min }$ & Modos computacionais \\
\hline$C M I<30 \%$ & Modos mal identificados \\
\hline
\end{tabular}

Após a qualificação dos modos através dos índices, são calculadas as freqüências naturais associadas a estes modos $\mathrm{e}$ os respectivos fatores de amortecimento são recalculados. 
Finalmente, é criada uma matriz dos modos reais obtidos dos modos complexos, a ser utilizada no algoritmo de representação gráfica.

Após o processo de identificação e geração dos gráficos dos modos, são selecionados e reservados os melhores resultados, ou seja, os modos cujos valores de $C M I$ forem os maiores possíveis.

\section{4 - RESULTADOS}

Nesta seção, são apresentados os dados experimentais obtidos no ensaio modal da estrutura aeronáutica e os resultados dos procedimentos de identificação através do $E R A$ e da qualificação utilizando os índices de confiança.

Os dados experimentais originais são as funções resposta em freqüência. A Figura 4.6 mostra os dados de três FRFs, do conjunto total das 60 FRFS medidas, apresentadas no Apêndice B. A notação utilizada para indicar a localização da entrada e da saída das FRFs é descrita em função das marcações assinaladas na asa, como mostra a Figura 4.5. Desta forma, por exemplo, a FRF A1 indica que esta função resposta em freqüência foi obtida medindo-se a força aplicada em $A$ e a aceleração no ponto 1, e a FRF B7 indica a força aplicada em $B$ e a aceleração no ponto 7.

A partir das FRFs medidas podem ser obtidas as seqüências de parâmetros de Markov correspondentes. O conjunto dos parâmetros de Markov formam os dados de entrada para o $E R A$, obtidos aplicando-se a transformada inversa de Fourier nos dados experimentais. A Figura 4.7 mostra os três gráficos das respostas ao impulso obtidas pela transformada inversa de Fourier, correspondentes às FRFs mostradas na Figura 4.6.

Na Figura 4.8, é apresentado o resultado do espectro de potência médio (EPM), aplicado ao conjunto total de FRFs obtidas, conforme apresentado no (Capítulo 3). Este gráfico nos permite visualizar possíveis freqüências naturais da estrutura. 

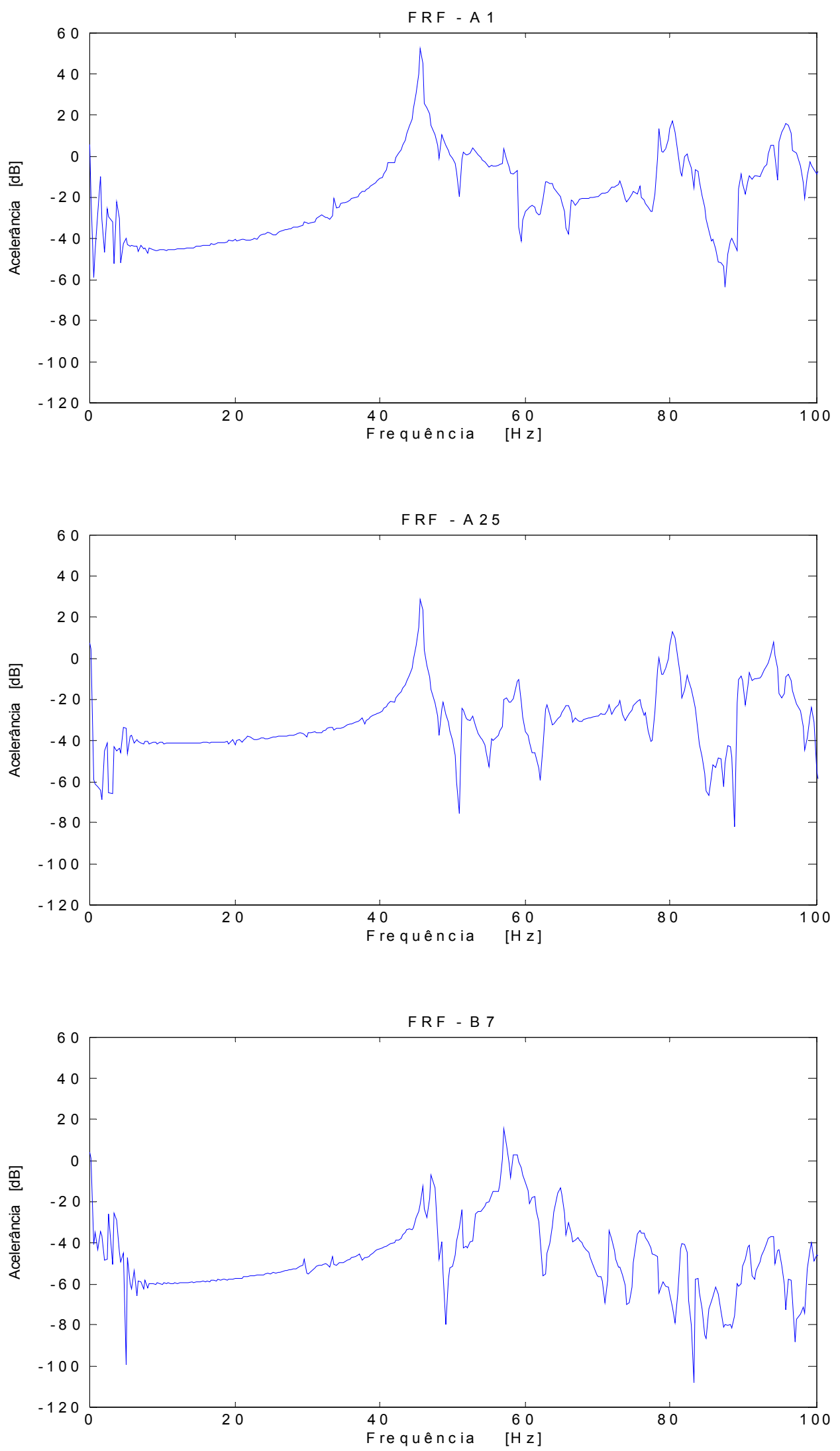

Figura 4.6 - FRFs obtidas no ensaio modal da semi-asa do Neiva Regente. 

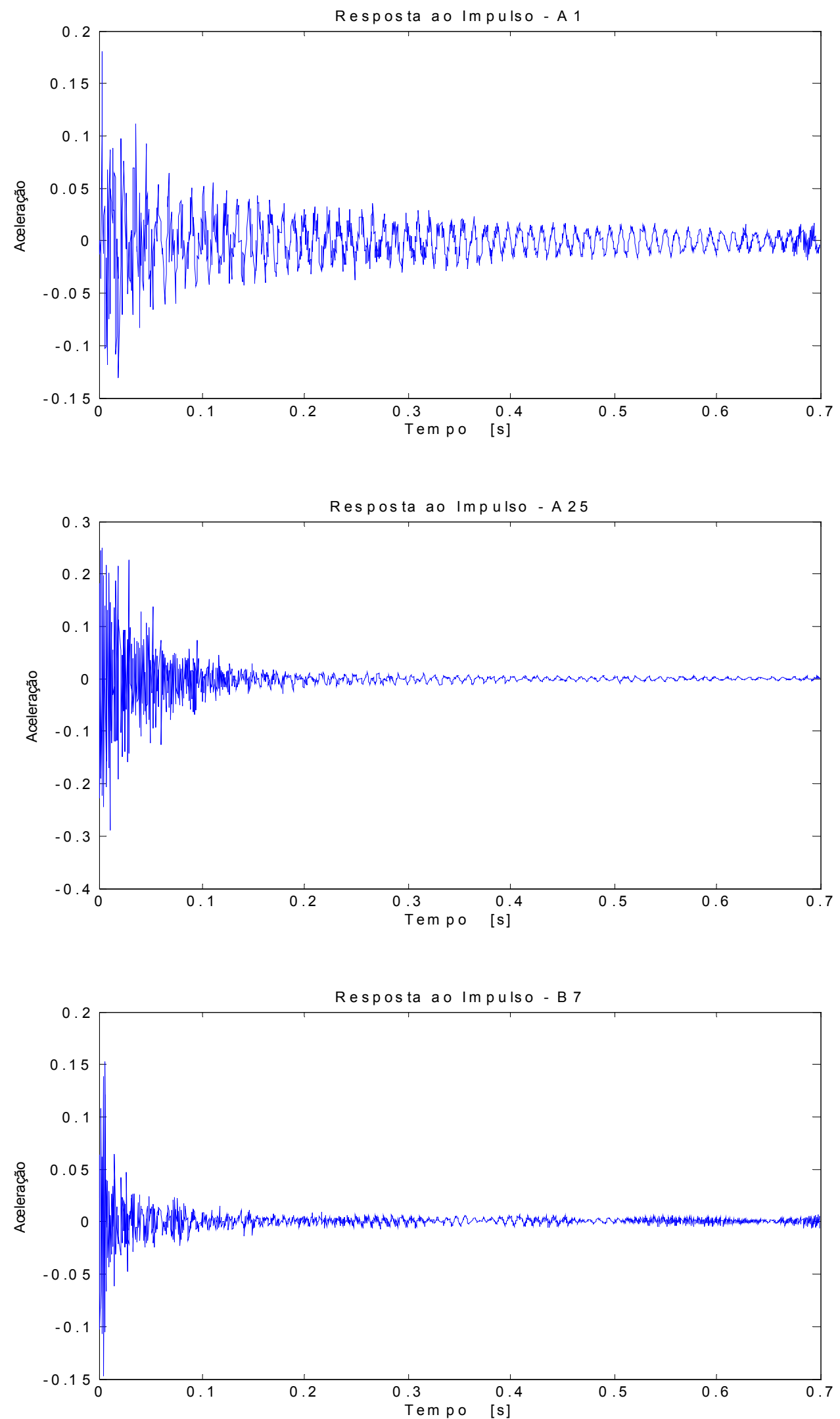

Figura 4.7 - Respostas ao impulso obtidas pela transformada inversa de Fourier para as FRFs dadas na Figura 4.6. 


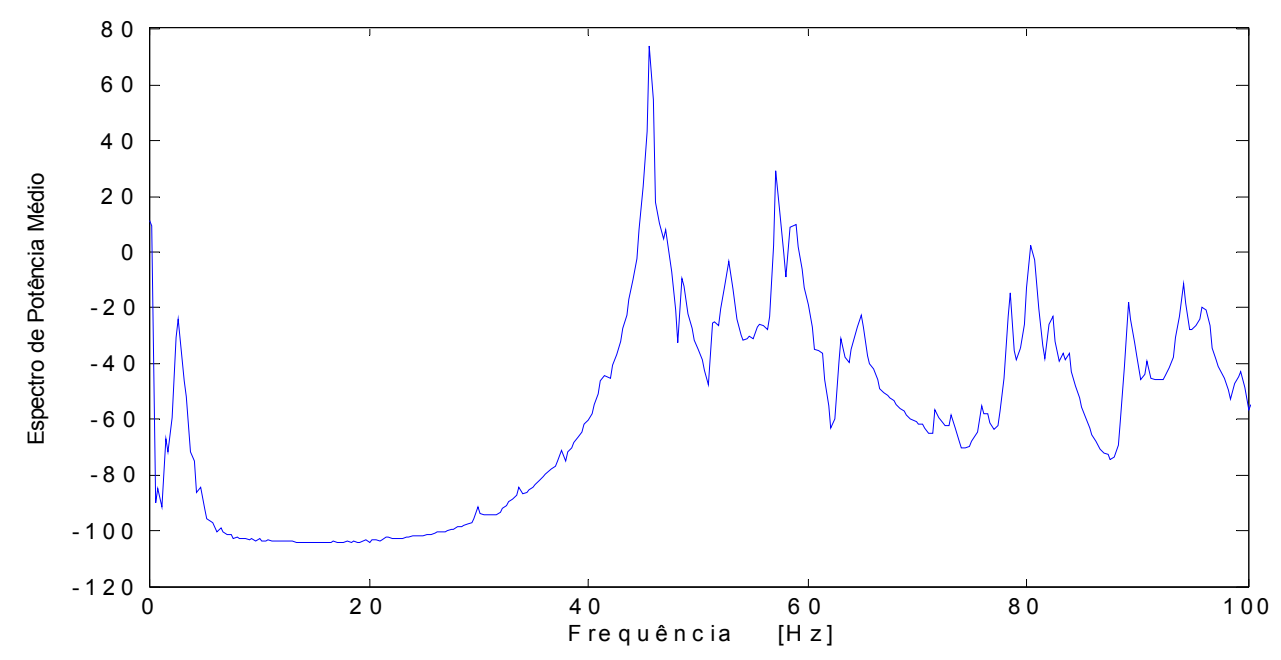

Figura 4.8 - Espectro de potência médio - EPM.

\subsection{1 - RESULTADOS DA IDENTIFICAÇÃO}

Com os dados das respostas ao impulso montam-se as matrizes Hankel no tempo $k=1,[H(0)]$, e no tempo $k=2[H(1)]$ (equação (2.35)), cuja dimensão é determinada pelos parâmetros $\alpha$ e $\beta$ (números de parâmetro de Markov numa coluna e numa linha da equação (2.35), respectivamente). No caso, a dimensão escolhida é de 1200 linhas ( $\alpha=40 m=30)$ por 480 colunas $(\beta=240, r=2)$.

Através do $E R A$, a identificação é realizada decidindo-se o número de modos existentes nas matrizes Hankel para análise dos valores singulares. O número de modos assumidos é estabelecido ao se reter os $2 n$ primeiros valores singulares da decomposição em valores singulares de $[H(0)]$ e as correspondentes $2 n$ primeiras colunas das matrizes de vetores singulares, ou seja, escolhendo-se a dimensão de $\left[\sum_{2 n}\right],\left[R_{2 n}\right]$ e $\left[S_{2 n}\right]$ (equações $(2.53,2.55$ e 2.56$)$ ).

A identificação dos modos de vibrar da semi-asa segue o mesmo procedimento utilizado no experimento da viga engastada (Capítulo 3). Inicialmente, foram realizadas algumas análises para proporcionar a melhor identificação do 
sistema. Nestas análises, valores diferentes de modos assumidos, $2 n$, foram inseridos no algoritmo, o qual forneceu resultados diferentes para as diversas combinações de valores fornecidos. Utilizando todas as estimativas do número de modos assumidos, $2 n$, os melhores resultados dos valores do índice de confiança $C M I$ identificados foram selecionados. Desta forma, foram tomados os melhores modos, assim como as respectivas freqüências naturais e fatores de amortecimento. Além disso, os modos que apresentaram $M P C W$ menor que $50 \%$ e $C M I$ menor que $30 \%$ simultaneamente não foram reproduzidos graficamente.

Conseqüentemente, o resultado final do processo de identificação é composto pelas freqüências naturais, os fatores de amortecimento modal e também dos modos de vibrar da estrutura. De modo a localizar a identificação de um determinado modo dentro do processo de identificação dos parâmetros modais da estrutura, a Tabela 4.3 fornece, além dos valores das freqüências naturais e dos fatores de amortecimento, as estimativas da ordem do sistema $2 n$. Desta forma, é possível conhecer qual estimativa foi capaz de fornecer a melhor identificação. Também é apresentado o valor do CMI de cada modo.

A Figura 4.9 apresenta a representação gráfica do primeiro modo de vibrar identificado e qualificado da estrutura de ensaiada. Para servir de parâmetro de comparação, na Figura 4.10 é apresentado o primeiro modo de vibrar da semi-asa obtido durante os ensaios experimentais.

Os métodos que identificam diretamente os modos reais podem ser agrupados num único conjunto denominado de Métodos de Apropriação de Força. Os métodos de apropriação de força são dos mais antigos métodos de identificação e são tradicionalmente utilizados na indústria aeronáutica para ensaios de vibração no solo. Estes métodos são uma classe especial de métodos de identificação modal, também conhecidos como métodos de sintonia modal ou ensaio da ressonância em fase. Eles são baseados essencialmente na isolação experimental de um único modo (ou sintonia dos modos reais de vibrar) por meio da excitação da estrutura a cada freqüência natural (MAIA \& SILVA, 1997).

Desta forma, através da análise do espectro de potência médio - EPM, Figura 4.8, observou-se uma possível freqüência natural em torno de 45,7 Hz. Conseqüentemente, a estrutura foi excitada com um seno desta freqüência natural e, 
através de um acelerômetro piezoelétrico (Tabela 4.1), foi medida a aceleração nos 30 pontos da estrutura ensaiada. Desta forma, a forma do modo medido durante os ensaios experimentais através da aceleração em cada um dos 30 pontos medidos da estrutura, pode ser visualizado, como mostra a Figura 4.10.

Finalmente, na Figura 4.11 é apresentada a representação gráfica do segundo modo de vibrar identificado e qualificado da estrutura de ensaio.

As FRFs identificadas podem ser obtidas através das matrizes que representam o modelo de estado nas coordenadas modais em tempo discreto identificadas. A Figura 4.12 apresenta o gráfico da função resposta em freqüência (FRF) do sistema real e do modelo identificado, correspondente as FRFs mostradas na Figura 4.6.

A comparação das funções resposta em freqüência do sistema real (medido) e do modelo identificado revelam uma certa inconsistência no processo de identificação realizado pelo $E R A$. Como já exposto, a precisão e a consistência na identificação de parâmetros modais depende diretamente da qualidade e da forma de obtenção dos dados experimentais. Pode-se observar pela Figura 4.8 a dificuldade em identificar quais são as freqüências naturais, devido a grande quantidade de ruído presente nos dados. Isto foi atribuído à influência das placas rebitadas na estrutura da asa. Acredita-se que a interferência de modos localizados foi significativa nos resultados obtidos. Esta é uma dificuldade inerente aos ensaios de estruturas aeronáuticas, já que é prática comum o uso de tais formas construtivas.

Tabela 4.3 - Características dinâmicas da semi-asa obtidas com o modelo identificado.

\begin{tabular}{|c|c|c|c|c|}
\hline \multicolumn{5}{|c|}{ Algoritmo de Realização de Sistemas - ER A } \\
\hline \hline \multirow{3}{*}{ Modo } & $\begin{array}{c}\omega_{n d} \\
{[\mathrm{~Hz}]}\end{array}$ & $\xi_{n}$ & $C M I$ & Estimativa \\
$\%$ & 0 & $2 n$ \\
\hline 1 & 45,6 & 0,72 & 72,0 & 240 \\
\hline 2 & 58,2 & 1,85 & 60,0 & 160 \\
\hline
\end{tabular}






Figura 4.9 - Primeiro modo identificado $-45,6 \mathrm{~Hz}$



Figura 4.10 - Primeiro modo medido - 45,7 Hz

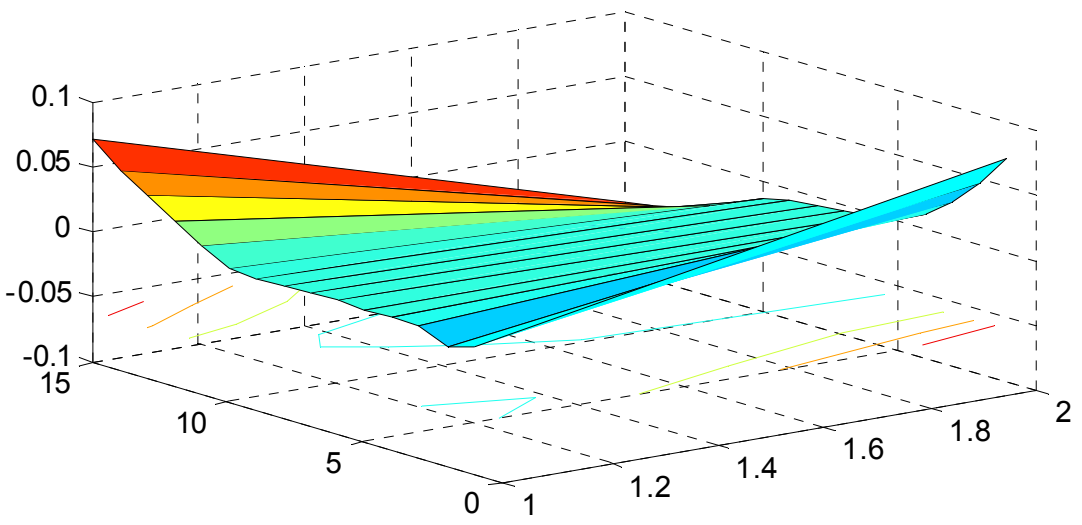

Figura 4.11 - Segundo modo identificado $-58,2 \mathrm{~Hz}$ 

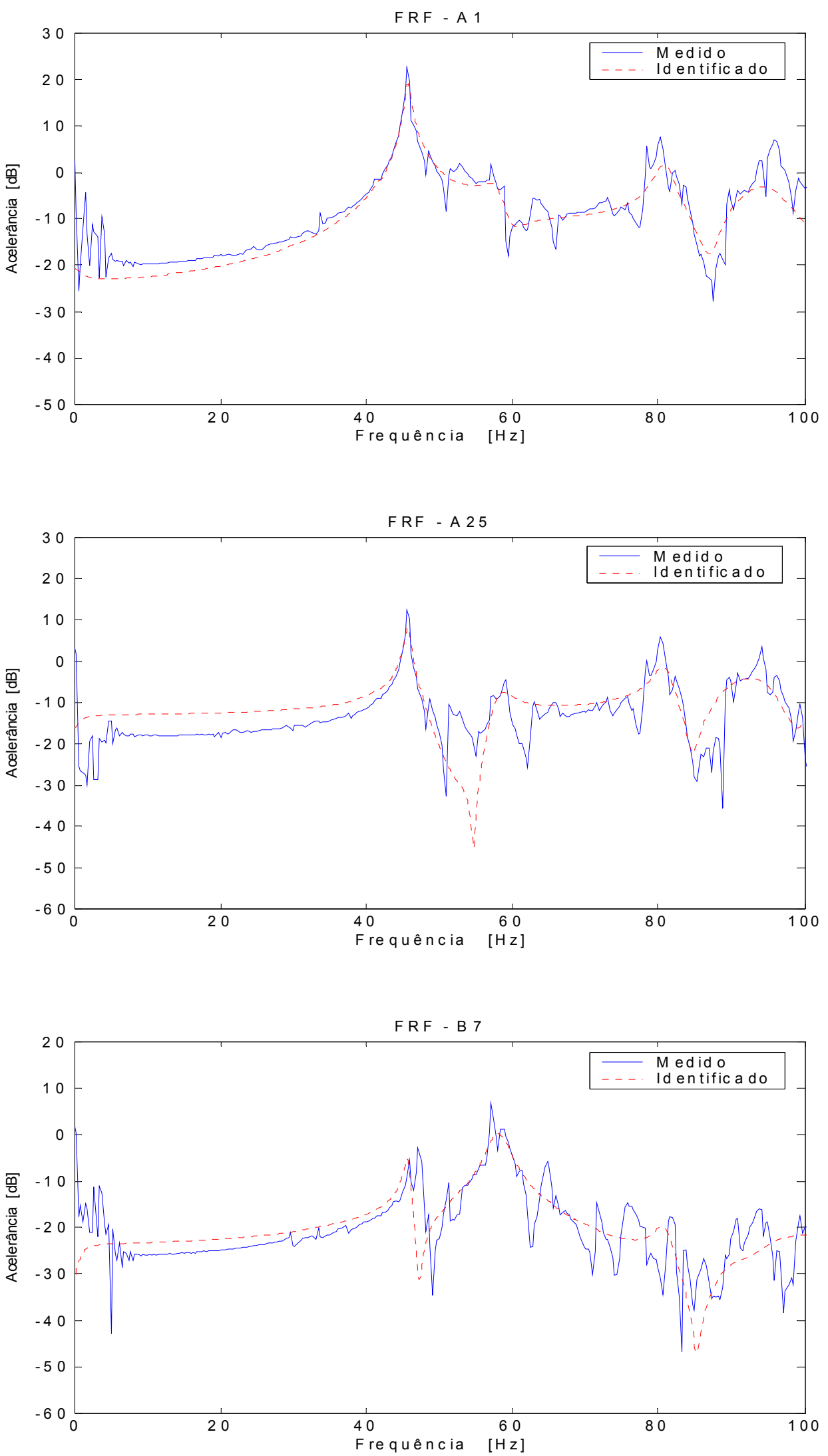

Figura 4.12 - Respostas em freqüência do sistema real (medido) e identificado. 


\section{CAPÍTULO 5}

\section{CONCLUSÕES E SUGESTÕES PARA}

TRABALHOS FUTUROS

Neste trabalho foi apresentado um estudo sobre o Algoritmo de Realização de Sistemas - ERA na identificação de parâmetros modais em uma estrutura aeronáutica utilizando dados experimentais.

A implementação e verificação do algoritmo proposto na identificação de parâmetros modais foram efetuados através de um exemplo simulado e através de um ensaio experimental em uma viga de alumínio.

É importante salientar que a utilização do algoritmo requer um aparato instrumental mínimo se levado em consideração à aplicação e acessibilidade de tecnologias relacionadas à área de instrumentação e computacional nos dias de hoje.

O tratamento dos dados experimentais efetuados pelo Algoritmo de Realização de Sistemas conduziu a resultados preliminares que posteriormente foram submetidos a um processo de qualificação através de três índices de confiança, $M P C W, E M A C$ e $C M I$. Desta forma, esta operação definiu o resultado final do processo de identificação de parâmetros modais na viga de alumínio e na semi-asa da aeronave Neiva Regente. 
Desta forma, considera-se como conclusões e contribuições deste trabalho:

- Na simulação obteve-se resultados satisfatórios na comparação entre as funções resposta em freqüência reais e identificadas, apesar dos níveis de ruído imposto aos parâmetros de Markov reais do sistema. Os resultados obtidos na simulação indicam que o algoritmo é eficiente na identificação de parâmetros modais;

- Os resultados obtidos a partir do ensaio experimental na viga de alumínio apresentam boa coerência na comparação das respostas em freqüência medidas e identificadas. $\mathrm{O}$ número de modos qualificados através dos índices de confiança corresponde ao número de modos presentes na faixa de freqüência analisada. Segundo os resultados, os valores das freqüências naturais e dos fatores de amortecimento obtidos revelaram-se coerentes e satisfatórios;

- A identificação dos parâmetros modais na semi-asa apresentou certas dificuldades, principalmente nos dados experimentais obtidos durantes os ensaios. As funções resposta em freqüência (FRF) medidas apresentaram uma quantidade considerável de ruído, dificultando assim, o processo de identificação. Isto foi atribuído à influência da forma construtiva da estrutura da asa, ou seja, placas rebitadas à reforçadores e mesas de longarina.

- Foram qualificados através dos índices de confiança dois modos de vibrar da estrutura da semi-asa na faixa de freqüência analisada. $\mathrm{O}$ primeiro modo identificado foi comparado com o primeiro modo obtido nos experimentos e revelaram-se satisfatórios, apesar de certas discrepâncias nas formas modais apresentadas. 
Como decorrência destas conclusões, apresentam-se algumas perspectivas para trabalhos futuros sobre este tema:

- Condução de testes experimentais na semi-asa utilizando diferentes metodologias de ensaios de vibração no solo, tais como, utilização de outras formas de excitação, realização de estudos sobre outras formas de suspensão (condições de contorno) para a estrutura ensaiada, entre outras;

- Automatização do processo de identificação facilitando a análise dos resultados. Algumas destas propostas, baseadas no ERA, fazem uso intensivo de índices de confiança e proporcionam a identificação autônoma de estruturas, como apresentado nos trabalhos de TSUNAKI (1999), PAPPA et al. (1997a), PAPPA et al. (1997b) e PAPPA (1997c);

- Realizar estudos sobre a influência do ruído presente nos dados experimentais da semi-asa utilizando duas variantes do ERA. A primeira, denominada $E R A / D C$, procura minimizar a influência de ruído nos resultados da identificação. A segunda, denominada Observer/Kalman Filter, tem como objetivo, comprimir a informação numa menor quantidade de dados e, desta forma, reduzir o esforço computacional e otimizar os resultados da identificação. 


\section{REFERÊNCIAS BIBLIOGRÁFICAS}

ABEL, I. (1997). Research and applications in aeroelasticity and structural dynamics at the Nasa Langley Research Center, NASA TM-112852.

ALLEMANG, R.J.; BROWN, D. L. (1993). Structural dynamic testing and instrumentation. In: NOOR, A.K.; VENNERI, S.L. Flight-vehicle materials, structures, and dynamics. New York, ASME. Vol.5, Parte III, Cap.1, p.439-509.

ALLEMANG, R.J.; BROWN, D.L. (1996). Experimental modal analysis, Shock and Vibration Handbook. 4.ed. New York, McGraw-Hill.

ALLEN, D.H.; HAISLER, W.E. (1985). Introduction to aerospace structural analysis, New York, John Wiley.

BAYARD, D.S. (1992). An algoritmo for state-space frequency domain identification without windowing distortions, Proceedings of the $31^{\text {st }}$ Conference on Decision and Control, v.2, p.1707-1712.

BISPLINGHOFF, R.L.; ASHLEY, H.; HALFMAN, R.L. (1955). Aeroelasticity. Massachusetts, Addison-Wesley.

BROWN, D.L.; ALLEMANG, R.J.; ZIMMERMAN, R.; MERGEAY, M. (1979).

Parameter estimation techniques for modal analysis, S.A.E paper, p.828-846.

BUEHRLE, R.D.; FLEMING, G.A.; PAPPA, R.S.; GROSVELD, F.W. (2001). Finite element model development for aircraft fuselage structures, Sound and Vibration, v.35, n.1, p.32-38, Jan.

CHEN, CHUNG-WEN.; JUANG, J-N.; LEE, G. (1994). Frequency domain statespace system identification, Journal of Vibration and Acoustics, v.116, p. 523528, Oct.

CHEN, J.C.; GARBA, J.A. (1980). Analytical model improvement using modal test results, AIAA Journal, v.18, n.6, p.684-690, Jun. 
COLLINS, J.D.; HART, G.C.; HASSELMAN, T.K.; KENNEDY, B. (1974). Statistical identification of structures, AIAA Journal, v.12, n.2, p.185-190, Feb. COOPER, J.E. (1997). On-line version of the eigensystem realization algorithm using data correlations, Journal of Guidance, Control, and Dynamics, v.20, n.1, p.137-142, Feb.

COX, T.H.; GILYARD, G.B. (1986). Ground vibration test results for Drones for Aerodynamic and Structural Testing (DAST)/Aeroelastic Research Wing (ARW1R) Aircraft, NASA Technical Memorandum 85906.

DOWELL, E.H.; CURTISS, Jr. H.C.; SCANLAN, R.H.; SISTO, F. (1978). A modern course in aeroelasticity. New Jersey, Sijtohoff \& Noordhoff International Publishers.

EWINS, D.J. (1984). Modal testing: Theory and practice. New York, John Wiley \& Sons.

FLEMING, G.A.; BUEHRLE, R.D.; STORAASLI, O.L. (1998). Modal analysis of an aircraft fuselage panel using experimental and finite-element techniques, Third International Conference on Vibration Measurement by Laser Techniques, v.3411, p.537-548.

FREUDINGER, L.C.; KEHOE, M.W. (1990). Flutter clearance of the F-14A variable-sweep transition flight experiment airplane - phase2, NASA Technical Memorandum 101717.

FUNG, Y.C. (1993). An introduction to the theory of aeroelasticity. New York, Dover.

FURUTA, K.; SANO, A.; ATHERTON, D. (1988). State variable methods in automatic control. Chichester, John Wiley \& Sons.

IBRAHIM, S.R. (1985). Modal identification techniques: Assessment and comparisons, Proceedings of the $3^{\text {rd }}$ International Modal Analysis Conference, v. 1, p. 831-839.

IBRAHIM, S.R. (1987). An upper hessenberg sparse matrix algorithm for modal identification on minicomputers, Journal of Sound and Vibration, v. 113, p. 4757. 
IBRAHIM, S.R.; MIKULCIK, E.C. (1977). A method for the direct identification of vibration parameters from the free response, The Shock and Vibration Bulletin, V.47, n.4, p.183-198.

JUANG , J-N.; PAPPA, R.S. (1986). Effects of noise on modal parameters identified by the eigensystem realization algorithm, Journal of Guidance, Control and Dynamic, v.9, n.3, p.294-303.

JUANG, J-N. (1987). Mathematical correlation of modal-parameter-identification methods via system-realization theory, The International Journal of Analytical and Experimental modal analysis, v.2, n.1, p.1-18.

JUANG, J-N. (1994). Applied system identification. New Jersey, Prentice Hall PTR.

JUANG, J-N.; COOPER, J.E.; WRIGHT, J.R. (1988). An eigensystem realization algorithm using data correlations (ERA/DC) for modal parameter identification, Control-Theory and Advanced Technology, v.41, n.1, p.5-14.

JUANG, J-N.; PAPPA, R.S. (1985). An eigensystem realization algorithm for modal parameter identification and model reduction, Journal of Guidance, Control, and Dynamic, v.8, n.5, p. 620-627, Sept.-Oct.

JUANG, J-N.; PAPPA, R.S. (1988). A comparative overview of modal testing and system identification for control of structures, Shock and Vibration Digest, v.20, n.5, p.4-15.

JUANG, J-N.; PHAN, M.; HORTA, L.G.; LONGMAN, R.W. (1993). Identification of observer/kalman filter markov parameters: theory and experiments, Journal of Guidance, Control, and Dynamic, v.16, n.2, p.320-329, Mar.-Apr.

KABE, A.M. (1985). Stiffness matrix adjustment using mode data, AIAA Journal, v.23, n.9, p.1431-1436, Sept.

KEHOE, M.W. (1987). Aircraft ground vibration testing at Nasa Ames-Dryden Flight Research Facility, NASA Technical Memorandum 88272.

KEHOE, M.W.; FREUDINGER, L.C. (1993). Aircraft ground vibration testing at the Nasa Dyrden Flight Research Facility, NASA Technical Memorandum 104275.

KEHOE, M.W.; VORACEK, D.F. (1989). Ground vibration test results of a JetStar airplane using impulsive sine excitation, NASA Technical Memorandum 100448.

KENNEDY, C.C.; PANCU, C.D.P. (1947). Use of vectors in vibration measurement and analysis, Journal of the Aeronautical Sciences, v.14, n.11, p. 603-625, Nov. 
LEURIDAN, J.M.; BROWN，D.L.; ALLEMANG，R.J. (1986). Time domain parameter identification methods for linear modal analysis: A unifying approach, ASME Journal of Vibration, Acoustics, Stress, and Reliability in Design, v.108, p.1-8, Jan.

LEW, J-S.; JUANG, J-N.; LONGMAN, R.W. (1993). Comparison of several system identification methods for flexible structures, Journal of Sound and Vibration, v.163, n.3, p.461-480.

LEWIS, R.C.; WRISLEY, D.L. (1950). A system for the excitation of pure natural modes of complex structure, Journal of the Aeronautical Sciences, v.17, n.11, p.705-722, Nov.

LIU, K.; SKELTON, R.E. (1993). Q-Markov covariance equivalent realization and its application to flexible structure identification, Journal of Guidance, Control, and Dynamics, v.16, n.2, p.308-319, Apr.

MAIA, N.M.M.; SILVA, J.M.M. (1997). Theoretical and experimental modal analysis, John Wiley \& Sons.

MARQUES, F.D.; VAROTO, P.S.; BENINI, G.R.; OLIVEIRA, L.P.R. (2001). An investigation on the modal characteristics of an aircraft wing structure. In: ESPÍNDOLA, J.J. et al., eds., Dynamic Problems of Mechanics. Rio de Janeiro. ABCM. p.465-469.

McCONNELL, K.G. (1995). Vibration testing: theory and practice. New York, John Wiley \& Sons.

MEIROVITCH, L. (1990). Dynamic and control of structures. John Wiley \& Sons, New Jersey, Prentice Hall PTR.

METWALLI, S.M.; FEIJÓ, F. (1985). Modal analysis by state-space approach in frequency domain, Proceedings of the $3^{\text {rd }}$ International Modal Analysis Conference, v.1, p.403-409.

MOONEM, M.; MOOR, B.D.; VANDENBERGHE, L.; VANDEWALLE, J. (1989). On-line and off-line identification of linear state-space models, International Journal of Control, v.49, n.1, p.219-232.

MOREIRA, F.J.O. (1998). Um controlador $H_{\infty}$ de banda limitada para o controle ativo de vibração estrutural. Campinas. 199p. Tese (Doutorado) - Faculdade de Engenharia Mecânica, Universidade Estadual de Campinas. 
NITZSCHE, F. Introductory aeroelasticity. Carleton: Carleton University Mechanical and Aerospace Engineering, 2001, Cap.1, p.1-19. Apostila.

OPPENHEIM, A.V.; SCHAFER, R.W. (1975). Digital Signal Processing, New Jersey, Prentice-Hall, Englewood Cliffs.

PAPPA, R.S. (1990). Identification challenges for large space structures,

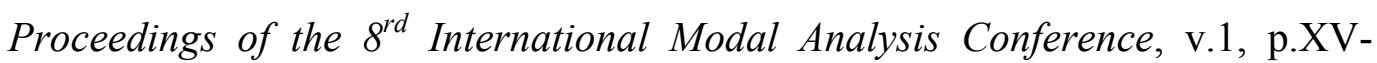
XXIII.

PAPPA, R.S. (1997c). Independent analysis of the space station node modal test data, NASA/TM-97-206262.

PAPPA, R.S.; ELLIOTT, K.B.; SCHENK, A. (1993). Consistent-mode indicator for the eigensystem realization algorithm, Journal of Guidance, Control, and Dynamics, v.16, n.5, p. 852-858, Sept.

PAPPA, R.S.; JAMES III, G.H.; ZIMMERMAN, D.C. (1997b). Autonomous modal identification of the space shuttle tail rudder, NASA Technical Memorandum 112866.

PAPPA, R.S.; SCHENK, A.; NOLL, C. (1991). Eigensystem realization system modal identification experiences with mini-mast, NASA TM-4307.

PAPPA, R.S.; WOODARD, S.E.; JUANG, J-N. (1997a). A benchmark problem for development of autonomous structural modal identification, NASA Technical Memorandum 110291.

PAZIANI, F.T. (2002). Identificação de parâmetros modais no domínio do tempo Método ITD. São Carlos. 111p. Dissertação - Escola de Engenharia de São Carlos, Universidade de São Paulo.

PETERSON, L.D. (1995). Efficient computation of the eigensystem realization algorithm, Journal of Guidance, Control, and Dynamics, v.18, n.3, p.395-403, June.

RAMSEY, K.A. (1983). Experimental modal analysis, structural modifications and FEM analysis on a Desk-top computer, Sound and Vibration, v.17, n.2, p.19-27.

REAVES, M.C.; BELVIN, W.K.; BAILEY, J.P. (1992). Finite-element-analysis model and preliminary ground testing of controls-structures interaction evolutionary model reflector, NASA TM-4293. 
RICKETTS, R.H. (1993). Experimental aeroelasticity in wind tunnels - history, status, and future in brief. In: NOOR, A.K.; VENNERI, S.L. Flight-vehicle materials, structures, and dynamics. New York, ASME. Vol.5, Parte II, Cap.2, p.151-178.

STOCKWELL, A.E. (1995). A verification procedure for MSC/NASTRAN finite element models, NASA Contractor Report 4675.

TASKER, F.; BOSSE, A.; FISHER, S. (1998). Real-time modal parameter estimation using subspace methods: theory, Mechanical Systems and Signal Processing, v.12, n.6, p.797-808.

TASKER, F.; BOSSE, A.; FISHER, S. (1998). Real-time modal parameter estimation using subspace methods: applications, Mechanical Systems and Signal Processing, v.12, n.6, p.809-823.

TSUNAKI, R.H. (1999). Identificação automatizada de modelos dinâmicos no espaço de estado. São Carlos. 143p. Tese (Doutorado) - Escola de Engenharia de São Carlos, Universidade de São Paulo.

VAROTO, P.S. (1991). Análise modal no domínio da freqüência: Um método de identificação multimodos. São Carlos. 193p. Dissertação - Escola de Engenharia de São Carlos, Universidade de São Paulo.

VOLD, H.; KUNDRAT, J.; ROCKLIN, G.T.; RUSSELL, R. (1982). A multi-input modal estimation algorithm for mini-computers, SAE Transaction, v.91, n.1, p.815-821.

YATES, Jr. E.C. (1971). Flutter and Unsteady-Lift Theory, Performance and Dynamics of Aerospace Vehicles, NASA SP-258.

ZHANG, L. (1985). Some experiences in experimental modal analysis, Proceedings of the $3^{\text {rd }}$ International Modal Analysis Conference, v.1, p.7-14. 


\section{APÊNDICE A}

\section{FUNÇÕES RESPOSTA EM FREQUÊNCIA MEDIDAS NO ENSAIO DE IMPACTO EM UMA VIGA DE ALUMÍNIO}

Este Apêndice apresenta os dados de funções resposta em freqüência (FRF) medidos em uma viga de alumínio durante os ensaios experimentais. Além disso, são apresentadas as localizações dos pontos de saída (medidas) e entrada (excitação) da estrutura.

Para a realização dos ensaios foram marcadas sobre a viga as localizações dos pontos de saída e entrada. A Figura A.1 apresenta os 2 pontos de entrada (excitação). A localização dos pontos de saída é apresentada na Figura A.2. A notação utilizada para indicar a localização da entrada e da saída das FRFs é descrita em função das marcações assinaladas na estrutura mostrada nas Figura A.1 e A.2. Desta forma, FRF-A01 indica que a função resposta em freqüência foi obtida medindo-se a força aplicada no ponto $\boldsymbol{A}$ e a aceleração no ponto 01 . Conseqüentemente, FRF-B15 indica que a função resposta em freqüência foi obtida medindo-se a força aplicada no ponto $\boldsymbol{B}$ e a aceleração no ponto 15 . Durante os ensaios experimentais realizados na viga não foram medidas FRFs de ponto.

Nas Figuras A.3 à A.22 são apresentados o conjunto total das 60 funções resposta em freqüência medidas nos ensaios experimentais da estrutura proposta. 


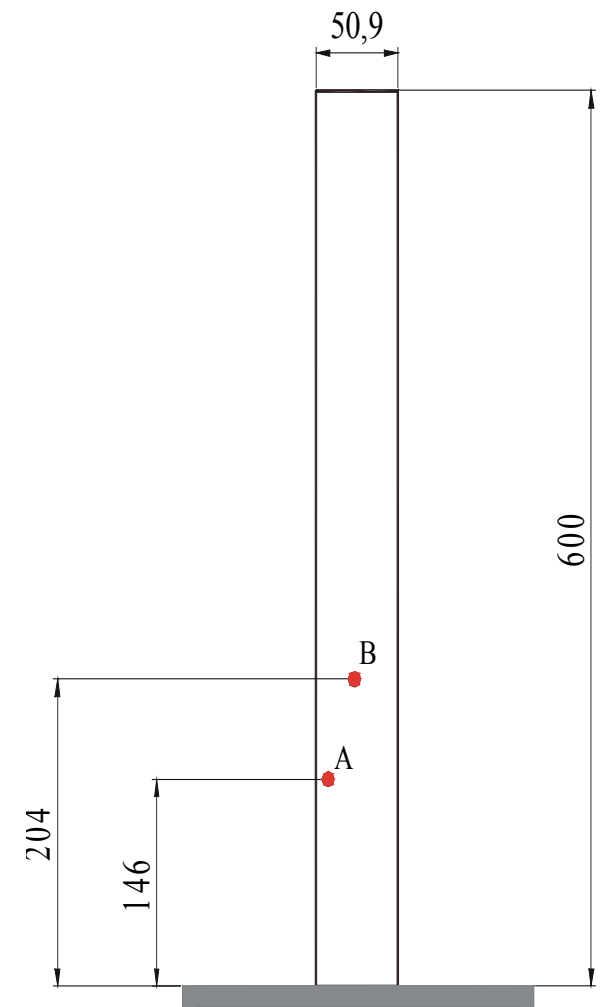

Figura A.1 - Localização dos pontos de entrada (excitação).
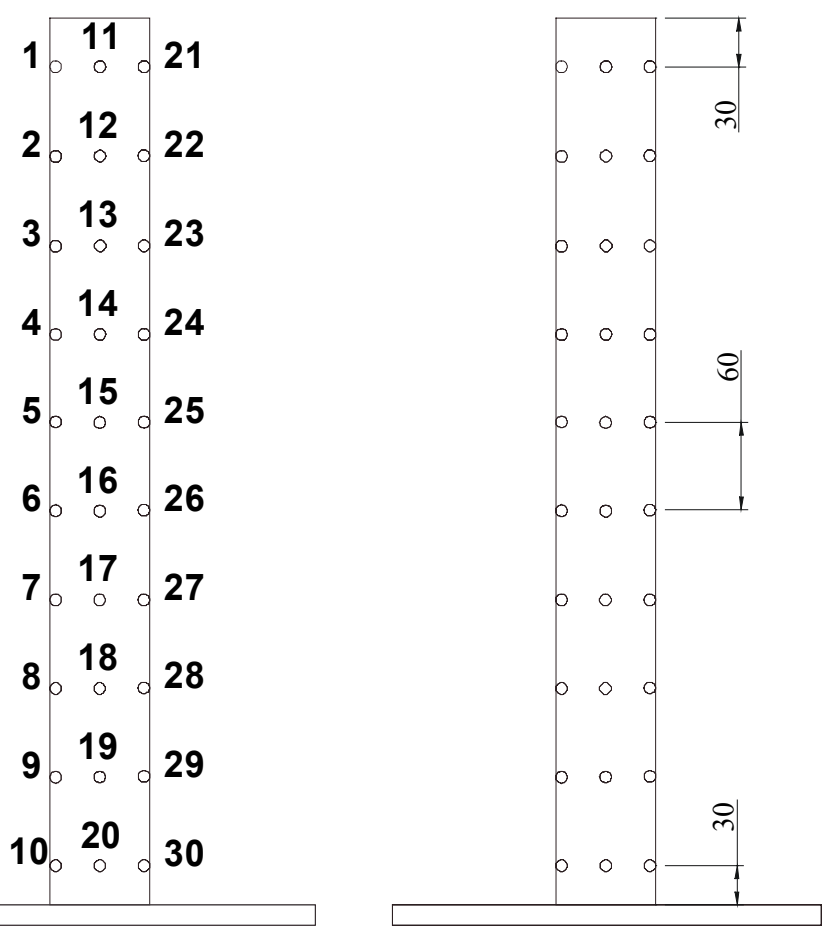

Figura A.2 - Localização dos pontos de saída (medidas). 

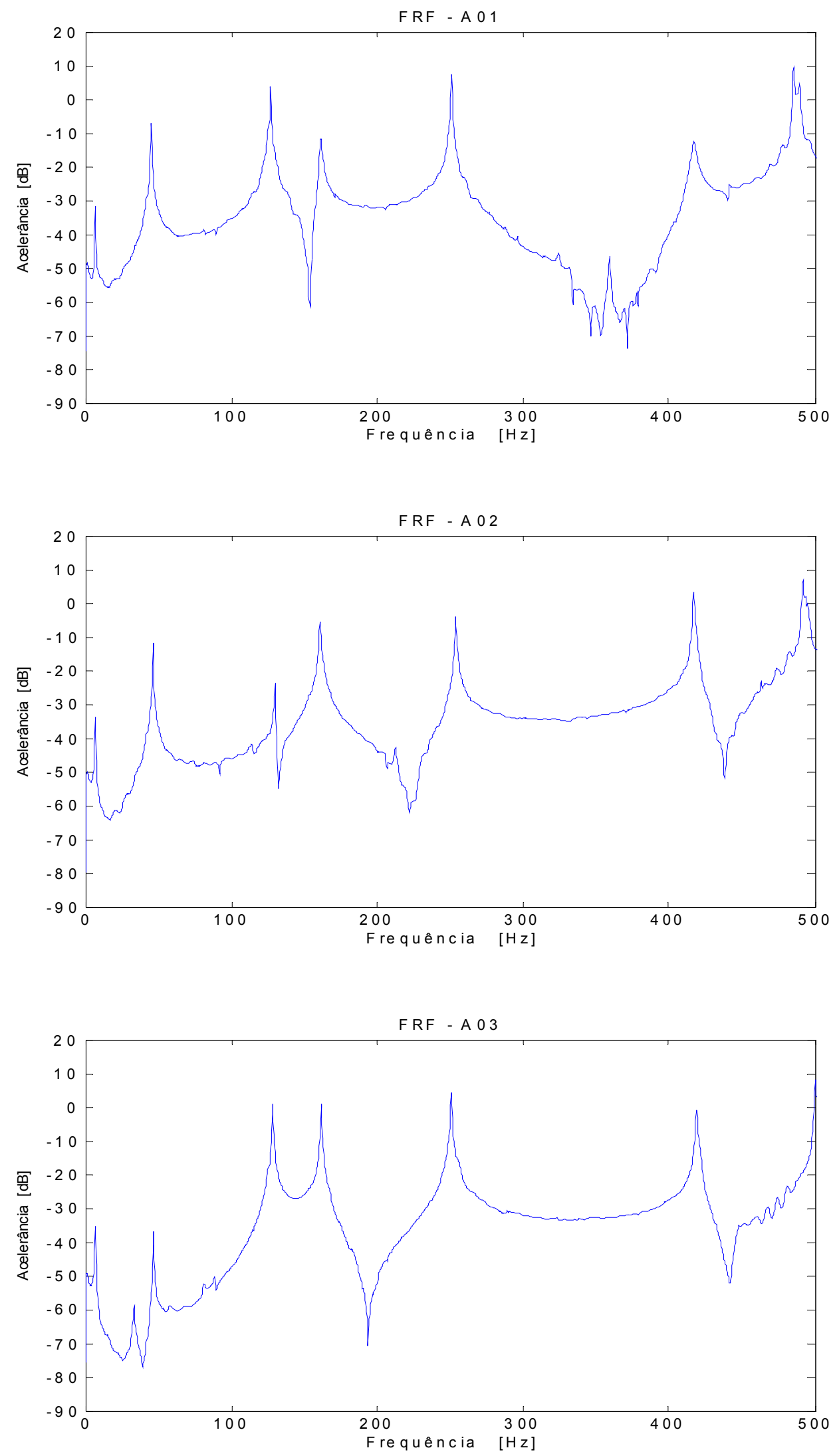

Figura A.3 - FRFs para a viga engastada - A01 a A03. 

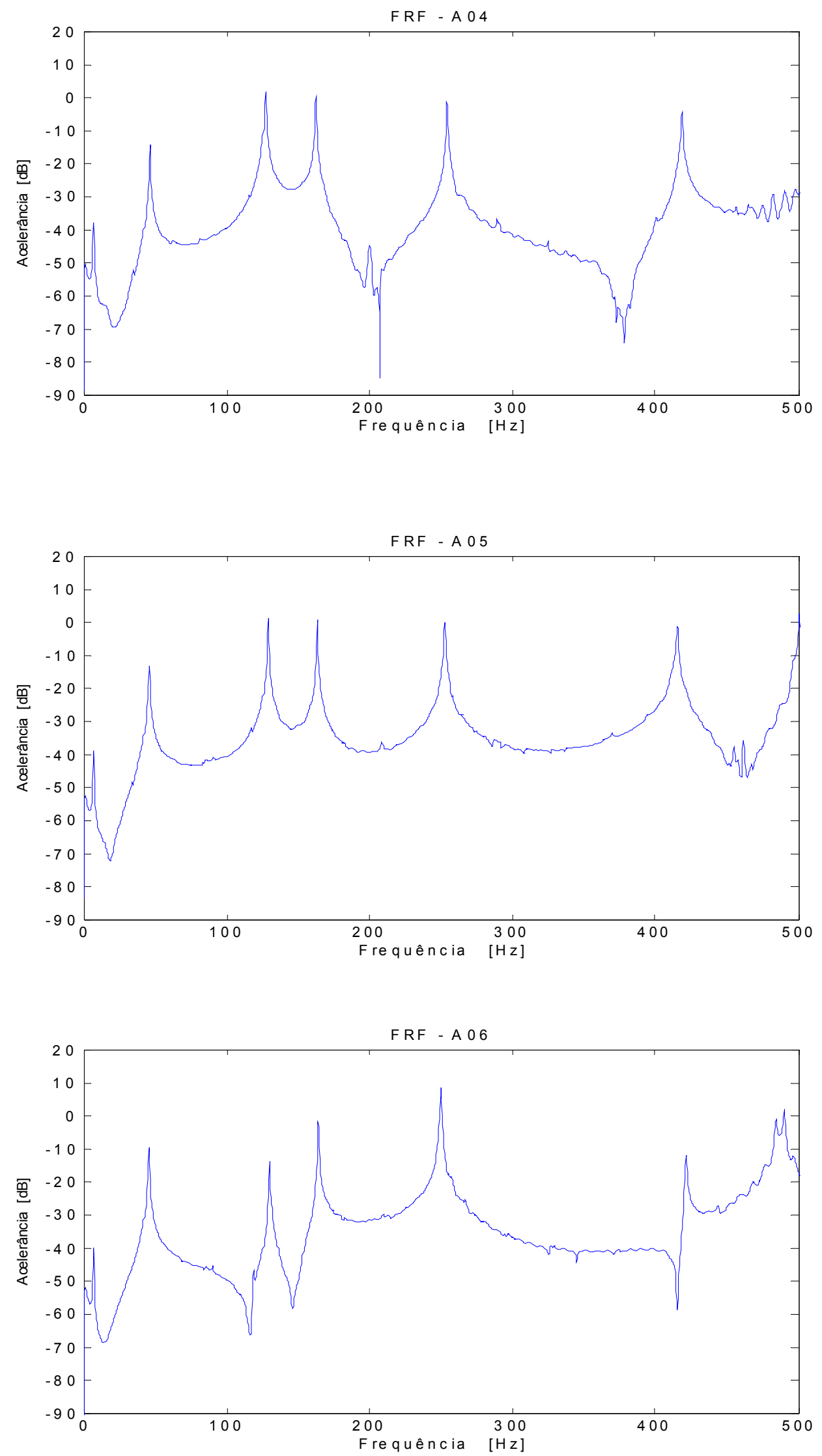

Figura A.4 - FRFs para a viga engastada - A04 a A06. 

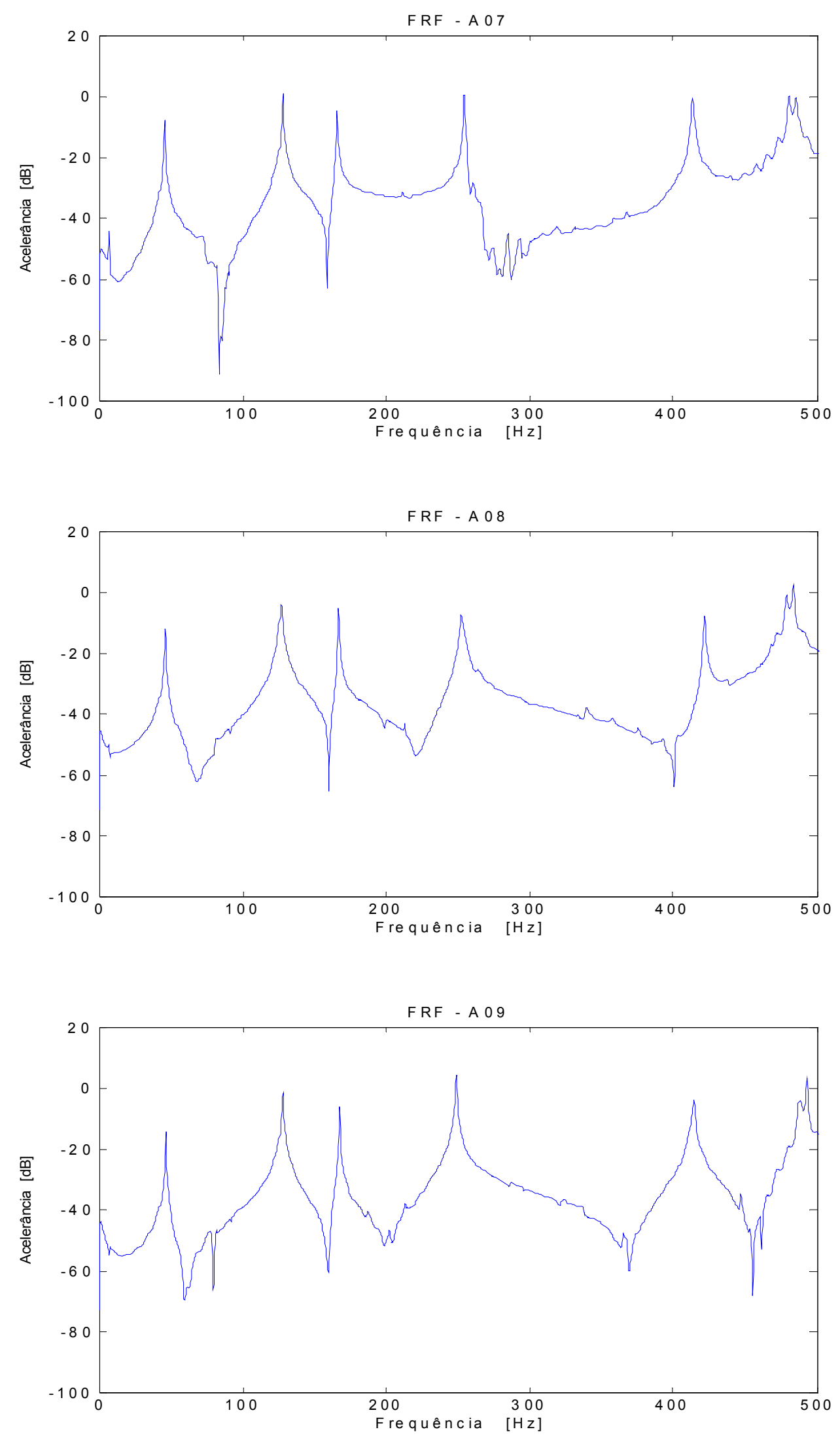

Figura A.5 - FRFs para a viga engastada - A07 a A09. 

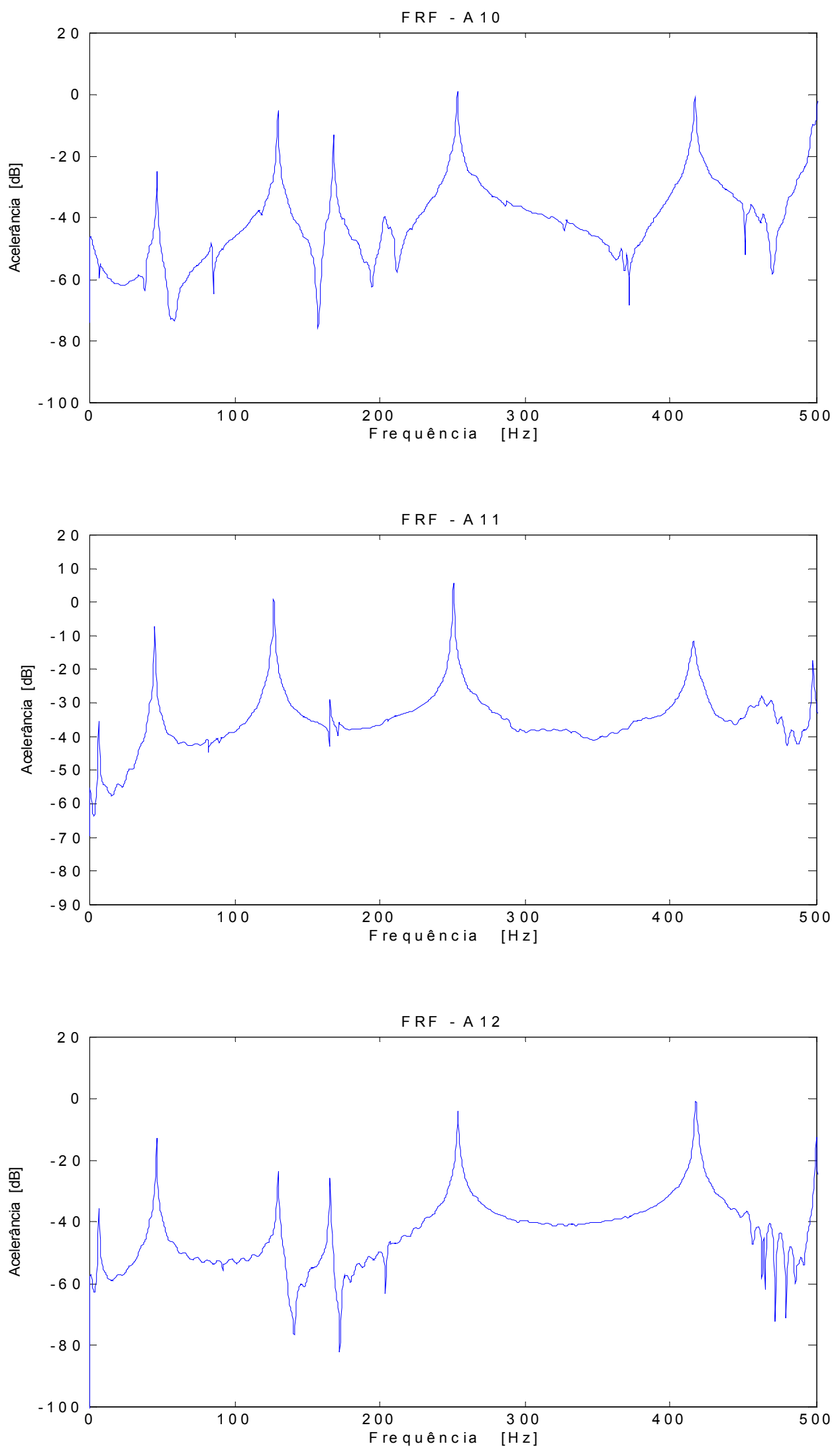

Figura A.6 - FRFs para a viga engastada - A10 a A12. 

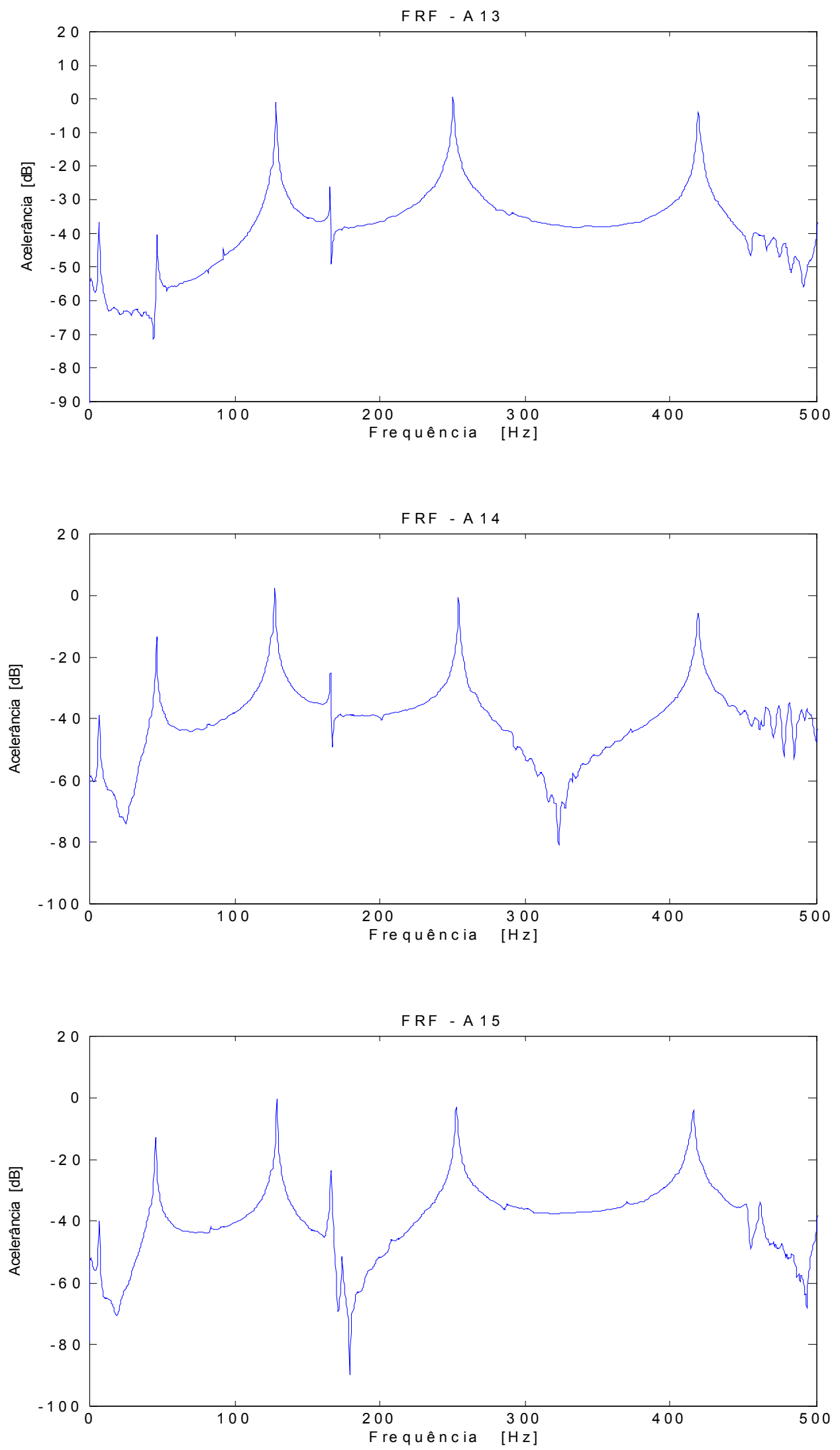

Figura A.7 - FRFs para a viga engastada - A13 a A15. 

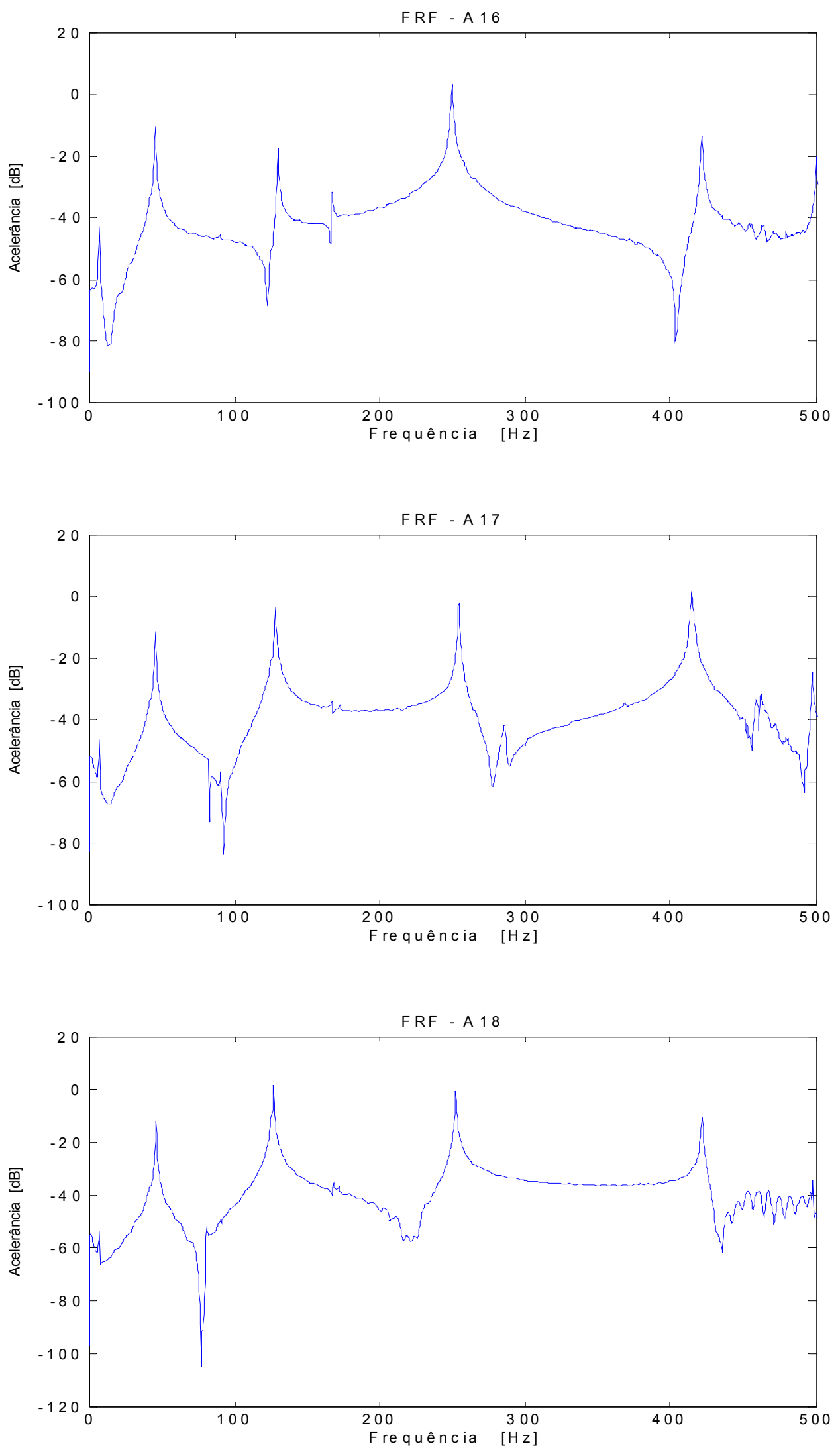

Figura A.8 - FRFs para a viga engastada - A16 a A18. 

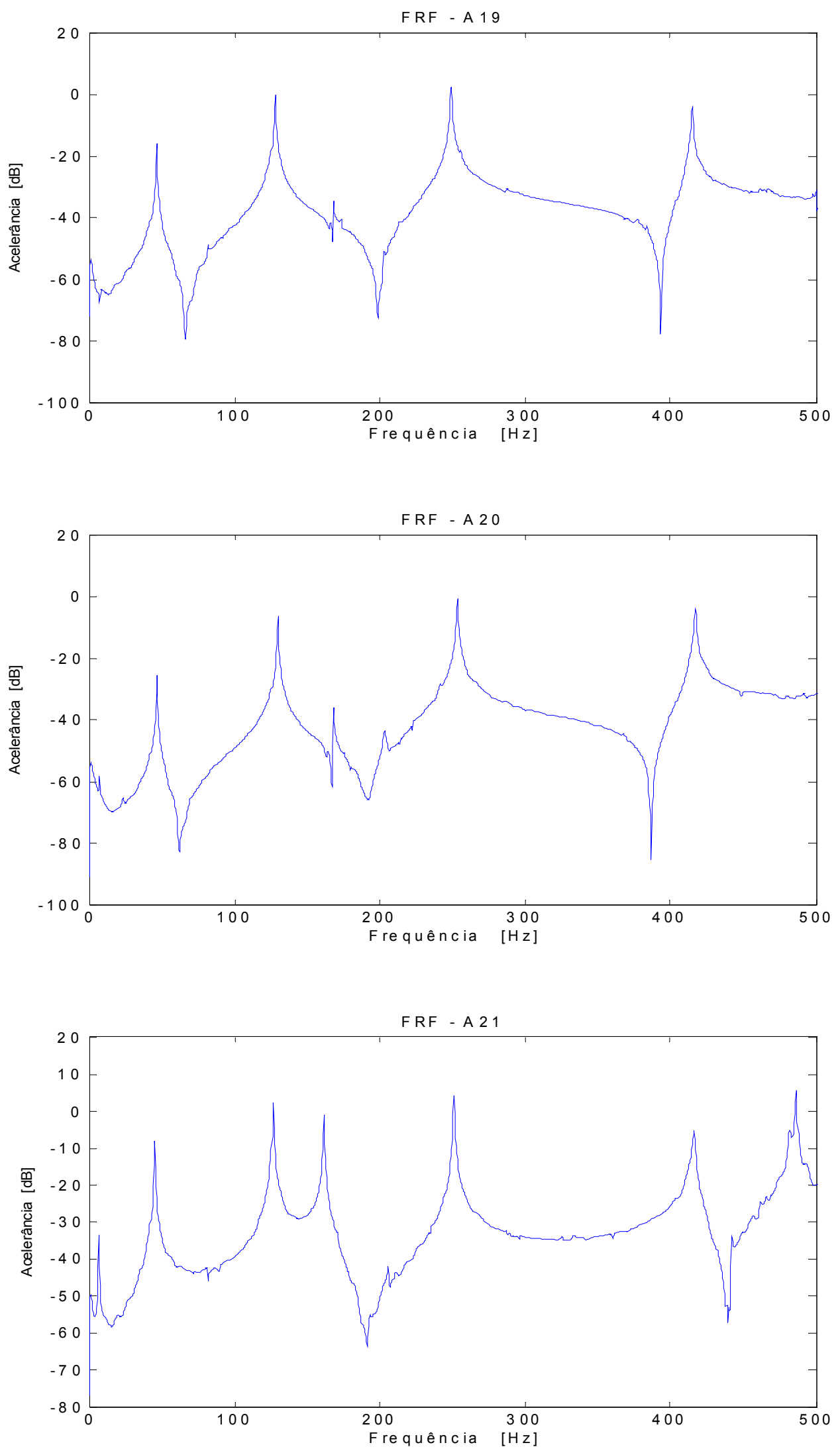

Figura A.9 - FRFs para a viga engastada - A19 a A21. 

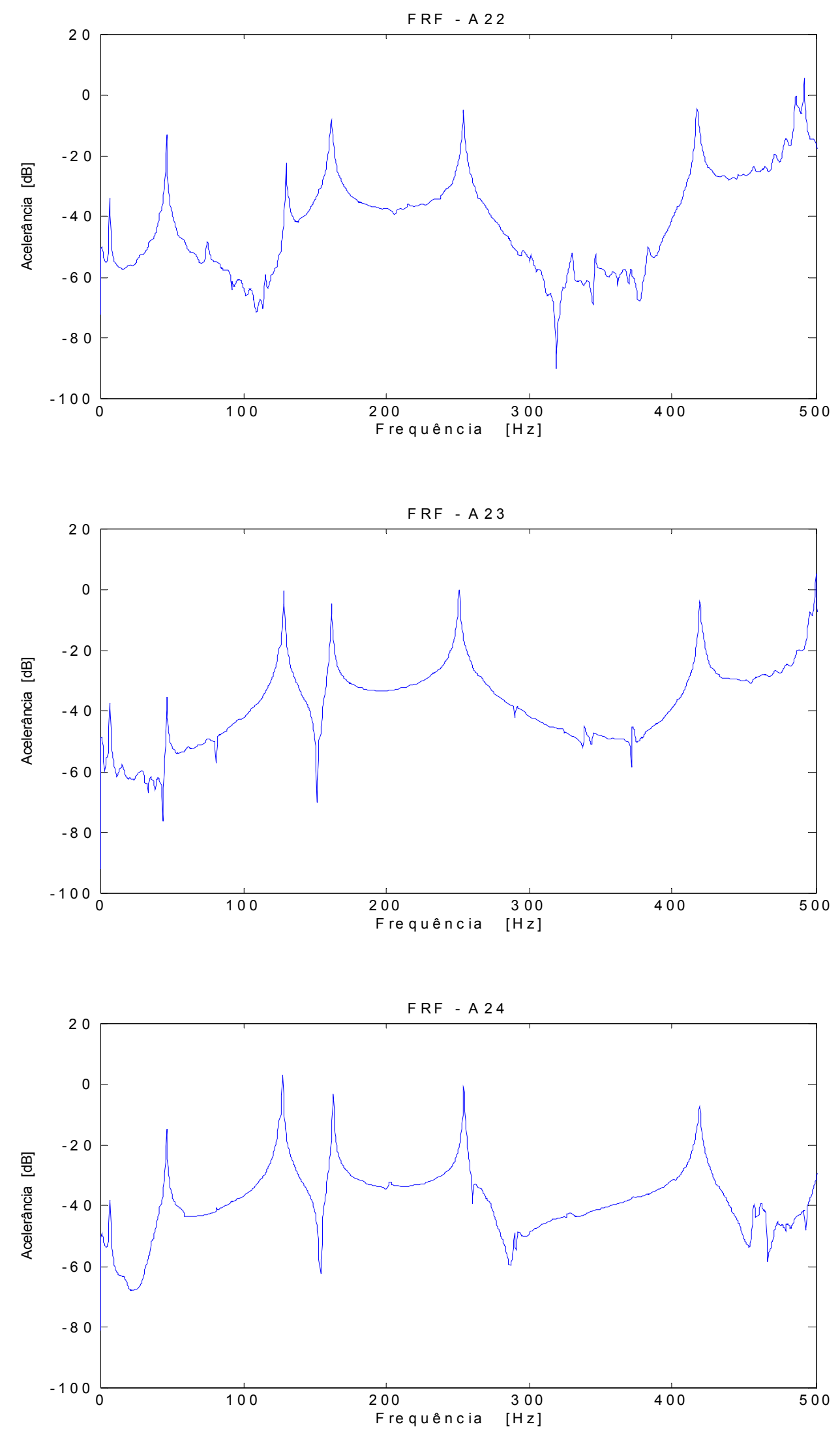

Figura A.10 - FRFs para a viga engastada - A22 a A24. 

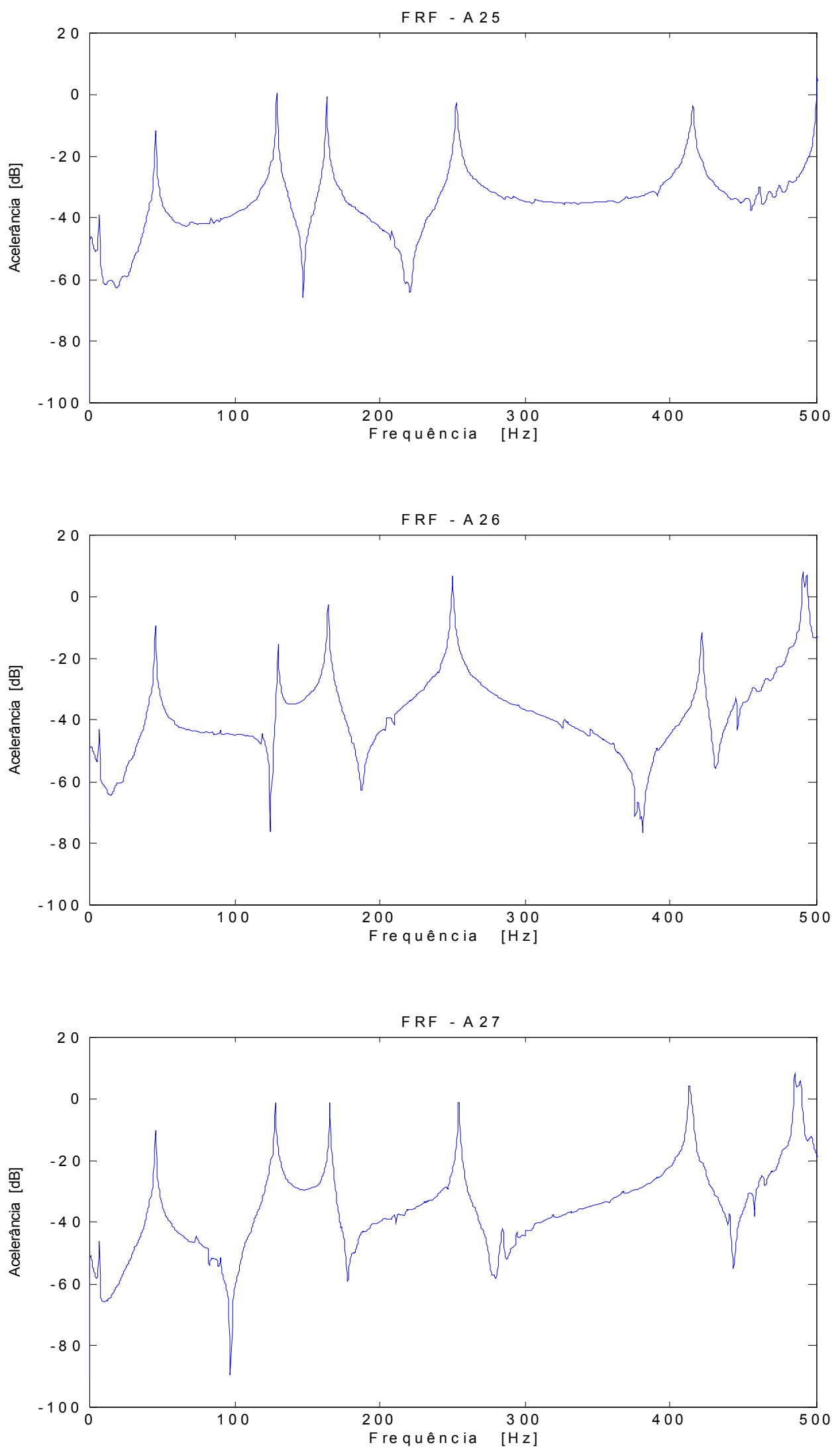

Figura A.11 - FRFs para a viga engastada - A25 a A27. 

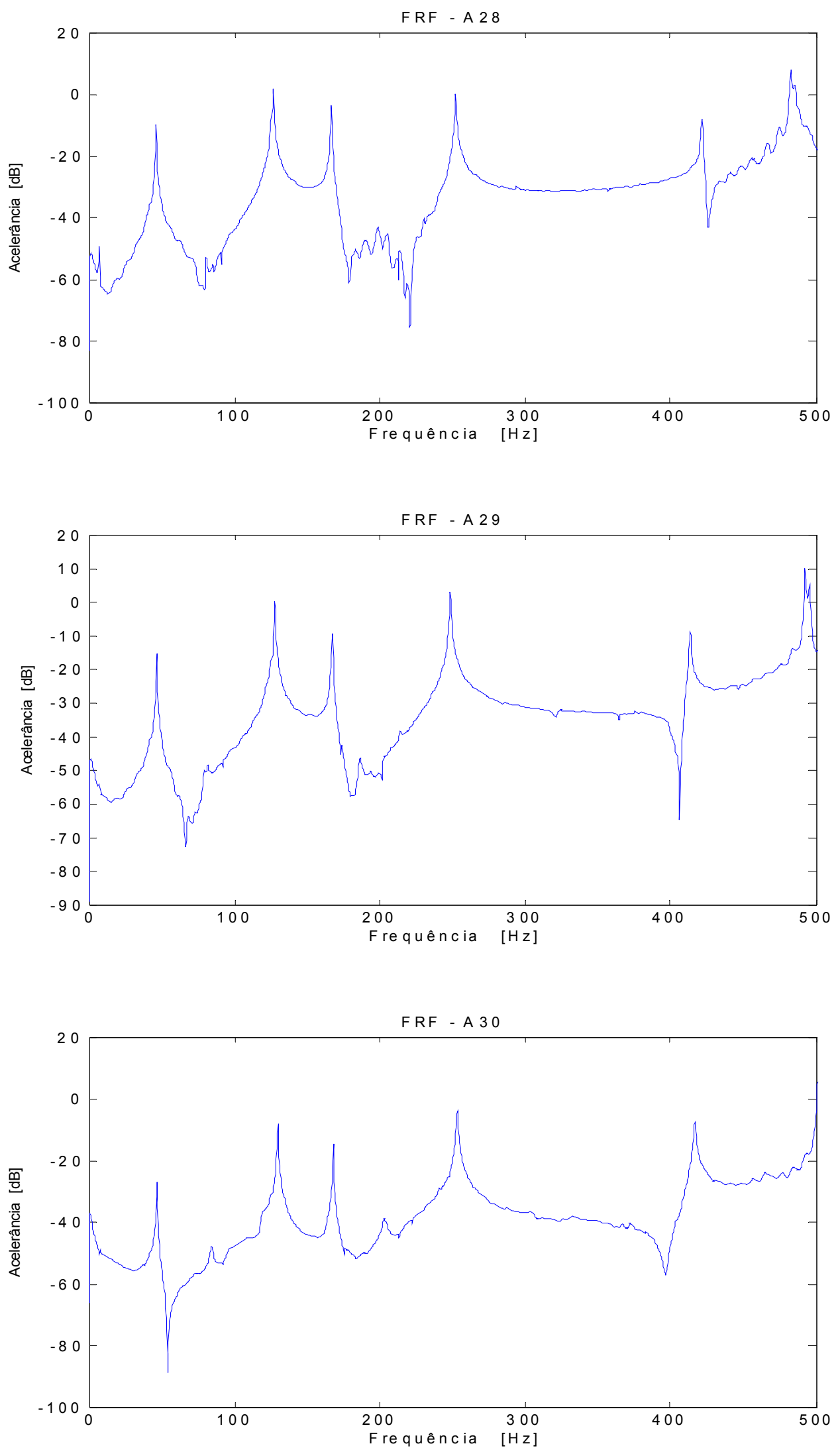

Figura A.12 - FRFs para a viga engastada - A28 a A30. 

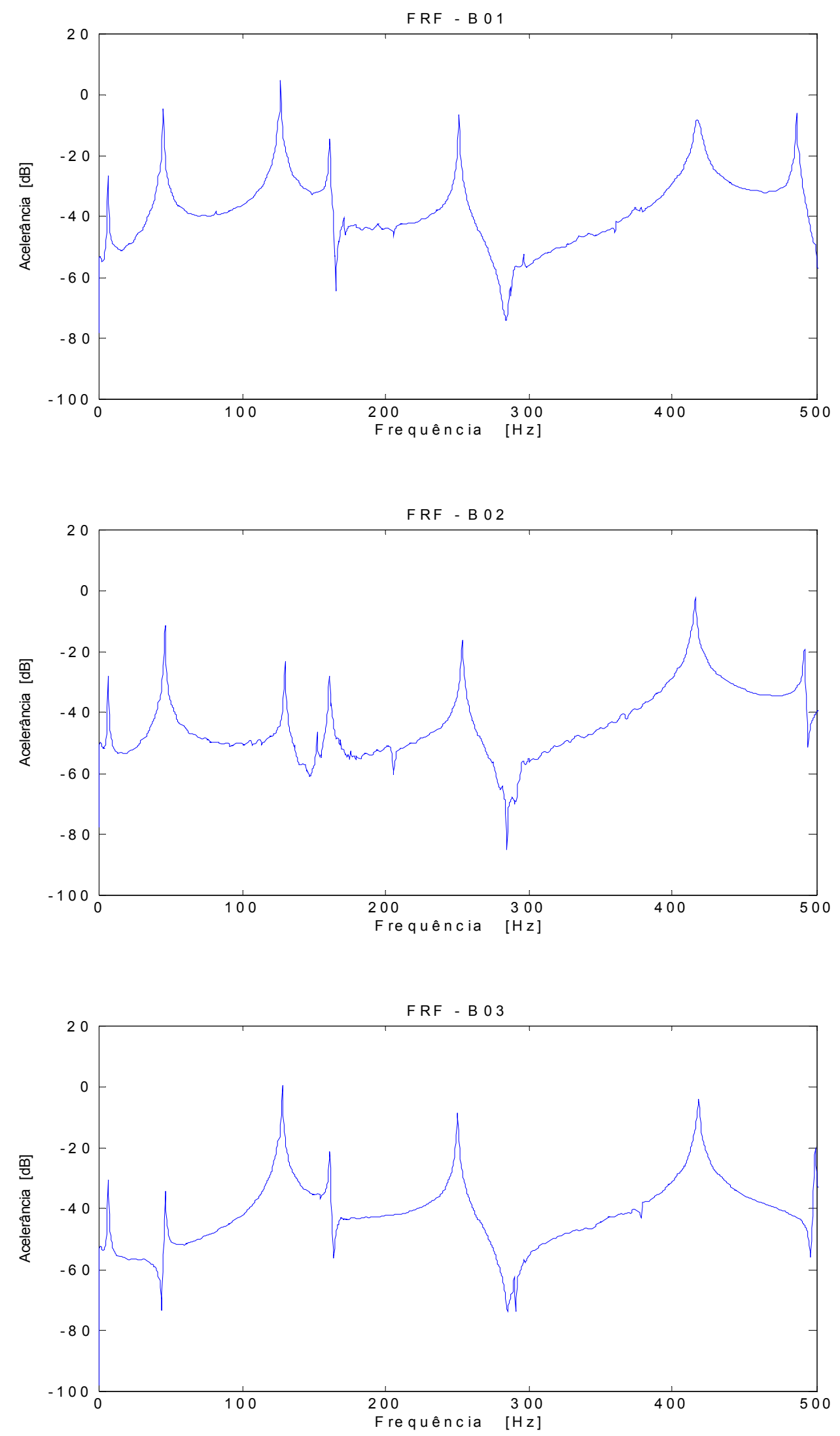

Figura A.13 - FRFs para a viga engastada - B01 a B03. 

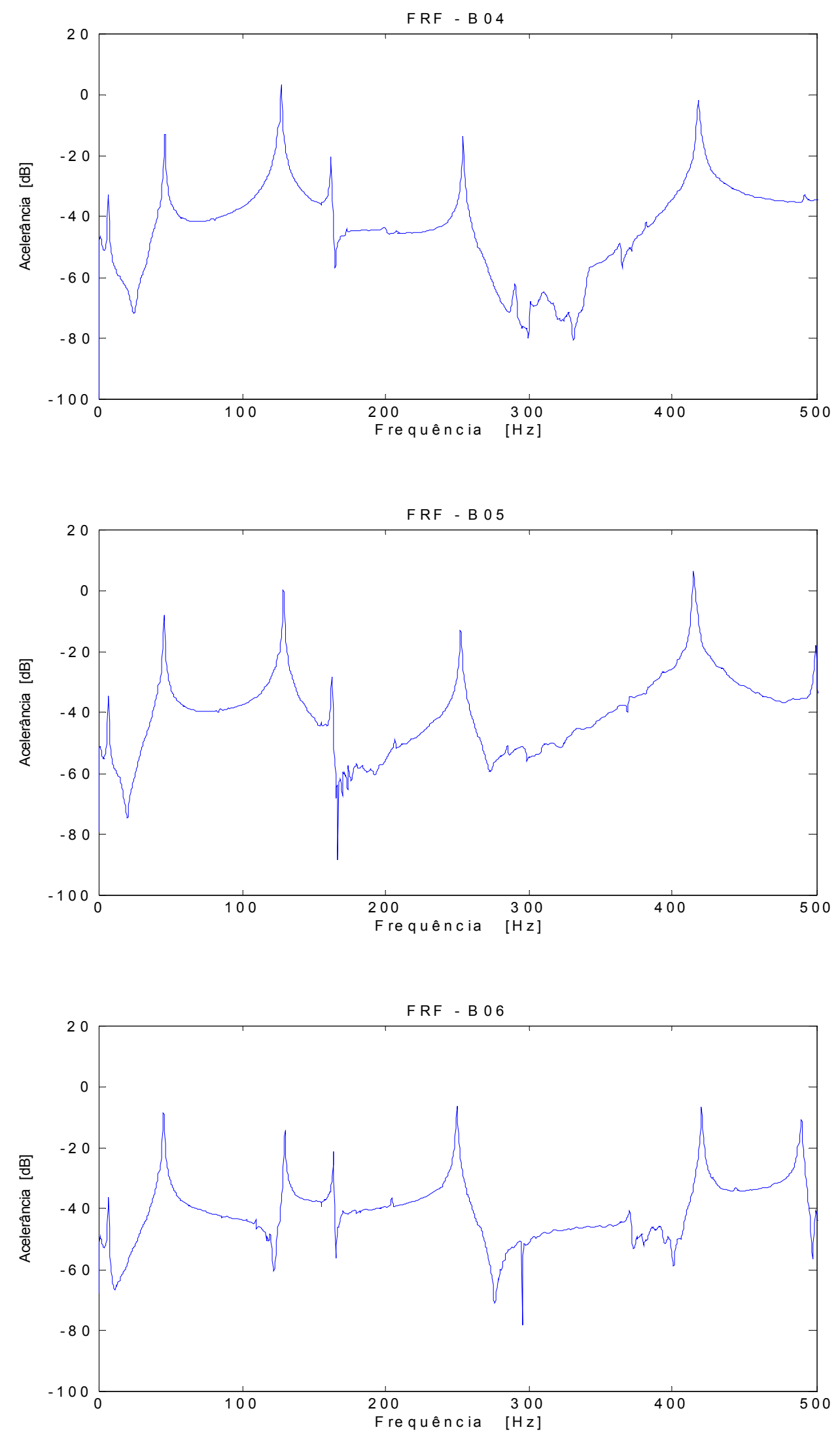

Figura A.14 - FRFs para a viga engastada - B04 a B06. 

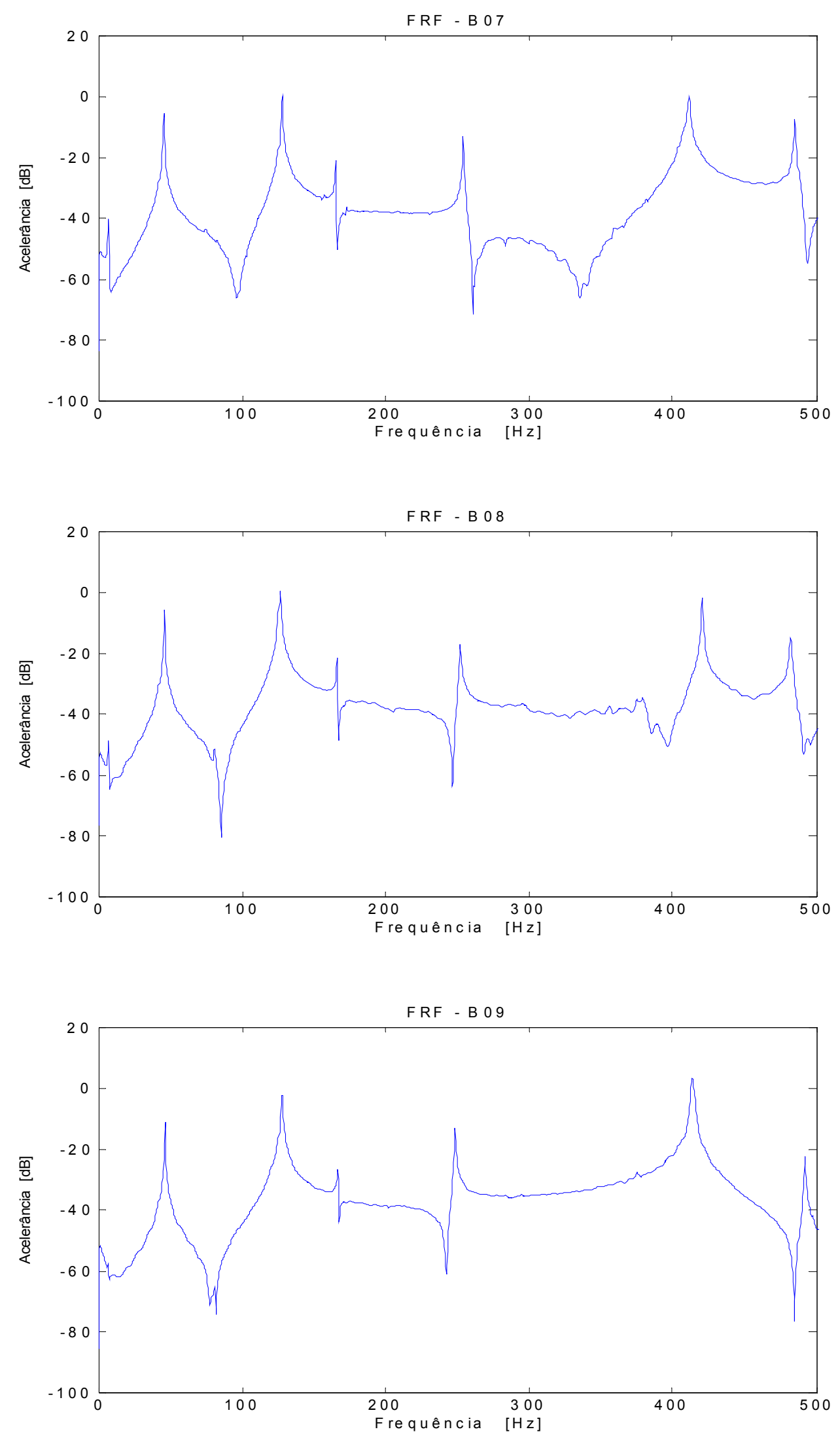

Figura A.15 - FRFs para a viga engastada - B07 a B09. 

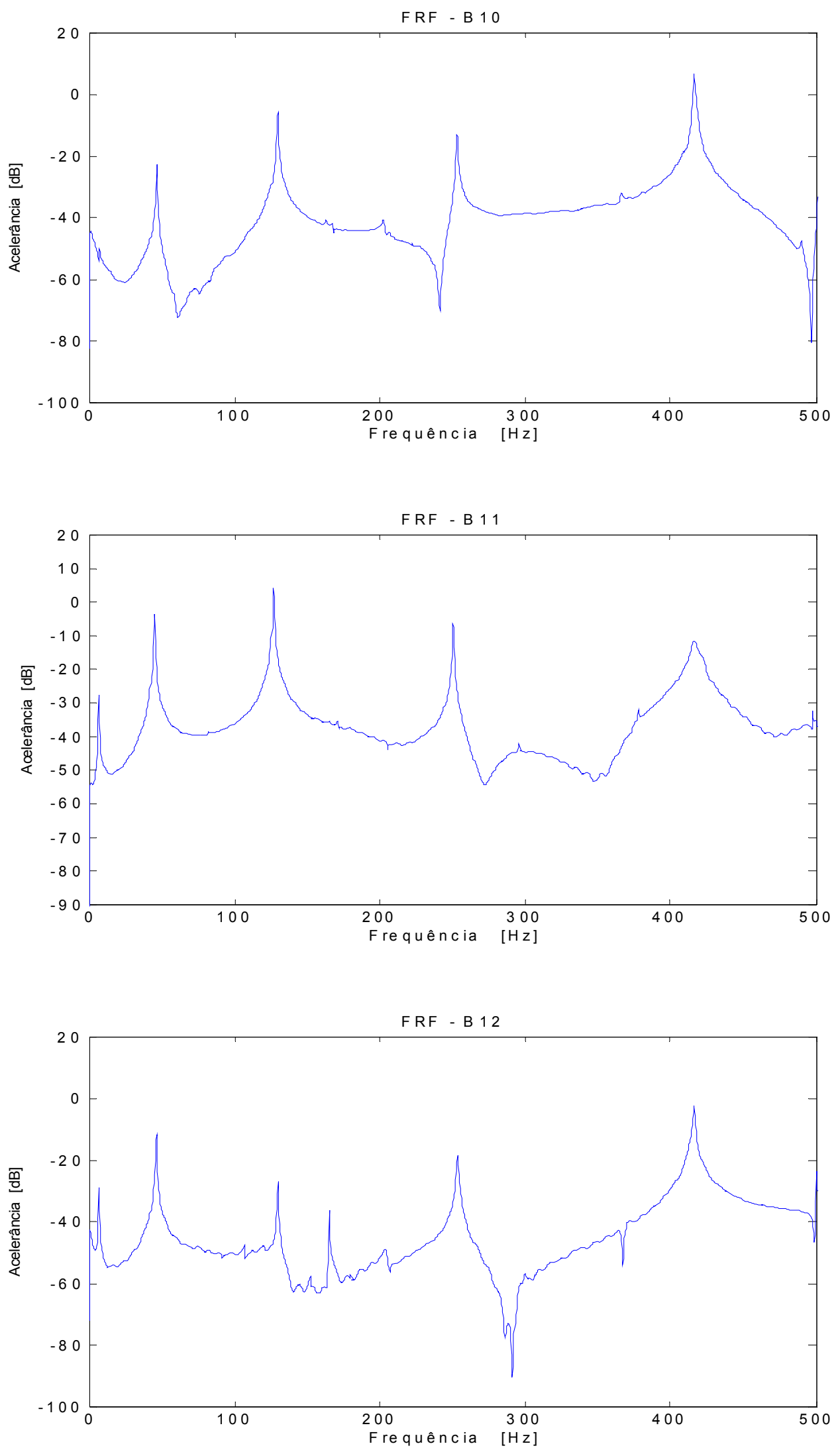

Figura A.16 - FRFs para a viga engastada - B10 a B12. 

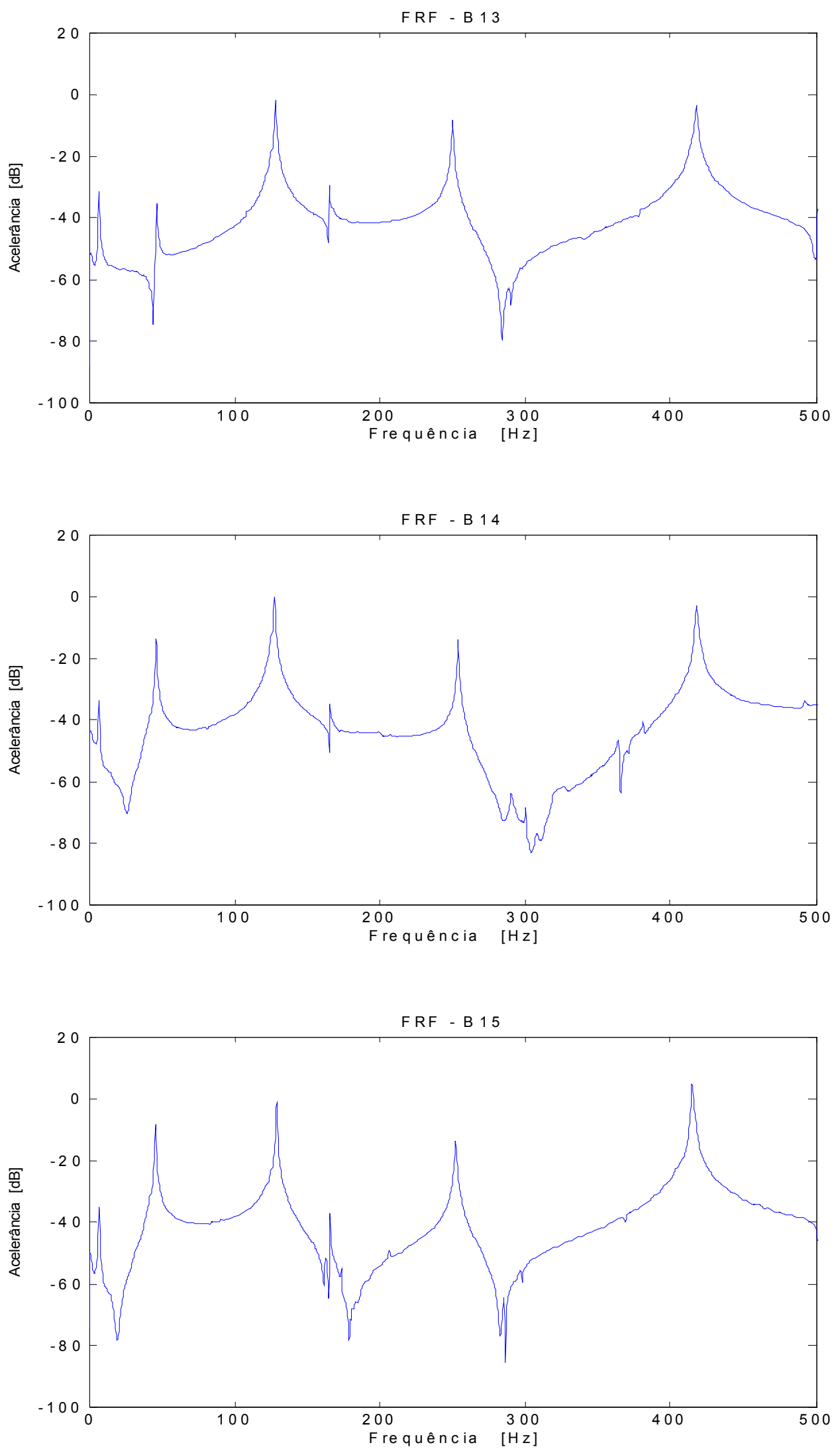

Figura A.17 - FRFs para a viga engastada - B13 a B15. 

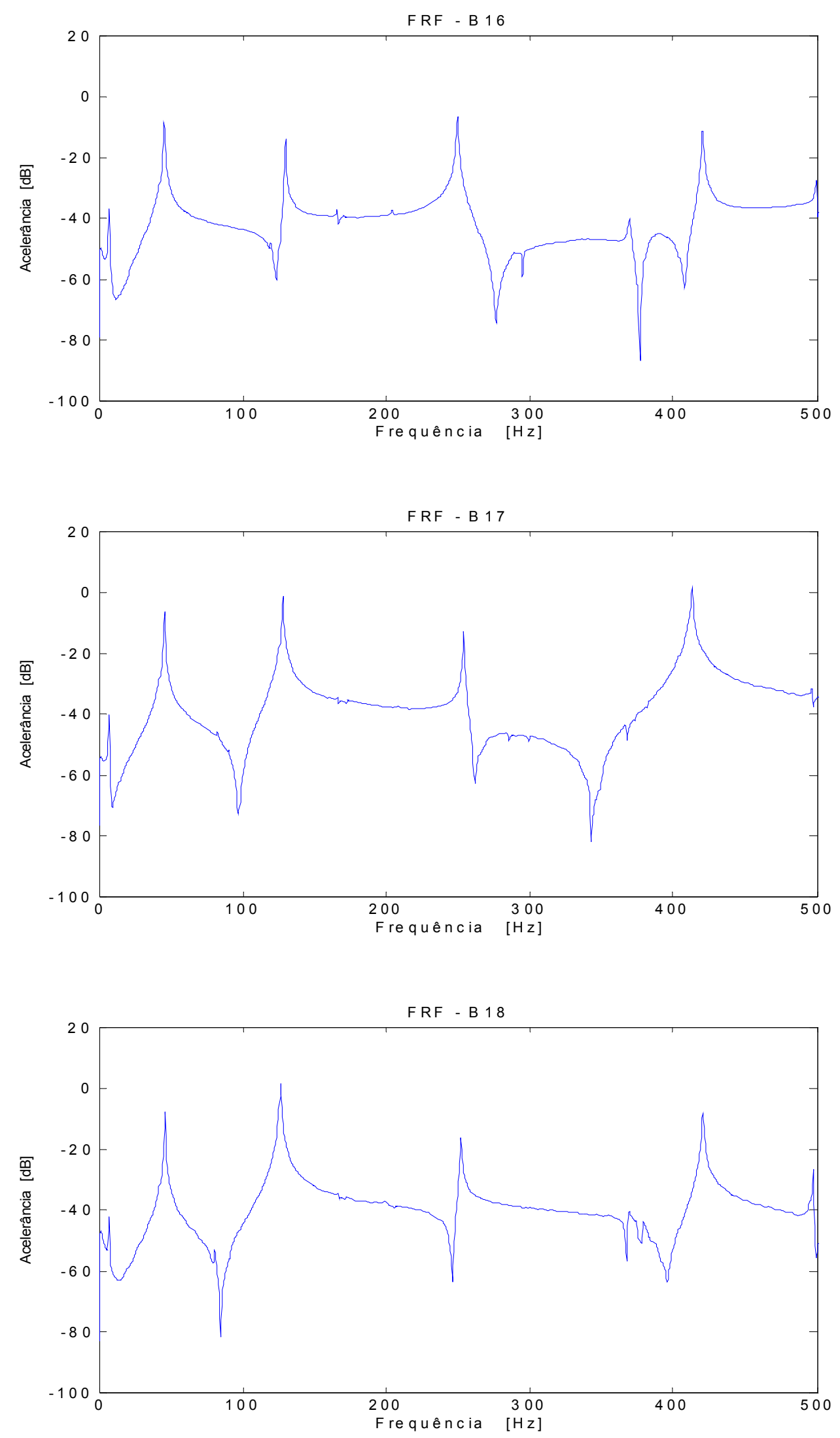

Figura A.18 - FRFs para a viga engastada - B16 a B18. 

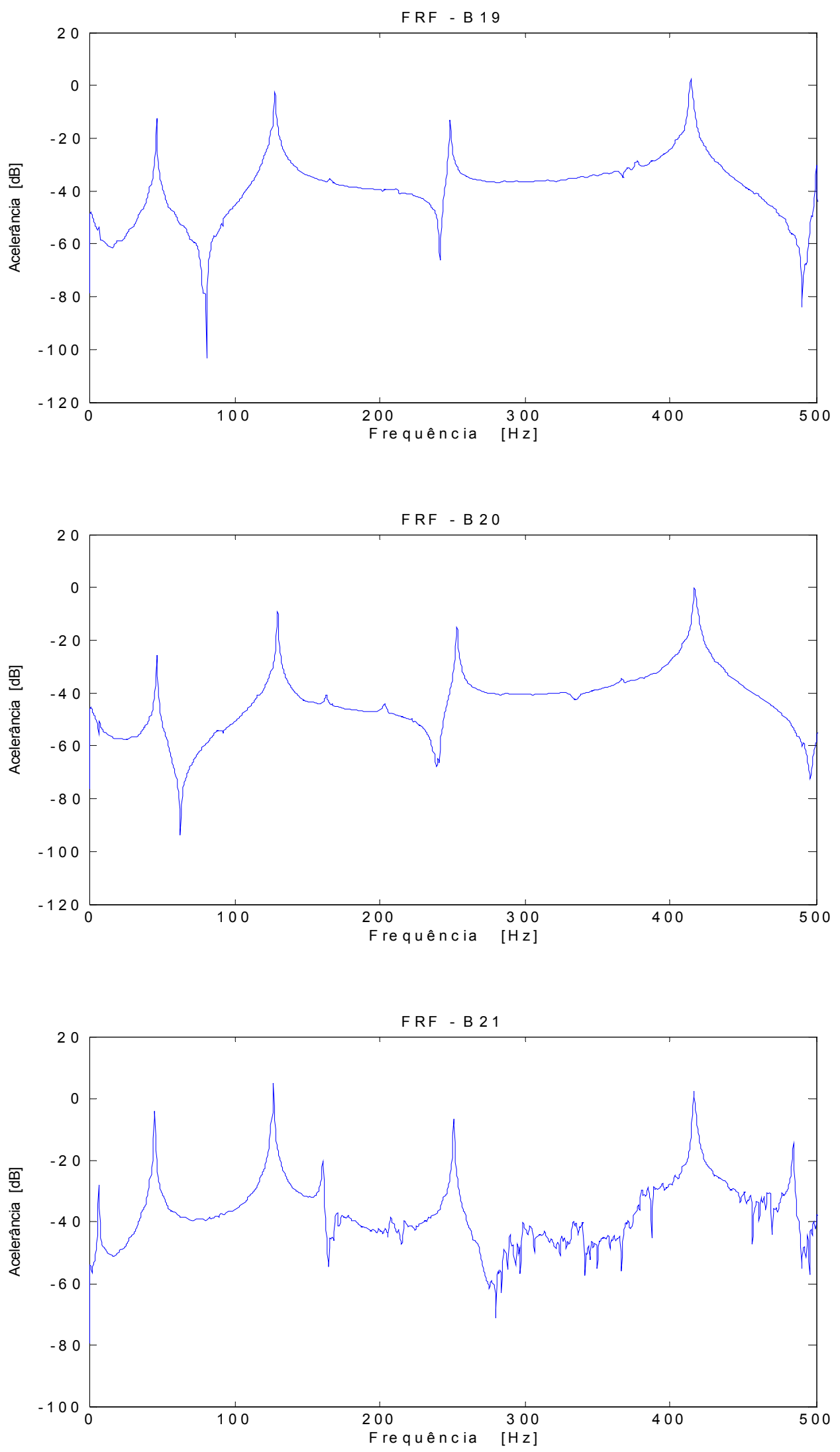

Figura A.19 - FRFs para a viga engastada - B19 a B21. 

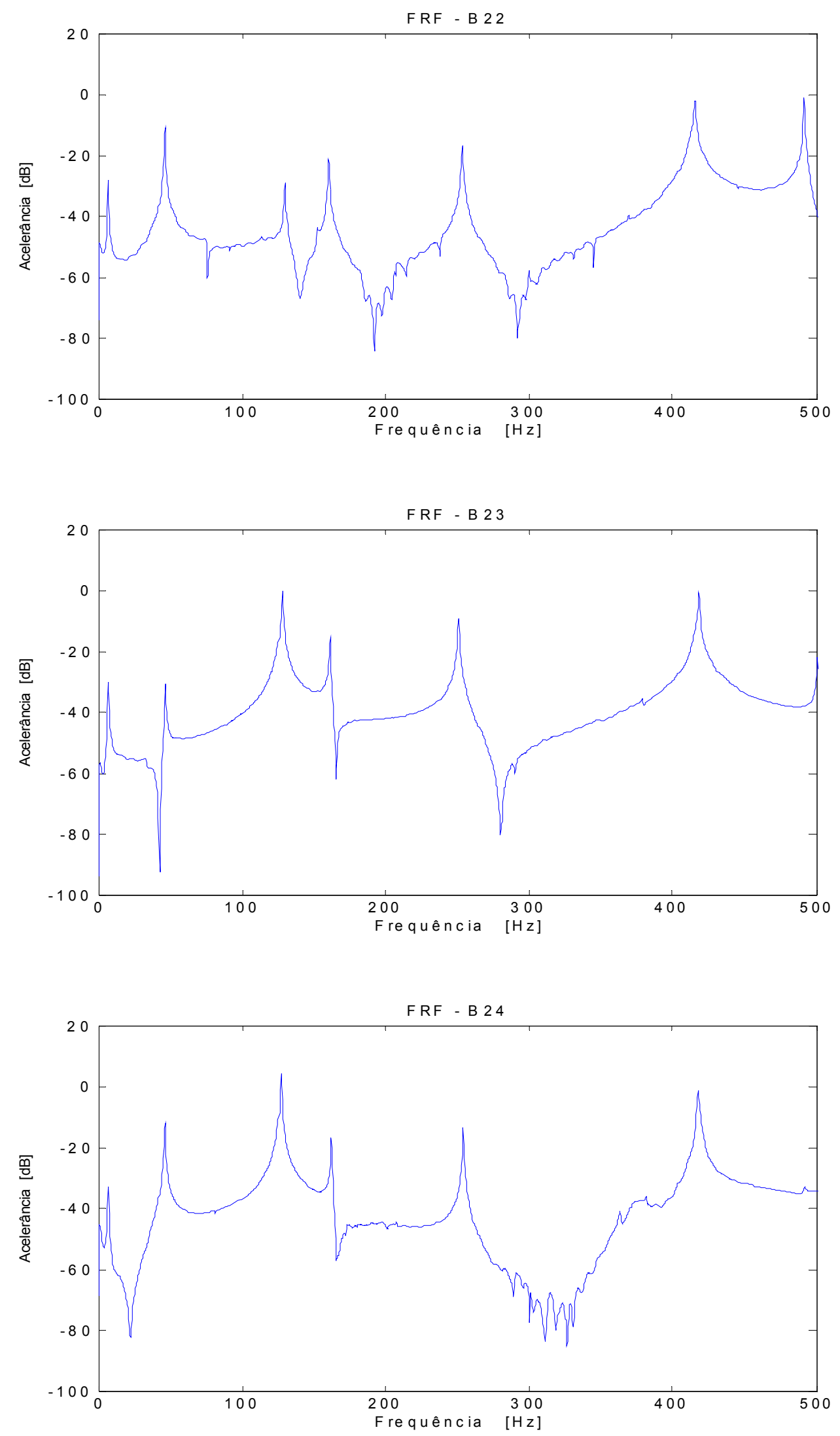

Figura A.20 - FRFs para a viga engastada - B22 a B24. 

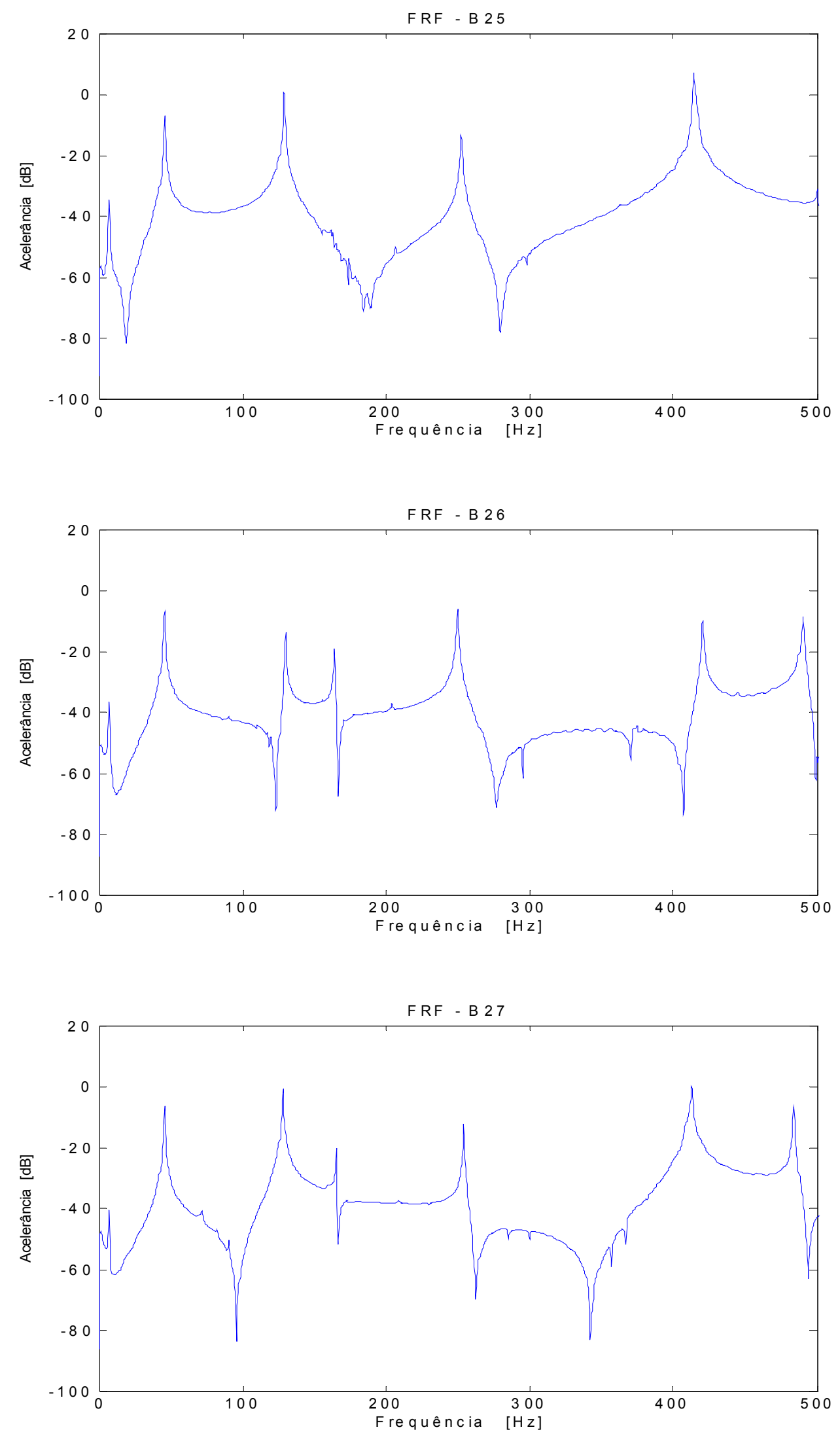

Figura A.21 - FRFs para a viga engastada - B25 a B27. 

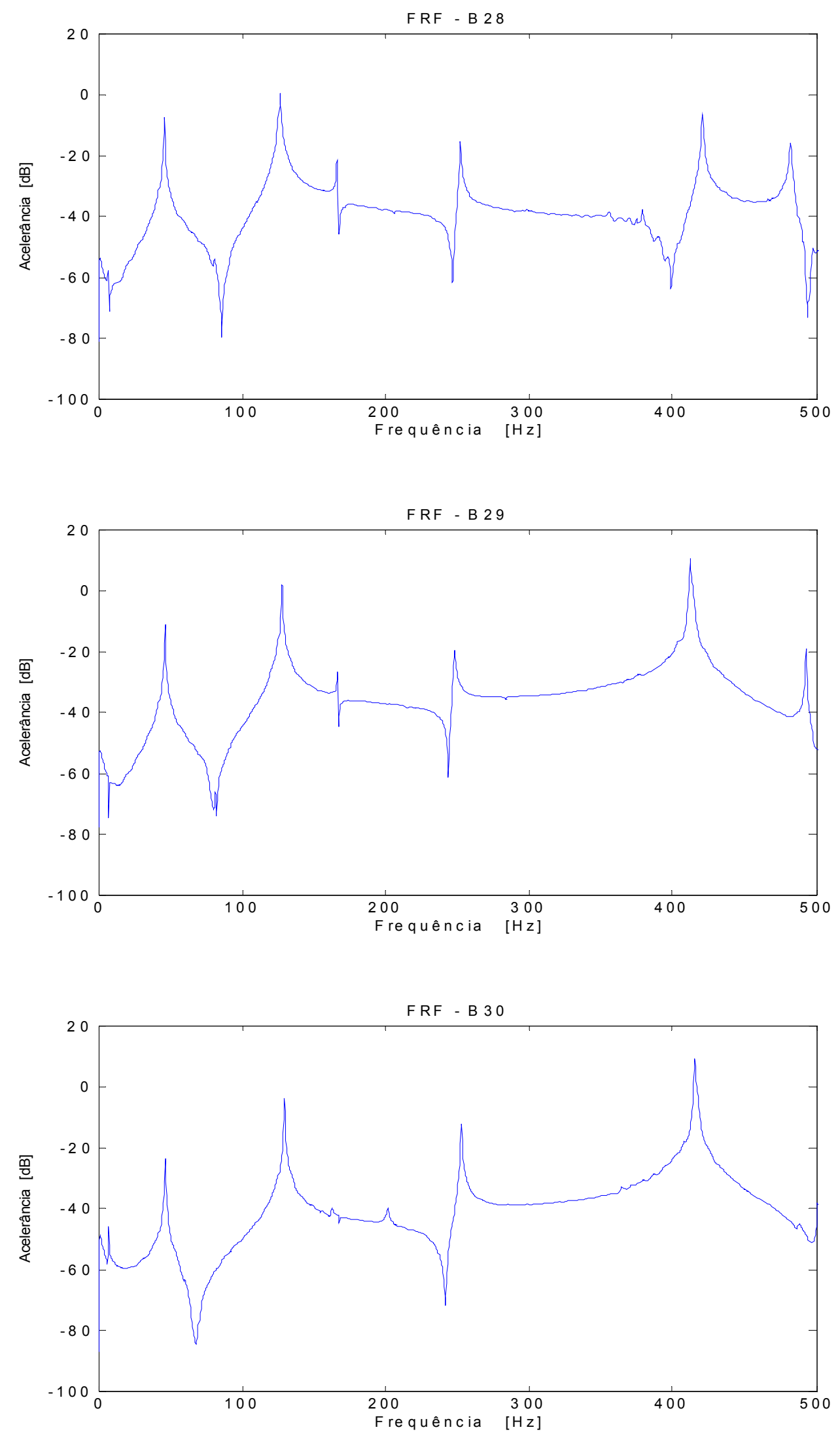

Figura A.22 - FRFs para a viga engastada - B28 a B30. 


\section{APÊNDICE B}

\section{FUNÇÕES RESPOSTA EM FREQUÊNCIA MEDIDAS NO ENSAIO DE VIBRAÇÃO NO SOLO NA SEMI-ASA DA AERONAVE NEIVA REGENTE}

São apresentados neste Apêndice os dados de funções resposta em freqüência (FRF) medidos na semi-asa da aeronave Neiva Regente durante os ensaios experimentais. A asa foi marcada com a localização dos pontos de saída e as entradas foram aplicadas nas fixações das duas longarinas com a fuselagem, ou seja, na longarina traseira $\boldsymbol{A}$ e longarina dianteira $\boldsymbol{B}$. Foram medidos quinze pontos ao longo de cada longarina, sessenta FRFs foram medidas no total. A Figura B.1 apresenta os 2 pontos de entrada (excitação) e os respectivos pontos de saída (medidas) utilizados nos ensaios experimentais da asa. Desta forma, FRF-A20 indica que a função resposta em freqüência foi obtida medindo-se a força aplicada no ponto $\boldsymbol{A}$ e a aceleração no ponto 20 .

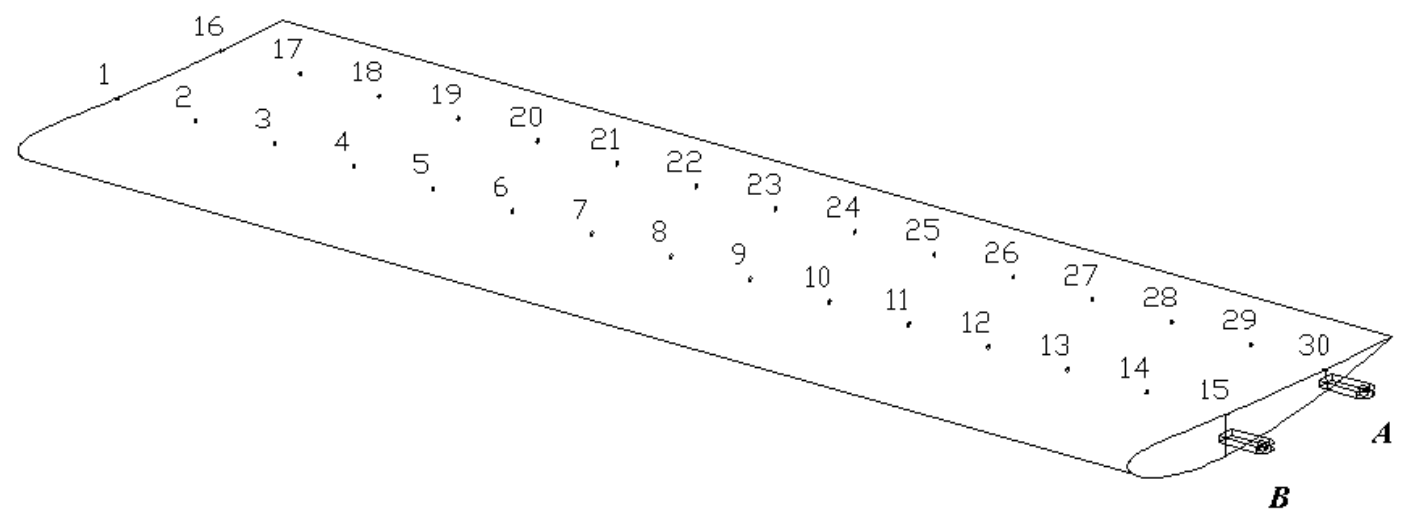

Figura B.1 - Pontos de entrada e saída utilizados no ensaio da semi-asa.

Finalmente, nas Figuras B.2 a B.22 são apresentados o conjunto total das 60 funções resposta em freqüência medidas nos ensaios de vibração no solo na semiasa da aeronave Neiva Regente. 

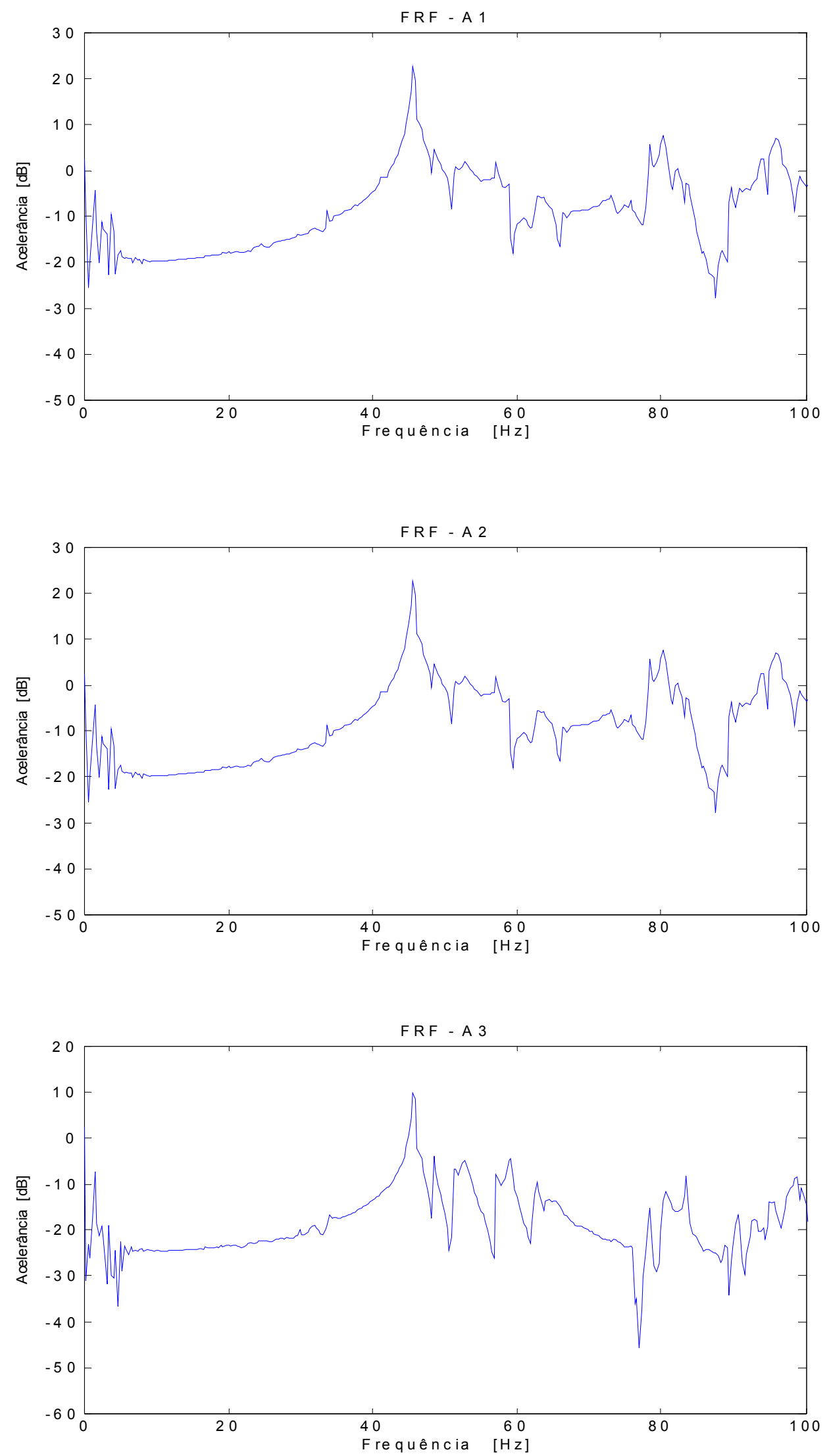

Figura B.2 - FRFs obtidas no ensaio da semi-asa - A1 a A3. 

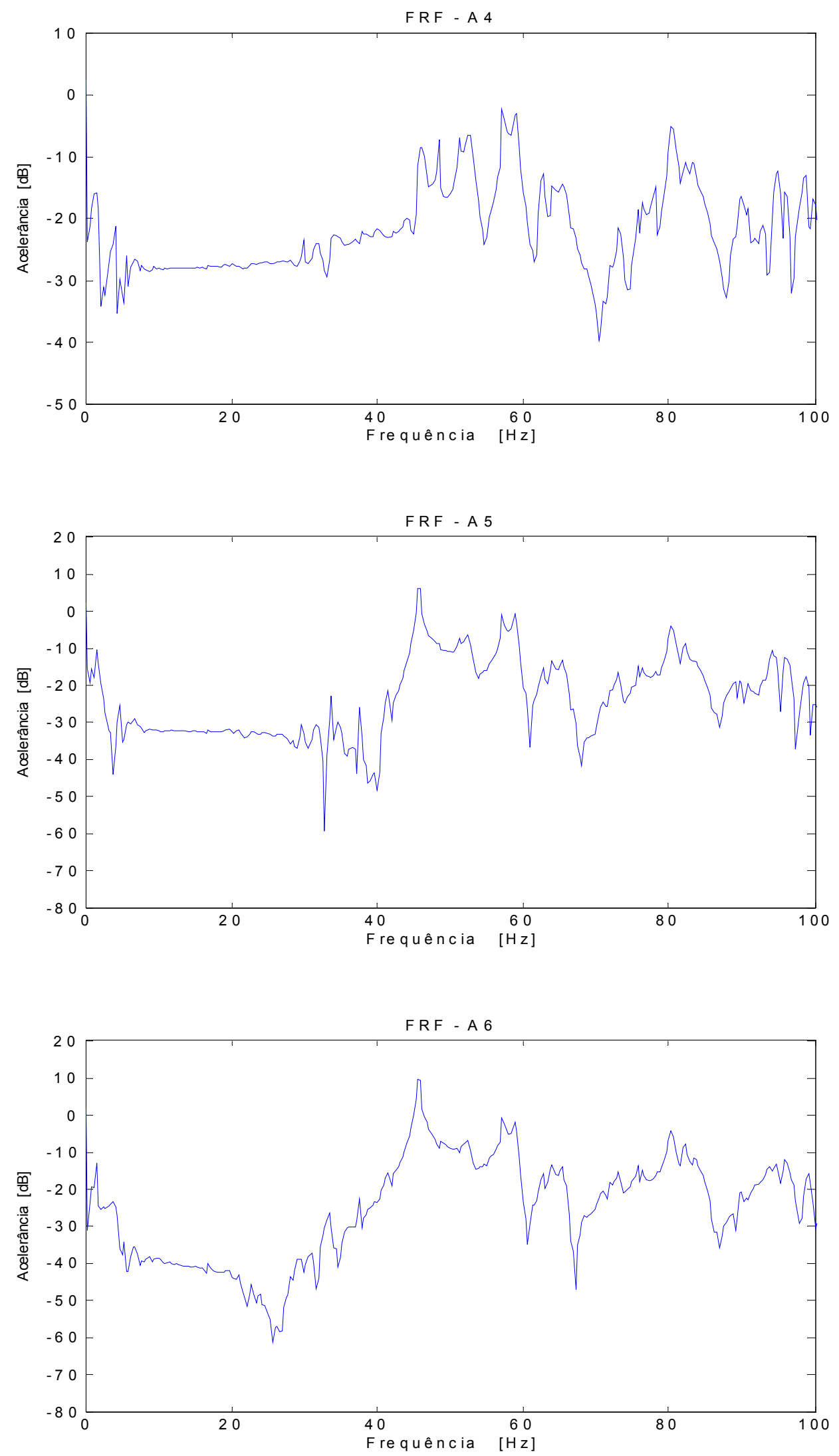

Figura B.3 - FRFs obtidas no ensaio da semi-asa - A4 a A6. 

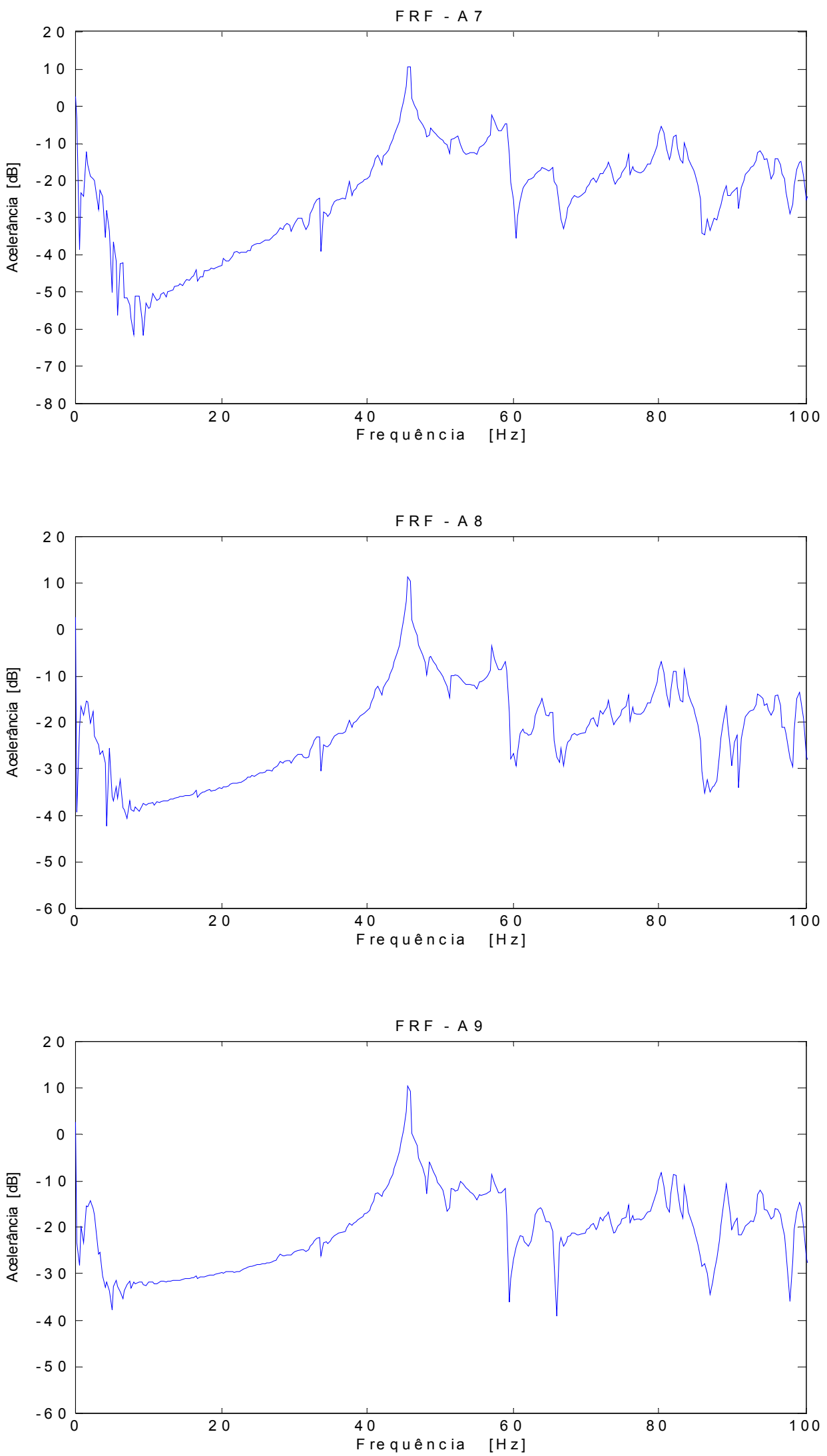

Figura B.4 - FRFs obtidas no ensaio da semi-asa - A7 a A9. 

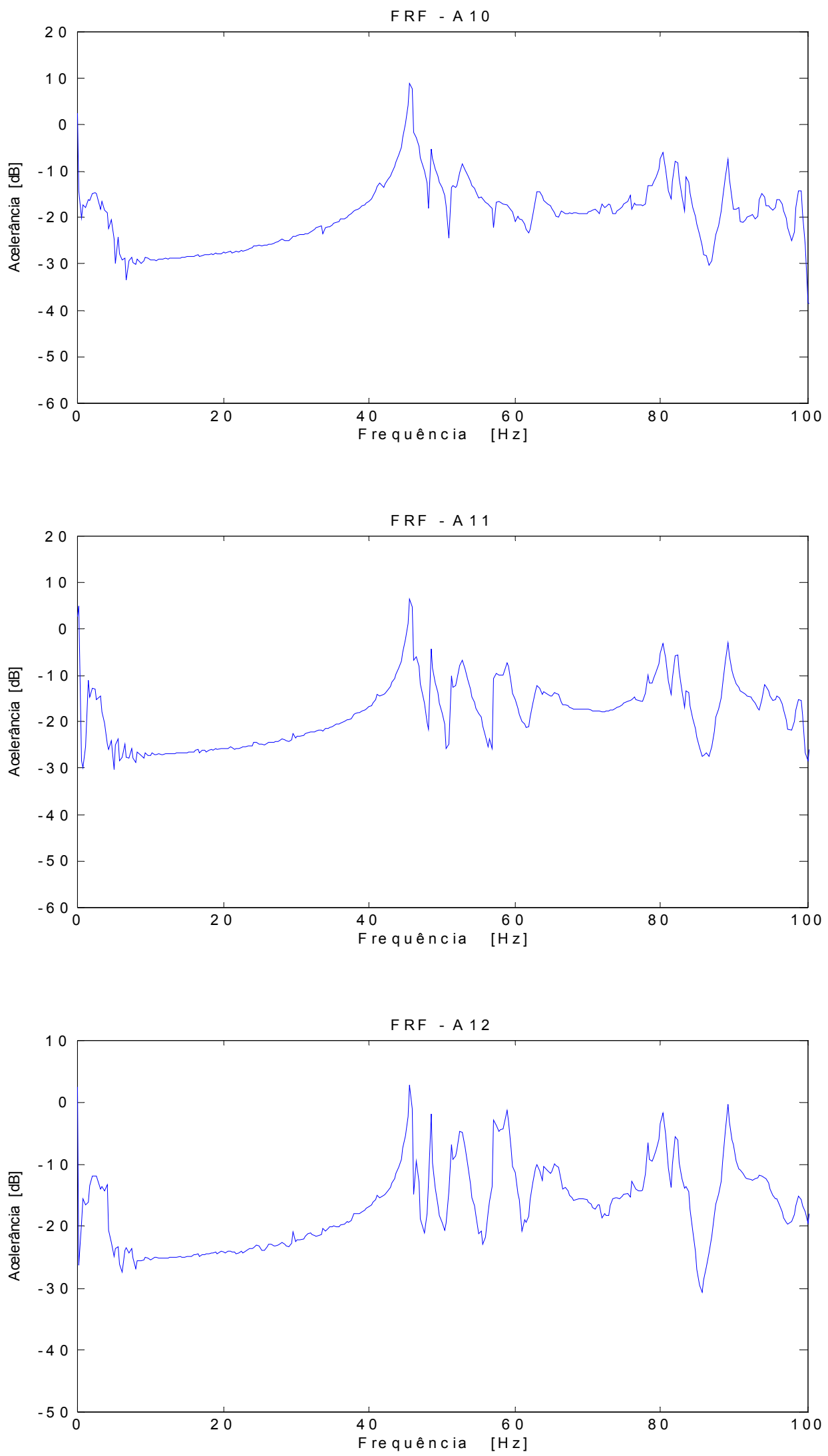

Figura B.5 - FRFs obtidas no ensaio da semi-asa - A10 a A12. 



Figura B.6 - FRFs obtidas no ensaio da semi-asa - A13 a A15. 

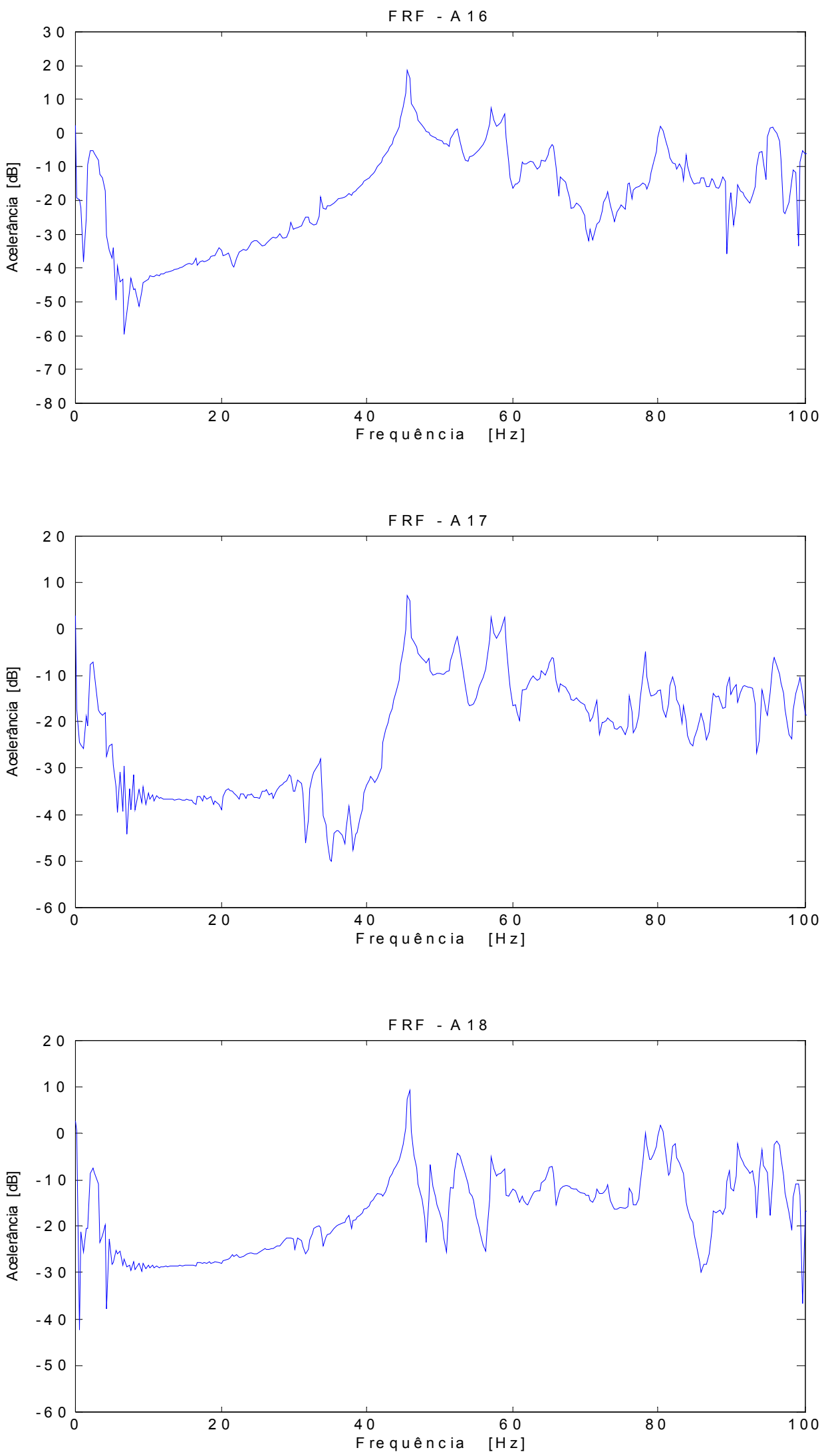

Figura B.7 - FRFs obtidas no ensaio da semi-asa - A16 a A18. 

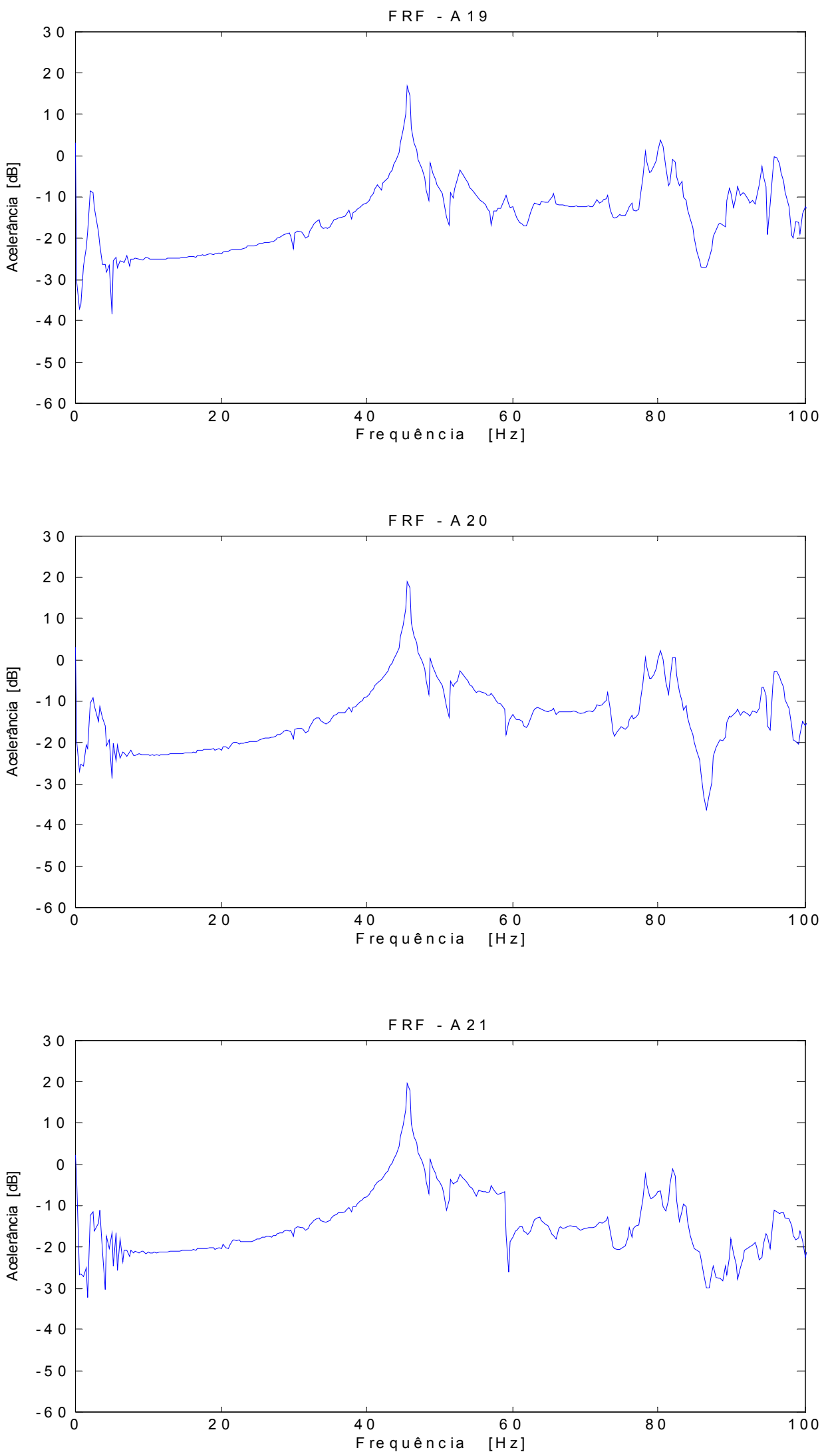

Figura B.8 - FRFs obtidas no ensaio da semi-asa - A19 a A21. 

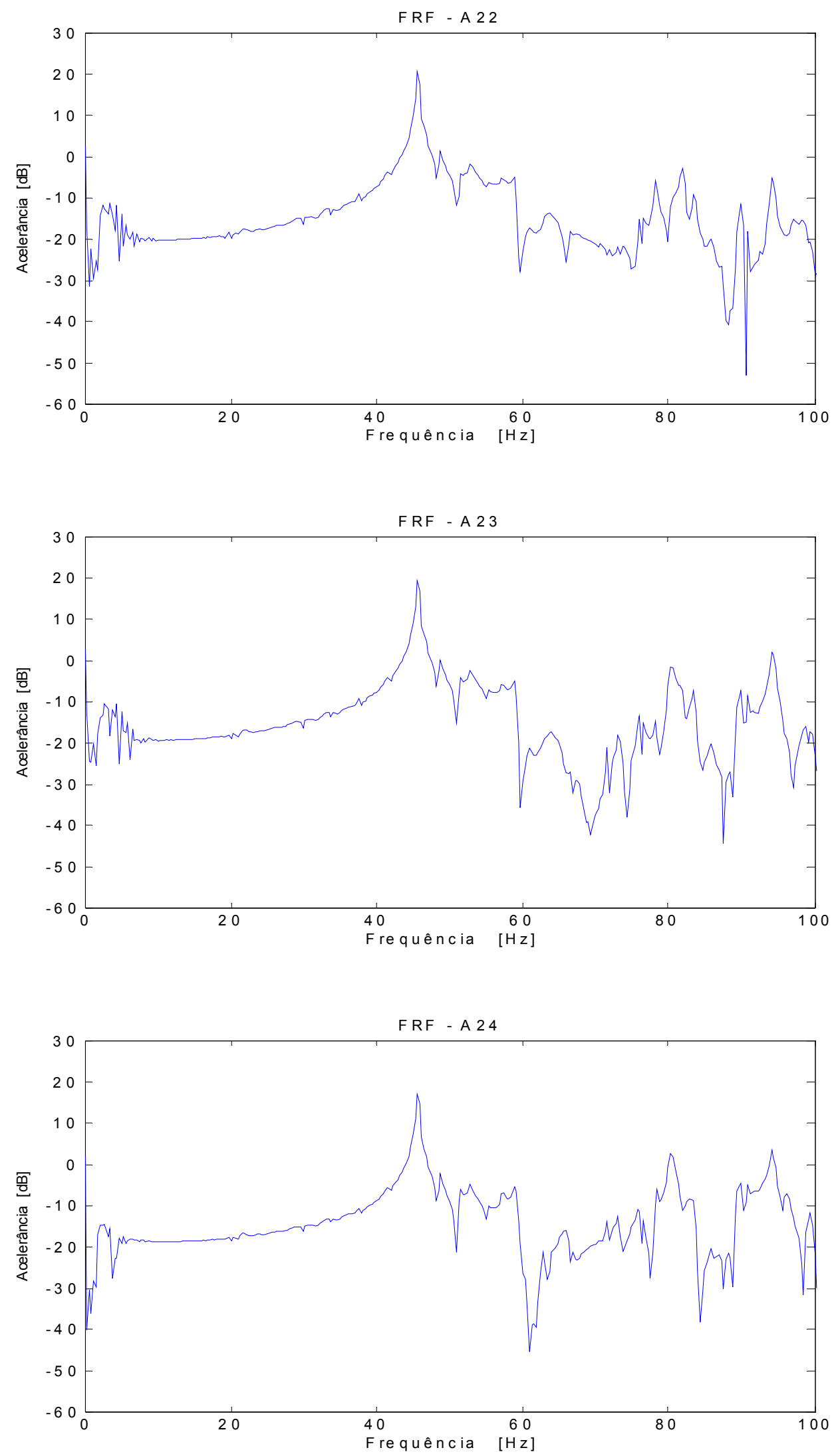

Figura B.9 - FRFs obtidas no ensaio da semi-asa - A22 a A24. 

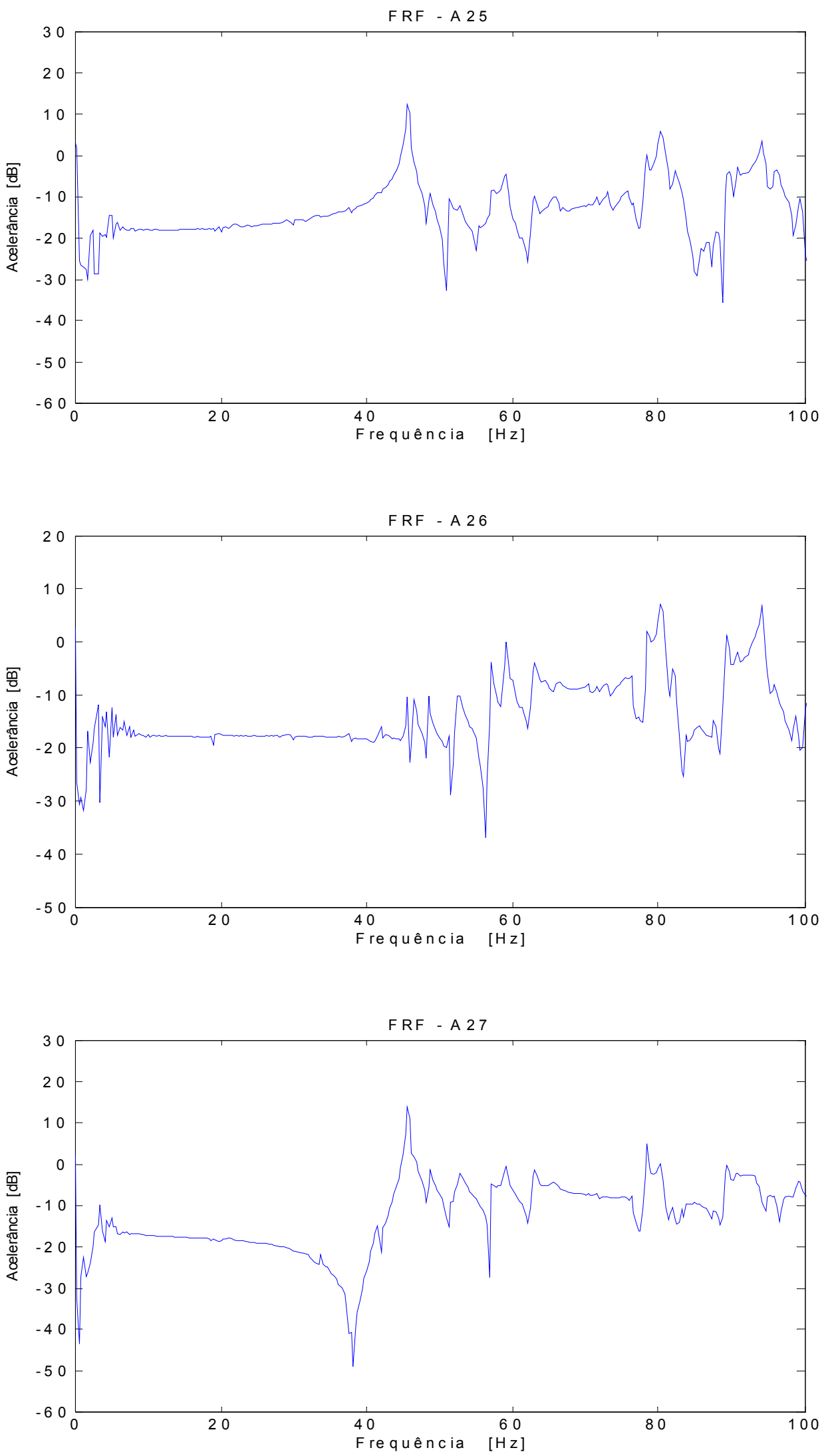

Figura B.10 - FRFs obtidas no ensaio da semi-asa - A25 a A27. 



Figura B.11 - FRFs obtidas no ensaio da semi-asa - A28 a A30. 

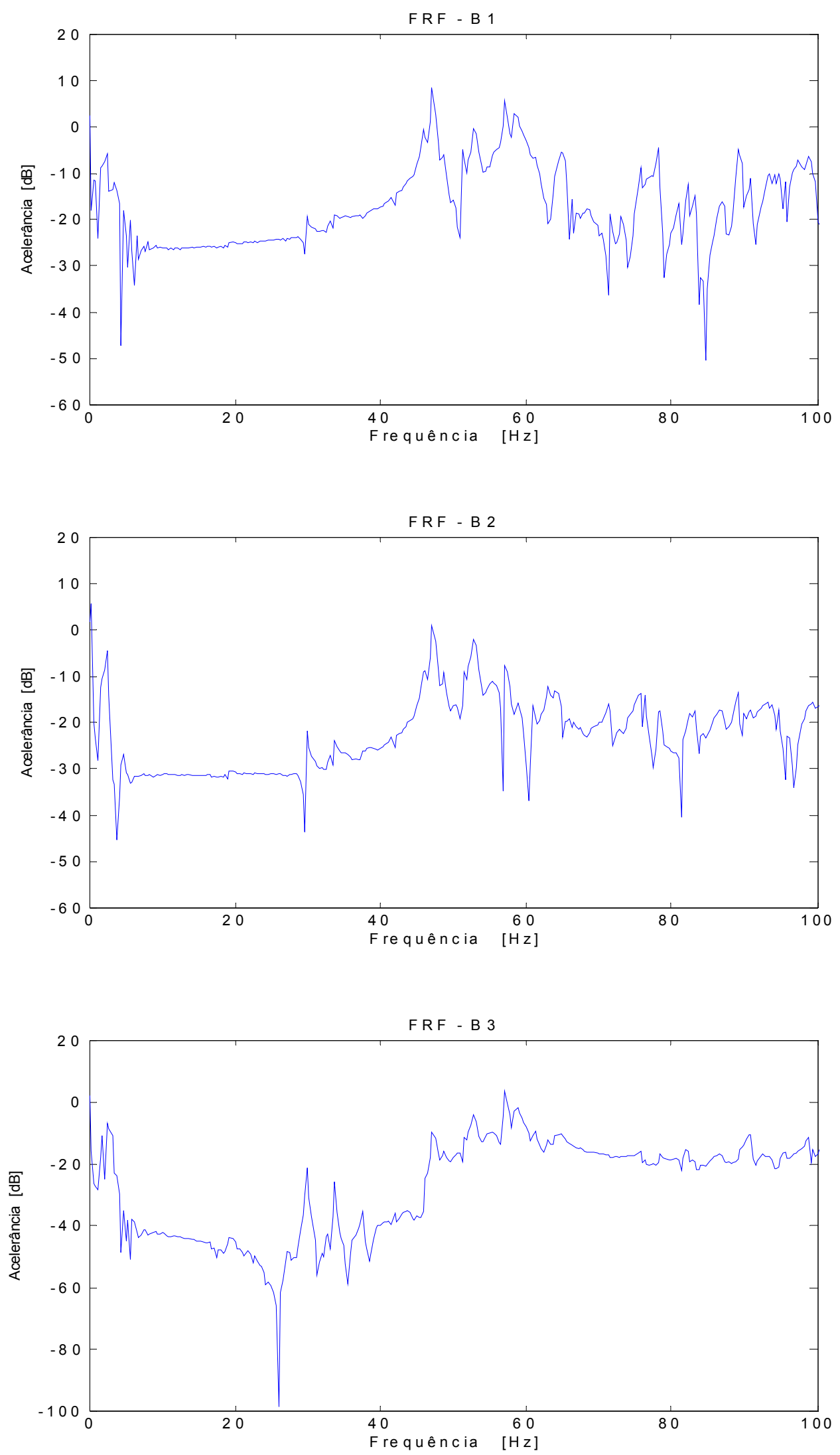

Figura B.12 - FRFs obtidas no ensaio da semi-asa - B1 a B3. 

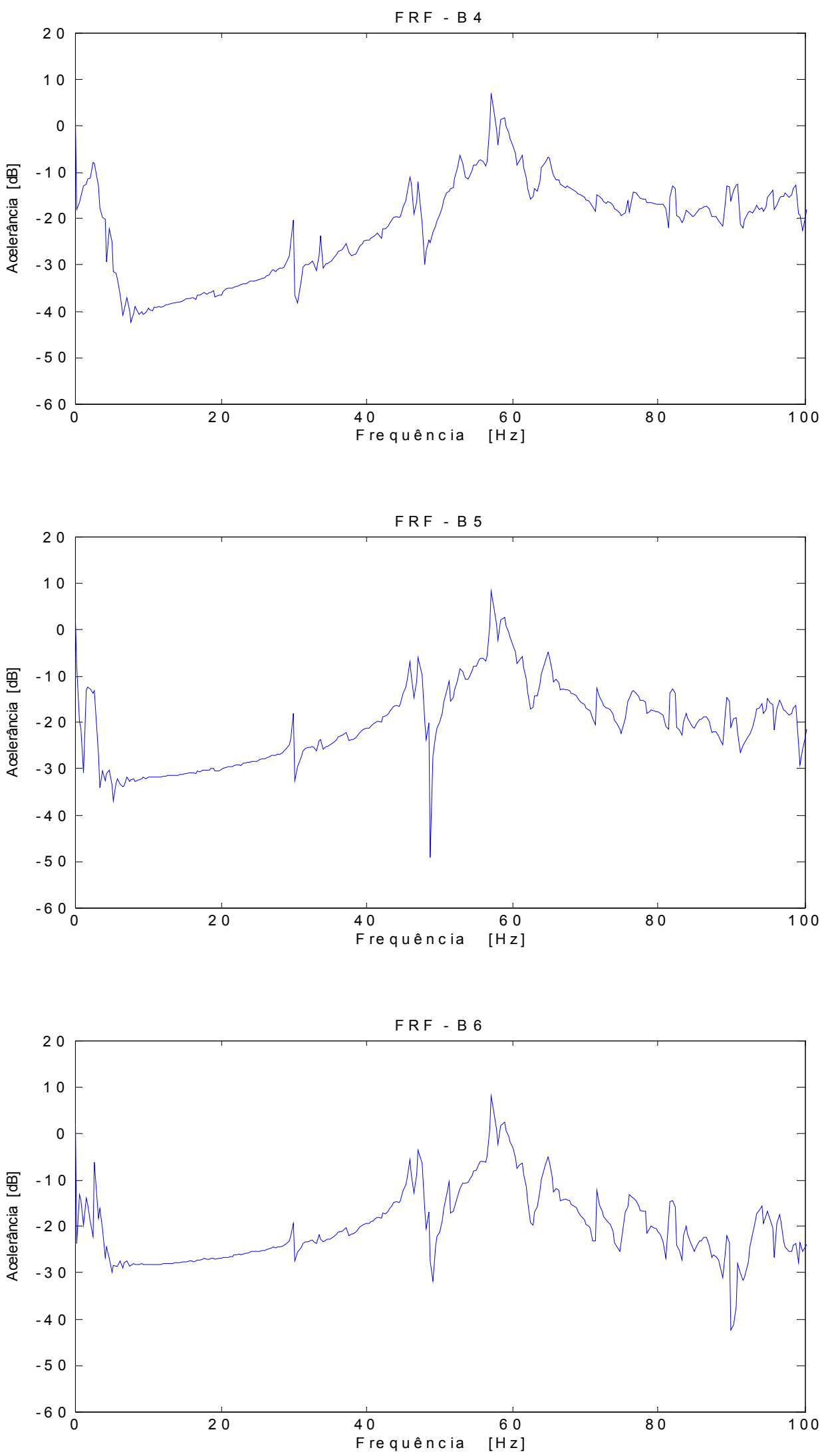

Figura B.13 - FRFs obtidas no ensaio da semi-asa - B4 a B6. 

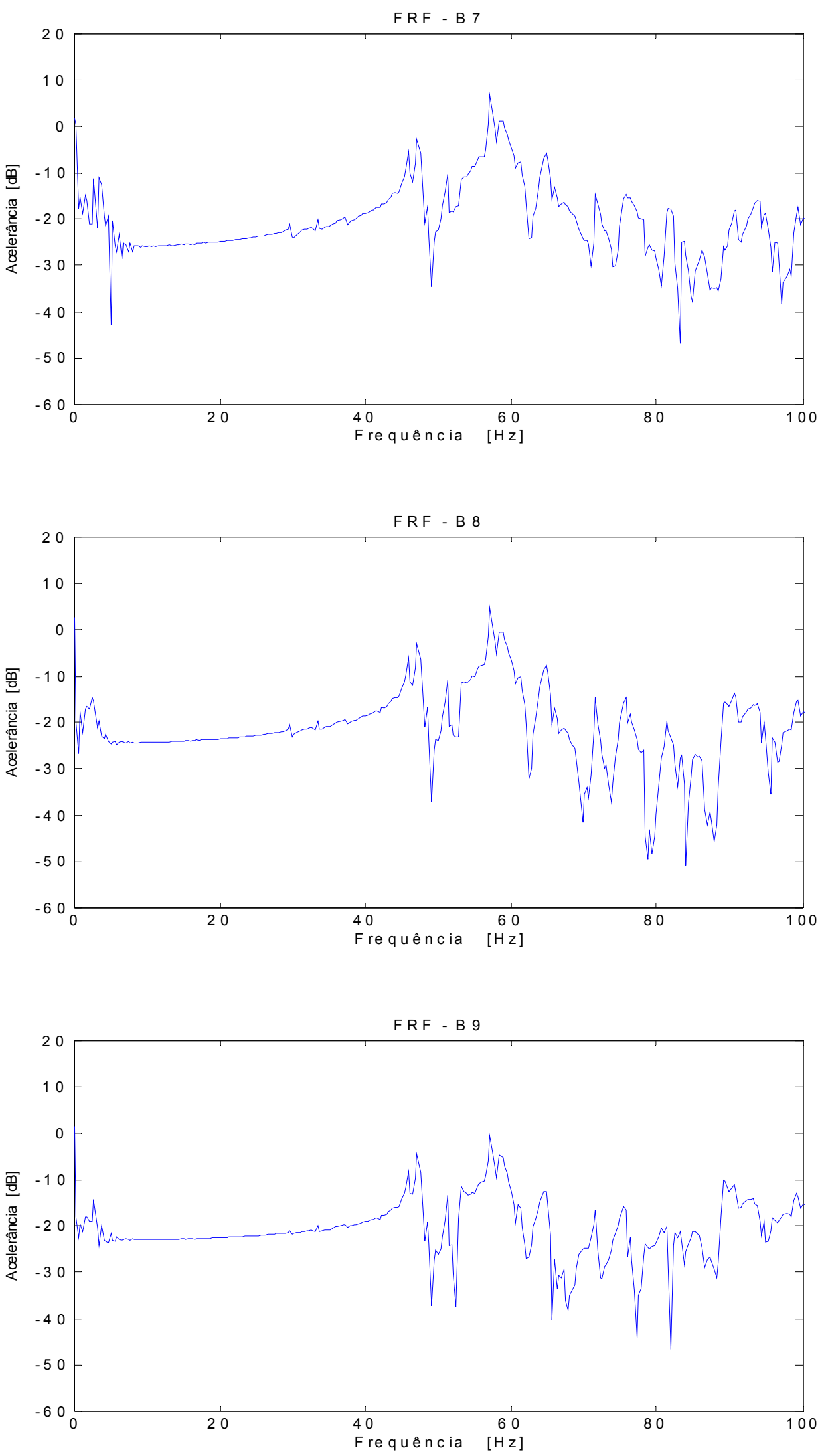

Figura B.14 - FRFs obtidas no ensaio da semi-asa - B7 a B9. 

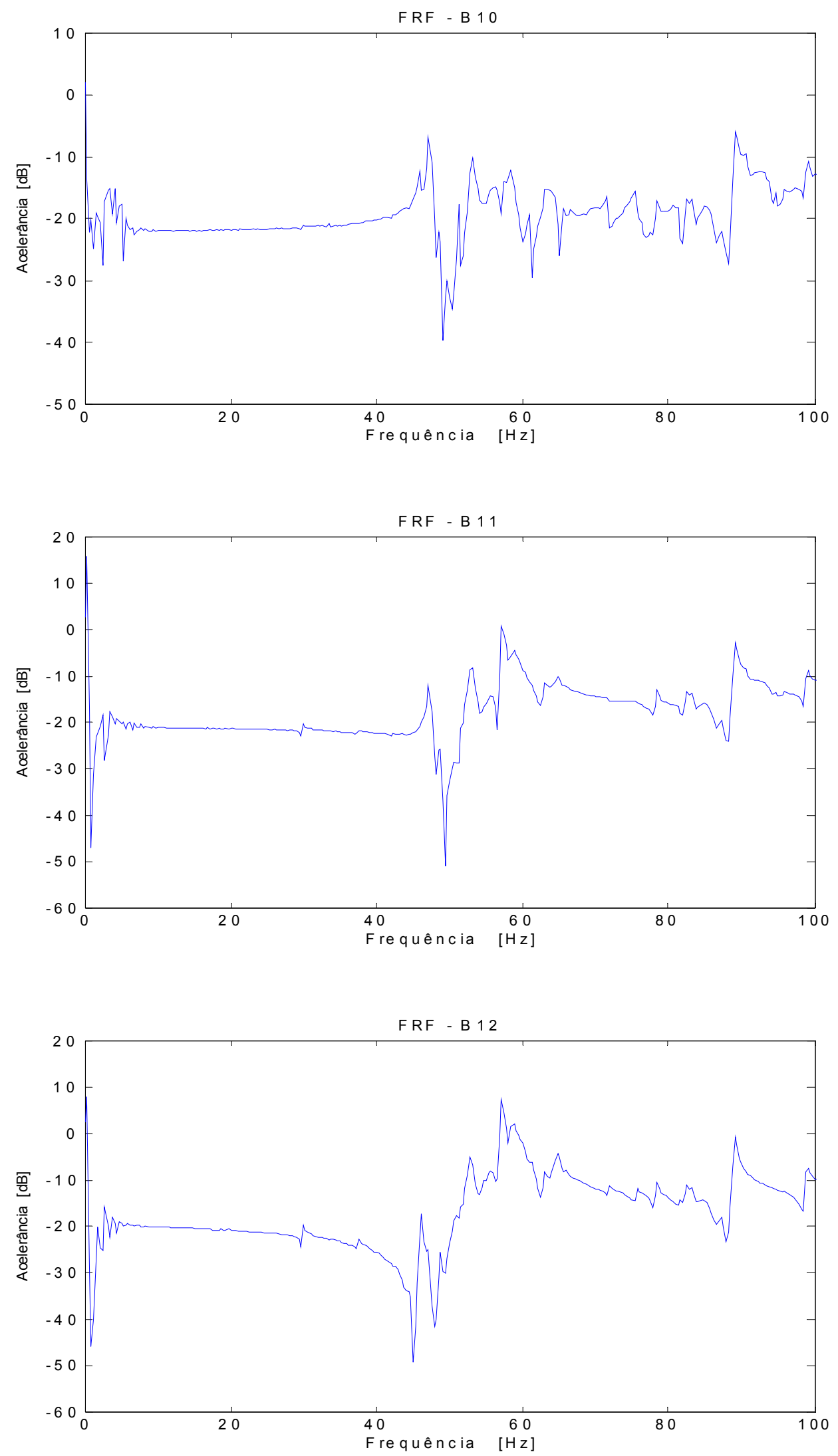

Figura B.15 - FRFs obtidas no ensaio da semi-asa - B10 a B12. 

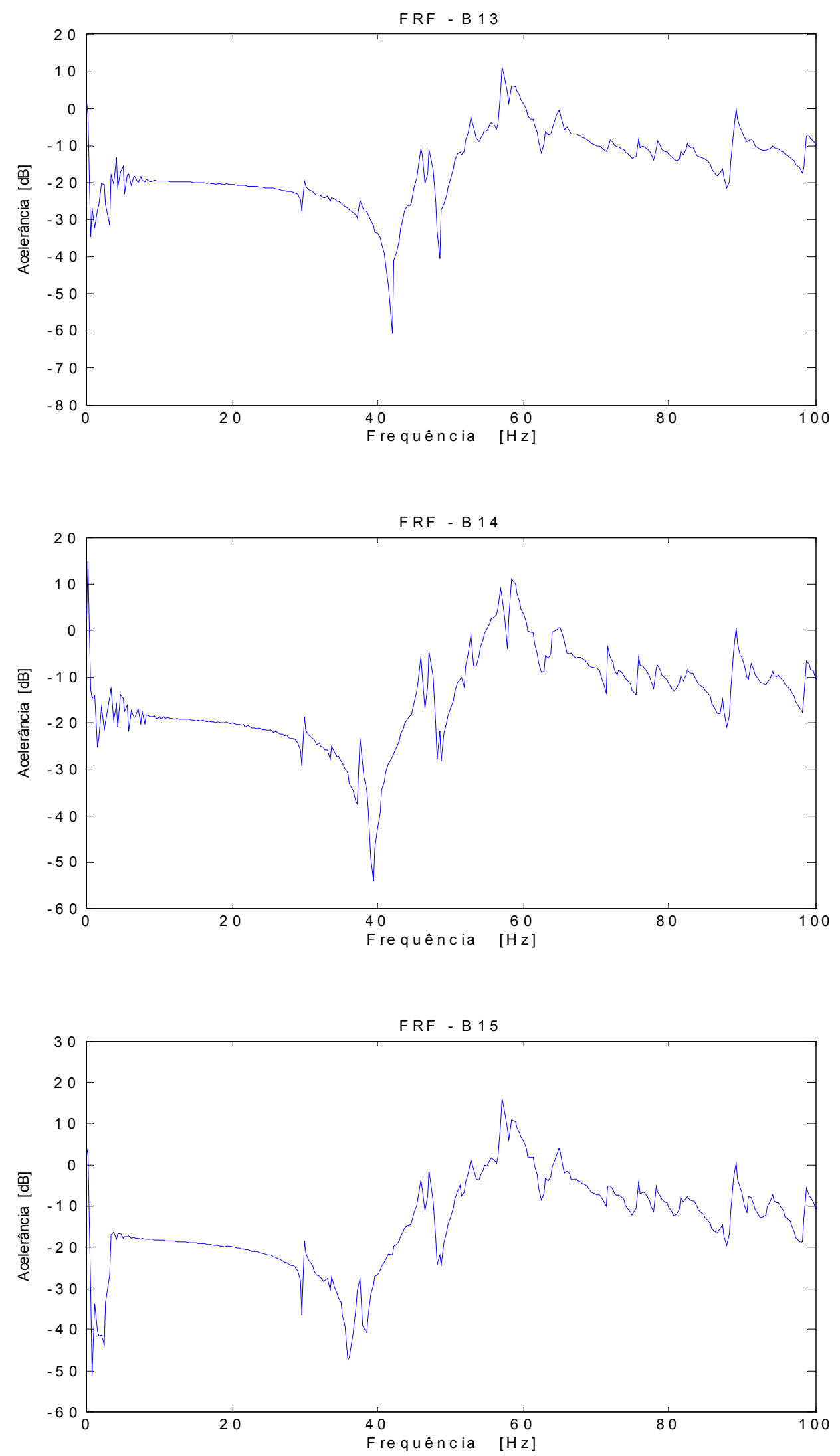

Figura B.16 - FRFs obtidas no ensaio da semi-asa - B13 a B15. 

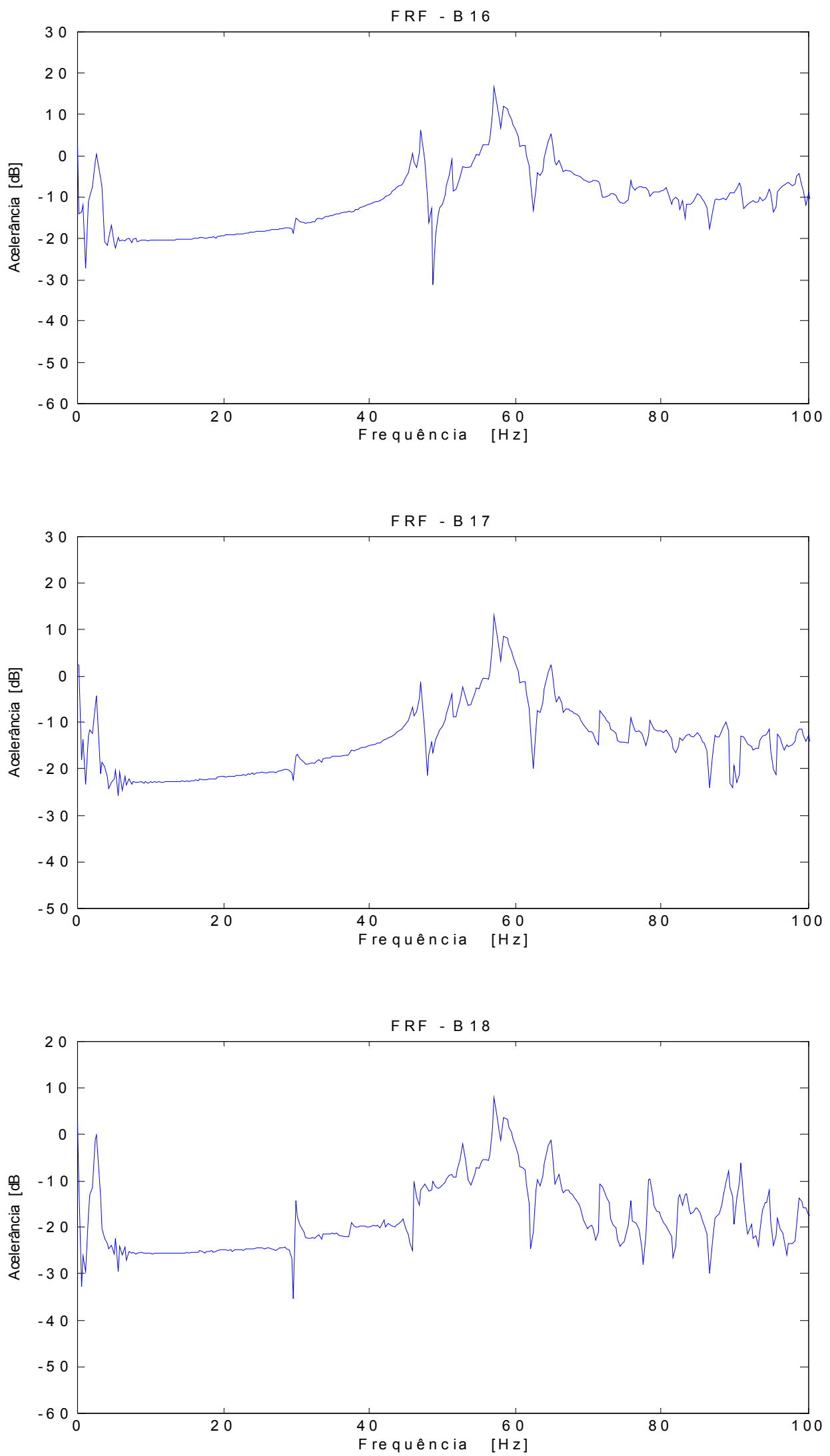

Figura B.17 - FRFs obtidas no ensaio da semi-asa - B16 a B18. 



Figura B.18 - FRFs obtidas no ensaio da semi-asa - B19 a B21. 

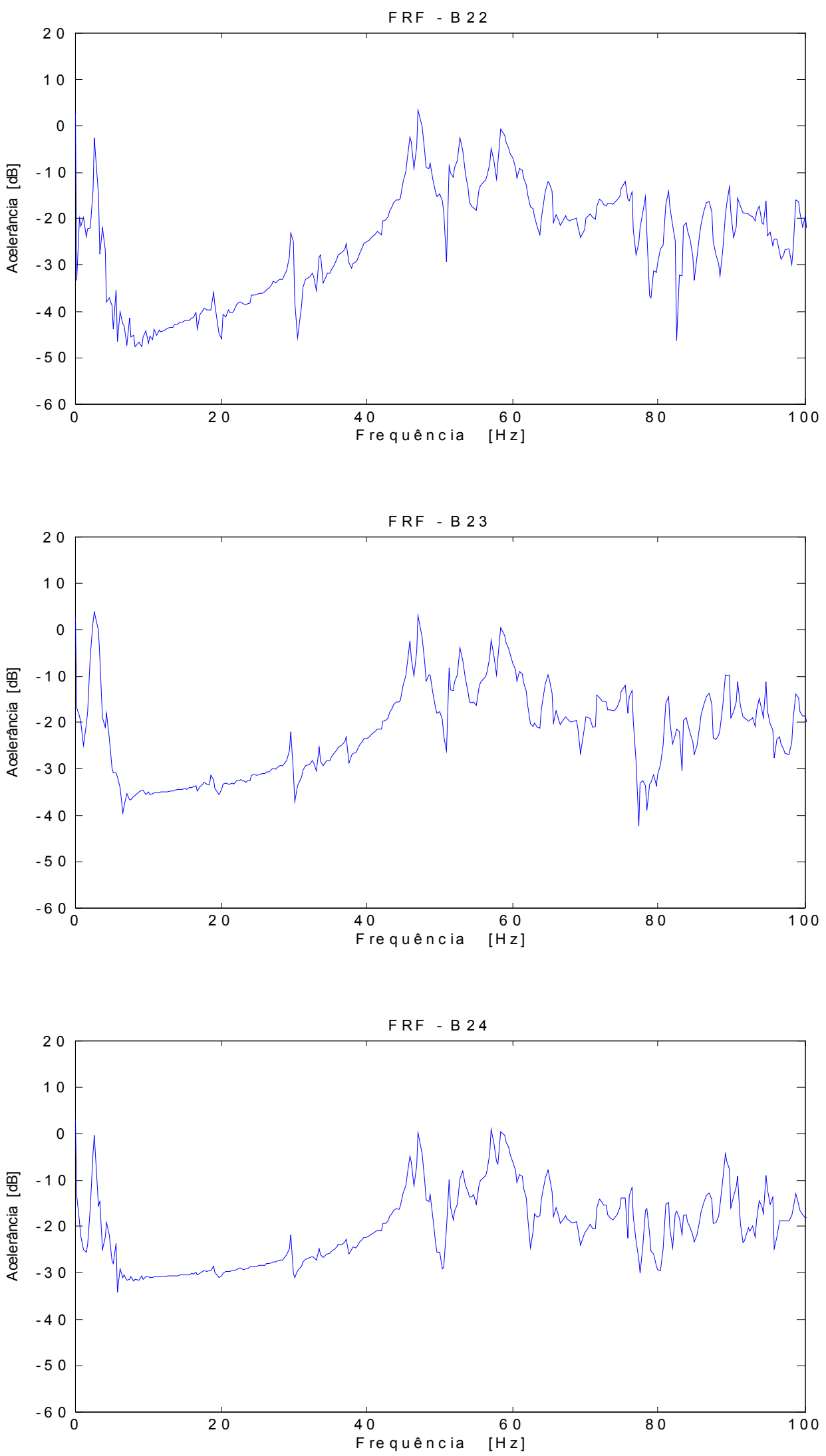

Figura B.19 - FRFs obtidas no ensaio da semi-asa - B22 a B24. 

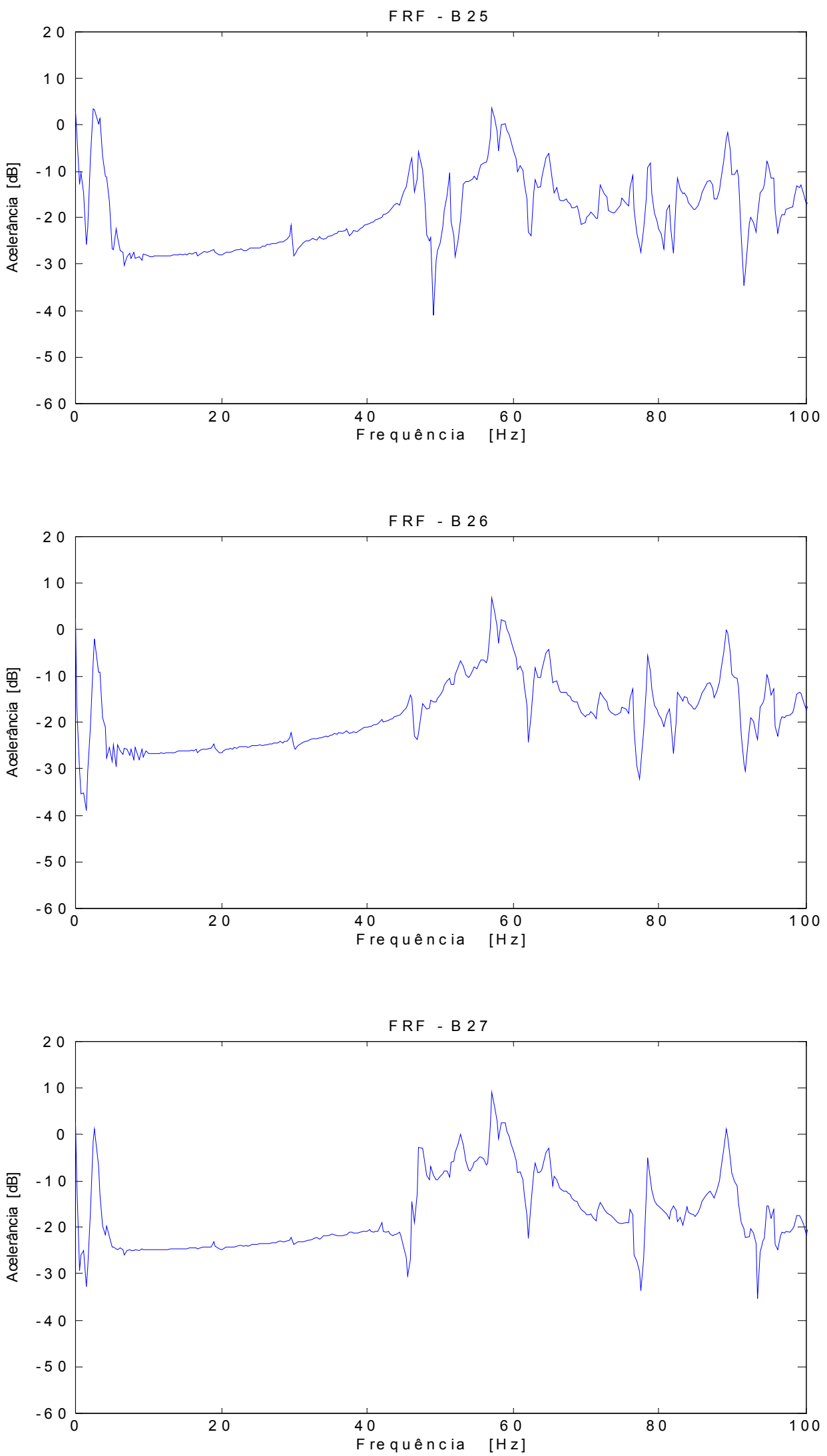

Figura B.20 - FRFs obtidas no ensaio da semi-asa - B25 a B27. 

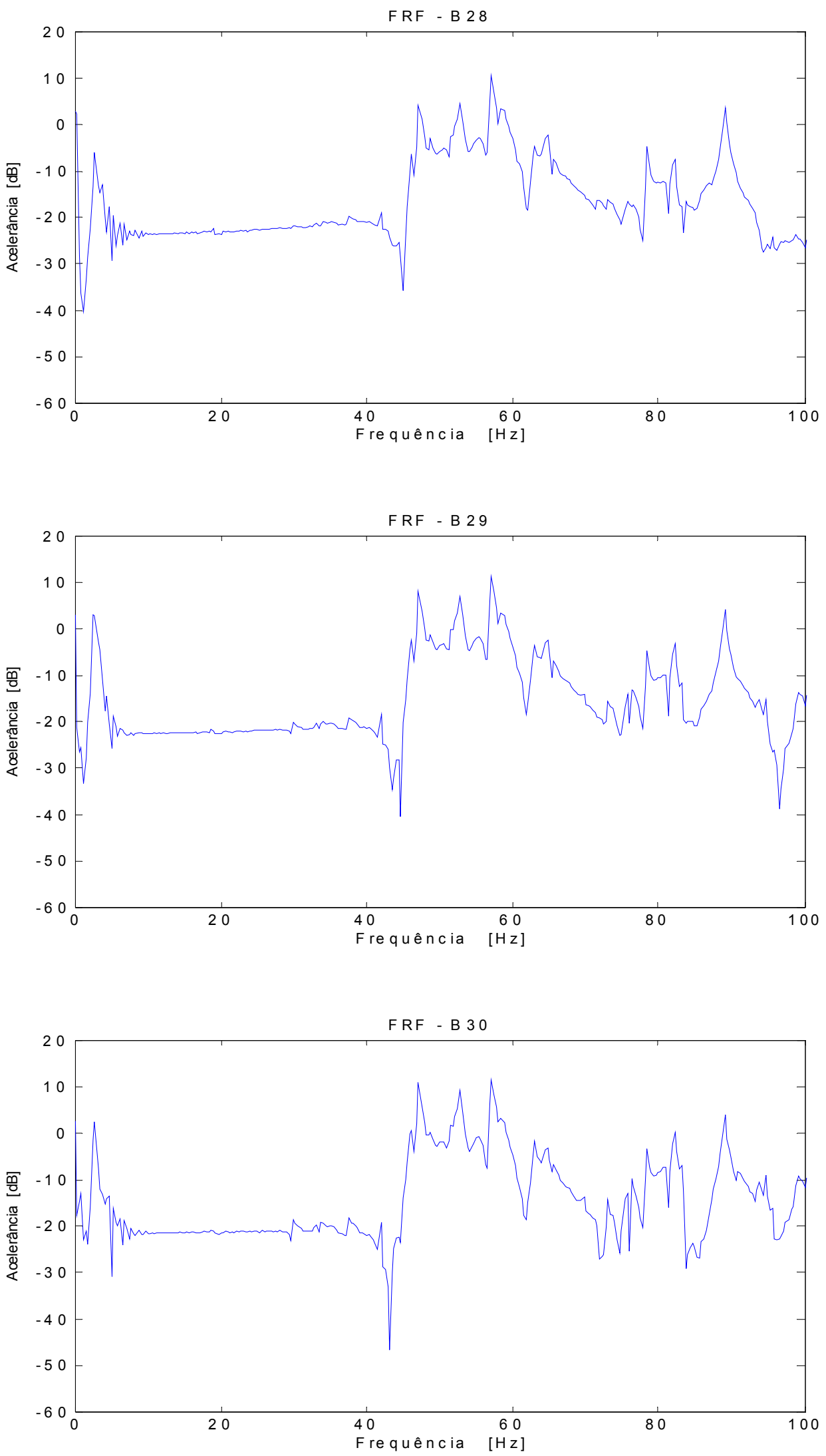

Figura B.21 - FRFs obtidas no ensaio da semi-asa - B28 a B30. 